\title{
Carbohydrate/protein hydrogels as responsive scaffolds in controlling inorganic crystallization
}

By

Saeedeh Afsar

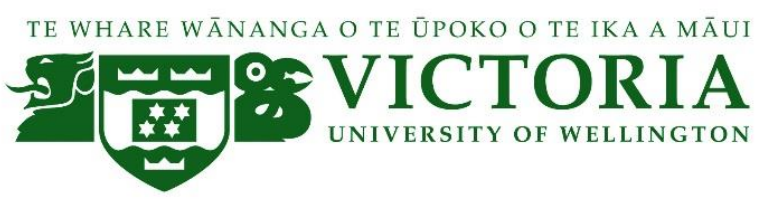

\begin{abstract}
A thesis
Submitted to Victoria University of Wellington In fulfilment of the requirements for the degree of Doctor of Philosophy in Chemistry
\end{abstract}

Victoria University of Wellington

2015 



\section{Abstract}

The strategies that both invertebrate and vertebrate organism use to produce organicinorganic composite materials for different purposes such as mechanical support and protection for the body are fascinating. While extensive research has been done on understanding the basic principles of biomineral formation, mimicking the critical principles of the mechanisms of biomineralization in vitro and fully capturing the structural information and characteristics remain challenging issues for scientists.

Calcium is an essential element in biological systems. It plays a central role in the mineralization and maintenance of the skeleton as well as in fundamental physiological processes including growth and development in vertebrates. Within a biological organism calcium ions are stored, delivered, or released in the presence of different anions such as phosphate, carbonate and citrate. Competition between the different anions which interact with calcium ions in different hydrogel matrices leads to manipulation of the various composite materials produced such as bone and nacre. Soluble anionic acidic macromolecules associated with biominerals play a vital role in modulating the mineral morphology and hierarchy of the organized composite. Understanding the interaction between the constituent ions and the organic matrix is crucial if we are to make synthetic materials, the structure and properties of which replicate those of native biominerals, or materials that have the storage and/or release characteristics of foods, for example.

Carbohydrate-based hydrogels versus protein-based hydrogels are used here as scaffolds for the synthesis of calcium carbonate and calcium phosphate biominerals. Water soluble acidic additives are used to modulate the nucleation and growth of the minerals. In particular chitosan and gelatin hydrogel templates were used as the mineralization scaffolds. Three different mineralization methods were used: the Kitano, alternate soaking and McGrath methods. Monomeric vs. polymeric additives (acrylic acid, glutamic acid, aspartic acid and their corresponding polymers) were introduced into all systems in order to control the nucleation and growth of the so-formed minerals. The morphology, crystallinity, polymorphism and composition of the synthesized organic-inorganic composites were investigated. Analyses were carried out using a number of techniques including Scanning Electron Microscopy (SEM), Transmission Electron Microscopy (TEM), X-ray Diffraction (XRD), micro-Raman spectroscopy and solid-sate NMR. 
In the case of calcium carbonate the morphology and crystallinity were more affected by the use of polymeric additives compared with their monomeric equivalents. In particular the calcium carbonate preferentially grew laterally within and on the periphery of the chitosan or gelatin hydrogel scaffold. This results from the formation of a polyelectrolyte complex between the chitosan or gelatin hydrogels and the added polymer. The presence of the polyelectrolyte complex modifies the nucleation of the mineral. Nanoparticles are preferentially formed which then aggregate together maintaining a lateral perspective with the scaffold.

In the case of calcium phosphate mostly spherical and platelet-shaped morphologies composed of amorphous calcium phosphate and poorly crystalline hydroxylapatite respectively were always formed within both chitosan and gelatin hydrogel scaffolds. $\mathrm{pH}$ was also found to be a key factor in controlling which polymorph of calcium phosphate precipitates. The crystallinity is influenced by the presence of additives for chitosan scaffold. For systems with added aspartic or polyaspartic acid platelet-shaped $\mathrm{CaP}$ forms. These crystals are more highly crystalline compared to those where predominately the porous spherical calcium phosphate morphology is observed which form when L-glutamic acid is added. In the presence of polymeric additives nanoparticles form which then aggregate to yield larger crystals. Such aggregation was preferentially observed for gelatin scaffolds.

Citrate anions are particularly important in calcium phosphate precipitation in bone. Biomimetic hydroxylapatite-chitosan and hydroxylapatite-gelatin nanocomposite were synthesized where citrate ions were used to control the size and crystallinity of the hydroxylapatite crystals. TEM data show that the size of the hydroxylapatite crystals decreases upon introducing citrate ions into the systems. Solid-state NMR dipolar dephasing data indicate the hydroxylapatite precipitation can be stabilized with $2.5 \mathrm{wt} \%$ sodium citrate with respect to the chitosan and gelatin mass.

The data included within this thesis illustrate that both gelatin and chitosan hydrogel scaffolds display similar ability in modulating calcium carbonate or calcium phosphate crystallization in the absence and presence of additives. The role of soluble acidic additives is significant in the formation of biominerals. These results reveal therefore the possibility that carbohydrate-based systems, which have many advantages over protein-based systems, could be used to provide more options for fabricating new implantable materials for humans and animals. The results from the combination of techniques used including XRD, SSNMR 
and TEM showed the possibility of in vitro synthesis of a bio-nanocomposite material in the presence of citrate similar to that of natural bone (in terms of composition and morphology). The achievement of this work demonstrates that new advanced materials with various composite structures and morphologies can be synthesized through a biomimetic biomineralization mechanism under ambient conditions similar to natural materials such as bone and nacre. These advancements have potential application in biomedical research and more specifically in fabrication of implantable materials. 


\section{Acknowledgements}

This thesis would never have been possible without the help of a large group of excellent people. First and foremost, I would like to thank my lovely supervisor Prof. Kate McGrath for her guidance, encouragement and patience, believing in me and giving me the opportunity to study at Victoria University of Wellington. I greatly appreciate your guidance in thesis writing and constant support (emotionally, scientifically and financially) over the past four years. I also learned a lot from your inspiring ideas and broad knowledge in biomineralization, and I really enjoyed the interdisciplinary research that you introduced me to. Additionally I appreciate your assistance and kindness through many of the tough times in my personal life during this $\mathrm{PhD}$ program. Thank you so much Kate, it was a great experience working with you.

I would also like to thank my co-supervisor Prof. John Spencer for discussions about my results and for his ongoing support throughout this time. I am very grateful for your help in reading my thesis. Your comments and suggestions helped a lot to improve my scientific work.

Very special thanks to Dr. Ruth Knibbe, I greatly admire your invaluable Knowledge and curiosity in electron microscopy. You are truly a great mentor, and the TEM results presented in my thesis would not have been possible without your help and comments.

As part of this degree, I had the opportunity to go to the University of Queensland, The Centre for Advanced Imaging (CAI) to use solid-state NMR. Thank you to Dr. Katia Strounina for training me on the Solid-state NMR and helping with the solid-state NMR experiments.

I want to thank all the past and current people in Kate's lab and make my time in the lab really a wonderful memory. Thanks to Dr. Natasha Evans for her help with my first calcium carbonate experiments by giving me an overview of her work, and teaching me a number of techniques she had practiced. Very special thanks to Dr. Mario Alayon for making the lab a pleasant place to work and being an amazing friend. I really enjoyed all the parties and nights out for dinner and will never forget your family-like support during the past four years. I also greatly acknowledge my lovely Indian friend Mima Kurian (Dr to be) for being a great friend and always there to talk about anything.

While not directly associated with the Kate group, I would also like to thank Raman group for being friendly and training me micro-Raman spectroscopy. A big thanks is owed to 
David Flynn for training me Electron Microscopes and for his ongoing help and support. Thanks also to The MacDiarmid Institute for Advanced Materials and Nanotechnology and Victoria university of Wellington for financial support throughout my $\mathrm{PhD}$. A big thank you to all my Iranian friends, Dr. Siamak Dehghan, Dr. Mahroo Falahpour and Dr. Sara Shakouri for being so supportive and having so many great tea times and talks in Persian.

I would like to express my deepest gratitude to my family. Dear Dad and Mom, thank you very much for your endless support in my life. Love from you is beyond words! Thanks also to my lovely sisters and brothers, for their help and for always being best friends.

Lastly and most importantly, I gratefully acknowledge to my deeply-loved husband Davoud. I have valued and appreciated all the things you have done for me especially during my writing time. Thanks for being next to my side during this $\mathrm{PhD}$ and I really owe you a big apology for interrupting you a thousand times by asking what does this mean in Persian! Thanks for the constant understanding, support and laughter throughout. Your love and unwavering support meant millions to me. I can't say enough, so let me just say I love you and thank you. 


\section{Table of content}

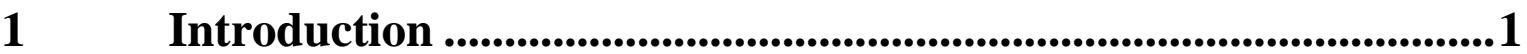

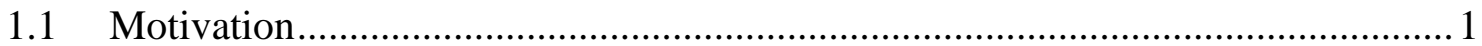

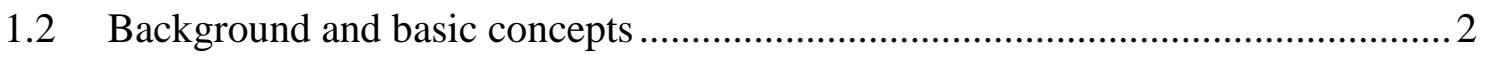

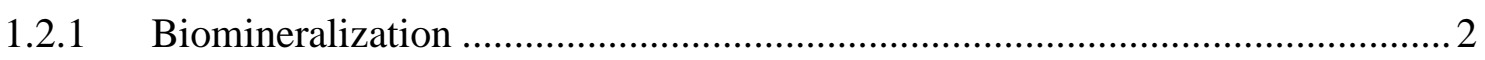

1.2.2 Biomineralization mechanisms................................................................. 3

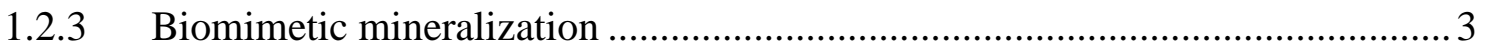

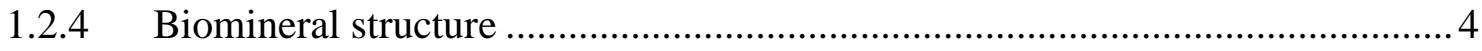

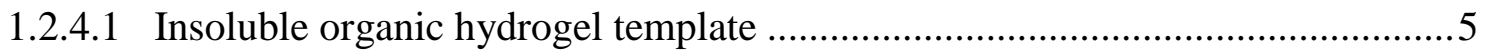

1.2.4.2 Chitosan as a carbohydrate hydrogel scaffold ............................................. 6

1.2.4.3 Gelatin protein hydrogel template ..........................................................

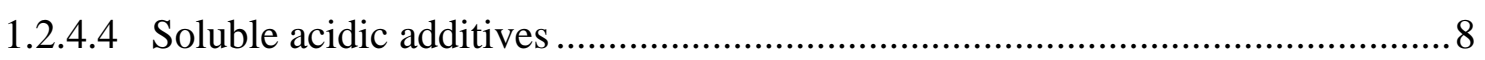

1.3 Example of calcium-based minerals in marine and mammalian materials............. 9

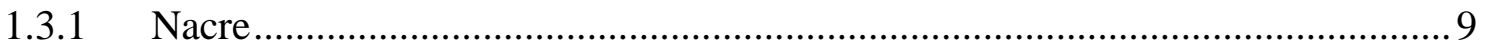

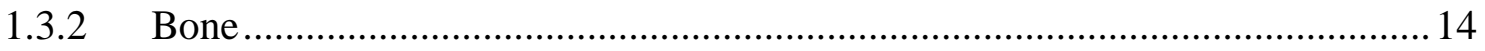

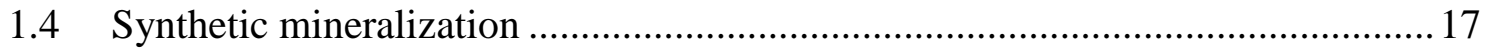

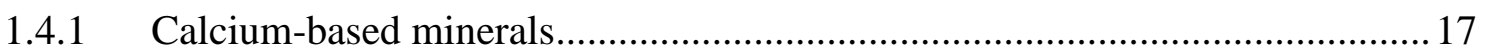

1.4.1.1 Calcium carbonate growth on hydrogel templates ...................................... 18

1.4.1.2 Calcium phosphate growth on hydrogel templates.......................................2 22

1.4.1.3 The place and role of citrate in calcium phosphate growth in bone .................24

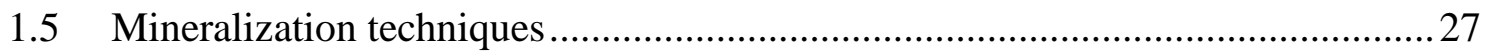

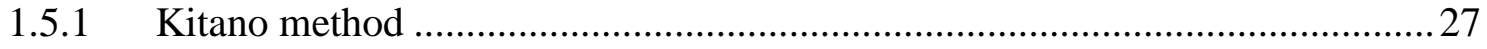

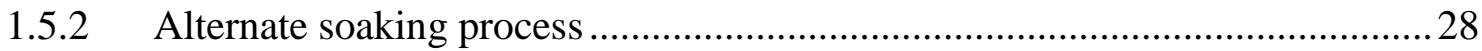

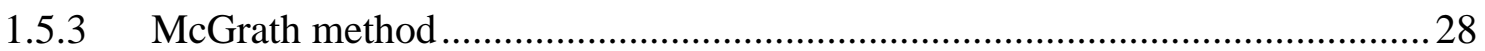

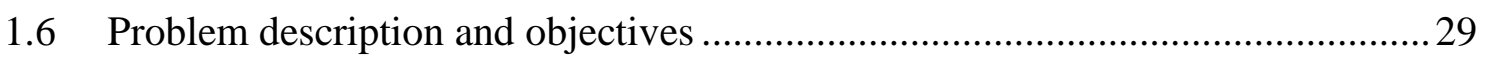

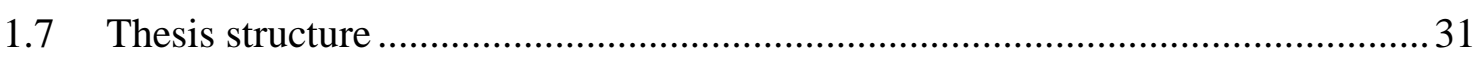

2 Additive controlled biomimetic mineralization of calcium carbonate in carbohydrate vs. protein hydrogel scaffolds .............................38

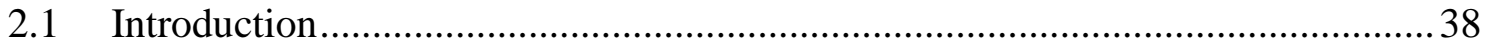

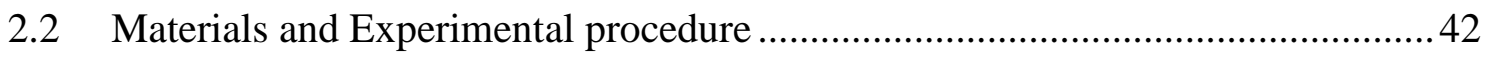

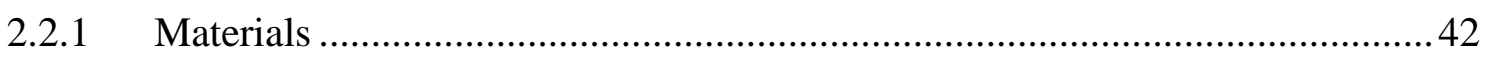




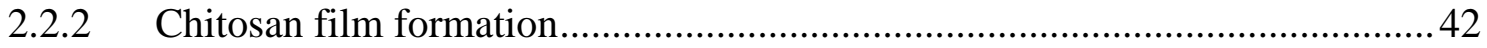

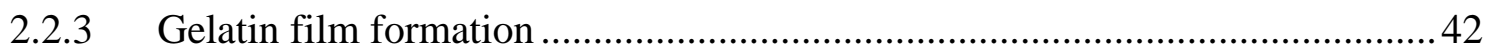

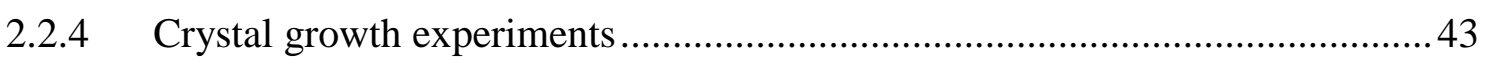

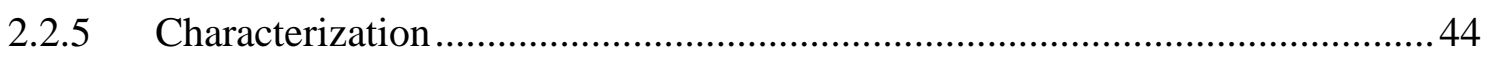

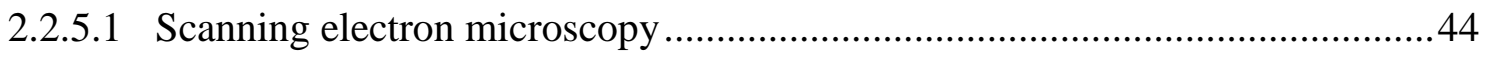

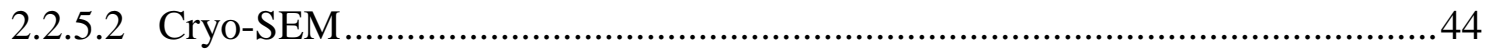

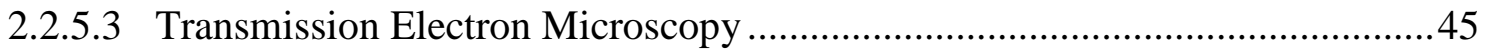

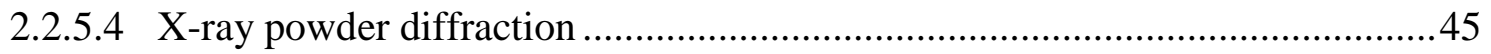

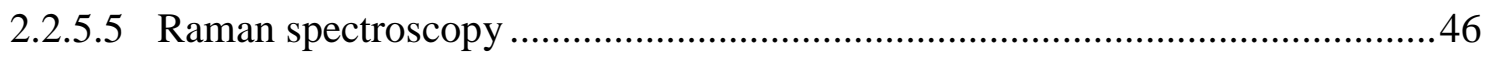

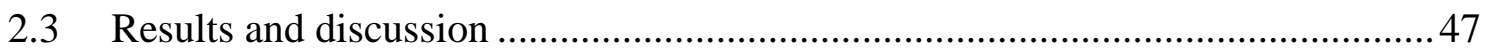

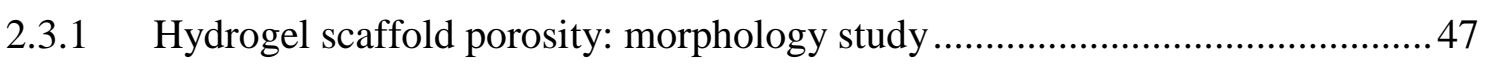

2.3.2 Hydrogel scaffold mineralization: Calcium carbonate with no additive .......... 48

2.3.3 Hydrogel scaffold mineralization: Calcium carbonate with water-soluble

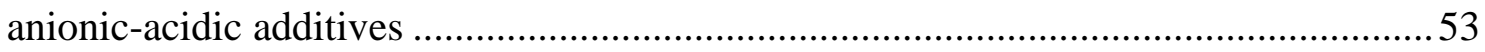

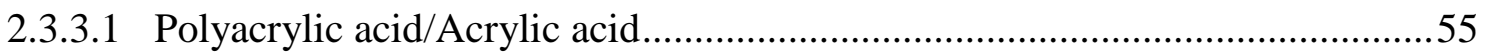

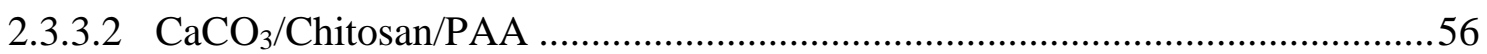

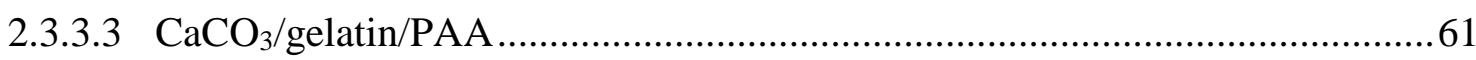

2.3.3.4 $\mathrm{CaCO}_{3} /$ chitosan/AA and $\mathrm{CaCO}_{3}$ /gelatin/AA............................................6 65

2.3.3.5 Glutamic acid/polyglutamic acid and aspartic acid/poly aspartic acid.............68

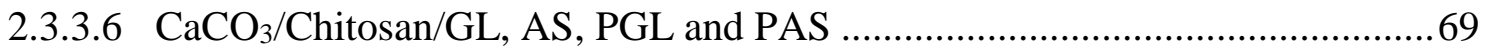

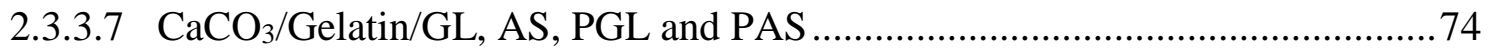

2.3.4 Effect of concentration variation: McGrath method........................................ 78

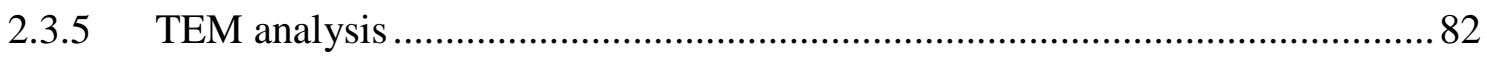

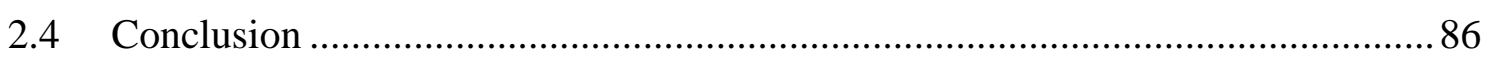

3 Calcium phosphate mineralization within chitosan vs. gelatin hydrogel scaffolds with and without additives ..........................................92

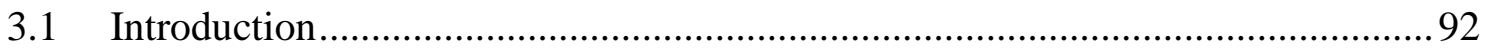

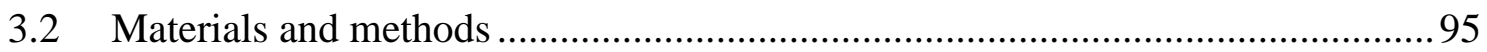

3.2.1 Calcium phosphate crystal growth experiments .........................................95

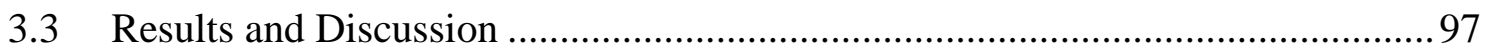

3.3.1 Calcium phosphate/chitosan and calcium phosphate/gelatin composites: No additive 97

3.3.2 Chitosan and gelatin hydrogel scaffold mineralization: with additives.......... 104 


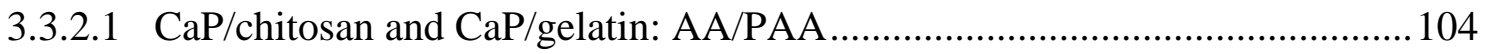

3.3.2.2 CaP/chitosan/GL, AS, PGL and PAS composite........................................... 107

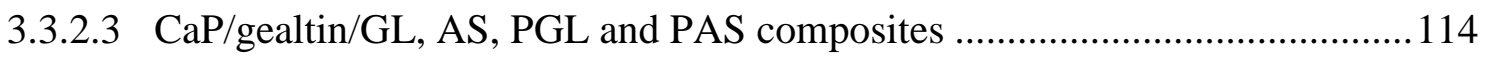

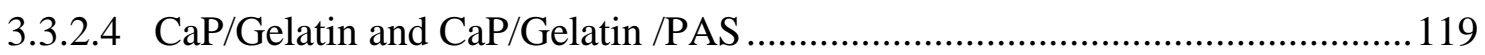

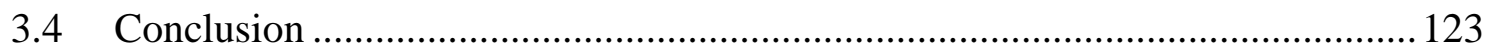

4 Citrate controlled hydroxylapatite formation ...........................128

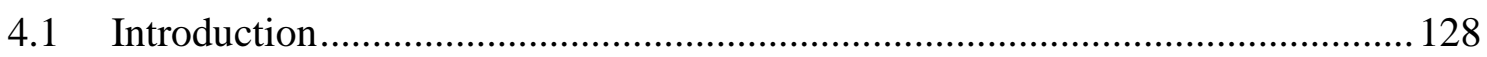

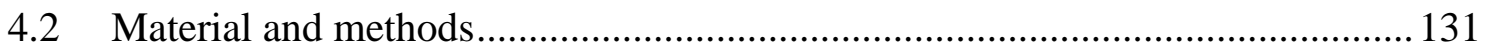

4.2.1 HAp-citrate formation on chitosan and gelatin hydrogels............................. 131

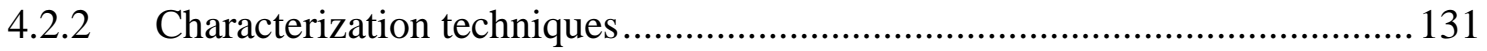

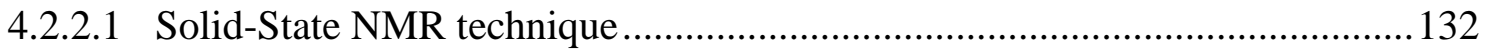

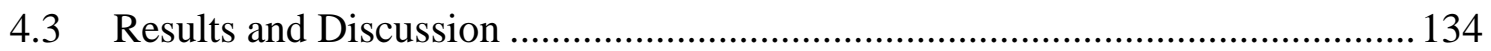

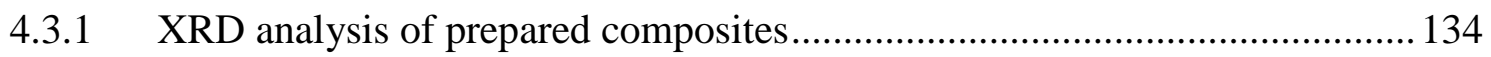

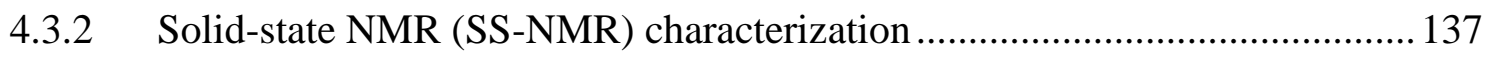

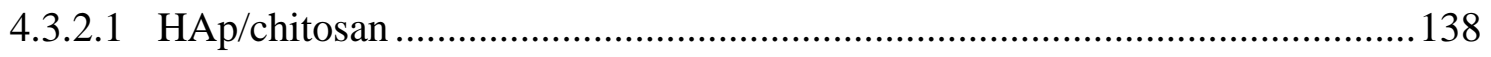

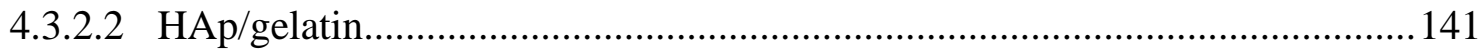

4.3.3 Morphological analysis of prepared composites .......................................... 145

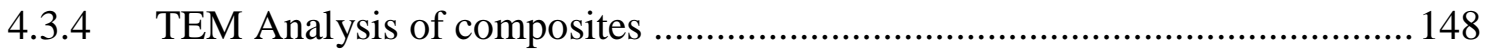

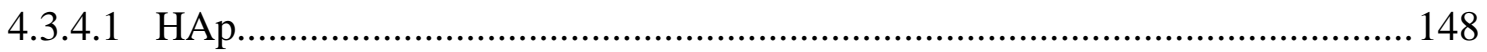

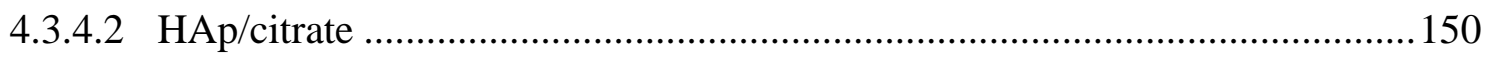

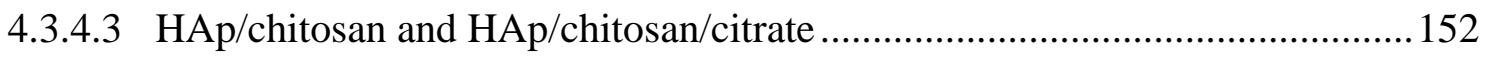

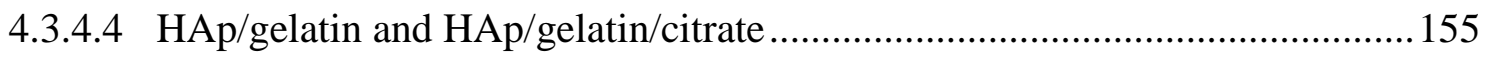

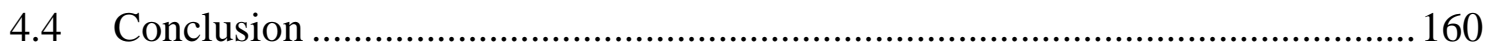

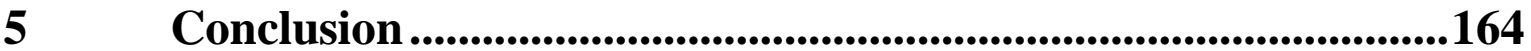





\section{Chapter 1}

\section{Introduction}

\subsection{Motivation}

The worldwide demands for functional skeletal material, such as bone, are high due to bone defects and disorders $[1,2]$. Bone regeneration materials have long been accepted as an alternative to bone replacements [3]. Despite the outstanding effort of researchers with regard to designing synthetic implantable materials, the available substitutions for bone defects are still far from ideal in comparison with bone itself, particularly in terms of the mechanical and physiochemical properties. For example metallic alloys, such as stainlesssteel and titanium alloys, the traditional replacement materials, show a mechanical mismatch due to their high modulus compared with that of bone and with time can ultimately lead to resorption of the bone [3]. Hence the development of synthetic substitute materials, for any regeneration or implant application, should be based on a firm understanding of the structure that is to be replaced [4]. Therefore there is the need to understand the function and structure of a variety of natural mineralized materials, such as bone and nacre, in order to design biomimetic materials such as synthetic bone.

Biominerals, in both marine invertebrate skeleton material and vertebrate mammalian systems, are well known for their unique crystal morphologies and hierarchically structured composite materials [5-7]. The distinctive qualities of architectural natural systems such as physicochemical and mechanical characteristics make these natural materials different from geological minerals [8]. Hybrid organic-inorganic composites such as nacre and bone, which are highly mineralized in ambient conditions, are just two examples of these natural composites materials. Both systems are comprised of inorganic calcium-based minerals (calcium carbonate for nacre and calcium phosphate in the case of bone) and an organic matrix of polysaccharide or protein as template scaffolds for nucleation and growth of the mineral phase. The morphology of the mineral grown within the organic matrix is engineered and modulated through the presence of soluble acidic macromolecules [9].

Despite the structural and compositional differences between bone and nacre, they share similar mechanical properties such as stiffness, toughness, and robustness. Based on the Ashby plot the fracture toughness of nacre was reported to be about $10 \mathrm{MPa} \mathrm{m}{ }^{1 / 2}$ which is 
40 times higher than its mineral constituent aragonite $\left(0.25 \mathrm{MPa} \mathrm{m}^{1 / 2}\right)$ and for bone the fracture toughness is about the same range but with a 10 fold lower Young's modulus (GPa) (see Figure 1b ref 8) [8]).

Bone has a complex structural organization with up to seven levels of hierarchical structure, whereas nacre exhibits similar properties with a simpler structure. In their base state both are laminated systems comprising either platelet hydroxylapatite (bone) or aragonite (nacre). These minerals alone are not capable of providing such great strength to bone and nacre. The mineral, distributed along organic matrices (chitin and collagen in nacre and bone respectively), in the presence of another organic component such as non-collagenous protein in the case of bone and silk in the case of nacre is only an element. The organic macromolecules interface strongly with the minerals and repeatedly dissipate energy when stress is applied $[8,10]$. The remarkable structural and compositional similarities, in addition to inelasticity, toughness and resistance to propagation in nacre and bone act to inspire us to design synthetic biomimetic materials with potential applications in implantable materials $[11,12]$. Understanding the processes involved in biomineralization in nacre and bone, including considering the role of each of the components of these organic/inorganic composites enables us to design synthetic protocols that can be manipulated to optimize the function and properties of novel materials [13].

\subsection{Background and basic concepts}

\subsubsection{Biomineralization}

Biomineralization is a frequently used term in a variety of fields including nanotechnology, biology, materials science, engineering, geology, chemistry and medicine. Biomineralization refers to the process by which composite biogenic materials are produced by organisms [14-17]. These materials have a complicated structure from the nanometre to the micrometre scale and beyond [18, 19]. Biomineralization is a diverse, widespread, and common phenomenon in the biosphere and generally many different minerals are formed or assisted to form by most living organisms from bacteria to humans [6, 20]. For example bacteria called magnetotactic bacteria produce iron oxide, molluscs form calcium carbonate and vertebrates create the crystals of apatite which are found in bones and teeth [21]. Biomineralization is a field that is based on understanding the structure of the mineral phase, the macromolecules that comprise the scaffold in which the mineral forms and the interplay 
between the materials. The variety of minerals and macromolecules, as well as the diversity of structures that are formed as a result of the interactions between the different components has made this field a rich playground for various areas of science. Chemists focus on understanding the mineralization mechanism and controlling the process under different conditions (e.g. ambient, acidic and basic) in order to create single crystal, polycrystalline and amorphous structures and determining the molecular structure of them by mimicking nature to design advanced materials with outstanding properties not present in the constituent materials.

\subsubsection{Biomineralization mechanisms}

Understanding the process of mineralization or crystallization by biological organisms should aid greatly in the ability to design and manipulate useful and novel materials. Based on the type of control the organism utilizes during mineralization, biomineralization mechanisms have traditionally been divided into two fundamental pathways: "biologically induced mineralization" and "biologically controlled mineralization" [20]. In biologically induced mineralization the organisms have little control over mineral formation. Hence the size, shape and type of the crystal formed are not specifically dictated by the organism. Furthermore crystal orientation can vary significantly along with random aggregation. In contrast, in biologically controlled mineralization, the biological system directs the nucleation, growth and morphology of the mineral phase. In fact a specific threedimensional macromolecular matrix comprised of proteins and polysaccharides can regulate and/or organize the nucleation, growth and crystal orientation of the mineral formation [15, 20-22]. While the process of biologically controlled mineralization is utilized in vivo, key features of the system can be considered to be employed in the replication of these kinds of materials in vitro in order to design and synthesize new organic/inorganic hybrid materials with highly controlled structural properties.

\subsubsection{Biomimetic mineralization}

Taking inspiration from natural processes such as biomineralization and applying that knowledge in the design of synthetic materials is called biomimicry. In order to make the best use of natural strategies in the fabrication of novel materials for example, a firm understanding of the design principles and the mechanism of biomineral composite materials formation is required [23]. Through the process of biomineralization, nature precisely controls the combination of organic macromolecules and inorganic minerals into specific 
architectural structures under ambient processing conditions. Researchers in the fields of chemistry and materials science use biomimicry to reproduce and engineer highly controlled and defined materials in the laboratory where organic macromolecules are used to direct crystal growth. One of the most extensive fields of biomimetic research is focused upon recreating the nacre of mollusk shells and mammalian bone tissue. Therefore, these two examples of biomimetic mineralization will be covered in detail below [24].

\subsubsection{Biomineral structure}

The term biomineral refers to a composite material comprised of not only mineral phases, but also organic biopolymers. The main organic components are proteins, carbohydrates and lipids and the inorganic metal ion is present normally as an ionic complex with carbonate, phosphate, citrate or oxalate anions in the case of calcium. In Table 1 are examples of the wide range of biomaterials formed by organisms. In biological materials nucleation and growth of mineral is often mediated, initiated and/or controlled by organic molecules and/or self-assembled templates. During the mineralization process the organic macromolecule matrix aids in the production of mineral crystals of precise form, uniform particle size and specific crystallographic orientation. For example chitin and collagen are widely used as the insoluble organic matrix in three-dimensional frameworks in conjunction with calcium phosphate or carbonate minerals as protective hard tissue structures such as bone and shell $[19,25-27]$. Pure inorganic crystals generally exhibit very complex crystal structures but have simple geometrical shape, dictated by their unit cell. In contrast, biominerals are comprised of simple inorganic systems and simple crystal structures (Table 1), but often have complicated hierarchical structures. Suitable examples that illustrate this kind of structure are calcium carbonate mineralization in nacre and calcium phosphate mineralization in bone. Both will be described in detail later in this chapter.

Understanding the interaction between the constituent ions and the organic matrix is crucial if we are to generate synthetic materials. Insight into how the mineralization process can be controlled under ambient conditions by using biomimetic routes, enables us to produce mineralized structures that can be optimized for example in their mechanical properties [27]. 


\begin{tabular}{|c|c|c|c|}
\hline mineral & Form & formula & Organism/function \\
\hline $\begin{array}{l}\text { Calcium } \\
\text { carbonate }\end{array}$ & $\begin{array}{l}\text { Calcite } \\
\text { Aragonite } \\
\text { Vaterite } \\
\text { Amorphous }\end{array}$ & $\begin{array}{l}\mathrm{CaCO}_{3} \\
\mathrm{CaCO}_{3} \\
\mathrm{CaCO}_{3} \\
\mathrm{CaCO}_{3} \cdot \mathrm{nH}_{2} \mathrm{O}\end{array}$ & $\begin{array}{l}\text { Birds eggshells/protection } \\
\text { Molluscs/exoskeleton } \\
\text { Gastropods/exoskeleton } \\
\text { Echinoids/precursor phase }\end{array}$ \\
\hline $\begin{array}{l}\text { Calcium } \\
\text { phosphate }\end{array}$ & $\begin{array}{l}\text { Hydroxylapatite } \\
\text { Octa-calcium } \\
\text { phosphate } \\
\text { Amorphous }\end{array}$ & $\begin{array}{l}\mathrm{Ca}_{5}(\mathrm{PO} 4)_{3}(\mathrm{OH}) \\
\mathrm{Ca}_{8} \mathrm{H}_{2}\left(\mathrm{PO}_{4}\right)_{6} \\
\mathrm{CaHPO}_{4}\end{array}$ & $\begin{array}{l}\text { Vertebrate teeth and bone/ } \\
\text { exoskeleton } \\
\text { Vertebrate/precursor phase in bone } \\
\text { Vertebrate/precursor phase in bone }\end{array}$ \\
\hline
\end{tabular}

\subsubsection{Insoluble organic hydrogel template}

The hierarchical structures of biominerals involve the mineral phases as well as the organic constituents. The main organic constituents are usually insoluble, porous and hydrated network macromolecules which provide a scaffold for mineral deposition. Organic matrices serve as more than a passive scaffold; they are crucial elements of the strength of biominerals and also act to modify the nucleation and growth events in order to control the crystal polymorph and morphology, both critically important in the behaviour and property profiles of biminerals [28, 29]. For example in invertebrate marine biominerals $\beta$-chitin is the responsive substrate in nacre for precipitation of aragonite. In the case of bone hydroxylapatite nanoscopic crystals are deposited on an ordered type-1 collagen scaffold $[26,30]$.

The use of templates in synthetic mineralization dates back to 1988, when Mann et al. used Langmuir monomolecular membranes, taking advantage of their ordered arrangement of molecules to mediate calcium carbonate grown. They investigated the controlled crystallization of calcium carbonate from supersaturated solution in the absence and presence of stearic acid monolayers. They concluded that in the absence of monolayers rhombohedral calcite crystals formed and the presence of the monolayer leads to orientated vaterite formation [31].

More recently hydrogel templates have emerged as promising materials for the in situ formation of composite biomaterials [32]. Hydrogels are water-swollen polymeric materials 
which can uptake large amounts of water within their structure and are able to mimic tissue environments. The size of the internal pores of the hydrogels can be altered from micropores (under $2 \mathrm{~nm}$ ) to mesopores $(2-100 \mathrm{~nm}$ ) and macropores (>100 nm) [33]. Gels are able to exchange gases, nutrients and waste products from cells living in the hydrogel matrices by diffusion processes [34]. In similarity cations and anions can diffuse readily through the hydrogel template enabling mineral formation throughout the matrix. In addition, like natural biomineralization the synthetic polymer scaffold can provide compartmentalized crystallization environments, and pre-concentration of the cations and anions.

Based on the type of linkage in hydrogel networks, hydrogels can be classified as physical or chemical cross-linked systems. Physical cross-linked hydrogels consist of physical entanglements and ionic interactions. These can be reversible linkages. However in chemically cross-linked hydrogels a covalent bond is formed between polymer chains, creating the cross-links. In chemically cross-linked hydrogels the linkages between crosslinks are permanent hence these hydrogels will not dissolve once the cross links are formed.

\subsubsection{Chitosan as a carbohydrate hydrogel scaffold}

Chitosan is a cationic polysaccharide derived via alkaline deacetylation of chitin and is comprised of $\beta$-1,4 linked 2-amino-2deoxy-D-glucopyranose (D-glucosamine) (Figure 1-1). Chitosan is insoluble in water but soluble in dilute organic acidic environments such as acetic and formic acids below $\mathrm{pH}$ 6. A $1 \mathrm{v} / \mathrm{v} \%$ acetic acid solution is the preferred solvent used for dissolving chitosan. When chitosan is dissolved in dilute acid solutions, the amine groups are protonated to $\mathrm{NH}_{3}{ }^{+}$and a cationic polyelectrolyte is formed. The soluble chitosan can then be transformed into an insoluble hydrogel by driving the $\mathrm{pH}$ up when the polyelectrolyte chitosan is exposed to base. The electrostatic interactions become dominant for physical cross-linking. The main advantage of using a physically cross-linked hydrogel over others is that there is no need for auxiliary cross-linkers, therefore these materials are more favorable in biomedical and food applications [35]. Although the cross-links in physically cross-linked hydrogels are able to be broken, such hydrogels are often sufficiently stable in aqueous environments as to represent a well-defined scaffold. 


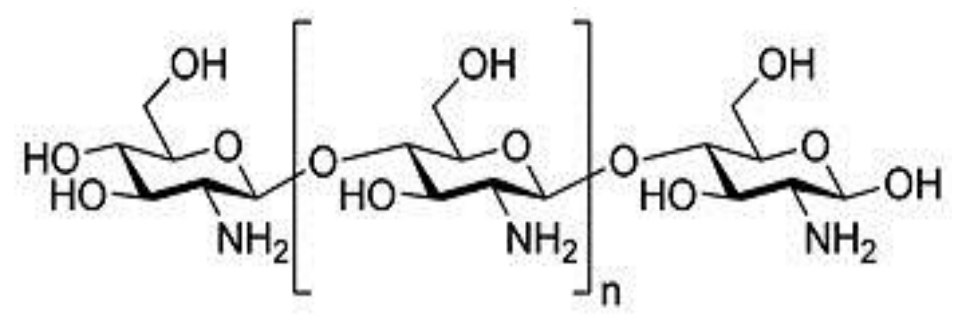

Figure 1-1: The chemical structure of chitosan.

Chitosan is widely used in synthetic biomineralization due to several factors including low cost, abundance, nontoxicity and biocompatibility. Compared to other polysaccharides chitosan, due to its unique chemical properties and film forming ability, has emerged as a promising material in hydrogel preparation and for use as an organic framework for mineralization.

\subsubsection{Gelatin protein hydrogel template}

Gelatin is partially denatured collagen comprised of variable-length peptides. Gelatin has a fibril structure with a lack of configurational order. Figure 1-2A shows how the fibril collagen forms and is denatured to gelatin (Figure1-2B). Compared to collagen, gelatin is water soluble with a lower temperature gelation capacity. Physically cross-linked gelatin hydrogels can be fabricated at low temperatures for concentrations above $2 \% \mathrm{w} / \mathrm{v}$ [36]. Gelatin due to its abundance, biocompatibility and low price has been used in a variety of biomedical applications. We will investigate how gelatin can be utilized as a soft protein scaffold in biomimetic mineralization of calcium-based minerals.

For gelatin, chemical cross-linking is required as while gelatin films are easily formed they readily dissolve in aqueous solutions. The gelation process occurs due to formation of hydrogen bonds between gelatin chains which leads to a conformational change from a random coil to a triple helix. However the physically gelled hydrogels are reversibly formed and are easily broken above $30^{\circ} \mathrm{C}[36,37]$. Therefore the obtained gelatin hydrogels are unstable with poor elasticity. To improve the stability and mechanical strength of gelatin chemical cross-linking is required. 


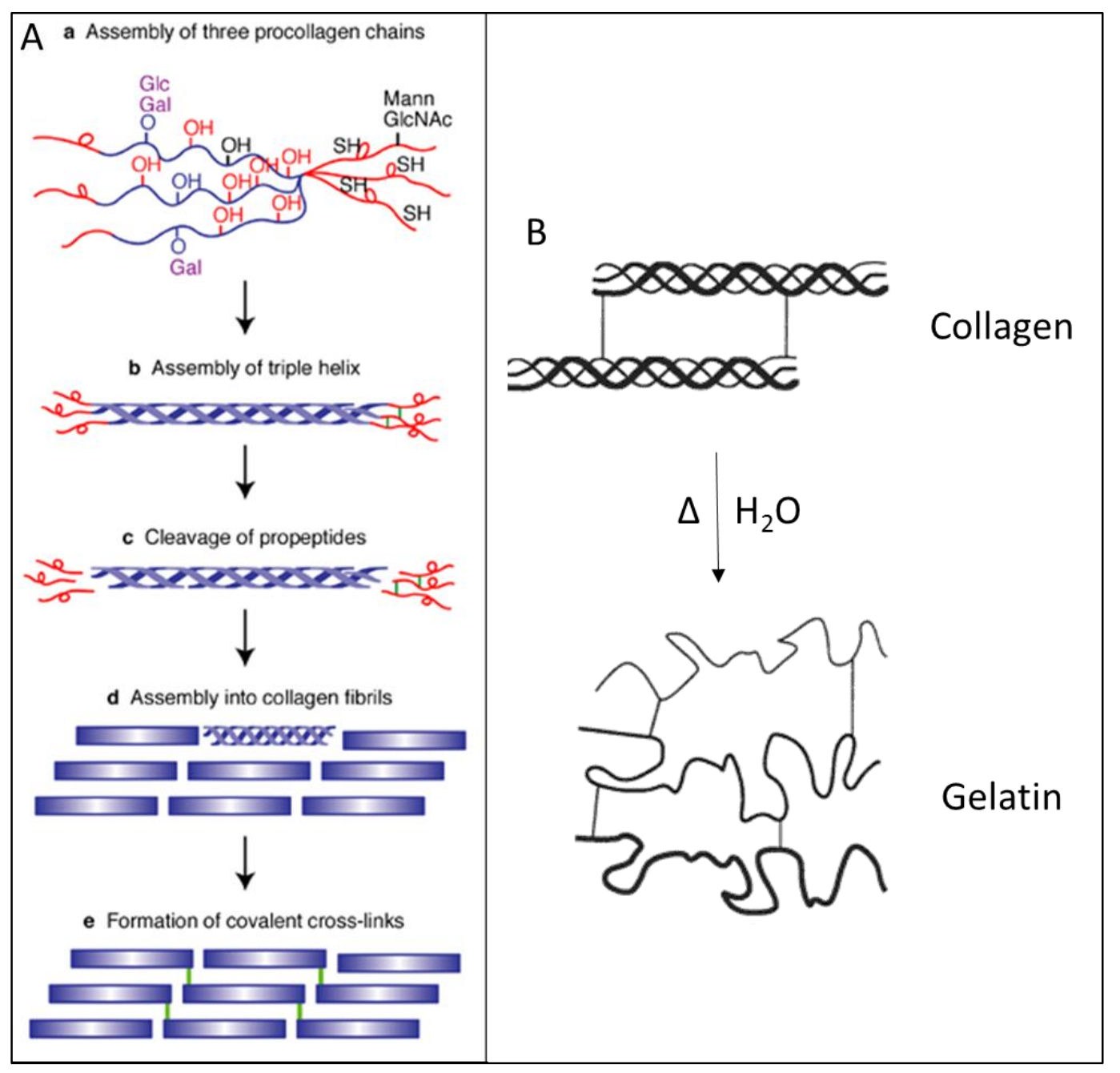

Figure 1-2: (A) Schematic of collagen fibril formation, (B) denaturation of collagen to gelatin.

\subsubsection{Soluble acidic additives}

While insoluble organic scaffold compartments play an essential role in controlling mineral growth in biominerals, it is generally believed that the template acts as the site of nucleation for mineral formation and then has a more minor influence on crystal orientation and morphology than their soluble counterparts. It is assumed that the mineral morphology is modulated due to the interactions between the mineral phase and the soluble additives. Polyaspartic acid, polyglutamic acid and polyacrylic acid, due to their abundant carboxylate groups, are very commonly used as additives in synthetic mineralization. Water soluble acidic poly-anionic macromolecules with high negative charge are found in both vertebrate [38] and invertebrate biominerals [27] and are popular candidates to facilitate the interactions at charged mineral faces as well as carrying calcium cations into nucleation sites 
in the calcium-based mineralization. These polymers exhibit remarkable control over calcium carbonate and calcium phosphate crystal nucleation, growth, polymorph selection and morphology. In bone biomineralization, these additives are known as non-collagenous protein, to make them distinct from the collagen matrix and in nacre they are referred to as acid-rich protein.

\subsection{Example of calcium-based minerals in marine and mammalian materials}

\subsubsection{Nacre}

Molluscs are invertebrates. They are soft-bodied animals protected by a hard external shell. Mollusc nacre, commonly known as mother-of-pearl, is a component of the shell and it is an example of a polycrystalline calcium carbonate biomineral which has excellent mechanical properties such as stiffness, strength and toughness [39-41]. Due to the attractive combination of these mechanical properties, the role of self-assembly in its formation and its complex hierarchical structure, nacre is an attractive target for the design of toughened synthetic materials [42, 43]. For example, nacre is about 3000 times more resistant to fracture than a single crystal of the pure mineral aragonite. This is attributed to the structural organization of the nacre which contains layers of interlocking aragonite tablets separated by a thin layer of organic matrix. The organic adhesive between the plates plays a vital role in, for example, the fracture resistance of the nacre, it elongates by pulling unfolded domains and loops, or breaking inter-chain bonds [44, 45].

Nacre is made up of $\sim 95 \mathrm{wt} \%$ aragonite tablets and $\sim 5 \mathrm{wt} \%$ organic materials comprising proteins and polysaccharides. Although the organic matrix in nacre is only $5 \mathrm{wt} \%$, it plays a key role in controlling the orientation of the aragonite crystals, the microstructure of the composite and is used for toughness enhancement [42].

Nacre has a complex hierarchical structure, spanning over multiple length scales from the nanometre to macroscale. From the lowest length scale, it is considered as a nanocomposite material and at the microarchitecture it is often described as a brick-and-mortar structure as shown in Figure 1-3. The brick refers to the mineral phase i.e. aragonite crystals, and the organic matrix, composed of protein fiber and polysaccharide, is the mortar $[42,46]$. 


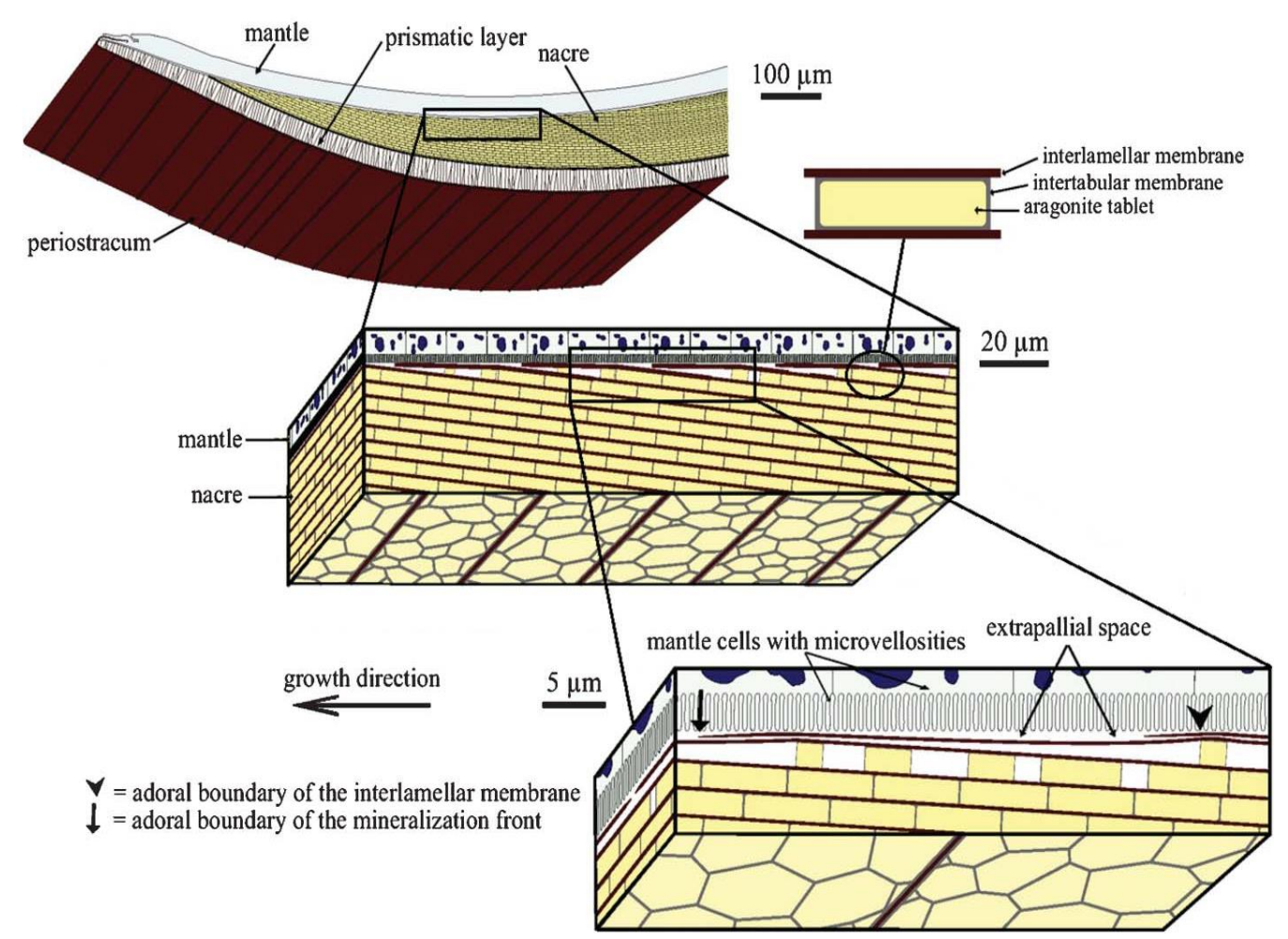

Figure 1-3: Schematic of bivalve mollusc shell anatomy, taken from reference [42].

Schaffer et al. observed that the fibrous core in the interlamellar sheets (i.e., the organic material sitting between the tablets of calcium carbonate which is called the interlamellar matrix), contain holes, 5-50 $\mathrm{nm}$ in diameter when investigating the organic matrix sheets of gastropod nacre by using atomic force microscopy (AFM) [47]. The authors suggested that there might be a number of inorganic bridges between successive layers within the nacre from one layer to the next, and proposed that the formation of nacre may be due to continuous growth of mineral bridges through nanopores in the organic matrix sheets (Figure 1-4) $[42,48]$. They confirmed the mineral connection between the layers via transmission electron microscopy (TEM).

Later Song et al. confirmed the existence of mineral bridges through the interlamellar organic sheets and suggested that the nacre microarchitecture should be considered as a "brick-bridge-mortar" structure rather than the traditional "brick and mortar" arrangement [43]. The graphical forms of the old and new paradigms of nacre formation are shown in Figure 1-5. Figure (a) represents the old paradigm of nacre layers which are heteroepitaxially nucleated on the surface of the interlamellar organic layers and (b) shows the new paradigm 
of nacre in which mineral bridges continuously grow through nanopores in the organic matrix layers.
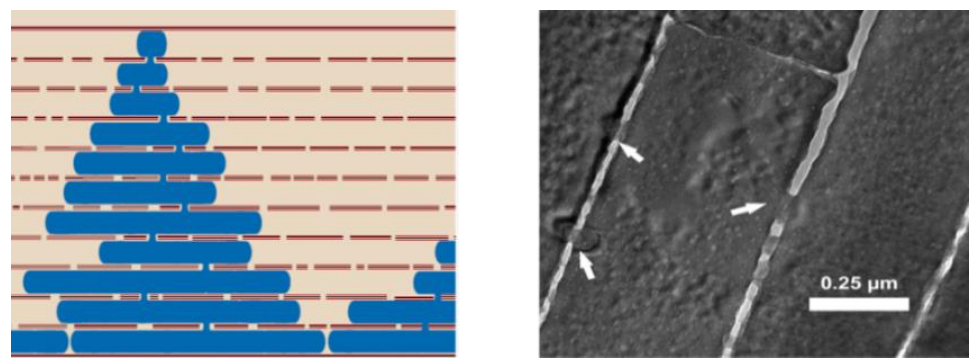

Figure 1-4: The growth of aragonite crystals from one layer to the next without interruption in gastropod nacre, reproduced from references $[42,48]$.

The tablets are connected together by inorganic bridges as a single crystal. Lateral growth of tablets, has the potential to provide more mineral bridges between the tablets, and allows the tablets to grow together in more than one location [47, 49]. It should be noted, however, that the aragonite crystals from one layer to the next are not perfectly aligned.
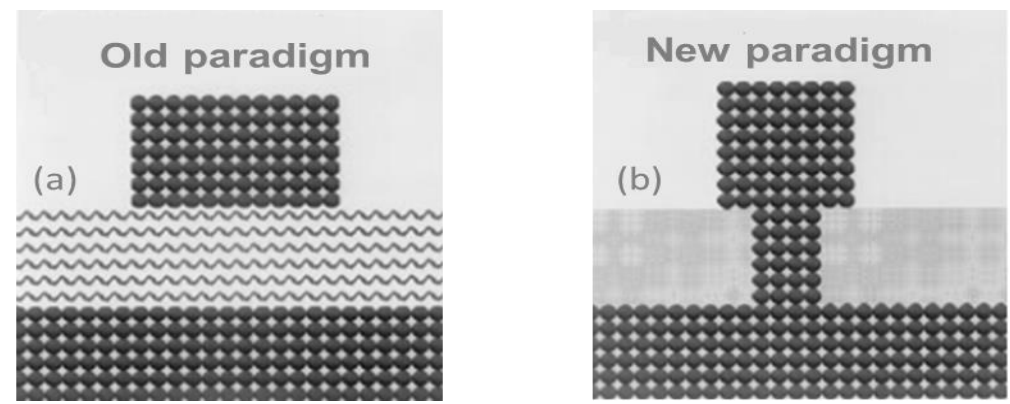

Figure 1-5: Schematic of two competing paradigms of nacre formation, reproduced from reference [47].

One of the vital steps in biological mineralisation is nucleation within an organic matrix. The organic matrix is the responsive framework in which mineral forms [45]. It primarily consists of proteins (in nacre hydrophobic silk protein and water soluble acidic protein) and polysaccharide (in nacre $\beta$-chitin (parallel chains)). Different organic materials play different roles. Chitin is organized in layers between the aragonite plates. It is thought that chitin provides the nucleation sites for the formation and growth of aragonite crystals and ultimately dictates the orientation of mature crystals $[45,50]$.

The silk is used to create a hydrogel-like material. It pre-fills the space that is subsequently mineralized. The silk is mainly located between the chitin matrix and crystals [51]. The acidic proteins have a role in selectivity. They adapt the $\beta$-sheet conformation in the presence 
of calcium ions, hence allowing the organism to selectivity nucleate aragonite rather than calcite for example [45].

The acidic matrix protein is widely believed to play a key role in controlling crystal nucleation and growth of the inorganic biocomposite. The proteins may pre-concentrate the calcium carbonate solution and induce aragonite crystal deposition as well as regulate the orientation of the c-axis $[48,52]$. Crystal growth begins with the secretion of proteins from extracellular space and it is presumed that acidic protein is sufficient to control and initiate precipitation of amorphous calcium carbonate (ACC), followed by a phase transition from ACC to aragonite [53].

To precipitate calcium carbonate a saturated solution is required [45]. It is believed that there are specific mineralization sites on the insoluble matrix [50]. For mineralization to occur it is necessary to transport sufficient mineral to the site and to remove large volumes of water [45]. Mineral-containing vesicles which exist in many different tissues in molluscs are thought to be involved in the mineralization process. The mineral-loaded vesicles are transported to the site of mineralization. If the vesicles are loaded only with calcium, it is assumed that the required carbonate anions are provided by the acidic protein from other sources and are transported to the mineralization site [45]. The schematic representation of the hypothetical scenario of nacre formation before and after mineralization following the above description was suggested by Addadi et al. in 2006 (Figure 1-6) [45].

The tiled aragonite grows along the vertical direction (c-axis), until it reaches the next delimiting sheet of chitin. During this stage the crystals grow laterally (only in the (a-, b-) directions), followed by the subsequent re-initiation of mineral growth on the new surface layer. This occurs in a "Christmas-tree pattern'” as seen in Figure 1-7 [53]. 


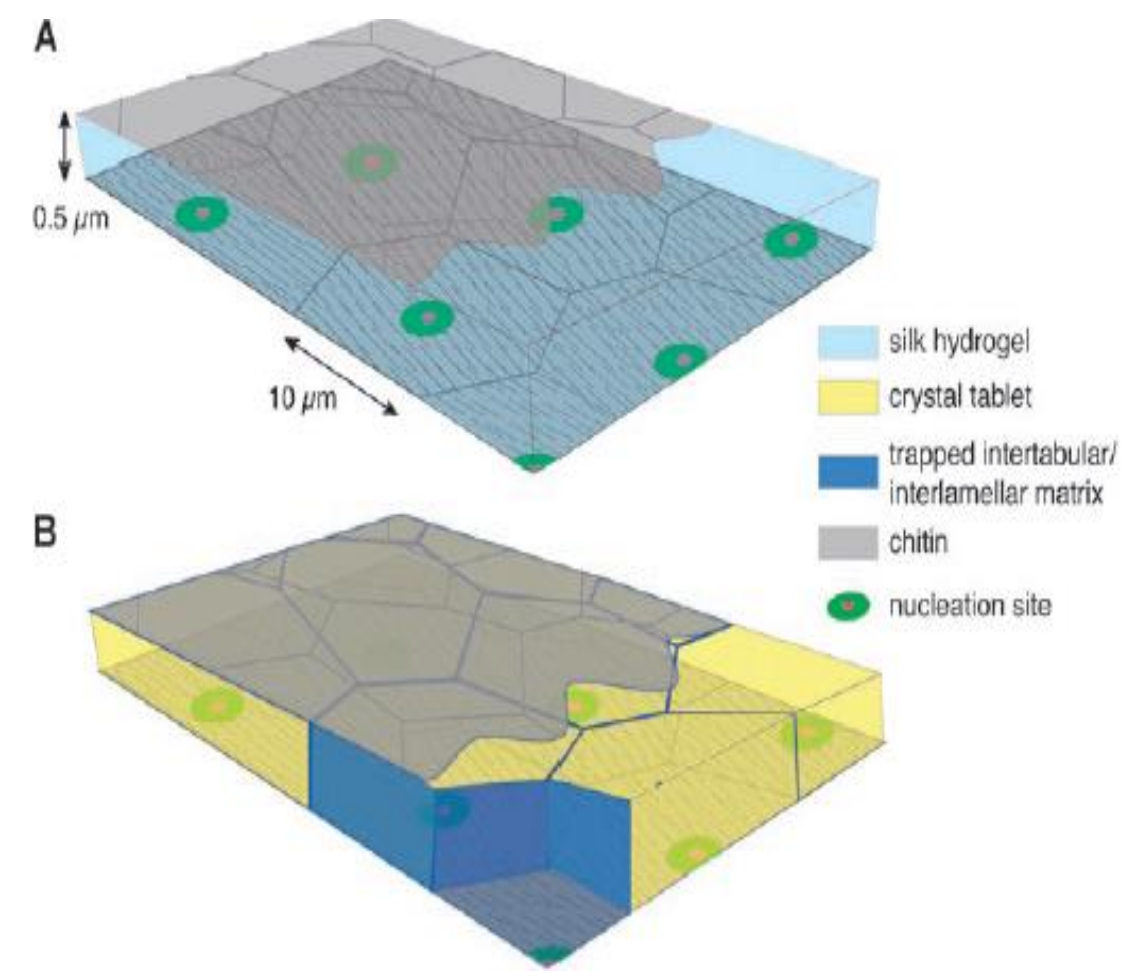

Figure 1-6: Schematic of the suggested model of the organic matrix structure prior to and after mineral formation. (A) Assembled organic matrix before mineral formation. The microenvironment is formed by two sheets of $\beta$-chitin which is filled by protein based on silk-like hydrogel and nucleation sites. (B) Aragonite nucleation is induced and as the mineral grows, water and silk are displaced, taken from reference [45].

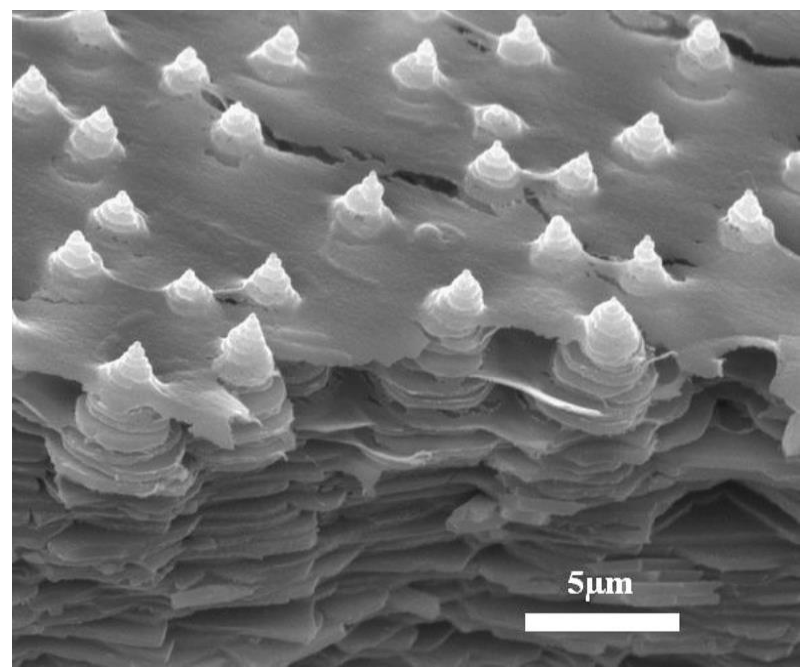

Figure 1-7: The "Christmas tree" like growth of tiled aragonite in nacre, taken from reference [53]. 


\subsubsection{Bone}

Bone is another example of a high-performance biomineral with a complex hierarchical structure which combines soft materials (collagen) with minerals (hydroxylapatite) to achieve for example stiffness. Weiner et al. broke down the structure of bone into several hierarchical levels starting from its individual elements such as the nanoscale plate-shaped hydroxylapatite crystals and collagen fibrils up to the organ level (Figure 1-8) [54, 55]. Briefly, the major components of bone consist of water, thin plate-shaped crystals of carbonated hydroxylapatite $\left(\mathrm{Ca}_{5}\left(\mathrm{PO}_{4}\right)_{3}(\mathrm{OH})\right)$ and type I collagen fibrils. The minerals are oriented and aligned with the self-assembled type I collagen fibrils [56]. Hence the mineralized collagen fibril is the basic building block of the family of bone structures, which constitutes the main component of the three-dimensional matrix for mineral precipitation [55].
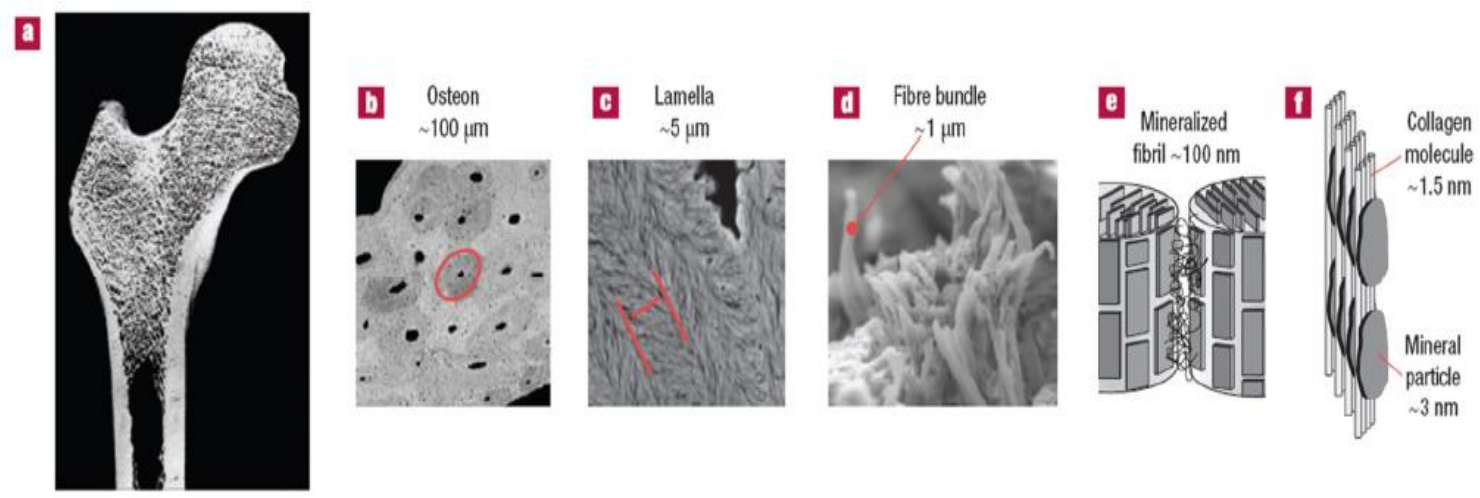

Figure 1-8: Schematic diagram of the hierarchical structure of bone. (a) Whole organ level, (b) Tissue level, (c) Bone lamellae (microscopic level), (d) Fibril arrays, (e) Nanoscale level (mineralised fibril $\sim 100 \mathrm{~nm}$ ), (f) Molecule level (mineral particles and collagen molecule), reproduced from reference [54].

The organic matrix not only influences the mechanical properties, generating biocomposites with both unique structures and properties, but it also plays a key role in regulating the formation of the composite. Understanding the function of the collagen matrix is therefore clearly central to understanding how bone is formed and how the collagen provides the basic building blocks of all bone tissues.

Type I collagen with its fibrous nature, is the most fibril-forming protein formed in the body. Each fibril is composed of three polypeptide chains with over 1000 amino acid residues. These three polypeptides twist together in a triple helix. A triple-helical molecule of collagen is shaped like a cylinder with an average diameter of about $1.5 \mathrm{~nm}$, and length $300 \mathrm{~nm}$ [55]. 
The fibril array varies considerably in different members of the bone family. The triplehelical molecules are all parallel to each other, but their ends are separated by gaps or holes. Fibrils associate together to form large structures called fibers [55].

Most of the tiny plate-shaped crystals of hydroxylapatite are located in gap regions in the collagen matrix organized into grooves or channels within the collagen fibril (Figure 1-9). The plate-shaped hydroxylapatite crystals of bone are on average $50 \mathrm{~nm} \times 25 \mathrm{~nm} \times 2 \mathrm{~nm}$. These minerals with hexagonal crystal structure are most likely the smallest known biologically-formed crystals [55].

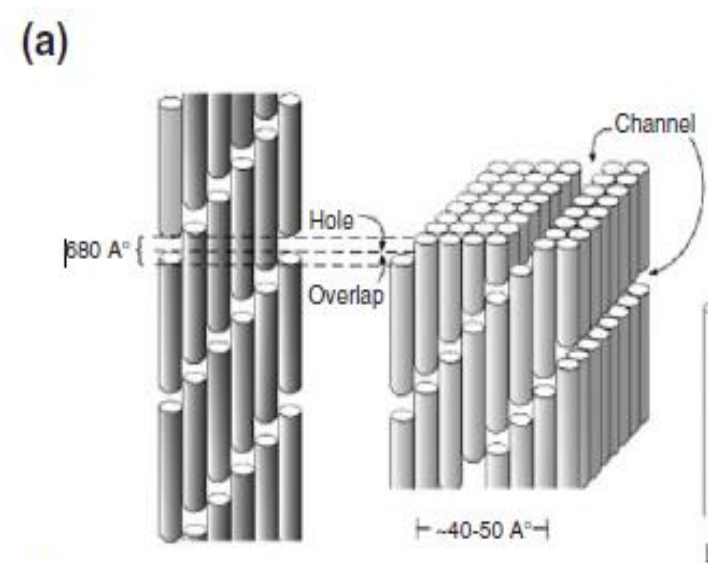

(b)

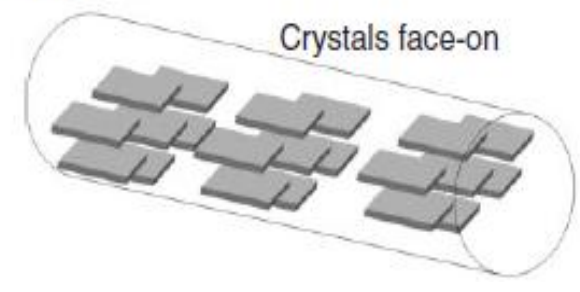

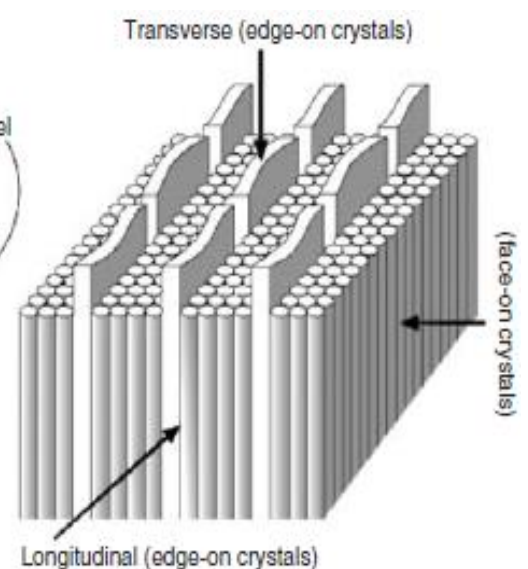

Longitudinal (edge-on crystals)
Crystals edge-on

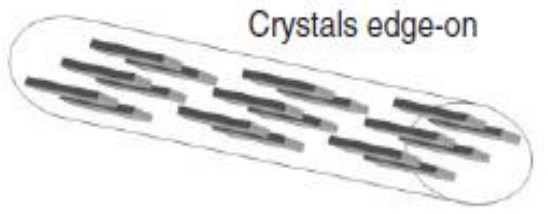

Figure 1-9: Schematic of collagen organization and mineralised collagen fibril, taken from reference [54].

Bone is produced by specialized cells called osteoblasts which generate a layer of nonmineralized matrix called the osteoid, comprising collagen fibrils and non-collagenous macromolecules (generally acidic proteins similar to those found in nacre). Although collagen fibrils are the major constituent of bone, they are not able to initiate the calcium phosphate nucleation and growth. It is believed that non-collagenous acidic proteins play an essential role in controlling the mineralization process [54]. Veis reported that these proteins, which have a high affinity for collagen and bind $\mathrm{Ca}^{2+}$, sit within the hole zones and promote the formation of HAp nuclei [57]. The non-collagenous matrix proteins nucleate crystals and determine their growth and orientation in the hole zones [21]. Minerals nucleate within 
the gap zones within the collagen matrix and subsequently grow rapidly along their c-axes (Figure 1-10). At the initial stage they are needle-shaped and crystalline.

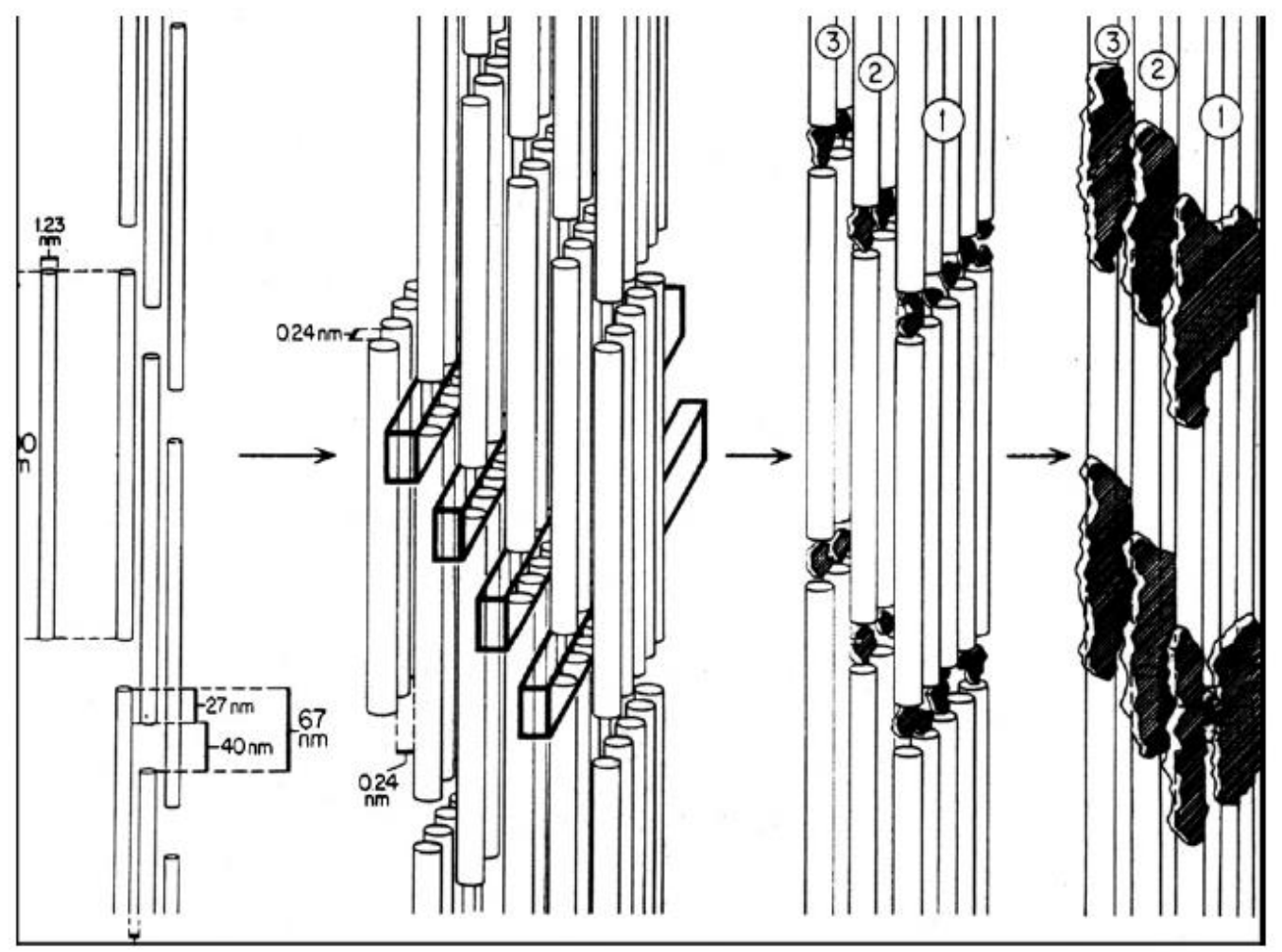

Figure 1-10: Schematic illustrating the preferential HAp growth along the c-axis which follows the long axis of the collagen (in this case for the turkey bone mineralisation system). The cylindrical rods show collagen units composed of triple helical collagen molecules that assemble into fibrils in a quarter-staggered fashion, which leaves periodic gaps and grooves within the fibrils. The $67 \mathrm{~nm}$ is the result of the combination of a $40 \mathrm{~nm}$ hole zone and $27 \mathrm{~nm}$ overlap zone, taken from reference [5].

The HAp crystals continue to grow into plates, filling the collagen fibril channels and finally the crystals push their way into the overlap zone between the layers of the triple-helical molecules. Therefore it is assumed that the collagen fibril plays a matrix framework function by defining the nucleation site location and controlling the initial crystal growth [58]. In Figure 1-11 is demonstrated how the collagen fibrils are filled and coated by flat plates of tiny mineral crystals of calcium phosphate. The minerals are arranged parallel to each other and also parallel to the collagen fibrils in a regularly repeating, staggered arrangement [16]. 


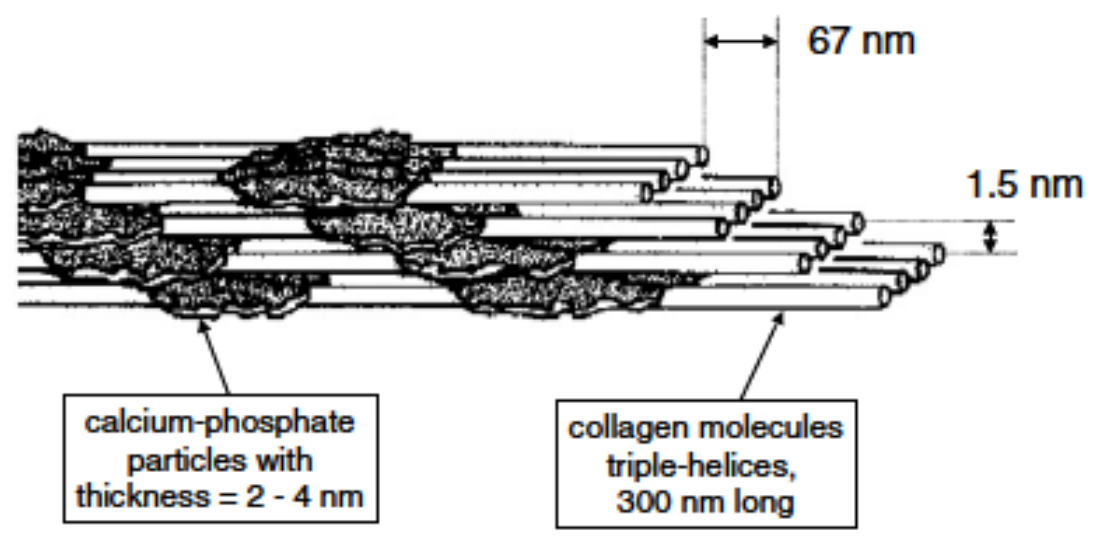

Figure 1-11: Nucleation of mineral particles inside the gap zone of collagen fibrils, reproduced from reference [16].

\subsection{Synthetic mineralization}

Synthetically manufactured minerals are used in a wide variety of applications from glass to microprocessors, as optical components and as implants in the human body. Calcium-based minerals are dispersed in nature (calcium carbonate in nacre and calcium phosphate in bone and teeth for example) and form many visually and mechanically attractive materials. Therefore, with biomineralization as an inspiration, the controlled synthesis of materials comprised of calcium-based minerals has become an attractive area of study [7, 59, 60]. Matrix-mediated mineralization is a sub-class of biologically controlled mineralization which involves organic matrices to regulate the nucleation and growth of minerals. Hence the matrix associates with the mineral and makes the final organic-inorganic composite materials. This class of material has yielded much more attention from the materials science perspective, particularly in the design of artificial human bone, muscles and teeth.

\subsubsection{Calcium-based minerals}

Calcium-containing minerals comprise nearly 50 percent of all known biominerals. Until the early 1980s, before the discovery of more biominerals that contained other cations, the field of biomineralization was known as "calcification" due to the prevalence of calciumbearing minerals [20]. Calcium is an essential element in all biological systems, for both soft and hard tissue function. In its various roles, calcium ions are paired with a variety of different anions, including phosphate, carbonate, oxalate and citrate. Many of the processes using calcium ions require the ions to be stored, or delivered, or released. While the different anions compete with each other to preferentially interact with the calcium ions, the various 
bio-organic molecules and assemblies manipulate the interactions resulting in, for example bone production (essentially calcium phosphate) in preference to urinary tract stone formation (calcium urate).

\subsubsection{Calcium carbonate growth on hydrogel templates}

Calcium carbonate is a major constituent of the structural architecture of biological composites, and as such considerable research has been devoted to understanding biomaterials and also mineralisation in combination with polymeric scaffolds. Calcium carbonate is also a material of considerable industrial interest, and the study of the factors that influence its formation has a long history [64]. Calcium carbonate can precipitate in eight forms, seven are crystalline and one is amorphous. The pure calcium carbonate polymorphs calcite, aragonite and vaterite will be examined here. Each of the three polymorphs can be expressed in a diversity of morphologies. Their crystal systems are rhombohedral, orthorhombic and hexagonal, respectively.

Calcite is the most thermodynamically stable form of calcium carbonate at ambient conditions. Calcite has rhombohedral symmetry. The typical rhombohedral synthetic calcite crystal grown in a beaker from a pure solution of calcium carbonate differs considerably from the macroscopic crystalline calcium carbonate forms produced in living organisms, several examples are shown in Figure 1-12 [59].

Aragonite has an orthorhombic crystal structure. The higher solubility of aragonite means that it is less stable than calcite. Due to its lower density and higher solubility, vaterite is the least thermodynamically stable of the three main polymorphs of calcium carbonate crystals. Vaterite is the kinetically favoured form of calcium carbonate. Despite this vaterite is also found in biominerals [27]. The metastable form of anhydrous calcium carbonate is vaterite which has a hexagonal unit cell. 

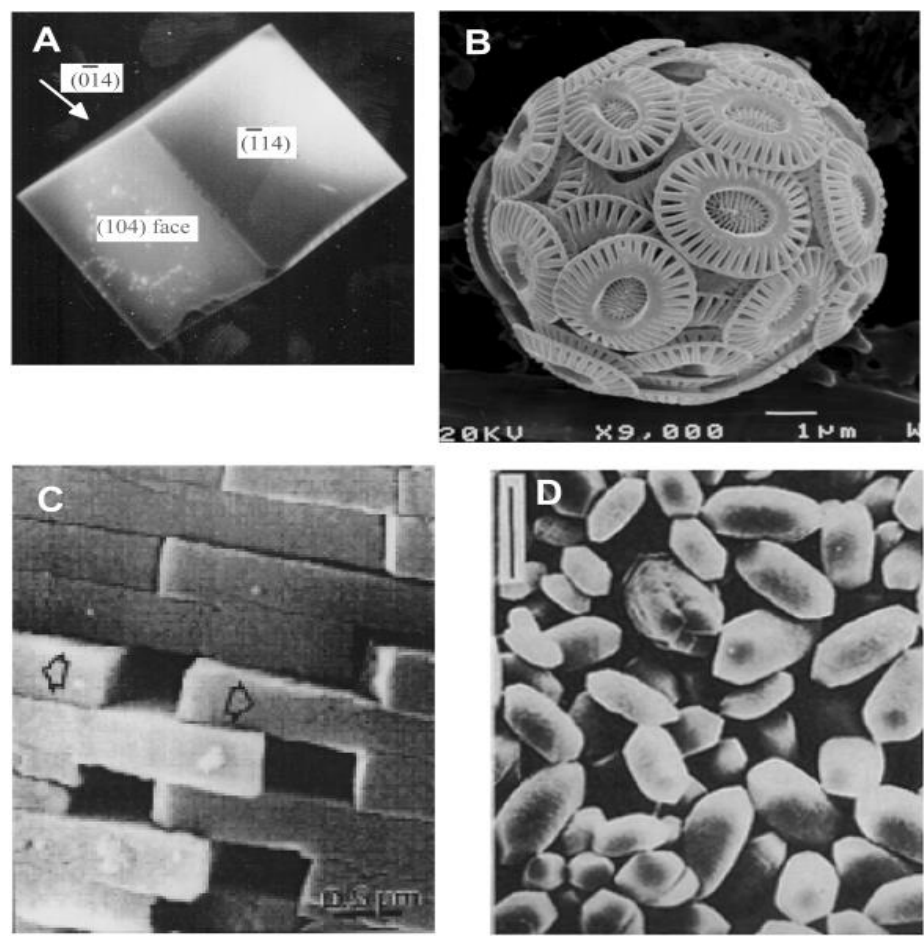

Figure 1-12: Scanning electron micrographs of (A) rhombohedral synthetic calcite, (B) coccolithophorid, (C) aragonitic layers from nacre, and (D) calcite crystals from the human inner ear, taken from reference [59].

One of the biggest challenges in the field of biomimetic calcium carbonate biomineralization is finding particular and realistic in vitro models for a specific mineralization process. Hydrogels represent excellent models for biomineralization studies in vitro including for solution growth of hydroxylapatite using a constant composition set-up, to in vitro mineralization using cells to induce growth in the hydrogel [61, 62]. Recently, particular attention has been devoted to biomimetic mineralization of hydrogel templates as a scaffold in order to fabricate ordered materials. The ability of materials with different molecular size to diffuse into the hydrogels makes these dry or swollen polymeric networks a good matrix as a controlled crystallization system.

Natural polymers like chitosan, chitin and gelatin due to their abundance, biocompatibility, biodegradablility, and bioactivity in the human body are widely used as scaffolds for calcium carbonate mineralization $[63,64]$. There have been several investigations focused on calcium carbonate mineralization using hydrogel templates in the absence and presence of soluble polymeric additives. It is generally concluded that the additives regulate the crystallization of calcium carbonate and control the size, shape, and polymorphism of calcium carbonate via polymer-induced liquid-precursor (PILP) process [26]. 
Using anionic acidic proteins to control crystallization process of synthetic, calcium-based minerals, it has been demonstrated that crystallization that proceeds via a liquid-phase mineral precursor, called as a polymer-induced liquid-precursor (PILP) process. The PILP phase can be used to generate specific inorganic/organic biocomposite structures observed in natural materials, thereby supporting the hypothesis that an amorphous liquid-phase mineral precursor plays a vital role in biomineralization. The PILP phase was first discovered during the investigation of the effect of polyaspartic acid (PAS) on the crystallization of $\mathrm{CaCO}_{3}$. In proposed PILP process for $\mathrm{CaCO}_{3}$ prior to adding carbonate counterion species, a polymeric additives such as PAS and PAA as a crystallization process directing agent is added to calcium solution such as calcium chloride which can be interact with calcium ions. When the carbonate ions introduces to the system the supersaturation is gradually increased, a critical concentration is reached at which point the solution undergoes liquid-liquid phase separation. It can be seen from optical microscopy investigation that a highly hydrated droplet-like amorphous precursor phase is formed. Due to the liquid behaviour, the droplet are able to settle and adsorb to the substrate. An amorphous phase is crystallized over time into a birefringent film of crystalline $\mathrm{CaCO} 3$, excluding the polymeric impurity. The key point here is that the crystals retain the shape of the precursor phase which determines the final crystal morphologies. Taking advantage of this point, with regards of the shape of the precursor phase scientist are able to create thin films and tablets of calcium carbonate similar to those find in nature [26].

The crystal growth of calcium carbonate on a chitosan-based hydrogel using a Kitano method (exposure to a saturated calcium carbonate solution) was reported by Zhang et al. [65]. They investigated the influence of additives such as poly acrylic acid (PAA) on the crystallization and crystal morphology of calcium carbonate growing on a chitosan substrate. By adding PAA into the chitosan-calcium carbonate system, protonated nitrogen and carboxylate anions are created on the chitosan film surface by reaction between the amino group in the chitosan and the carboxyl group in the PAA. These charges modify and induce the nucleation and deposition of vaterite as well as calcite crystals on the chitosan film surface [66]. However, in the absence of PAA only calcite crystals were observed. They concluded that nucleation and crystallization occurred at the film surface with a spherical morphology at low concentrations of PAA, but at high concentration of PAA crystallization was inhibited by the carboxylate anions of the PAA [65]. 
In another study $\mathrm{Wu}$ et al. investigated the mineralization of calcium carbonate on an insoluble chitosan matrix in the presence of regenerated silk fibroin, which closely resembles the nacre mineralization environment. Different polymorphs of calcium carbonate were formed by changing the reaction conditions e.g. solution $\mathrm{pH}$ and temperature. The morphology of the crystals were also influenced by the acid-rich silk protein. At high $\mathrm{pH}$ (about 9) and supersaturated solution of calcium carbonate, vaterite/calcite ratios, were modified with up to $100 \%$ vaterite formation being achieved. Furthermore, increasing the temperature for certain solution $\mathrm{pH}$ values led to the formation of aragonite due to its higher surface energy compared with that of calcite or vaterite [67]. The role of carboxylic acid oligomers such as succinic acid and glutamic acid and polymers such as PAA and polyaspartic acid additives as a modifier of calcium carbonate growth was investigated by Aschauer et al. [68]. They showed that although all additives display growth modifying effects, the large polymeric additives have a strong impact compared to the small molecule additives. This indicates that the binding between mineral ions and additives is not strong enough to be in residence for a long time.

Although there are few examples of calcium carbonate mineralization in mammalian hard tissues, it is a major constituent of marine structural components and therefore the deposition of calcium carbonate on protein hydrogel scaffolds such as collagen and gelatin as a synthetic biomaterial has received considerable attention. Shen et al. have used the collagen substrate to deposit calcium carbonate. The results of their investigation showed that calcite generally forms as large crystals. The size of these crystals prohibits nucleation within the gap zones of the type I collagen fibril network unlike for hydroxylapatite which mineralizes on the nanometre scale [69]. Thus the major focus has been on creating hydroxylapatite/collagen composites rather than calcium carbonate/collagen materials.

However Falini et al. studied calcium carbonate mineralization on cross-linked gelatin films containing different polyelectrolyte additives (e.g. polyaspartic acid) in order to reveal the fundamental role of the protein and additives during the biomineralization process [70, 71]. The calcium carbonate minerals were precipitated throughout the surface and within the gelatin film using the vapour diffusion crystallization approach (exposure of an aqueous calcium carbonate solution to ammonia vapour). Mineral analysis indicated that the type and concentration of additives are key factors in defining crystal orientation and polymorph. In the absence of additives only calcite deposition on the gelatin films was detected by XRD. At high concentration of polyaspartic acid as an additive (300 $\mathrm{mg}$ per gram of gelatin) 
vaterite was the sole phase of calcium carbonate polymorphism which implied kinetic control of the polymorphism. While at the lower concentration of polyaspartic acid, $100 \mathrm{mg}$ per gram of gelatin, only aragonite was formed. They also showed the formation of oriented vaterite in the presence of polyaspartic acid on stretched gelatin films and aragonite on the unstretched gelatin films. The orientation of these crystals was attributed to the interaction of the $\beta$-sheet structure of polyaspartic acid with the most positively charged vaterite crystal face. Under the same condition but using polyglutamic acid, whether using high or lower concentration, precipitation of both vaterite and aragonite was observed. These data reveal that polyglutamic acid is remarkably less polymorph selective than polyaspartic acid. They concluded that the polyaspartic acid $\beta$-sheet conformation on the uniaxial stretched gelatin matrix promoted both orientation and specific polymorph selection for the deposited crystal.

\subsubsection{Calcium phosphate growth on hydrogel templates}

Calcium phosphates are the main inorganic constituents of mammalian hard tissues. They exist in a rich variety of morphologies from spherical nanoparticles to micro-particles to rod and needle states. The stability, hardness, and function of bones and teeth are to a large extent based upon the presence of the carbonated hydroxylapatite (HAp) within the matrix $[72,73]$. Due to the presence of calcium phosphates in vertebrates calcium phosphate has elicited much interest particularly in the field of biomedicine. Dicalcium phosphate dihydrate $\left(\mathrm{CaHPO}_{4}: 2 \mathrm{H}_{2} \mathrm{O}\right.$; the mineral brushite which has a monoclinic symmetry) and hydroxylapatite $\left(\left[\mathrm{Ca}_{5}\left(\mathrm{PO}_{4}\right)_{3}(\mathrm{OH})\right]\right.$ which crystallizes into the hexagonal crystal system) can be easily crystallized from aqueous solution (often as indistinguishable morphologies) and are two critical minerals. Calcium phosphate mineral morphologies found in bones and teeth are generally less interesting in comparison with the beautifully sculpted calcium carbonates in marine invertebrate biominerals, from a morphological perspective. In bone for example, hydroxylapatite crystals are very small and even not easily identifiable on the macron scale. The more fascinating feature of mammalian biominerals such as bone is the structural arrangement of the calcium phosphate minerals [26]. In the hierarchical structure of bone the fundamental level is the nano-structure of bone where the HAp crystals are interpenetrating within the collagen matrix which makes bone an organic-inorganic composite [5, 55].

Manipulating mineralized tissues as substitutes for bone replacement is one of the major aspects of biomimetic biomineralization. It is notable that to synthesize the implantable 
material for bone, the substitute should match in either chemical or mechanical characteristics. One of the obvious choices for bone replacement in vitro would be organicinorganic composites such as collagen-HAp in the presence of additives to mimic the structure of bone at the nano-level. But due to the high cost of pure collagen, other naturally occurring biomaterials such as chitosan and gelatin (which is derived from type 1 collagen) have received considerable attention with respect to recreating bone-like materials. They can play roles analogous to that of the organic matrix in order to replicate the collagen role in bone formation.

One of the most promising methods of biomimetic mineralization is placing an organic substrate such as collagen into simulated body fluid (SBF) in order to induce calcification. The synthesis of spherically shaped carbonate apatite within collagen fibrils was reported by Rhee et al. [74, 75]. They indicated that the formation of HAp crystals occurred when SBF solution contained citric acid: (Figure 1-13a). They also found that spherulitic apatite minerals nucleate due to the interaction between the minerals and substitute within the collagen matrix after four weeks at $37^{\circ} \mathrm{C}$ (Figure 1-13b). A remarkable advance was made in 2007 in the development of implant materials that better mimic bone structure and composition [5]. It was demonstrated that calcium phosphate mineralization of a collagen matrix could occur in vitro by substituting the non-collagenous proteins with a synthetic acidic protein; polyaspartic acid. For the first time, artificial intrafibrillar mineralization of the collagen matrix was achieved under in vitro conditions, where the apatite crystals formed inside the collagen fibrils had the same morphology and orientation as in native bone (Figure 1-14). This kind of finding opened up many opportunities in developing new advanced materials like bone-replacement scaffolds composed entirely of mineralized collagen.
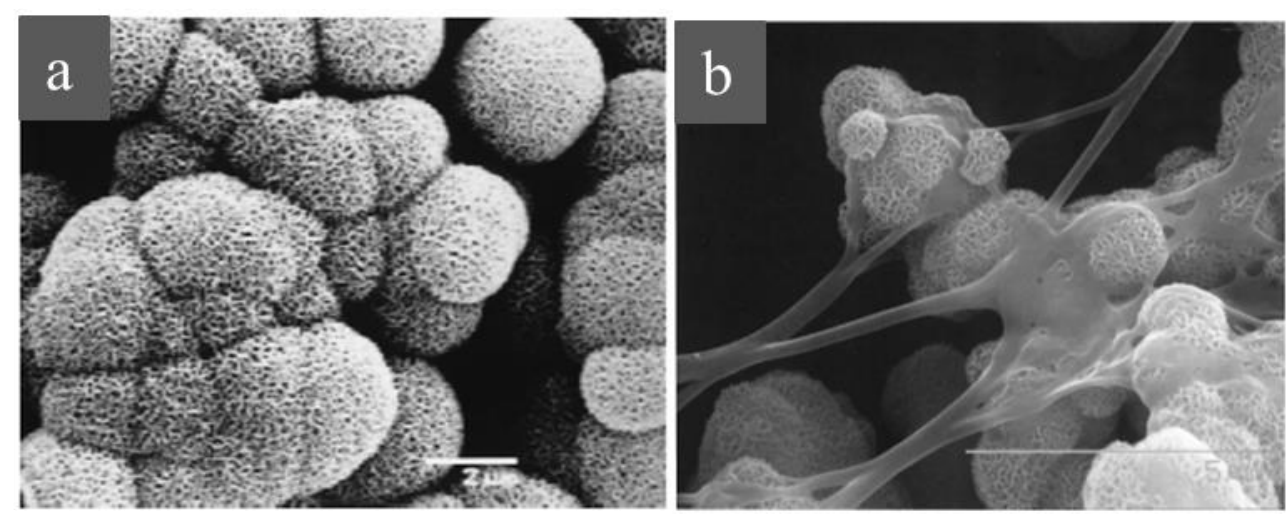

Figure 1-13: Examples of hydroxylapatite growth in collagen substrate. (a) spherical HAp crystals grown throughout the collagen matrix in the presence of citric acid, and (b) 
spherulite growth of HAp minerals in collagen substrate after four weeks, taken from reference $[74,75]$.
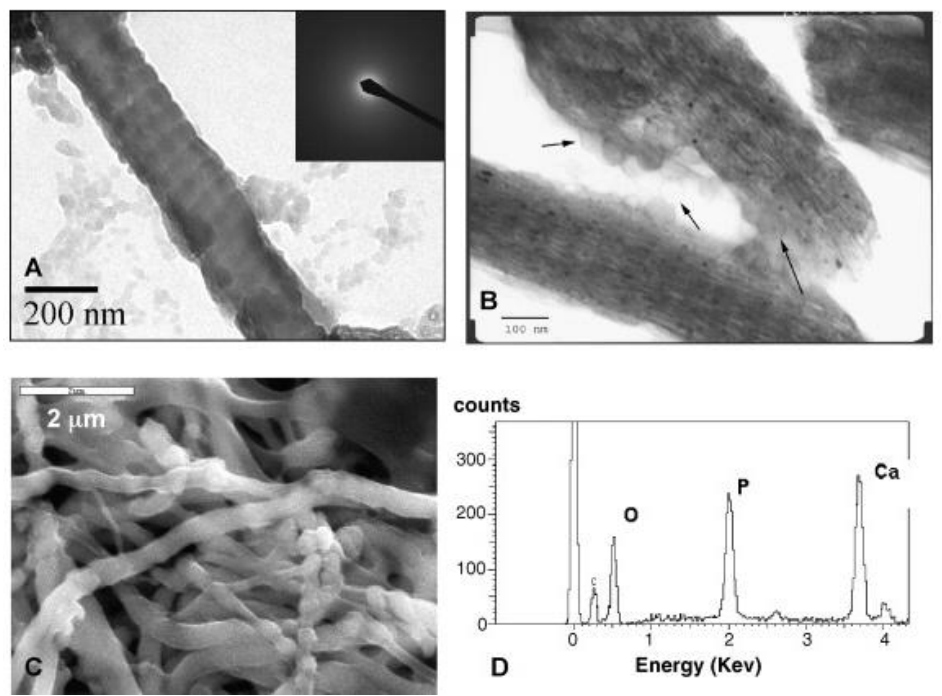

Figure 1-14: Mineralization of collagen in the presence of polyaspartic acid via polymerinduced liquid-precursor (PILP) process. (A) TEM image of amorphous hydroxylapatite during the early stage of mineralization, (B) growth of HAp minerals parallel to collagen fibrils, (C) SEM image shows the morphology of collagen/HAp composite and (D) energy dispersive spectroscopy (EDS) of the mineralized composites confirmed the presence of HAp minerals, taken from the reference [5].

\subsubsection{The place and role of citrate in calcium phosphate growth in bone}

One of the key aspects of biomaterials is how the organic matrix and mineral components hold together. While the role of macromolecules such as carboxylate-rich proteins on calcium phosphate nucleation and growth have been extensively investigated [76, 77], the effect of small organic molecules such as citrate has not $[78,79]$. Surprisingly there is little literature about calcium citrate precipitation (crystalline or amorphous minerals) in biomineralization investigations or tissue engineering despite the prevalence of citrate in the human body. The presence of citrate in bone and other mineralized tissues has been known for a long time [80]. However the role of citrate has been deemphasized in the literature for decades [78, 79]. Recently Hu et al. highlighted the role of citrate in bone biomineralization in particular how strongly citrate molecules are bound to the apatite nanocrystal surface. Through the use of advanced solid-state NMR they showed that the citrate controls the size and thickness of the crystal [78]. 
Figure 1-15 shows the schematic illustration of the citrate-binding apatite model. As can be seen on the Figure 1-15a; (A) presents the early stage of calcium phosphate nucleation, citrate ions partly bind with the early cluster of amorphous calcium phosphate (ACP) in order to inhibit further aggregation of calcium phosphate and increase induction time, (B) shows the later nucleation stage when the presence of non-collagenous protein promoted the nucleation of ACP resulting in a larger ACP cluster, (C) after apatite formation, citrate ions fully cover the surface of the hydroxylapatite crystals due to space matching and inhibit the crystal growth in the thickness direction but continues to allow growth in the longitudinal direction and at the same time bind with the collagen layer [79]. In the Figure 1-15b is presented evidence for the presence of citrate ions in different bones using the solid-state NMR technique [78].

Solid-state NMR investigation is well placed for the examination of molecular structure of final solid products of synthetic biomaterials [81-83]. Inspired by the citrate binding apatite model the in vitro studies on synthesis of self-assembled pluronic polymer-HAp nanocomposites has been done by Hu et al. [84]. They showed that the addition of citrate of similar levels to that present in body fluid, in order to mimic the native bone structure, allows precise molecular level control over the growth of the apatite crystal size from the thickness and size perspective view. The thickness of the HAp crystals changes from $4 \mathrm{~nm}$ to $2.3 \mathrm{~nm}$ which resembles that of bovine and avian bone structures.

In another case Reid et al., investigated the normal mineralized hard tissue, and mineralized articular cartilage, as well as biocalcifications arising in pathological conditions (urinary stones) using the solid-state NMR dipolar dephasing condition [85]. The three expected signals for citrate in ${ }^{13} \mathrm{C}-\mathrm{NMR}$ arise from the carboxylate groups $(\sim 180 \mathrm{ppm})$; quaternary carbon atom ( $76 \mathrm{ppm})$, methylene carbons with two attached hydrogen atoms ( 46 ppm). Using the dipolar dephasing method leads one to being able to distinguish the signals of the quaternary carbon of citrate from those carbon atoms directly bound to hydrogen. Ideally the reference spectrum is acquired with no dipolar dephasing then the dipolar-dephasing condition is applied. Figure 1-16 shows the typical dipolar-dephasing data for a model synthetic citrate-HAp composite. The black trace shows the signals of the reference spectrum without dipolar dephasing and the red dotted trace presents the dipolar dephasing spectrum. The signals attributed to methylene carbons with two attached hydrogen atoms at 46 ppm disappear while the signals from the quaternary carbon atom and carboxylate groups 
are retained as expected. They conclude that citrate is present in healthy bone minerals as well as in those of stones containing apatite minerals.

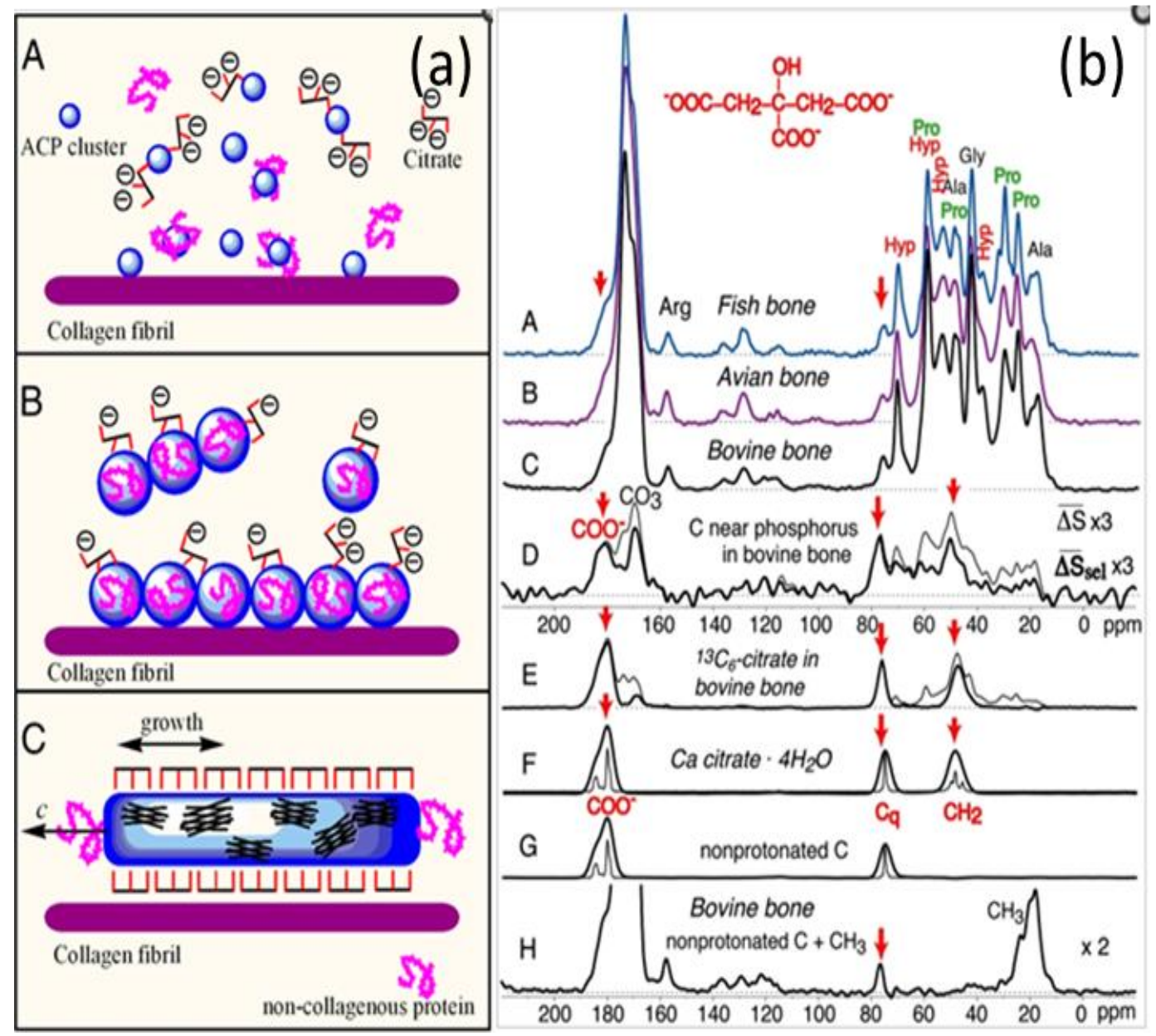

Figure 1-15: (a) the schematic illustration of how the citrate ions stabilize the hydroxylapatite nanocrystal size and thickness refer to text for explanation. (b) ${ }^{13} \mathrm{C}$ NMR spectra of different bone and calcium citrate materials as labelled on the figure to confirm the presence of citrate in bone structure, taken from references $[78,79]$ respectively. 


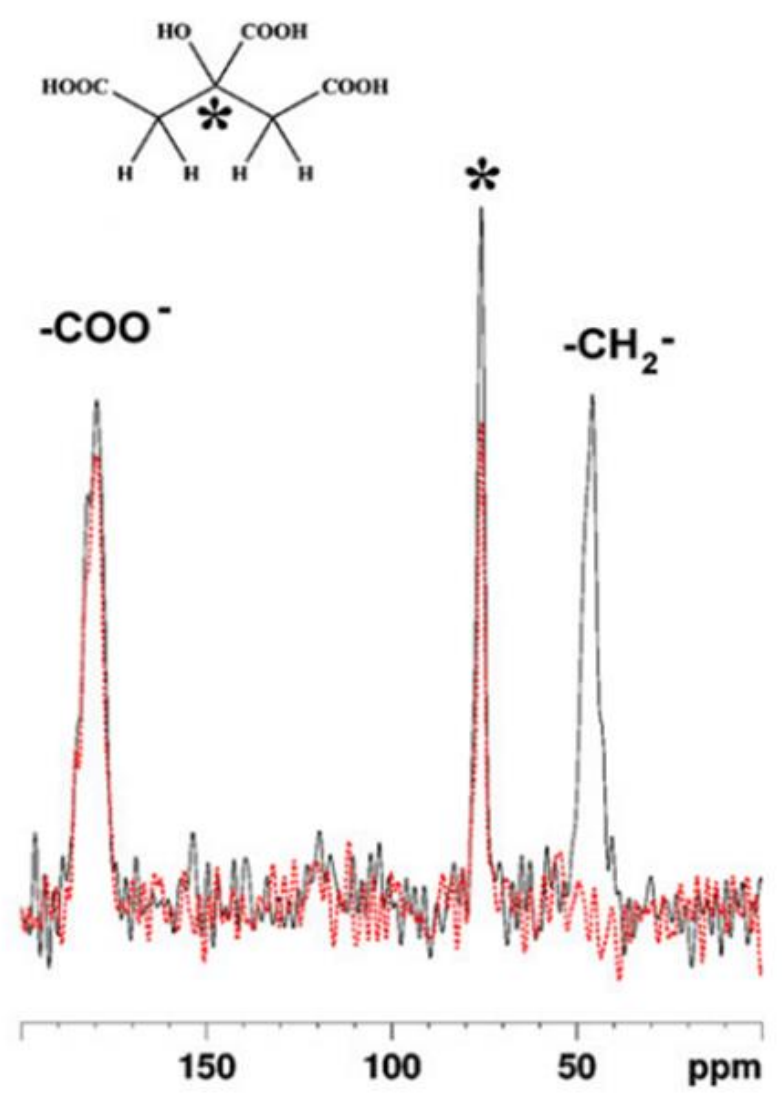

Figure 1-16: Dipolar-dephasing data for a model synthetic citrate-HAp composite: black trace shows a reference peaks without applying dipolar-dephasing condition and red trace shows the effect of dipolar dephasing where the $-\mathrm{CH}_{2}$ carbon atom disappear entirely, taken from reference [85].

\subsection{Mineralization techniques}

In order to study biomimetic mineralization of calcium-based minerals, it is first necessary to consider suitable and adaptable methods of crystallization. In this work the Kitano method, the alternative soaking process and the combined approach of alternative soaking and Kitano, the so-called McGrath method, were used. Each will be described below.

\subsubsection{Kitano method}

The Kitano method is a slow method of crystallization. It was initially developed to induce nucleation at the air/water interface and it is generally used for the growth of calcium carbonate [86]. The method can be modified for other acid-base crystallization systems and to nucleate at sites other than the air/water interface. The Kitano method involves the use of carbon dioxide bubbled through a saturated solution of the mineral of interest. For example, when a suspension of calcium carbonate is bubbled with carbon dioxide the equilibrium of 
$\mathrm{CaCO}_{3} / \mathrm{HCO}_{3}{ }^{-}$is shifted to the right (Equation 1-1) and as a result the solubility of calcium carbonate increases as the $\mathrm{pH}$ decreases. Bubbling $\mathrm{CO}_{2}$ through the saturated solution dissolves $\mathrm{CaCO}_{3}$ until a new equilibrium is established [87].

$$
\begin{array}{ll}
\mathrm{CaCO}_{3}(\mathrm{~s})+\mathrm{H}_{2} \mathrm{O}(\mathrm{l})+\mathrm{CO}_{2}(\mathrm{~g}) \rightleftharpoons \mathrm{HCO}_{3}{ }^{-}(\mathrm{aq})+\mathrm{Ca}^{2+}(\mathrm{aq}) & \text { Eq. 1-1 } \\
2 \mathrm{HCO}_{3}{ }^{-}(\mathrm{aq}) \rightarrow \mathrm{H}_{2} \mathrm{O}(\mathrm{l})+\mathrm{CO}_{3}{ }^{2-}(\mathrm{aq})+\mathrm{CO}_{2}(\mathrm{~g}) & \text { Eq. 1-2 }
\end{array}
$$

The subsequent outgassing of carbon dioxide from a saturated solution of calcium carbonate raises the $\mathrm{pH}$ and induces the crystallization due to the reverse reaction (Eq. 1-2). As carbon dioxide gas effuses from a calcium bicarbonate solution calcium carbonate is formed [88].

The Kitano method is useful as a crystallization technique because it typically allows homogeneous precipitation of calcium carbonate by inorganic processes in the hydrosphere. Furthermore only calcium, carbonate and bicarbonate ions are present in solutions in the case of calcium carbonate crystallization. This makes for better reproducibility, and a simpler system [87, 89]. The Kitano method has been applied to other calcium-based materials the solubility equilibrium of which can be manipulated straightforwardly through solution $\mathrm{pH}$. Growth can occur at sites such as macromolecules in solution, aqueous soluble templates and surfaces (such as water/air interface), which allows a greater interaction with template materials.

\subsubsection{Alternate soaking process}

In the late 1990s Akashi et al. developed the alternate soaking method in order to overcome the time-taking obstacle of other slow crystallization processes. They used a poly (vinyl alcohol) hydrogel as a model matrix and inorganic hydroxylapatite to form a hydrogelhydroxylapatite composite. In this process a hydrogel matrix is alternately soaked with aqueous solution which contains the respective cation and anion of the target mineral. For example in the hydrogel-HAp composite system the hydrogel is soaked with $\mathrm{CaCl}_{2}$ solution for $2 \mathrm{~h}$ and subsequently is soaked with $\mathrm{Na}_{2} \mathrm{HPO}_{4}$ for $2 \mathrm{~h}$ to form hydroxylapatite. This process can be easily applied for many kinds of synthetic or biopolymer hydrogels [90]. The limitation of this method is that it often involves a large number of soaking cycles.

\subsubsection{McGrath method}

Recently Munro et al. developed a method based on the combination of the alternative presoaking and Kitano approaches in order to increase the extent of mineralization that occurs 
within and on the hydrogel matrix. This method allows for hybrid materials to be fabricated where 1) the ratio of organic to inorganic can be readily modified, 2) mineralization occurs in the interior of the organic material and 3) the process can be scaled to materials of different sizes and dimensions. The method is readily adapted to allow formation of final composite materials with different size and shape [11, 12]. Furthermore, many kinds of hydrogel templates may be used with different chemical functionality and/or macroscopic porosity $[91,92]$.

\subsection{Problem description and objectives}

The strategies that living organisms use to produce organic-inorganic composite materials for different purposes such as mechanical support of the body and protection, are complex and fascinating. Mineral nucleation and growth is often mediated, initiated and/or controlled by bio-organic molecules and/or self-assembled templates. The main bio-organic components are proteins, carbohydrates and lipids and the final materials are inherently inorganic/organic composites which have a specific three-dimensional structure such as is the case for bone and mollusc shell. Achieving this combination is aided through the wellchosen use of bimolecular additives that work synchronously to create intricate and precisely controlled architectural structures. The structural design of these composite materials is important in the synthesis and function of hard tissues such as bones and also the storage of essential minerals such as calcium.

Calcium is an essential element in all biological systems. Within a biological organism calcium ions are stored, delivered, or released in the presence of different anions such as phosphate, carbonate, oxalate and citrate. Competition between the different anions which interact with calcium ions in different hydrogel matrices (e.g. carbohydrate or protein) leads to manipulation of the various composite materials produced such as bone (a so-called good example of biomineralization) vs. kidney stones (bad biomineralization). Understanding the role of the hydrogel organic matrices, additives and the method of mineralization in defining crystal nucleation and growth will allow materials with specific structure/function relationships to be engineered.

Although considerable research has been done regarding biomimetic biomineralization of calcium-bearing minerals like calcium carbonate, phosphate and oxalate, there is little literature directly investigating the role of citrate ions in for example the processes of hard 
tissue formation. Citrate ions play a number of important roles in maintaining the calcium cycle in the body and it is stated that these ions have good characteristics in comparison with oxalate ions for example, because most stones formed in the body are oxalate alone or in combination with other anions. It is considered that the place and the role of citrate ions remain unexplored from the perspective of biomineralization.

Our goal is to understand the trends and approaches that organisms use for creating skeleton biominerals and deciphering the processes involved in biomineralisation that are essential for the fabrication of specialized organic-inorganic hybrid synthetic materials for use in biomedical applications, particularly implantable materials. In particular our major focus is using the simplicity of nacre and the components involved in nacre such as nacre-like additives, to fabricate not only mammalian mineralized tissue but advanced novel materials.

Here we have utilized two different matrices; chitosan and gelatin (carbohydrate vs. protein) to regulate the crystallization and crystal morphology of calcium carbonate and calcium phosphate formed within the chitosan and gelatin hydrogel templates. In particular an understanding of how the different matrices behave in controlled crystal nucleation and growth for different mineralization processes coupled with the use of carbonate, phosphate and citrate anions is gained. The similarities and differences between the two hydrogel templates, carbohydrate versus protein have been gained. Three different crystallization methods were used (Kitano method, alternative soaking method and the McGrath method). The morphology of the crystals was influenced by the mineralization method as well as which matrix was used.

The influence of organic acidic additives on the nucleation, growth and inhibition of calcium carbonate and phosphate precipitation throughout chitosan and gelatin hydrogels films was investigated in order to mimic the role of proteins in bone and nacre systems. The possible role of these additives in controlling calcium carbonate and calcium phosphate mineralization processes were observed. Surprisingly there is little literature directly investigating the role of citrate ions in for example the processes of hard tissue formation. Due to the known inhibitory effect of citrate on mineralization we have focused on understanding what happens when the system has a choice to associate with a different anion (i.e. we will consider competition processes) [93]. 


\subsection{Thesis structure}

This thesis is presented in 4 chapters beyond the introduction presented above:

Chapter 2: The deposition of the $\mathrm{CaCO}_{3}$ through a chitosan vs. gelatin hydrogel template was investigated. Precipitation of calcium carbonate within a chitosan matrix aided us to mimic nacre to create new nacre-like materials. Additionally because calcium carbonate is a major element of invertebrate marine skeleton structure it serves as a good candidate for combination with vertebrate mammalian protein matrix elements like collagen. Here gelatin substrates were used as a scaffold in order to study the $\mathrm{CaCO}_{3}$ crystallization within a protein matrix template with a potential application being implantable material. When studying the influence of carbohydrate vs. protein on calcium carbonate growth however, it is important to consider the effect of the mineralization method as well. The effect of the monomeric additives and their corresponding polymeric water soluble acidic additives (mimicking the acidic protein roles in natural biomineral formation) on calcium carbonate nucleation and growth for both chitosan and gelatin hydrogel templates in order to control the crystallization process were synthetically examined. The additives used are acrylic acid, L-glutamic acid, L-aspartic acid and their corresponding polymers.

Chapter 3: Here the focus is switched to calcium phosphate precipitation within chitosan vs. gelatin hydrogel templates in the presence of the same additives as explored in Chapter 2. The differences and similarities between the carbonate and phosphate anions are considered.

Chapter 4: The role of citrate as an additive on calcium phosphate growth is presented. Due to the importance of citrate on hydroxylapatite growth in bone biomineralization, calcium phosphate deposition is used as the focus for both chitosan and gelatin hydrogel templates. Advanced solid state nuclear magnetic resonance (SSNMR) techniques we used to enable identification of the synthetic biominerals at the atomic level.

Chapter 5: The major outcomes from this work are summarized and suggestions for future research are provided. 


\section{References}

1. Amini, A.R., C.T. Laurencin and S.P. Nukavarapu, Bone Tissue Engineering: Recent Advances and Challenges. 2012. 40(5): p. 363-408.

2. Baroli, B., From natural bone grafts to tissue engineering therapeutics: Brainstorming on pharmaceutical formulative requirements and challenges. Journal of Pharmaceutical Sciences, 2009. 98(4): p. 1317-1375.

3. Ruys, A.J., Biomimetic Biomaterials: Structure and Applications. 2013: Elsevier Science.

4. Luz, G.M. and J.F. Mano, Biomimetic design of materials and biomaterials inspired by the structure of nacre. Vol. 367. 2009. 1587-1605.

5. Olszta, M.J., X. Cheng, S.S. Jee, R. Kumar, Y.-Y. Kim, M.J. Kaufman, E.P. Douglas and L.B. Gower, Bone structure and formation: A new perspective. Materials Science and Engineering: R: Reports, 2007. 58(3-5): p. 77-116.

6. Kunz, W. and M. Kellermeier, Beyond Biomineralization. Science, 2009. 323(5912): p. 344-345.

7. Nudelman, F. and N.A.J.M. Sommerdijk, Biomineralization as an Inspiration for Materials Chemistry. Angewandte Chemie International Edition, 2012. 51(27): p. 6582-6596.

8. Wegst, U.G.K., H. Bai, E. Saiz, A.P. Tomsia and R.O. Ritchie, Bioinspired structural materials. Nat Mater, 2015. 14(1): p. 23-36.

9. Gebauer, D., H. Cölfen, A. Verch and M. Antonietti, The Multiple Roles of Additives in $\mathrm{CaCO}_{3}$ Crystallization: A Quantitative Case Study. Advanced Materials, 2009. 21(4): p. 435-439.

10. Wang, R. and H.S. Gupta, Deformation and Fracture Mechanisms of Bone and Nacre. Annual Review of Materials Research, 2011. 41(1): p. 41-73.

11. Munro, N.H., D.W. Green and K.M. McGrath, In situ continuous growth formation of synthetic biominerals. Chemical Communications, 2013. 49(33): p. 3407-3409.

12. Munro, N.H. and K.M. McGrath, Biomimetic approach to forming chitin/aragonite composites. Chemical Communications, 2012. 48(39): p. 4716-4718.

13. Yao, H.-B., J. Ge, L.-B. Mao, Y.-X. Yan and S.-H. Yu, 25th Anniversary Article: Artificial Carbonate Nanocrystals and Layered Structural Nanocomposites Inspired by Nacre: Synthesis, Fabrication and Applications. Advanced Materials, 2014. 26(1): p. 163-188.

14. Addadi, L. and S. Weiner, Control and Design Principles in Biological Mineralization. Angewandte Chemie International Edition in English, 1992. 31(2): p. 153-169.

15. Lowenstam, H.A.W., S, on biomineralization. 1989, Oxford University Press.

16. Fratzl, P. and R. Weinkamer, Nature's hierarchical materials. Progress in Materials Science, 2007. 52(8): p. 1263-1334.

17. Weber, E. and B. Pokroy, Intracrystalline inclusions within single crystalline hosts: from biomineralization to bio-inspired crystal growth. CrystEngComm, 2015. 17(31): p. 5873-5883.

18. Pokroy, B., J.P. Quintana, E.a.N. Caspi, A. Berner and E. Zolotoyabko, Anisotropic lattice distortions in biogenic aragonite. Nat Mater, 2004. 3(12): p. 900-902. 
19. Mann, S., Molecular recognition in biomineralization. Nature, 1988. 332(6160): p. 119-124.

20. Weiner, S. and P.M. Dove, An Overview of Biomineralization Processes and the Problem of the Vital Effect. Reviews in Mineralogy and Geochemistry, 2003. 54(1): p. 1-29.

21. Veis, A., A Window on Biomineralization. Science, 2005. 307(5714): p. 1419-1420.

22. Veis, A., Mineralization in Organic Matrix Frameworks. Reviews in Mineralogy and Geochemistry, 2003. 54(1): p. 249-289.

23. Colfen, H., Biomineralization: A crystal-clear view. Nat Mater, 2010. 9(12): p. 960-961.

24. Sanchez, C., H. Arribart and M.M. Giraud Guille, Biomimetism and bioinspiration as tools for the design of innovative materials and systems. Nat Mater, 2005. 4(4): p. 277-288.

25. Cai, Y.-r. and R.-k. Tang, Towards understanding biomineralization: calcium phosphate in a biomimetic mineralization process. Frontiers of Materials Science in China, 2009. 3(2): p. 124-131.

26. Gower, L.B., Biomimetic Model Systems for Investigating the Amorphous Precursor Pathway and Its Role in Biomineralization. Chemical Reviews, 2008. 108(11): p. 4551-4627.

27. Meldrum, F.C., Calcium carbonate in biomineralisation and biomimetic chemistry. International Materials Reviews, 2003. 48(3): p. 187-224.

28. Keene, E.C., J.S. Evans and L.A. Estroff, Silk Fibroin Hydrogels Coupled with the $n 16 N-\beta$ Chitin Complex: An in Vitro Organic Matrix for Controlling Calcium Carbonate Mineralization. Crystal Growth \& Design, 2010. 10(12): p. 5169-5175.

29. Asenath-Smith, E., H. Li, E.C. Keene, Z.W. Seh and L.A. Estroff, Crystal Growth of Calcium Carbonate in Hydrogels as a Model of Biomineralization. Advanced Functional Materials, 2012. 22(14): p. 2891-2914.

30. Ozawa, H., K. Hoshi and N. Amizuka, Current Concepts of Bone Biomineralization. Journal of Oral Biosciences, 2008. 50(1): p. 1-14.

31. Mann, S., B.R. Heywood, S. Rajam and J.D. Birchall, Controlled crystallization of $\mathrm{CaCO}_{3}$ under stearic acid monolayers. Nature, 1988. 334(6184): p. 692-695.

32. McGrath, K.M., N.H Munro, Hydrogels as biomimetic mineralisation scaffolds. Bioinspired, Biomimetic and Nanobiomaterials, 2011. 1(1): p. 26-37.

33. Barbucci, R., Hydrogels. 2009: Springer.

34. Slaughter, B.V., S.S. Khurshid, O.Z. Fisher, A. Khademhosseini and N.A. Peppas, Hydrogels in Regenerative Medicine. Advanced Materials, 2009. 21(32-33): p. 3307-3329.

35. Masutani, E.M., C.K. Kinoshita, T.T. Tanaka, A.K.D. Ellison and B.A. Yoza, Increasing Thermal Stability of Gelatin by UV-Induced Cross-Linking with Glucose. International Journal of Biomaterials, 2014. 2014: p. 9.

36. Xing, Q., K. Yates, C. Vogt, Z. Qian, M.C. Frost and F. Zhao, Increasing Mechanical Strength of Gelatin Hydrogels by Divalent Metal Ion Removal. Sci. Rep., 2014. 4.

37. Bode, F., M.A. da Silva, A.F. Drake, S.B. Ross-Murphy and C.A. Dreiss, Enzymatically CrossLinked Tilapia Gelatin Hydrogels: Physical, Chemical, and Hybrid Networks. Biomacromolecules, 2011. 12(10): p. 3741-3752. 
38. Mann, S., Biomineralization: Principles and Concepts in Bioinorganic Materials Chemistry. 2001: Oxford University Press.

39. Maekiniemi, R., P. Das, D. Hoenders, K. Grygiel, D. Cordella, C. Detrembleur, J. Yuan and A. Walther, Conducting, self-assembled, nacre-mimetic polymer/clay nanocomposites. ACS Applied Materials \& Interfaces, 2015.

40. Xia, S., Z. Wang, H. Chen, W. Fu, J. Wang, Z. Li and L. Jiang, Nanoasperity: Structure Origin of Nacre-Inspired Nanocomposites. ACS Nano, 2015. 9(2): p. 2167-2172.

41. Gilbert, P.U.P.A., R.A. Metzler, D. Zhou, A. Scholl, A. Doran, A. Young, M. Kunz, N. Tamura and S.N. Coppersmith, Gradual Ordering in Red Abalone Nacre. Journal of the American Chemical Society, 2008. 130(51): p. 17519-17527.

42. Sun, J. and B. Bhushan, Hierarchical structure and mechanical properties of nacre: a review. RSC Advances, 2012. 2(20): p. 7617-7632.

43. Song, F., A.K. Soh and Y.L. Bai, Structural and mechanical properties of the organic matrix layers of nacre. Biomaterials, 2003. 24(20): p. 3623-3631.

44. Smith, B.L., T.E. Schaffer, M. Viani, J.B. Thompson, N.A. Frederick, J. Kindt, A. Belcher, G.D. Stucky, D.E. Morse and P.K. Hansma, Molecular mechanistic origin of the toughness of natural adhesives, fibres and composites. Nature, 1999. 399(6738): p. 761-763.

45. Addadi, L., D. Joester, F. Nudelman and S. Weiner, Mollusk Shell Formation: A Source of New Concepts for Understanding Biomineralization Processes. Chemistry - A European Journal, 2006. 12(4): p. 980-987.

46. Suzuki, M., Y. Dauphin, L. Addadi and S. Weiner, Atomic order of aragonite crystals formed by mollusks. CrystEngComm, 2011. 13(22): p. 6780-6786.

47. Schäffer, T.E., C. Ionescu-Zanetti, R. Proksch, M. Fritz, D.A. Walters, N. Almqvist, C.M. Zaremba, A.M. Belcher, B.L. Smith, G.D. Stucky, D.E. Morse, and P.K. Hansma, Does Abalone Nacre Form by Heteroepitaxial Nucleation or by Growth through Mineral Bridges? Chemistry of Materials, 1997. 9(8): p. 1731-1740.

48. Addadi, L. and S. Weiner, Biomineralization: A pavement of pearl. Nature, 1997. 389(6654): p. 912-915.

49. Smith, B.L., The importance of molecular structure and conformation: learning with scanning probe microscopy. Progress in Biophysics and Molecular Biology, 2000. 74(1-2): p. 93-113.

50. Meldrum, F.C. and H. Cölfen, Controlling Mineral Morphologies and Structures in Biological and Synthetic Systems. Chemical Reviews, 2008. 108(11): p. 4332-4432.

51. Pereira-Mouriès, L., M.-J. Almeida, C. Ribeiro, J. Peduzzi, M. Barthélemy, C. Milet and E. Lopez, Soluble silk-like organic matrix in the nacreous layer of the bivalve Pinctada maxima. European Journal of Biochemistry, 2002. 269(20): p. 4994-5003.

52. Suzuki, M., K. Saruwatari, T. Kogure, Y. Yamamoto, T. Nishimura, T. Kato and H. Nagasawa, An Acidic Matrix Protein, Pif, Is a Key Macromolecule for Nacre Formation. Science, 2009. 325(5946): p. 1388-1390.

53. Meyers, M.A., P.-Y. Chen, A.Y.-M. Lin and Y. Seki, Biological materials: Structure and mechanical properties. Progress in Materials Science, 2008. 53(1): p. 1-206. 
54. Beniash, E., Biominerals—hierarchical nanocomposites: the example of bone. Wiley Interdisciplinary Reviews: Nanomedicine and Nanobiotechnology, 2011. 3(1): p. 47-69.

55. Weiner, S. and H.D. Wagner, THE MATERIAL BONE: Structure-Mechanical Function Relations. Annual Review of Materials Science, 1998. 28(1): p. 271-298.

56. Weiner, S. and P. Zaslansky, Structure-Mechanical Function Relations in Bones and Teeth, in Learning from Nature How to Design New Implantable Biomaterialsis: From Biomineralization Fundamentals to Biomimetic Materials and Processing Routes, R.L. Reis and S. Weiner, Editors. 2005, Springer Netherlands. p. 3-13.

57. Veis, A., Mineral-matrix interactions in bone and dentin. Journal of Bone and Mineral Research, 1993. 8(S2): p. S493-S497.

58. Weiner, S. and L. Addadi, Design strategies in mineralized biological materials. Journal of Materials Chemistry, 1997. 7(5): p. 689-702.

59. De Yoreo, J.J. and P.G. Vekilov, Principles of Crystal Nucleation and Growth. Reviews in Mineralogy and Geochemistry, 2003. 54(1): p. 57-93.

60. Ren, D., Q. Feng and X. Bourrat, Effects of additives and templates on calcium carbonate mineralization in vitro. Micron, 2011. 42(3): p. 228-245.

61. Boskey, A.L. and R. Roy, Cell Culture Systems for Studies of Bone and Tooth Mineralization. Chemical Reviews, 2008. 108(11): p. 4716-4733.

62. Dorvee, J.R., A.L. Boskey and L.A. Estroff, Rediscovering hydrogel-based double-diffusion systems for studying biomineralization. CrystEngComm, 2012. 14(18): p. 5681-5700.

63. Muzzarelli, C. and R.A.A. Muzzarelli, Natural and artificial chitosan-inorganic composites. Journal of Inorganic Biochemistry, 2002. 92(2): p. 89-94.

64. Butler, M.F., N. Glaser, A.C. Weaver, M. Kirkland and M. Heppenstall-Butler, Calcium Carbonate Crystallization in the Presence of Biopolymers. Crystal Growth \& Design, 2006. 6(3): p. 781-794.

65. Zhang, S. and K.E. Gonsalves, Chitosan-calcium carbonate composites by a biomimetic process. Materials Science and Engineering: C, 1995. 3(2): p. 117-124.

66. Kato, T., T. Suzuki, T. Amamiya, T. Irie, M. Komiyama and H. Yui, Effects of macromolecules on the crystallization of $\mathrm{CaCO}_{3}$ the Formation of Organic/Inorganic Composites. Supramolecular Science, 1998. 5(3-4): p. 411-415.

67. Wu, Y., C. Cheng, J. Yao, X. Chen and Z. Shao, Crystallization of Calcium Carbonate on Chitosan Substrates in the Presence of Regenerated Silk Fibroin. Langmuir, 2011. 27(6): p. 28042810.

68. Aschauer, U., J. Ebert, A. Aimable and P. Bowen, Growth Modification of Seeded Calcite by Carboxylic Acid Oligomers and Polymers: Toward an Understanding of Complex Growth Mechanisms. Crystal Growth \& Design, 2010. 10(9): p. 3956-3963.

69. Shen, F.H., Q.L. Feng and C.M. Wang, The modulation of collagen on crystal morphology of calcium carbonate. Journal of Crystal Growth, 2002. 242(1-2): p. 239-244. 
70. Falini, G., M. Gazzano and A. Ripamonti, Calcite crystallization on gelatin films containing polyelectrolytes. Advanced Materials, 1994. 6(1): p. 46-48.

71. Falini, G., S. Fermani, M. Gazzano and A. Ripamonti, Oriented Crystallization of Vaterite in Collagenous Matrices. Chemistry - A European Journal, 1998. 4(6): p. 1048-1052.

72. Wang, L. and G.H. Nancollas, Pathways to biomineralization and biodemineralization of calcium phosphates: the thermodynamic and kinetic controls. Dalton Transactions, 2009(15): p. 2665-2672.

73. Dorozhkin, S.V. and M. Epple, Biological and Medical Significance of Calcium Phosphates. Angewandte Chemie International Edition, 2002. 41(17): p. 3130-3146.

74. Rhee, S.-H. and J. Tanaka, Hydroxyapatite Coating on a Collagen Membrane by a Biomimetic Method. Journal of the American Ceramic Society, 1998. 81(11): p. 3029-3031.

75. Rhee, S.-H., J.D. Lee and J. Tanaka, Nucleation of Hydroxyapatite Crystal through Chemical Interaction with Collagen. Journal of the American Ceramic Society, 2000. 83(11): p. 2890-2892.

76. Deshpande, A.S., P.-A. Fang, J.P. Simmer, H.C. Margolis and E. Beniash, Amelogenin-Collagen Interactions Regulate Calcium Phosphate Mineralization in Vitro. Journal of Biological Chemistry, 2010. 285(25): p. 19277-19287.

77. Yang, Y., Q. Cui and N. Sahai, How Does Bone Sialoprotein Promote the Nucleation of Hydroxyapatite? A Molecular Dynamics Study Using Model Peptides of Different Conformations. Langmuir, 2010. 26(12): p. 9848-9859.

78. Hu, Y.-Y., A. Rawal and K. Schmidt-Rohr, Strongly bound citrate stabilizes the apatite nanocrystals in bone. Proceedings of the National Academy of Sciences, 2010. 107(52): p. 2242522429.

79. Xie, B. and G.H. Nancollas, How to control the size and morphology of apatite nanocrystals in bone. Proceedings of the National Academy of Sciences, 2010. 107(52): p. 22369-22370.

80. Hartles, R.L. and A.G. Leaver, Citrate in mineralized tissues -I: Citrate in human dentine. Archives of Oral Biology, 1960. 1(4): p. 297-303.

81. DiMasi, E. and L.B. Gower, Biomineralization Sourcebook: Characterization of Biominerals and Biomimetic Materials. 2014: Taylor \& Francis.

82. Duer, M.J., The contribution of solid-state NMR spectroscopy to understanding biomineralization: Atomic and molecular structure of bone. Journal of Magnetic Resonance, 2015. 253: p. 98-110.

83. Davies, E., K.H. Müller, W.C. Wong, C.J. Pickard, D.G. Reid, J.N. Skepper and M.J. Duer, Citrate bridges between mineral platelets in bone. Proceedings of the National Academy of Sciences, 2014. 111(14): p. E1354-E1363.

84. Hu, Y.Y., X.P. Liu, X. Ma, A. Rawal, T. Prozorov, M. Akinc, S.K. Mallapragada and K. SchmidtRohr, Biomimetic Self-Assembling Copolymer-Hydroxyapatite Nanocomposites with the Nanocrystal Size Controlled by Citrate. Chemistry of Materials, 2011. 23(9): p. 2481-2490.

85. Reid, D., M. Duer, G. Jackson, R. Murray, A. Rodgers and C. Shanahan, Citrate Occurs Widely in Healthy and Pathological Apatitic Biomineral: Mineralized Articular Cartilage, and Intimal 
Atherosclerotic Plaque and Apatitic Kidney Stones. Calcified Tissue International, 2013. 93(3): p. 253-260.

86. Neira-Carrillo, A.n., D.F. Acevedo, M.C. Miras, C.A. Barbero, D. Gebauer, H. Cölfen and J.L. Arias, Influence of Conducting Polymers Based on Carboxylated Polyaniline on In Vitro $\mathrm{CaCO}_{3}$ Crystallization. Langmuir, 2008. 24(21): p. 12496-12507.

87. Kitano, Y., The Behavior of Various Inorganic Ions in the Separation of Calcium Carbonate from a Bicarbonate Solution. Bulletin of the Chemical Society of Japan, 1962. 35(12): p. 1973-1980.

88. Dobson, P.S., L.A. Bindley, J.V. Macpherson and P.R. Unwin, Atomic Force Microscopy Investigation of the Mechanism of Calcite Microcrystal Growth under Kitano Conditions. Langmuir, 2005. 21(4): p. 1255-1260.

89. Kitano, Y., K. Park and D.W. Hood, Pure Aragonite Synthesis. J. Geophys. Res., 1962. 67(12): p. $4873-4874$.

90. Taguchi, T., A. Kishida and M. Akashi, Hydroxyapatite Formation on/in Poly(vinyl alcohol) Hydrogel Matrices Using a Novel Alternate Soaking Process. Chemistry Letters, 1998. 27(8): p. 711-712.

91. Munro, N.H., D.W. Green, A. Dangerfield and K.M. McGrath, Biomimetic mineralisation of polymeric scaffolds using a combined soaking and Kitano approach. Dalton Transactions, 2011. 40(36): p. 9259-9268.

92. Munro, N.H. and K.M. McGrath, Biomimetic mineralisation of polymeric scaffolds using a combined soaking approach: adaptation with various mineral salts. Dalton Transactions, 2011. 40(36): p. 9269-9275.

93. Weaver, M.L., S.R. Qiu, J.R. Hoyer, W.H. Casey, G.H. Nancollas and J.J. De Yoreo, Inhibition of calcium oxalate monohydrate growth by citrate and the effect of the background electrolyte. Journal of Crystal Growth, 2007. 306(1): p. 135-145. 


\section{Chapter 2}

\section{Additive controlled biomimetic mineralization of calcium carbonate in carbohydrate vs. protein hydrogel scaffolds}

\subsection{Introduction}

Inspiration from natural processes such as biomineralisation is a key tool for designing new advanced materials. Naturally occurring materials like nacre and bone are receiving considerable attention in the drive to create synthetic hard tissues and also in developing materials with enhanced storage capacity of essential minerals such as calcium $[1,2]$. Through the process of biomineralisation, nature achieves the combination of organic macromolecules (carbohydrate and protein) as hydrogels representing the responsive scaffold, and inorganic minerals in a single integrated material [3, 4]. This combination is aided by well-chosen additives creating intricate precisely controlled architectural structures under ambient processing conditions.

Throughout history biomaterials have been used in medical applications. Nacre is a good example which has been used as an implantable material in the body. Nacre was used by Mayans as an artificial tooth replacement because it integrates into the body after implantation [5]. This integration is due to nacre's specific highly organized micro-structure which has, among other things similar mechanical strength to human hard tissue. Nacre's hardness combined with its excellent stiffness, strength and toughness is attributed to its internal structural organization which contains layers of interlocking calcium carbonate (aragonite) tablets separated by a thin layer of organic hydrogel matrix and water soluble acidic protein additives $[4,6]$. Understanding and applying the processes involved in nacre synthesis will lead to the development of bioinspired materials using self-assembly to create hierarchically-ordered composites. Investigating the role of each component in nacre formation such as the organic macromolecules including the organic scaffold and the acidic additives in addition to the mineralization pathway enables better understanding of, for example, how to control mineral crystal size, shape and polymorph.

The essential components required to replicate nacre under laboratory condition can be narrowed down to the following: the organic insoluble scaffold, the soluble acid-rich 
proteins and the presence of precursor ions from calcium and carbonate sources. [7]. Nacre, which contains calcium carbonate, is one of the most studied biominerals due to its abundance and high degree of crystallographic control over mineral formation. Calcium carbonate forms different polymorphs such as calcite, aragonite, vaterite and amorphous (in decreasing order of thermodynamic stability) and displays a large array of morphologies. Nacre is comprised of aragonite platelets and is about 3000 times more resistant to fracture than a single crystal of the pure mineral aragonite [4].

The three-dimensional macromolecular assembly structure of the proteins, polysaccharides and lipids is also a key to mimicking tissue environments. Hydrogel templates have emerged as promising materials for the in situ formation of composite biomaterials [8, 9]. These hydrated networks are often porous which can provide the framework for mineralization. The porous three dimensional structure of the hydrogel facilitates easy diffusion of cations and anions of the target mineral enabling mineral formation throughout the hydrogel matrix [8-11].

Despite hydrogel scaffolds being insoluble matrices (as is the case of the chitin scaffold in nacre for example), they still serve as a source of chemical functionalities to direct nucleation and growth of the mineral crystals. This is known as matrix-mediated biomineralization: the matrix moieties are intimately associated within the resulting biominerals as well as any soluble additives forming a unique inorganic-organic hybrid composite material $[12,13]$. Polysaccharide biopolymers such as chitosan $[14,15]$ as well as proteins such as gelatin [16] are the most commonly used hydrogel scaffolds in mimicking biomineralization systems due to their biocompatibility.

The porous chitosan network on the one hand, and the extensive protonation of the amine functional groups of chitosan on the other gives the chitosan an active role in biomineralization. These scaffolds can be used to control for example calcium carbonate crystallization due to the following aspects: 1) the presence of different functional groups in the matrix has the potential to interact with introduced solutes (e.g. $\mathrm{Ca}^{2+}$ and $\mathrm{CO}_{3}{ }^{2-}$ ), which change the local concentration of the reactants; and 2) they can serve as nucleation sites to modulate the symmetry orientation of the growing inorganic crystals with the hydrogel scaffold $[8,14,17]$.

Gelatin is an example of a protein-based hydrogel which contains both acidic (carboxylic acid) and basic (amine) functional groups and it is considered to be a good candidate as a 
comparative material to the carbohydrate-based biomineralization study $[16,18]$. A number of successful nacre-like materials have been fabricated using chitosan and gelatin as scaffolds for calcium carbonate mineralization [19, 20].

Although the organic hydrogel matrices are active scaffolds in facilitating and controlling crystallization [21], the use of additives which mimic the role of acid-rich protein in biological systems as inhibitors or promoters of crystal growth, has been identified as an important element in controlling mineralization in vitro [12, 22-25]. It has been shown that in a living system there are different additives present which play different roles or work in concert to direct crystallization [26, 27]. The use of organic anionic water-soluble additives can lead to excellent control over size, structure, morphology and hierarchy of the inorganic phase [28]. In multi-component materials such as nacre the calcium carbonate not only interacts with the organic hydrogel polymer, in order to generate the observed hierarchical structures, but other components such as acidic proteins from the carboxylate part or cterminate polymeric additives interact with calcium ions and carry them to nucleation sites to initiate crystallization.

It is widely believed that soluble and insoluble additives are responsible for defining and controlling precipitation of calcium carbonate in vivo [29]. Diverse synthetic and natural additives have been used for modulating the crystallization process in hydrogel templating scaffolds [22, 23, 28, 30, 31]. For example anionic polyelectrolytes such as polyacrylic acid (PAA) has been shown to be a potent additive in controlling mineral morphology resulting in a structure similar to that seen in natural systems due to its ability to associate with the mineral phase. In similarity to biological additives, PAA can also stabilize the unstable polymorph vaterite with respect to calcite in the case of calcium carbonate mineralization in a carbohydrate matrix [14]. While the role of additives in vitro has been widely explored, to the best of our knowledge no studies using the full set of additive systems investigated here; monomers and their corresponding polymers have been undertaken previously.

In order to fabricate nacre-like hybrid composite materials under laboratory conditions three different approaches have commonly been used. 1) The alternative soaking approach which involves alternatively soaking the hydrogel template in aqueous solutions of the respective cation and anion of the target mineral one or more times. 2) The Kitano method which involves exposing the template to a saturated solution of the mineral that has been prebubbled with carbon dioxide. 3) The McGrath method, recently developed in our laboratory 
which is based on the combination of the alternative pre-soaking and Kitano approaches in order to increase the extent of mineralization that occurs within and on the hydrogel matrix $[14,32]$.

The work presented here provides a systematic study of calcium carbonate crystallization within chitosan and gelatin scaffolds in the absence and presence of additives. In this Chapter the following investigation is reported:

First, the effect of two different hydrogel matrices: chitosan vs. gelatin in controlling calcium carbonate crystallization in the absence of additives in order to understand the contribution of the scaffolds alone on the calcium carbonate mineralization. Here we want to mimic not only the structure of nacre, creating a nacre-like material under laboratory conditions, but also to develop an understanding of the effect of protein-based hydrogels (gelatin) in controlling calcium carbonate mineralization in comparison with carbohydrate-based hydrogels (chitosan).

Second, we investigate how the mineralization techniques used in this study influence calcium carbonate nucleation and growth in both $\mathrm{CaCO}_{3} /$ chitosan and $\mathrm{CaCO}_{3}$ /gelatin composite systems.

Finally we introduced monomeric vs. polymeric soluble anionic additives to both the gelatin and chitosan systems in order to control the crystallization process. In particular the small monomeric additives behaviour versus the corresponding polymers was studied. The additives used were acrylic acid, L-glutamic acid, L-aspartic acid and their corresponding polymers. 


\subsection{Materials and Experimental procedure}

\subsubsection{Materials}

Analytical grade chitosan ( $\mathrm{M}_{\mathrm{w}}$ : 100,000-300,000 g/mol), gelatin type A (from porcine skin with gel strength $\sim 300 \mathrm{~g}$ bloom), calcium chloride dihydrate $\left(\mathrm{CaCl}_{2} \cdot 2 \mathrm{H}_{2} \mathrm{O}\right)$, sodium phosphate dibasic $\left(\mathrm{Na}_{2} \mathrm{HPO}_{4}\right)$, L-aspartic acid, L-glutamic acid, acrylic acid, polyacrylic acid ( $\mathrm{M}_{\mathrm{w}}$ : average $\left.1800 \mathrm{~g} / \mathrm{mol}\right)$, poly(L-glutamic acid) $\left(\mathrm{M}_{\mathrm{w}}\right.$ : average $\left.1200-15000 \mathrm{~g} / \mathrm{mol}\right)$ and glutaraldehyde 50\% (v/v) were purchased from Sigma Aldrich. Acetic acid (Univar, AR grade), $\mathrm{CaCO}_{3}$ (Univar, $\mathrm{AR}$ grade), $\mathrm{NaHCO}_{3}$ (Panreac) and poly L-aspartic acid sodium salt (Chem Cruz (USA) Mw: average 3000-15000 g/mol) were used as received. For all solutions $18 \mathrm{M} \Omega \cdot \mathrm{cm}$ water (purified by Sartorius arium 611UV purification system, $18.2 \mathrm{M} \Omega \mathrm{cm}$ resistivity) was used in this study.

\subsubsection{Chitosan film formation}

Typically a $2 \mathrm{wt} \%$ chitosan solution in $1 \%(\mathrm{v} / \mathrm{v})$ aqueous acetic acid was used to form cast chitosan films. The hydrogel solution was stirred for $1 \mathrm{~h}$ at room temperature $\left(25^{\circ} \mathrm{C}\right)$ and then centrifuged at $3000 \mathrm{rpm}$ for $20 \mathrm{~min}$ to obtain a homogeneous solution. Depending on the shape and size of the dish used for casting, films of different shape and size can be produced. In this work, in general, $20 \mathrm{~mL}$ of chitosan solution was placed into a $9 \mathrm{~cm}$ diameter plastic Petri dish and dried in an oven at $40^{\circ} \mathrm{C}$ for $48 \mathrm{~h}$ to ensure complete drying. The achieved films are transparent, robust and pliable with a thickness of about $50 \mu \mathrm{m}$. The film is cured by soaking in sodium hydroxide solution $(1 \mathrm{M}, 30 \mathrm{~mL})$ for $1 \mathrm{~h}$ resulting in an electrostatic interaction between the chains to form an insoluble film. In order to investigate the mineralization process in the ambient atmosphere, the film was then thoroughly washed with M.Q. water until neutral $\mathrm{pH}$ was achieved

\subsubsection{Gelatin film formation}

Type-A porcine gelatin (5 wt\% aqueous solution) was used to prepare the cast hydrogel gelatin films. Typically $1 \mathrm{~g}$ of gelatin was dissolved in $19 \mathrm{~mL}$ of warm M.Q. water $\left(\sim 50^{\circ} \mathrm{C}\right)$ and stirred for about $30 \mathrm{~min}$. The solution was then poured into a $9 \mathrm{~cm}$ diameter plastic Petri dish and left at $\sim 37^{\circ} \mathrm{C}$ for one day resulting in a partially dehydrated gelatin hydrogel film. The hydrogel film was subsequently treated overnight with $30 \mathrm{~mL}$ of a $1 \%(\mathrm{v} / \mathrm{v})$ glutaraldehyde solution in phosphate buffer solution $(100 \mathrm{mM}$ at $\mathrm{pH}=7)$ as a chemical cross-linking agent to produce a water insoluble film. Gelatin films were cross-linked with 
bifunctional glutaraldehyde agent to reduce the solubility of gelatin in the mineralization solutions. Soaking the films in glutaraldehyde overnight, results in chemical cross-linking between the free amine groups of the lysine residue of the protein and aldehyde leading to network formation. Schiff base linkage $(\mathrm{CH}=\mathrm{N})$ formation is accompanied by an obvious colour change from very pale yellow to orange.

The 50\% (v/v) commercial stock glutaraldehyde solution was diluted with either M.Q. water or a $100 \mathrm{mM}$ phosphate buffer solution $(\mathrm{pH}=7)$ to make a $1 \%(\mathrm{v} / \mathrm{v})$ glutaraldehyde solution. The $\mathrm{pH}$ of the $1 \%(\mathrm{v} / \mathrm{v})$ water diluted, and $1 \%(\mathrm{v} / \mathrm{v})$ buffer diluted glutaraldehyde solutions were 3.97 and 7.4 respectively. The $1 \%(\mathrm{v} / \mathrm{v})$ buffered solution of glutaraldehyde was preferentially used to provide a neutral environment for crystallization.

\subsubsection{Crystal growth experiments}

All hydrogel films were treated using four different mineralization solutions. This included immersing hydrogel in the following solutions:

1- Kitano solution: a solution of calcium carbonate was prepared by dissolving $2.61 \mathrm{~g}$ of $\mathrm{CaCO}_{3}$ in $1 \mathrm{~L}$ of M.Q. water. The solution was bubbled with $\mathrm{CO}_{2}$ gas at approximately $3 \mathrm{~L}$ $\mathrm{h}^{-1}$ for about $6 \mathrm{~h}$ then filtered. The filtrate was bubbled with $\mathrm{CO}_{2}$ for another 30 min at $3 \mathrm{~L}$ $\mathrm{h}^{-1}$ prior to introducing the wet hydrogel films.

2- Alternative soaking: two variants on the alternative soaking system were used: a) aqueous solutions of $0.5 \mathrm{M} \mathrm{CaCl}_{2} .2 \mathrm{H}_{2} \mathrm{O}$ and $0.5 \mathrm{M} \mathrm{NaHCO}_{3}$ (2 cycles); and b) $0.5 \mathrm{M} \mathrm{CaCl}_{2} .2 \mathrm{H}_{2} \mathrm{O}$ and saturated $\mathrm{CaCO}_{3}$ (one cycle). Wet hydrogel films were immersed in each solution for approximately $24 \mathrm{~h}$, prior to immersing in the second solution.

3. McGrath method: this is the combination of the above two methods. In this method after alternatively soaking the hydrogel film in the $0.5 \mathrm{M}$ of $\mathrm{CaCl}_{2} .2 \mathrm{H}_{2} \mathrm{O}$ and $0.5 \mathrm{M} \mathrm{NaHCO}_{3}$ solutions for $24 \mathrm{~h}$ each respectively, Kitano solution (saturated calcium carbonate solution) is introduced.

For all these methods the crystallization solutions contained either no additives or 1 or $2 \mathrm{wt}$. $\%$ of the different additive referenced to the mass of the chitosan or gelatin films.

The hydrogel films were generally left to mineralize for up to one week at room temperature in the final solution. After this time, the films were washed and the excess solution removed. The films were then dried in a covered container for two days. These mineralization methods 
resulted in mineral formation accruing throughout the interior of the hydrogel scaffold as well as on the peripheral surface.

\subsubsection{Characterization}

\subsubsection{Scanning electron microscopy}

The morphology of the produced minerals was characterized by scanning electron microscopy (SEM). SEM (JEOL-JSM 6610F) was used to image mineralized films in SEI and backscatter mode using a $10 \mathrm{kV}$ accelerating voltage. Energy dispersive spectroscopy (EDS) was obtained using the backscattered electron image (BEI) mode using a $15 \mathrm{kV}$ accelerating voltage. The mineralized films were mounted on aluminium stubs using double sided carbon tape and coated three times using a Quorum Q150T carbon coater. Fractured cross-sectional samples were prepared by freezing the sample in liquid nitrogen, and then fracturing the sample while the sample was still frozen. The fractured sample was mounted against a carbon-tape coated cut stub, with the sample standing out above the top of the stub. Another piece of carbon tape was used to cover the sample (i.e. the sample was sandwiched between two piece of carbon tape), then coated and stored in a vacuum desiccator prior to use.

\subsubsection{Cryo-SEM}

Cryo-scanning electron microscopy (cryo-SEM) is widely utilized to investigate wet and pristine samples, particularly biological samples. Here, the microstructure of chitosan and gelatin hydrogels was observed and images were acquired using a $5 \mathrm{kV}$ acceleration voltage in a JEOL 6500F SEM equipped with a cryo-stage which allows imaging of hydrated specimens. Since sample preparation for cryo-SEM is a key in obtaining reproducible and representative images, using the jet freezing system enables us to minimize the formation of ice crystals and other defects and artefacts. A small amount of hydrogel was sandwiched between two $\mathrm{Cu}$ holders. The copper disc was mounted onto a sample holder and transferred to the jet freezer chamber which contains a constant flow of propane gas. After pressure freezing the sample, it was dropped into a propane/liquid $\mathrm{N}_{2}$ mix and then transferred into the cryo-chamber within the cooled $-130{ }^{\circ} \mathrm{C}$ high vacuum environment. The sample was then sublimated for $10 \mathrm{~min}$ at $-100^{\circ} \mathrm{C}$ in order to expose the internal features of the sample. After sublimation the sample was twice coated with $\mathrm{Pt}$ and transferred to the microscope 
chamber with the temperature stabilized at $-130^{\circ} \mathrm{C}$ for imaging. A secondary electron detector (SEI) was standardly used.

\subsubsection{Transmission Electron Microscopy}

Transmission electron microscopy (TEM) allows materials to be analyzed down to the atomic scale range and identify the phases and crystal structures present in the material. High resolution TEM (HRTEM) analysis of mineralized chitosan and gelatin films was performed using a JEOL $2100 \mathrm{~F}$ operated at $200 \mathrm{kV}$ accelerating voltage. The JEOL $2100 \mathrm{~F}$ is equipped with an EDS (which provides elemental composition information) composed of a diffraction CCD camera (SC2000 35 mm) and a HR CCD camera (SC1000B).

TEM samples were prepared by scraping the grown mineral from the surface of the film with a scalpel blade to dislodge the minerals from the chitosan and gelatin substrate. The scraped area was rinsed with a small amount of high grade ethanol and then the sample was ground. A drop of the ethanol mineral mixture was pipetted onto a carbon copper grid and air dried. The sample was then cleaned in a plasma cleaner for 15-30 min prior to use.

A Gatan digital camera with Gatan digital micrograph software was used to capture images and diffraction patterns and also used for post processing the HRTEM micrographs. For EDS analysis the software Analysis Station was used.

\subsubsection{X-ray powder diffraction}

Powder X-ray diffraction (XRD) was used to determine the crystallinity of each of the produced samples. Ground mineralized hydrogel samples were prepared by first freezing the samples using liquid nitrogen followed by grinding with a pestle and mortar. The ground sample was loaded into a spinner stage sample holder. XRD analysis was carried out on a PANalytical X'Pert Pro powder diffractometer with $\mathrm{Cu}-\mathrm{K} \alpha$ radiation X-ray source. The voltage was set to $45 \mathrm{kV}$ and the current to $40 \mathrm{~mA}$. Scans were typically run between $5^{\circ}$ and $70^{\circ} 2 \theta$. The software X'Pert Highscore was used for XRD data analysis. The diffraction patterns of samples were compared to the reference of known crystals from the database. 


\subsubsection{Raman spectroscopy}

Micro-Raman spectroscopy was employed to determine the polymorphic information from individual crystals by mapping numerous crystals from the selected parts of mineralized films using a Renishaw RM2000 ramanscope. The sample was mounted, using double-sided tape to a glass microscope slide. Before measuring the Raman spectrum the spectrometer was calibrated using a silicon standard setting the major peak to $520 \mathrm{~cm}^{-1}$. For identifying the sample morphology the incident laser beam of a Jobin-Yvon LabRam spectrometer was centred on a selected crystal and the spectrum was recorded using a red HeNe laser (633 $\mathrm{nm})$ for chitosan mineralized films and a near infrared diode laser $(785 \mathrm{~nm})$ for gelatin mineralized films. The Raman spectrometer was fitted with an inverted microscope allowing individual crystals to be observed. A 50x (NA 1/4 0.75) objective was used to focus the laser beam onto the specific region of the sample, enabling the polymorph of an individual crystal to be determined.

One of the major challenges of using micro-Raman in conjunction with the gelatin system is the dominant fluorescence background which arises from the fluorescence of the gelatin itself. In order to reduce the background fluorescence observed when using a $633 \mathrm{~nm}$ laser, a near infrared diode laser $(783 \mathrm{~nm})$ was used which gives a more workable though still not horizontal baseline $[33,34]$.

In order to explore the sample, and obtain information on polymorph distribution, the mineralized film was mapped. A camera was used to find the mineralized regions of the sample. Here, instead of individual crystals being examined, a sample area was selected and the sample was mapped point by point across the chosen area. A programmed sweep of the selected area (for example $200 \times 300 \mu \mathrm{m}^{2}$ using a step size of $10 \mu \mathrm{m}$ and $15 \mu \mathrm{m}$ in the $\mathrm{X}$ and Y directions, respectively) was then completed. Depending on the step size and the area of the selected region many Raman spectra were obtained for analysis. 


\subsection{Results and discussion}

\subsubsection{Hydrogel scaffold porosity: morphology study}

Physically cross-linked chitosan and chemically cross-linked gelatin were used as scaffolds for calcium carbonate mineralization. High porosity of the hydrogels is crucial to make them applicable as scaffolds in synthetic biomineralization. This porosity enables diffusion of anions and cations throughout the scaffold and therefore ensures that nucleation and growth can occur throughout the entire scaffold. The morphology and porosity of chitosan ( $2 \mathrm{wt} \%)$ and gelatin $(5 \mathrm{wt} \%)$ hydrogels were probed using cryo-SEM using the high pressure jet freezing sample preparation technique. The results obtained show that both chitosan and gelatin are highly porous and interconnected with pore size ranging from $50-600 \mathrm{~nm}$ for chitosan (average pore size $=150 \pm 114 \mathrm{~nm}$, obtained from analysis of at least 150 pores per image) (Figure 2-1a) and $50-300 \mathrm{~nm}$, with an average size of $105 \pm 53 \mathrm{~nm}$ for gelatin (Figure 2-1b).
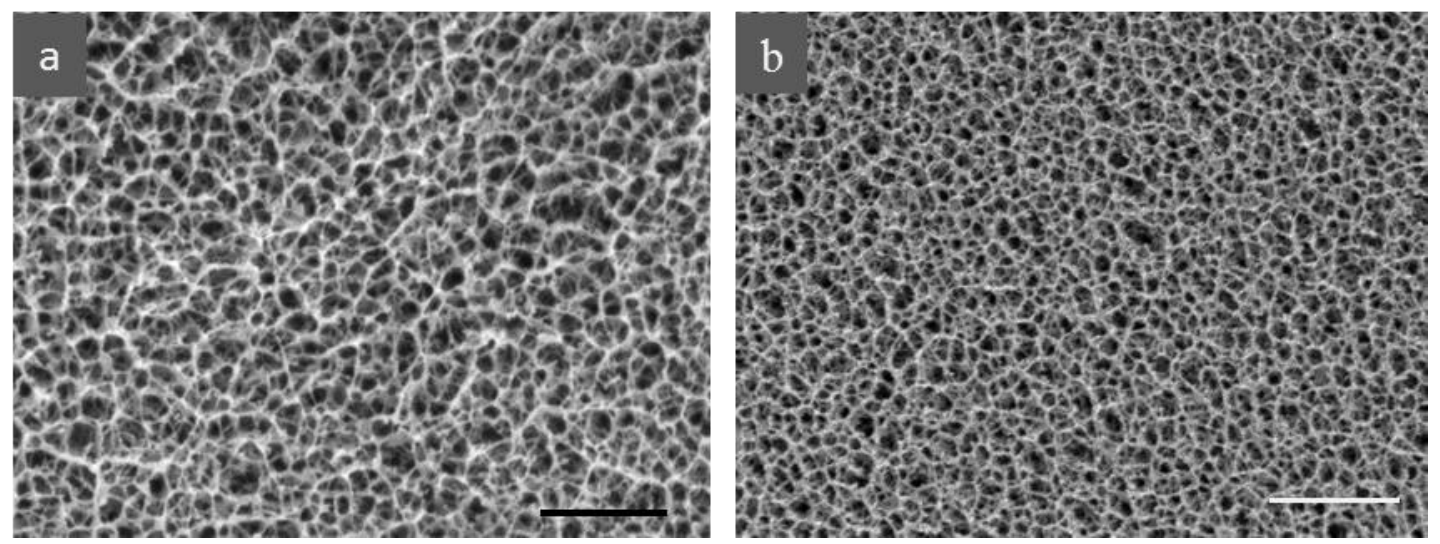

Figure 2-1: Cryo-SEM image of a) chitosan and b) cross-linked gelatin hydrogels. Scale bars are $1 \mu \mathrm{m}$.

Other than the difference in pore size no significant structural differences could be observed from the cryo-SEM images, despite the chitosan system being a physically cross-linked gel vs. the chemically cross-linked gelatin system. It should be noted that the pore size of hydrogels is a function of the concentration of the polymer, increasing the polymer concentration leads to decreasing the pore size [8, 35-37]. Hence the pore size within the gelatin hydrogel may be smaller due to two factors: 1) the higher gelatin concentration (5 $\mathrm{wt} \%$ ) compared to chitosan ( $2 \mathrm{wt} \%)$ and 2$)$ the use of a chemical based cross-linking agent which increases the molecular entanglements in the gelatin hydrogel [38]. The pores present 
in the gels are sufficient for the permeation and diffusion of calcium and carbonate ions. The extensively interconnected pores facilitate and ensure that the ionic precursors are able to populate into the small cavities throughout the three-dimensional structure hence promoting crystal nucleation and growth throughout the gel [8].

The porous nature of the chitosan and gelatin hydrogels provides an environment that is similar to the organic scaffolds in biomineralization systems, thereby making both systems ideal for a comparative study of carbohydrate vs. protein hydrogel scaffolds in controlling mineralization. These two standard hydrogel scaffolds were used in all subsequent mineralization investigations.

\subsubsection{Hydrogel scaffold mineralization: Calcium carbonate with no additive}

Studies of calcium carbonate mineralization of the hydrogel scaffold were performed on both the chitosan and gelatin hydrogel films in the absence of any additives. Four crystallization methods were explored: the alternative soaking ( $\mathrm{a}$ and b), Kitano and McGrath methods (details are given in 2.2).

Since the crystallization process is $\mathrm{pH}$ dependent, the $\mathrm{pH}$ of all mineralization solutions was measured prior to addition to the chitosan and gelatin hydrogel films (Table 1). The final $\mathrm{pH}$ of the crystallization solutions was also measured. The final $\mathrm{pH}$ of all presoaking solutions increased due to degassing of $\mathrm{CO}_{2}$ leading to the initiation of crystal nucleation and growth. The mineralization methods used here rely on degassing of $\mathrm{CO}_{2}$ and subsequent $\mathrm{pH}$ variation to initiate nucleation and growth hence the final $\mathrm{pH}$ of the solutions is higher than the initial $\mathrm{pH}$. All measured final $\mathrm{pH}$ values of all crystallization solutions were in good agreement with the range required for calcium carbonate crystallization.

Table 1: Initial and final $\mathrm{pH}$ of presoaking $\left(\mathrm{CaCl}_{2}\right.$ and $\left.\mathrm{NaHCO}_{3}\right)$ and post-crystallization $\left(\mathrm{CaCO}_{3}\right)$ solutions.

\begin{tabular}{llll}
\hline Solution & Initial $\mathrm{pH}$ & $\begin{array}{l}\text { Final } \mathrm{pH} \\
\text { (chitosan film) }\end{array}$ & $\begin{array}{l}\text { Final } \mathrm{pH} \\
\text { (gelatin film) }\end{array}$ \\
$\mathrm{CaCl}_{2}(500 \mathrm{mM})$ & 5.06 & 6.01 & 6.23 \\
$\mathrm{NaHCO}_{3}(500 \mathrm{mM})$ & 7.22 & 8.49 & 8.80 \\
$\mathrm{CaCO}_{3}($ Kitano) & 5.86 & 9.49 & 8.62 \\
\hline
\end{tabular}


Figure 2-2 shows a comparative analysis of the calcium carbonate morphologies arising from each of the four methods for the two different hydrogel systems. In the case of chitosan, although polycrystalline calcite is formed in all four mineralization methods, the McGrath method resulted in a greater extent of calcification with a more homogenous distribution of crystals with much smaller crystal size than formed in the other systems. Crystals range in size from $\sim 3-8 \mu \mathrm{m}$ (individual polycrystalline calcite diameter, see Figure 2-3c). The rhomohedral symmetry for all crystals in all systems is evident but with a highly defected texture. The increased degree of calcification in the McGrath method is related to the abundance of ions within the chitosan template due to alternative soaking of the hydrogel in solutions of the cations and anions followed by exposure to Kitano solution, which leads to higher local concentration of ions and a large number of nucleation sites. The McGrath method thereby ensures complete coverage of minerals across the hydrogel compared to the other three methods.

Magnified views of the $\mathrm{CaCO}_{3}$ /chitosan composites are presented in Figure 2-3. They reveal a stepped morphology of the calcite crystals, the steps being parallel to each other. Step sizes vary step by step with the step on the top being smaller than the previous one and so on. The thickness of individual steps varied from $200 \mathrm{~nm}-1.4 \mu \mathrm{m}$ in the case of alternative soaking using $\mathrm{CaCl}_{2}$ and saturated $\mathrm{CaCO}_{3}$ (Figure 2-3a inset), $300 \mathrm{~nm}$ to $2 \mu \mathrm{m}$ for alternative soaking using $\mathrm{CaCl}_{2}$ and $\mathrm{NaHCO}_{3}$ (Figure 2-3b) and from 100-400 nm when the McGrath method was used (Figure 2-3c black arrows). Mineral bridges and nanoparticle aggregates between two steps are clearly evident (Figure 2-3d, white circl). Hence the calcium carbonate platelet crystals are densely stacked together and interconnected by calcite bridges and nanoparticles. This mirrors features seen in native nacre.

To the best of our knowledge the mineralization of gelatin films has not been investigated previously using the methods investigated here. Similar results were obtained for the $\mathrm{CaCO}_{3}$ /gelatin system with respect to the influence of the different crystallization methods on the crystal nucleation and growth, though fewer morphological variations are observed compared with the $\mathrm{CaCO}_{3} /$ chitosan composites. Hence, despite the chemical differences between chitosan and gelatin, gelatin hydrogel scaffolds behave similarly to chitosan ones with respect to modulating calcite crystallization. Defected rhombohedral calcite crystals predominaate and the amount of mineralization is increased when the McGrath method is applied (Figure 2-2 e, f, g, h). Again smaller crystals (3-5 $\mu \mathrm{m}$ in diameter) were obtained 
using the McGrath crystallization method which is consistent with the $\mathrm{CaCO}_{3} /$ chitosan system.

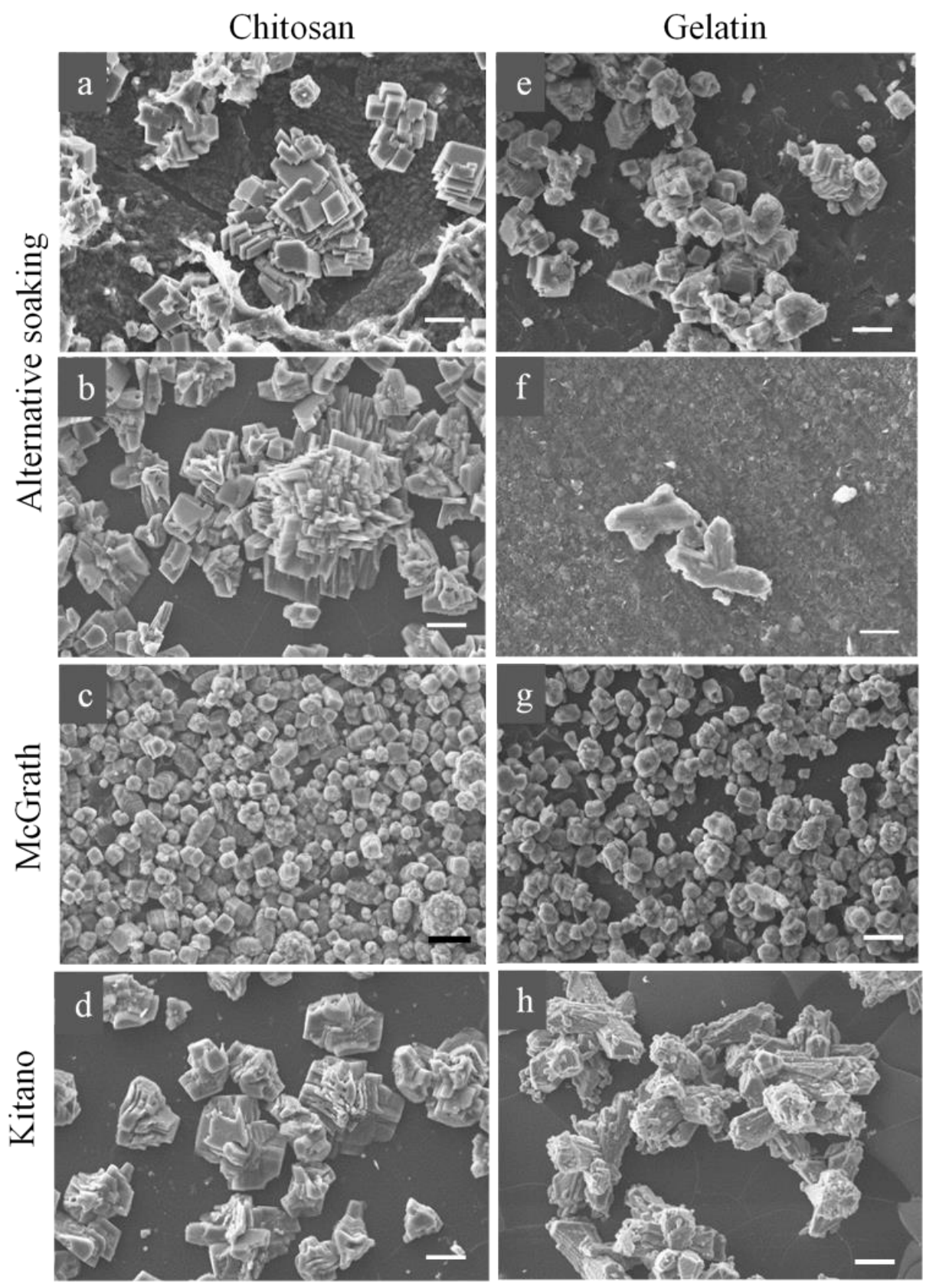

Figure 2-2: Polycrystalline calcium carbonate crystals grown in chitosan and gelatin films using the four different mineralization techniques, with composites prepared using (a, e) alternative soaking with $\mathrm{CaCl}_{2}$ followed by $\mathrm{NaHCO}_{3}$, (b, f) alternative soaking with $\mathrm{CaCl}_{2}$ followed by $\mathrm{CaCO}_{3}$ (Kitano solution), (c, g) McGrath method, and (d, f) the Kitano method. Scale bars: $10 \mu \mathrm{m}$. 


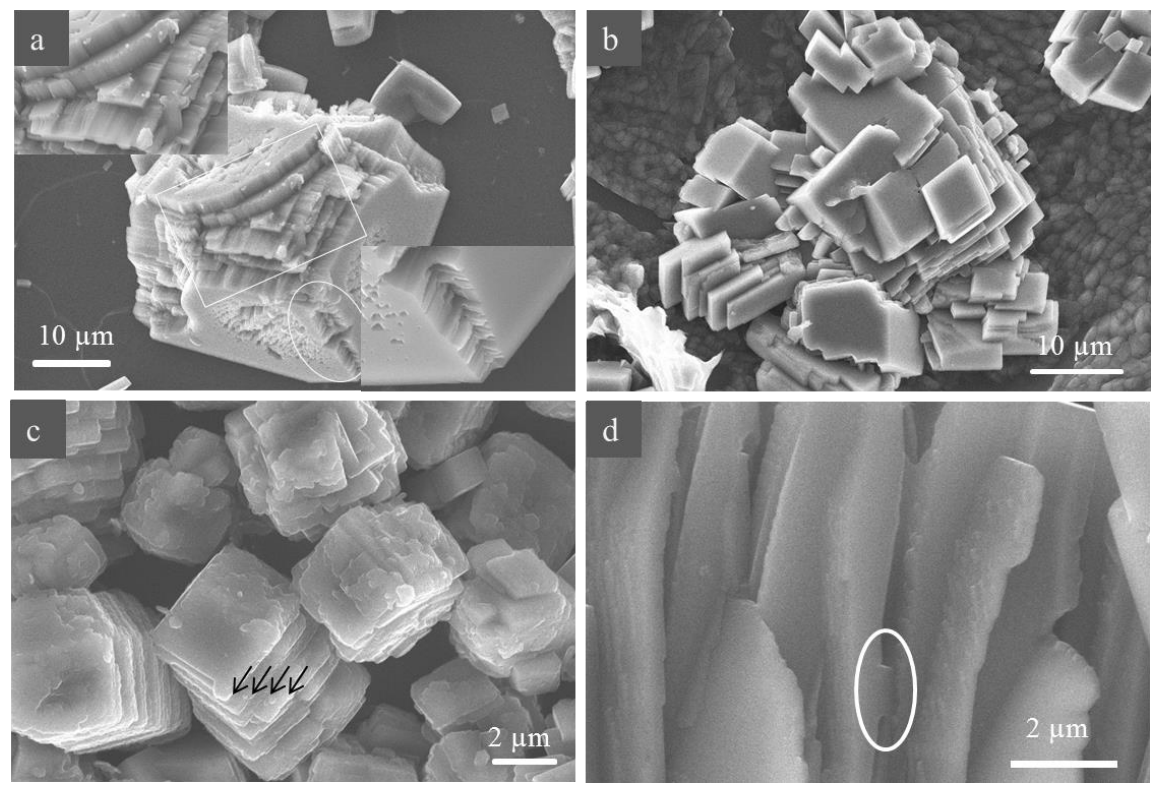

Figure 2-3: Polycrystalline, highly facetted a) stepped growth of calcite crystals at high magnification observed in the case of alternative soaking with $\mathrm{CaCl}_{2}$ and saturated $\mathrm{CaCO}_{3}$, (b) alternative soaking with $\mathrm{CaCl}_{2}$ and $\mathrm{NaHCO}_{3}$, (c) McGrath, and (d) Kitano method.

$\mathrm{XRD}$ and micro-Raman spectroscopy confirmed that calcite was the only polymorph formed for all crystallization methods used for $\mathrm{CaCO}_{3} /$ chitosan composite. However some differences are observed in the XRD spectra due to differences in crystal size, morphology and the extent of crystallization for each of the three systems (Figure 2-4). Because of the increased extent of crystallization when using the McGrath method and alternative $\mathrm{CaCl}_{2}$ and $\mathrm{NaHCO}_{3}$ an intense sharp peak was observed at $2 \theta=29.4^{\circ}$ (104 plane) compared to the two other crystallization methods [14]. Additional peaks at $2 \theta=10.2^{\circ}(020), 19.8^{\circ}(022)$ and $22.0^{\circ}(200)$ are attributed to crystalline sites within the chitosan template (Figure 2-5 shows the XRD of the pure chitosan template). These peaks dominate in the case of the Kitano method indicating the lowest extent of crystallization as expected. Micro-Raman allows individual crystals to be interrogated. The peaks at 284,712 and $1086 \mathrm{~cm}^{-1}$ in the Raman spectrum (Figure 2-6) are attributed respectively to librational, bending $\left(v_{4}\right)$ and stretching ( $v_{1}$ vibration) modes of the carbonate anion in the calcite structure. All preparation methods resulted in the same Raman data being obtained. These results conform with the findings of Munro et al. [14]. To undertake the same analysis on the gelatin system which has no literature precedence, first it is imperative to understand the crystallinity or amorphous character of the hydrogel matrix itself. The powder XRD pattern of a crosslinked gelatin film shows a single broad peak at $\sim 20^{\circ}\left(20.9^{\circ}\right)$, reflects the highly amorphous nature of gelatin (Figure 2-7). It was determined that the XRD and micro-Raman 
characterization of the $\mathrm{CaCO}_{3}$ /gelatin hybrid materials mirrored the results obtained for the chitosan templates (data not shown).

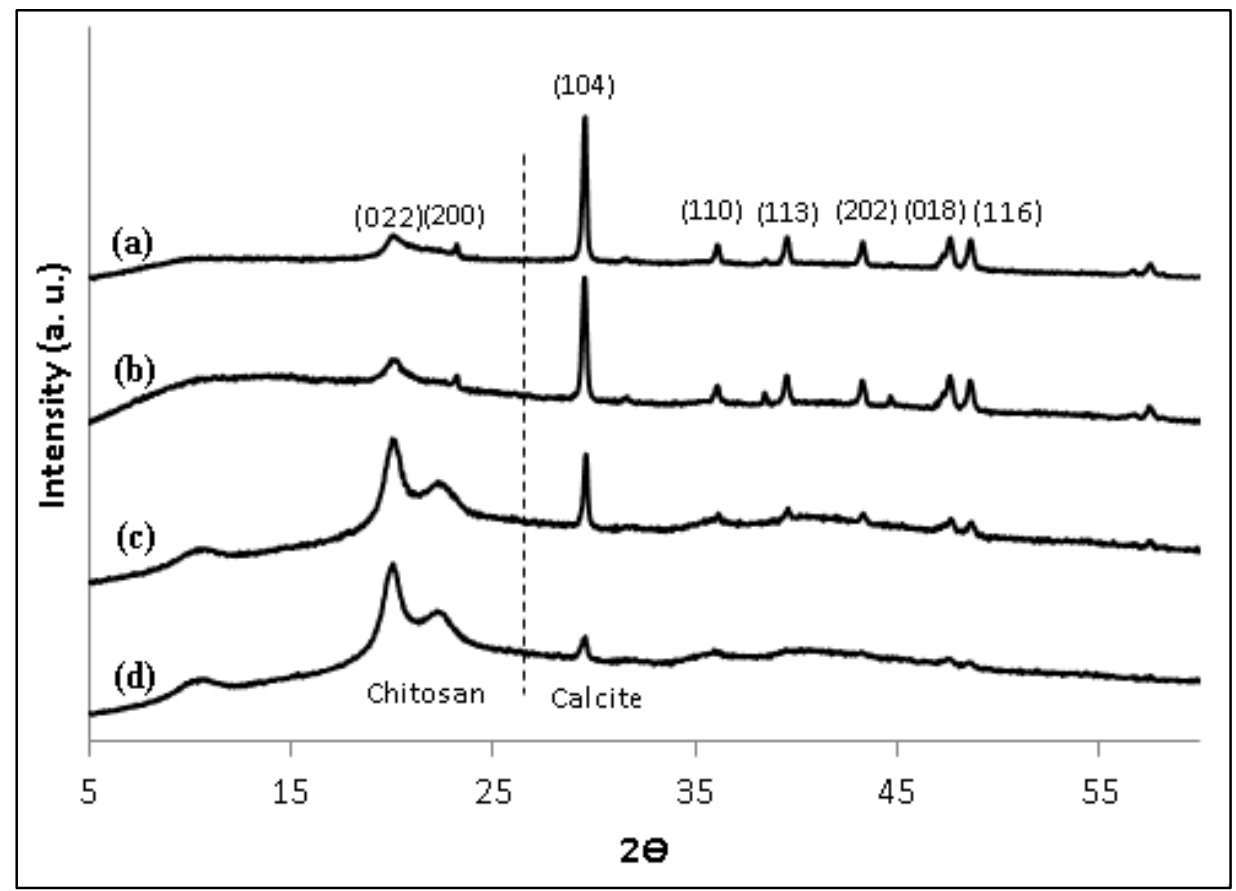

Figure 2-4: Powder XRD patterns for the different $\mathrm{CaCO}_{3} /$ chitosan composites prepared using: a) the McGrath method, b) alternative soaking using $\mathrm{CaCl}_{2}$ and $\mathrm{NaHCO}_{3}$,c) alternative soaking using $\mathrm{CaCl}_{2}$ and saturated $\mathrm{CaCO}_{3}$, and d) the Kitano Method. The dash-line is present to aid interpretation only. Chitosan peaks occur at $2 \theta$ values below the dash-line while calcite peaks are at higher $2 \theta$ values.

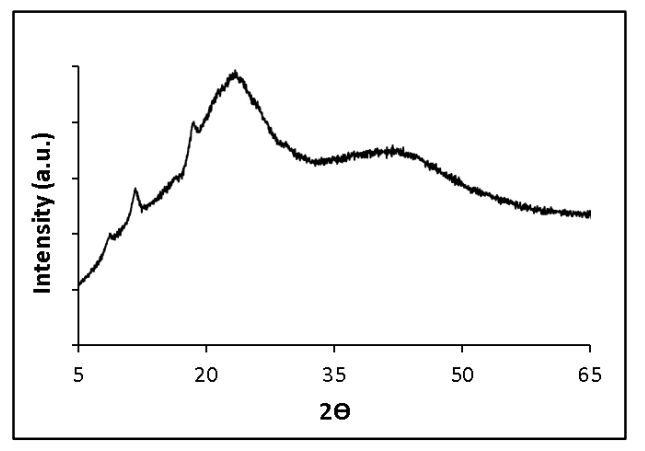

Figure 2-5: Powder XRD pattern of a pure chitosan film.

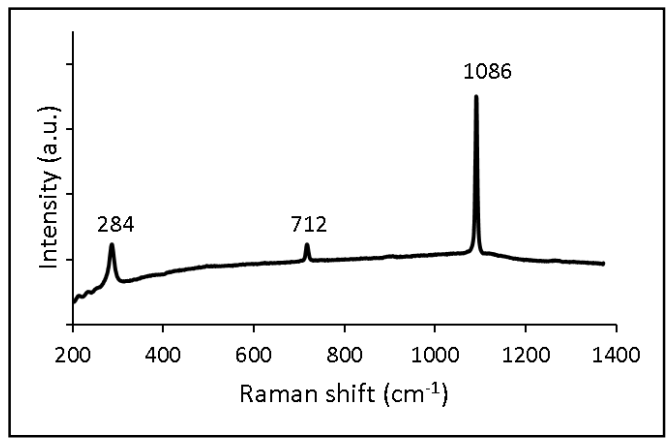

Figure 2-6: Raman spectrum representative of all $\mathrm{CaCO} 3 /$ chitosan composites prepared using the McGrath method. 


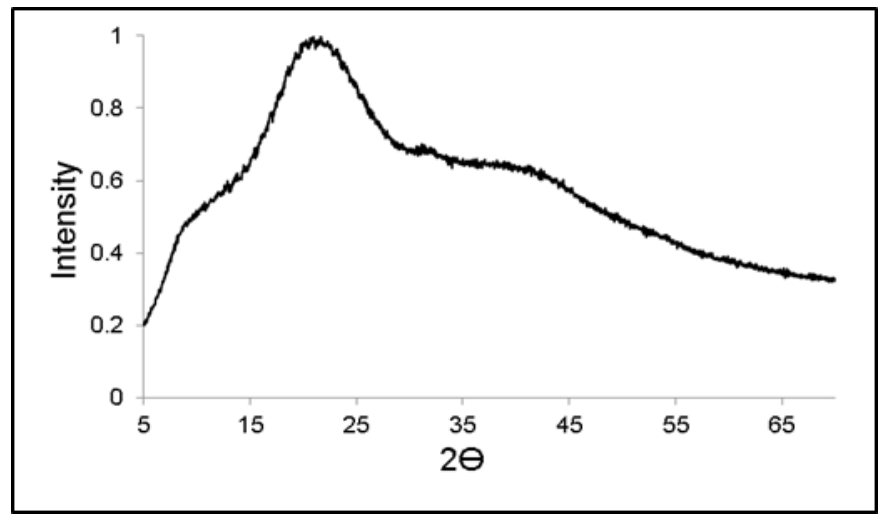

Figure 2-7: Powder XRD pattern of a cross-linked gelatin film.

\subsubsection{Hydrogel scaffold mineralization: Calcium carbonate with water-soluble anionic-acidic additives}

It is widely believed that soluble and insoluble additives are responsible for defining and controlling precipitation of calcium carbonate in vivo [29]. While the use of additives in vitro has been widely explored, to our knowledge no investigations comparing the systems investigated here, three monomers and their corresponding polymeric additives as growth modifiers, have been undertaken previously.

It has been proposed that the calcium carbonate crystallization process in biological materials like nacre is affected by a combination of factors such as the method of crystallization and the chemical and physical characteristic of the hydrogel template itself, which were previously discussed in Chapter 1 . Another crucial factor for directing the crystallization process is believed to be the presence of additives [7, 22]. That is, in such multi-component materials not only does the calcium carbonate interact with the organic hydrogel, binding the organic polymer to the inorganic mineral in order to generate the observed hierarchical structures, which also have impressive mechanical strength, but other components such as acidic proteins, from the carboxylate part or c-terminate polymeric additives, also interact with calcium ions and carry them to nucleation sites to initiate crystallization [39].

The strategy that we have employed here for controlled mineralization using water soluble additives is represented in Figure 2-8. Acidic additives were used because of their common application in model biomineralisation. The specific additives used here (Table 2) have the same interacting functional groups but with different backbones. Polyaspartic acid and polyglutamic acid were chosen to mimic the role of negatively charged acidic proteins found 
in biominerals in nature. Commercially cheaper negatively charged polyacrylic acid was chosen to compare the results of this cheap with native additives behaviour. The corresponding of this polymeric additives was also used to see how the small monomers behave versus polymers in regulating calcium carbonate and calcium phosphate crystallization process. In particular we have investigated how these specific additives, with various structures but the same active functional groups, are involved in the calcium carbonate crystallization process in vitro for the two different scaffolds (chitosan vs. gelatin) inducing their effect on the morphologies of the minerals formed.

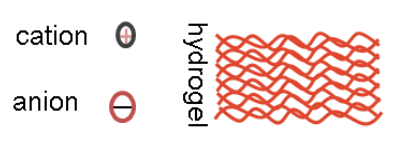

additive $f$ crystal $\square$
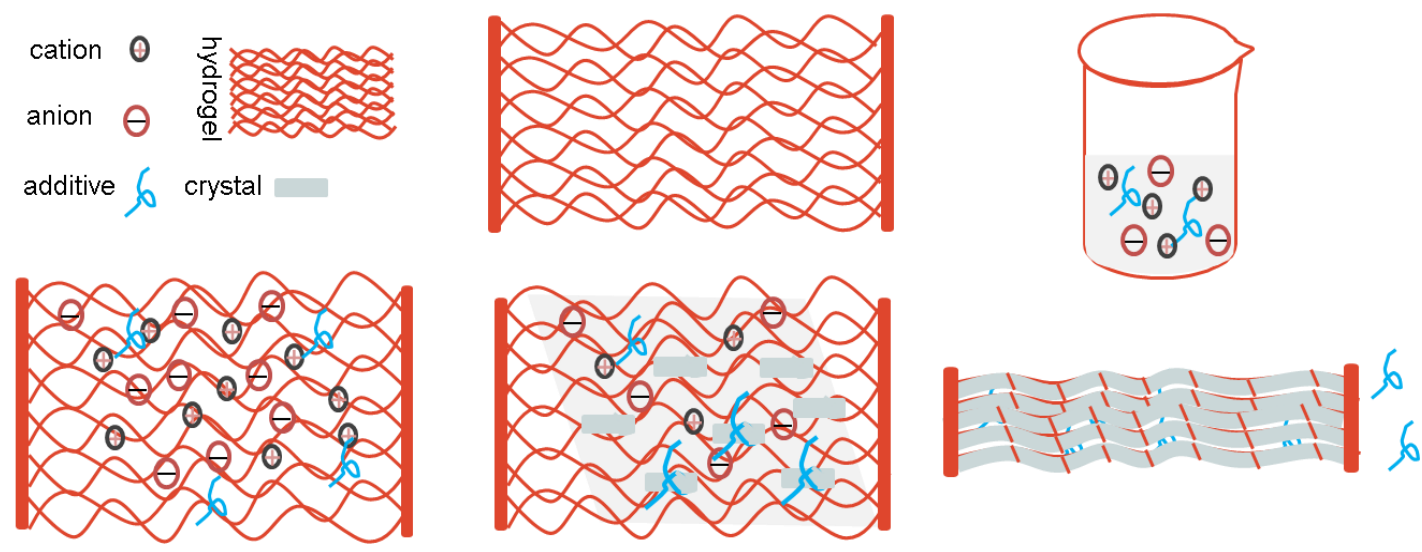

Figure 2-8: Schematic illustration of how the soluble anionic additives control the crystallization process; additives with negative ions can bind to calcium ions before addition to the hydrogel scaffold and allowing formation of polyelectrolyte complex upon addition to the scaffold altering the mineralization process.

Table 2. Structure of the monomeric and polymeric additives used.

Monomeric additive Structure




\subsubsection{Polyacrylic acid/Acrylic acid}

Polyacrylic acid (PAA) has been widely investigated with respect to its effect on the nucleation and growth of calcium carbonate $[13,14,19,40-43]$. The condition used here was addition of $2 \mathrm{wt} \%$ of PAA (with respect to the mass of chitosan and gelatin) in all or some crystallization solutions using the results of Munro et al. as the basis [14]. Full details are given in Table 3. Three crystallization solutions are used: (1) $\mathrm{CaCl}_{2}$ (500 mM), (2) $\mathrm{NaHCO}_{3}(500 \mathrm{mM})$ and Kitano solution. The crystallization approach, the morphology and the polymorph of the resulting calcium carbonate crystallites are summarized in Table 3.

\begin{tabular}{|c|c|c|c|c|c|}
\hline $\begin{array}{l}\text { Crystallizatio } \\
\text { n Method }\end{array}$ & $\begin{array}{l}\text { Presoak } \\
\text { solution (1) }\end{array}$ & $\begin{array}{l}\text { Presoak } \\
\text { solution (2) }\end{array}$ & $\begin{array}{l}\text { Crystallization } \\
\text { solution (3) }\end{array}$ & Crystal morphology & Polymorph \\
\hline $\begin{array}{l}\text { Alternative } \\
\text { soaking }\end{array}$ & $\begin{array}{l}\mathrm{CaCl}_{2}+ \\
\mathrm{PAA}\end{array}$ & $\begin{array}{l}\mathrm{NaHCO}_{3}+ \\
\text { PAA }\end{array}$ & - & $\begin{array}{l}\text { Aggregated and rounded } \\
\text { crystals (Figure 2-9a) }\end{array}$ & Calcite \\
\hline $\begin{array}{l}\text { Alternative } \\
\text { soaking }\end{array}$ & $\begin{array}{l}\mathrm{CaCl}_{2}+ \\
\text { PAA }\end{array}$ & - & $\mathrm{CaCO}_{3}+\mathrm{PAA}$ & Lateral growth (Figure 2-9b) & Calcite \\
\hline $\begin{array}{l}\text { Alternative } \\
\text { soaking }\end{array}$ & $\begin{array}{l}\mathrm{CaCl}_{2}+ \\
\mathrm{PAA}\end{array}$ & - & $\mathrm{CaCO}_{3}$ & Lateral growth (Figure 2-9c) & Calcite \\
\hline $\begin{array}{l}\text { Alternative } \\
\text { soaking }\end{array}$ & $\mathrm{CaCl}_{2}$ & - & $\mathrm{CaCO}_{3}+\mathrm{PAA}$ & Lateral growth (Figure 2-9d) & Calcite \\
\hline McGrath & $\begin{array}{l}\mathrm{CaCl}_{2}+ \\
\mathrm{PAA}\end{array}$ & $\begin{array}{l}\mathrm{NaHCO}_{3}+ \\
\text { PAA }\end{array}$ & $\mathrm{CaCO}_{3}+\mathrm{PAA}$ & $\begin{array}{l}\text { Lateral growth and defected } \\
\text { rhombohedra (Figure 2-9e) }\end{array}$ & $\begin{array}{l}\text { Calcite/vaterite/ } \\
\text { aragonite }\end{array}$ \\
\hline McGrath & $\begin{array}{l}\mathrm{CaCl}_{2}+ \\
\mathrm{PAA}\end{array}$ & $\begin{array}{l}\mathrm{NaHCO}_{3}+ \\
\text { PAA }\end{array}$ & $\mathrm{CaCO}_{3}$ & Lateral growth (Figure 2-9f) & $\begin{array}{l}\text { Calcite/vaterite/ } \\
\text { aragonite }\end{array}$ \\
\hline McGrath & $\begin{array}{l}\mathrm{CaCl}_{2}+ \\
\mathrm{PAA}\end{array}$ & $\mathrm{NaHCO}_{3}$ & $\mathrm{CaCO}_{3}+\mathrm{PAA}$ & $\begin{array}{l}\text { Rounded and stacked (Figure } \\
2-9 \mathrm{~g})\end{array}$ & Calcite/vaterite \\
\hline McGrath & $\mathrm{CaCl}_{2}$ & $\begin{array}{l}\mathrm{NaHCO}_{3}+ \\
\text { PAA }\end{array}$ & $\mathrm{CaCO}_{3}+\mathrm{PAA}$ & $\begin{array}{l}\text { Aggregated and lateral growth } \\
\text { (Figure 2-9h) }\end{array}$ & Calcite/vaterite \\
\hline Kitano & - & - & $\mathrm{CaCO}_{3}+\mathrm{PAA}$ & Lateral growth (Figure 2-9i) & Calcite \\
\hline
\end{tabular}

PAA has been extensively investigated previously in literature and as such is used here as the base-line comparison for the other additives. In particular PAA, with one acidic functional group is compared with the polymeric amino acids which contain multi-acidic functional groups [5]. 


\subsubsection{2 $\mathrm{CaCO}_{3} /$ Chitosan/PAA}

SEM images of $\mathrm{CaCO}_{3} /$ chitosan/PAA composites show significant morphological differences compared with when no PAA is present (Figure 2-2). PAA has been shown to be a potent additive in affecting $\mathrm{CaCO}_{3}$ mineral morphology due to the formation a polyelectrolyte complex between PAA and chitosan. The polyanionic PAA and polycationic chitosan interact through electrostatics and promote not only nucleation of calcium carbonate but also aggregating of the resulting nanoparticles lateral to the polyelectrolyte complex itself $[17,20,44,45]$. The enhanced nucleation is due to the interactions between the calcium ions and negatively charged polymer. Collectively the interactions inhibit growth of crystals in the direction normal to the scaffold surface [20].

Figure 2-9 shows the SEM images of the resulting $\mathrm{CaCO}_{3} /$ chitosan composite materials in the presence of PAA in three, two or just one of the crystallization solutions. Lateral growth of calcium carbonate was achieved when PAA was present in all crystallization solutions for the samples prepared using alternative soaking of $\mathrm{CaCl}_{2}$ and saturated $\mathrm{CaCO}_{3}$ solutions, the McGrath and Kitano methods (Figure 2-9b, e, i). When samples are prepared via two cycles of the alternative soaking using $\mathrm{CaCl}_{2}$ and $\mathrm{NaHCO}_{3}$ solutions (Figure 2-9a), the high concentration of the crystallization solutions results in the generation of aggregated crystals compared to the other three methods which minimize the control of the polyelectrolyte complex and hence the creation of flat crystals growing lateral to the complex.

Lateral growth of calcium carbonate crystals was achieved when alternative soaking using $\mathrm{CaCl}_{2}$ and saturated $\mathrm{CaCO}_{3}$ solutions was used irrespective of whether the PAA was present in only one crystallization solution or in all crystallization solutions (see Figure 2-9b, Figure 2-10a, b), compared to crystals formed at the same conditions without PAA present (Figure $2-2 b$ ). The lateral growth resulted in flat circular crystals on average 20-30 $\mu \mathrm{m}$ in diameter. These are the results of aggregation of calcite nanoparticles (Figure 2-9 c). Adding PAA to the second crystallization solution leads to the formation of crystals with a smoother surface and smaller size (5-11 $\mu \mathrm{m}$ in diameter) which is similar to when PAA is present in both the $\mathrm{CaCl}_{2}$ and saturated $\mathrm{CaCO}_{3}$ solutions.

The addition of PAA to the Kitano solution results in the same morphology as is achieved by alternative soaking the hydrogel with $\mathrm{CaCl}_{2}$ and saturated $\mathrm{CaCO}_{3}$ solutions (lateral growth of $\mathrm{CaCO}_{3}$ along the chitosan surface (Figure 2-9d)) compared to crystallization of chitosan films with Kitano solution without PAA present (Figure 2-2d). 
In common with the alternative soaking $\left(\mathrm{CaCl}_{2}\right.$ and saturated $\mathrm{CaCO}_{3}$ solutions) and Kitano, a significant morphological effect was observed upon addition of PAA in all three or only two of the crystallization solutions for the McGrath method (Figure 2-9e, f, g and h). Lateral growth of the calcium carbonate crystals occurred (Figure 2-9e). However once the control of the scaffold and polyelectrolyte complex is lost, large rhombohedral growth again dominates return to the system (Figure 2-9e black dashed circles). Interestingly when PAA was added to just one crystallization solution there is no evidence for lateral growth and polycrystalline calcite formed (data not shown) similar to the calcite morphology formed at the same conditions without PAA present (Figure 2-2d).

Cryo-SEM analysis of the wet $\mathrm{CaCO}_{3} /$ chitosan/PAA composite prepared using the McGrath method provided further evidence supporting the integration of the mineral within the chitosan hydrogel (Figure 2-10). In most regions the lateral growth of calcium carbonate is evident (Figure 2-10a), but in certain regions spherical $\mathrm{CaCO}_{3}$ crystalline aggregate are also seen (Figure 2-10c). A broken spherical $\mathrm{CaCO}_{3}$ crystal, broken during sample preparation reveals that the final morphology of the calcium carbonate is the result of calcium carbonate nanoparticle assembly from the core of the crystals to the outer layer where the outer layer growth is perpendicular to the core of the crystals (Figure 2-10c inset black arrows). 

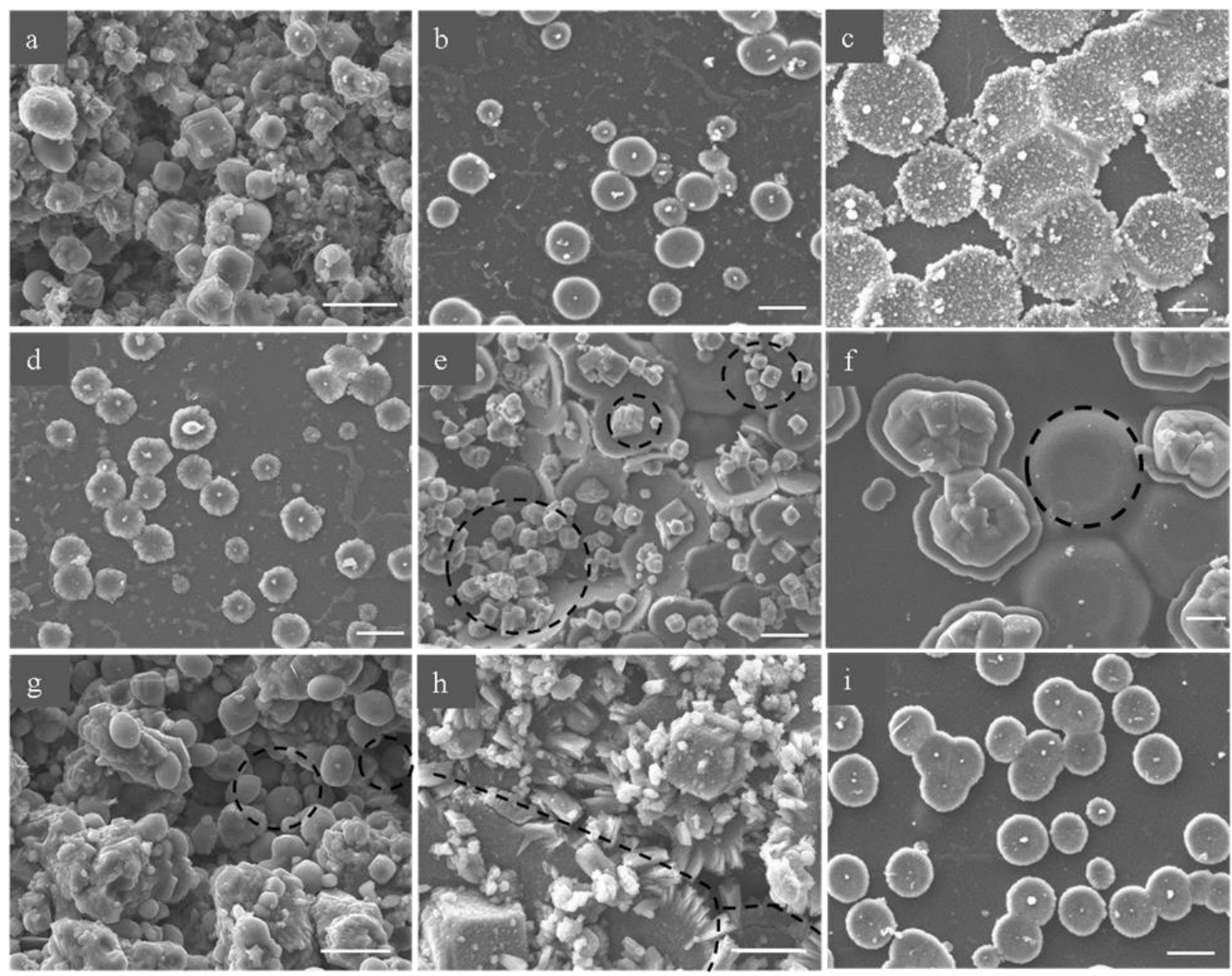

Figure 2-9: $\mathrm{SEM}$ images of $\mathrm{CaCO}_{3} /$ chitosan/PAA composites prepared using (a) alternative soaking with $\mathrm{CaCl}_{2}$ and $\mathrm{NaHCO}_{3}$, which contain PAA in all solutions, (b, c, d) alternative soaking with $\mathrm{CaCl}_{2}$ and $\mathrm{CaCO}_{3}$; (b) PAA in all crystallization solutions; (c) PAA present in the $\mathrm{CaCl}_{2}$ solution only; d) PAA present in the saturated $\mathrm{CaCO}_{3}$ solution only, (e, f, g, h). McGrath method where (e) contained PAA in all crystallization solutions. (f) PAA present in the $\mathrm{CaCl}_{2}$ and $\mathrm{NaHCO}_{3}$ (g) PAA present in the $\mathrm{NaHCO}_{3}$ and saturated $\mathrm{CaCO}_{3}$ solutions (h) PAA is present in the $\mathrm{CaCl}_{2} \cdot 2 \mathrm{H}_{2} \mathrm{O}$ and $\mathrm{CaCO}_{3}$ (in the (g) and (h) lateral growth is still evident (see the black dashed circle and line) but no longer dominates), and (i) Kitano solution containing PAA. Where crystallization solutions contained PAA the concentration was $2 \mathrm{wt} \%$ with respect to the mass of chitosan. Scale bars: $10 \mu \mathrm{m}$. 

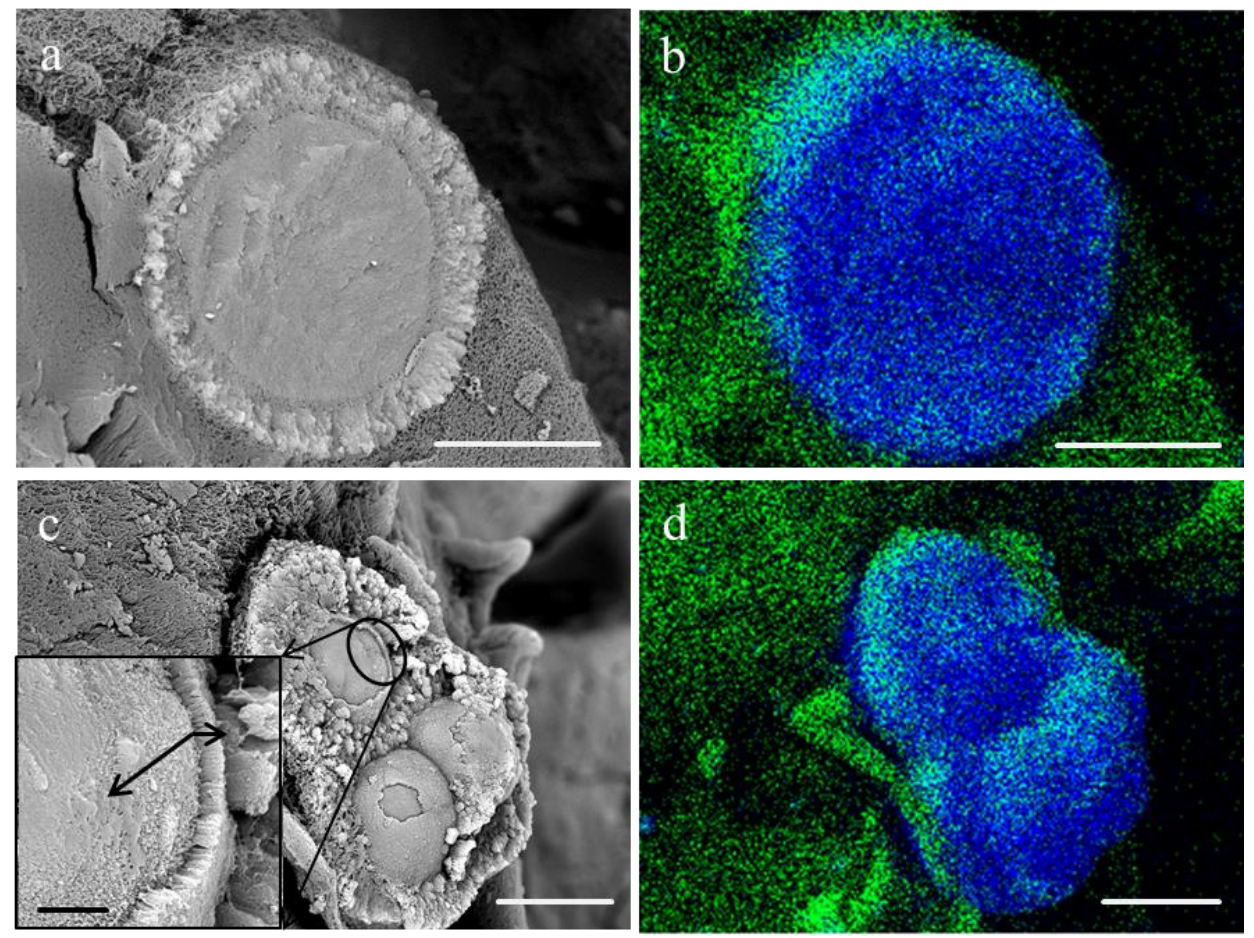

Figure 2-10: Cryo-SEM of $\mathrm{CaCO} /$ chitosan/PAA (prepared via the McGrath method) representing how the insoluble chitosan matrix integrates with the calcium carbonate (calcite or vaterite). EDS mapping of $\mathrm{CaCO} 3 /$ chitosan/PAA (calcium and carbon are shown in blue and green respectively). Scale bars: $10 \mu \mathrm{m}$, inset: $1 \mu \mathrm{m}$.

XRD and Raman analysis confirmed precipitation of calcite within the chitosan substrate for all crystals morphologies using the alternative soaking and Kitano methods. But in the case of the McGrath method when PAA was present in all three solutions all three polymorphs were obtained. Although the dominant polymorph was calcite, the presence of vaterite and aragonite (the ratio of calcite/vaterite/aragonite was 65:28:7 respectively) was confirmed by XRD and Raman analyses (Figures 2-11 and 2-12). The percentage of each polymorph was calculated according to the method of Dickinson and McGrath [46]. The mineralized film was mapped using micro-Raman spectroscopy. The acquired spectra confirmed that most of the crystals are calcite. Vaterite was also detected correlating with the XRD results. Aragonite was not observed in the micro-Raman investigation, mirroring the low level seen via XRD analysis. Figure 2-12 shows some of the mapping results from the micro-Raman investigation. The optical image in the top-left of the figure shows the sites probed. A doublet (red curve) at 1090-1079 cm-1 and $750 \mathrm{~cm}-1$ is attributed to vaterite. A peak at $300 \mathrm{~cm}^{-1}$ was identified as calcite contamination from a close-by calcite crystal due to the finite beam effect. 


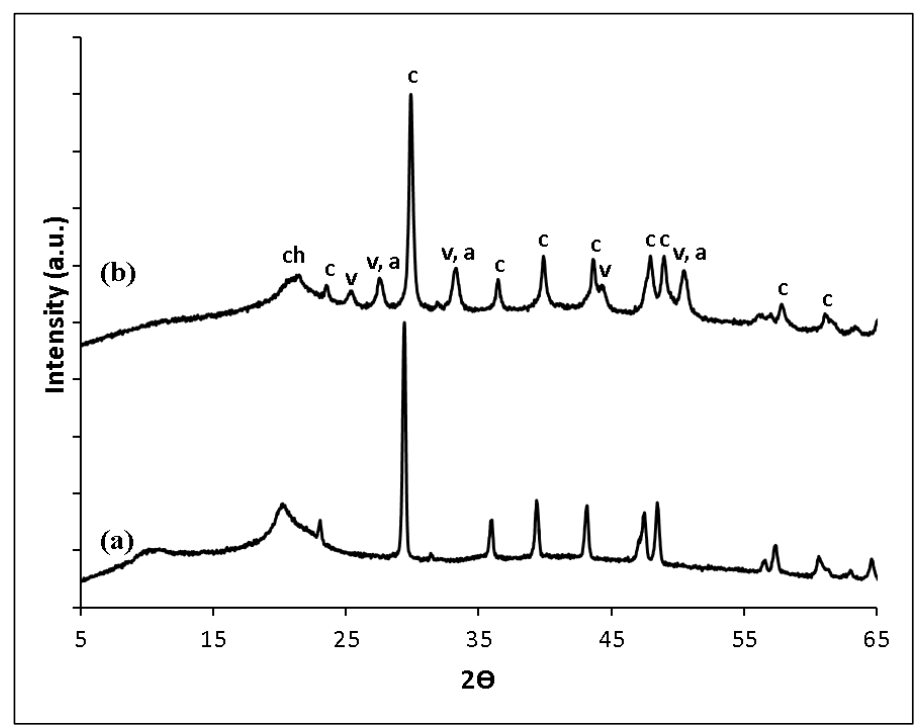

Figure 2-11: Powder $\mathrm{XRD}$ pattern of $\mathrm{CaCO}_{3} /$ chitosan composites synthesized using the McGrath method (a) without any additives and (b) in the presence of $2 \mathrm{wt} \%$ PAA $(0.008 \mathrm{~g}$ in each crystallization solutions). a, c, ch and $\mathrm{v}$ indicate aragonite, calcite, chitosan and vaterite peaks respectively.

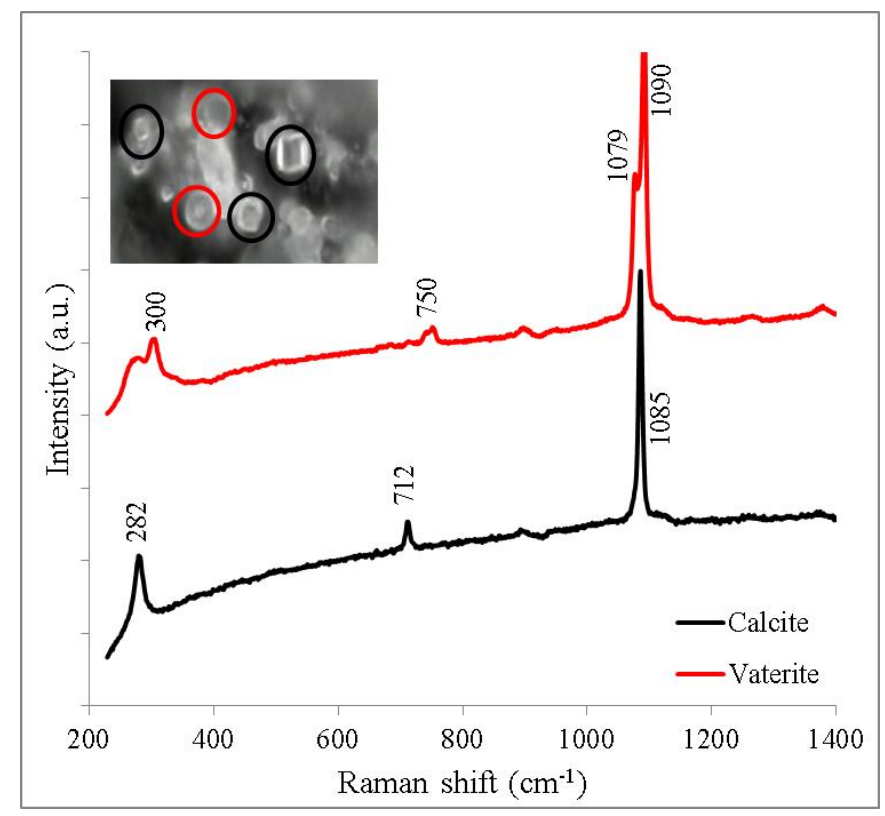

Figure 2-12: Micro-Raman spectra of $\mathrm{CaCO}_{3} /$ chitosan/PAA composites confirming the presence of both vaterite (red) and calcite (black) in the $\mathrm{CaCO}_{3} /$ chitosan/PAA composite. The inset shows the corresponding image to the calcite and vaterite spectra. 


\subsubsection{3 $\mathrm{CaCO}_{3} /$ gelatin/PAA}

The same experiments as described in the $\mathrm{CaCO}_{3} /$ chitosan/PAA section were then carried out using the gelatin hydrogel films. Based on the results from the $\mathrm{CaCO}_{3} /$ chitosan/PAA experiments, the addition of PAA to all crystallization solutions leads to the best control over the calcium carbonate crystallization. Therefore in the case of gelatin, PAA was added to all crystallization solutions (Figure 2-13).

Lateral growth of calcium carbonate was also observed when gelatin hydrogels were used (Figure 2-13b, c, d). In similarity to the $\mathrm{CaCO}_{3} /$ chitosan/PAA system the formation of the polyelectrolyte system due to interactions between the amino acids of gelatin and the carboxylate group of the PAA results in the lateral growth of calcium carbonate due to aggregation of nanoparticles. Soluble negatively charged PAA in combination with the insoluble gelatin substrate and the calcium ions is the main factor to determine which polymorph is formed. This combination aids higher calcite formation compared with vaterite (62:38) when using the McGrath method while for the three other methods it leads to just calcite formation. In similarity to the case where chitosan was used as the scaffold, greater crystallization was induced when the McGrath method was used. The crystals grow laterally along the internal and peripheral surfaces of the gelatin hydrogel scaffold with complete mineralization of the gelatin surface. However the size of the laterally grown crystals are very much larger (Figure 2-13c (35-50 $\mu \mathrm{m}$ in diameter)) compared to when chitosan was used as the scaffold (Figure $2-9 \mathrm{e}(10-20 \mu \mathrm{m}$ in diameter)). This shows that the McGrath method is a facile and readily adapted method for producing extensively mineralized hydrogels with different chemical functionality and porosity which is in accordance with the Munro et al. finding [14, 40].

Lateral growth of calcite crystals was also achieved when the gelatin was treated via alternatively soaking using $\mathrm{CaCl}_{2}$ and saturated $\mathrm{CaCO}_{3}$ solutions or with Kitano solution alone, although with markedly fewer crystals overall (Figure 2-12b and d), compared to the McGrath method (Figure 2-12c). Flat crystals growing laterally on the gelatin surface are also evident when the high concentration presoaking solutions of $\mathrm{CaCl}_{2}$ and $\mathrm{NaHCO}_{3}$ were used (Figure 2-13a), though the aggregated spherical calcite dominated. $\mathrm{CaCl}_{2}$ followed by $\mathrm{NaHCO}_{3}$ pretreatment showed mostly aggregated crystals as the scaffold was loaded with a high concentration of $\mathrm{CaCl}_{2}$ and $\mathrm{NaHCO}_{3}$ (Figure 2-13a). For the rest of the study instead of using $\mathrm{NaHCO}_{3}$, the $\mathrm{CaCl}_{2}$ solution was alternatively soaked with saturated $\mathrm{CaCO}_{3}$ in order 
to reduce the amount of growth and allow the role of the scaffold and additive to be more readily observed.

Powder XRD and micro-Raman spectroscopy (using the 2D mapping method) confirmed precipitation of vaterite and calcite (30:70 vaterite to calcite) throughout the gelatin hydrogel scaffold (Figures 2-14 and 2-15). In order to overcome the fluorescence issue a near infrared diode laser $(783 \mathrm{~nm})$ was used. Under these conditions, a more workable but not horizontal baseline results $[33,34]$.

In similarity to the chitosan scaffold, calcite growth dominates over vaterite growth when the McGrath method was used. However, based on the XRD and Raman data aragonite was not formed. Calcite was the only polymorph formed when the alternative soaking and Kitano methods were used in the presence of PAA which was consistent with the results obtained for $\mathrm{CaCO}_{3} /$ chitosan/PAA.
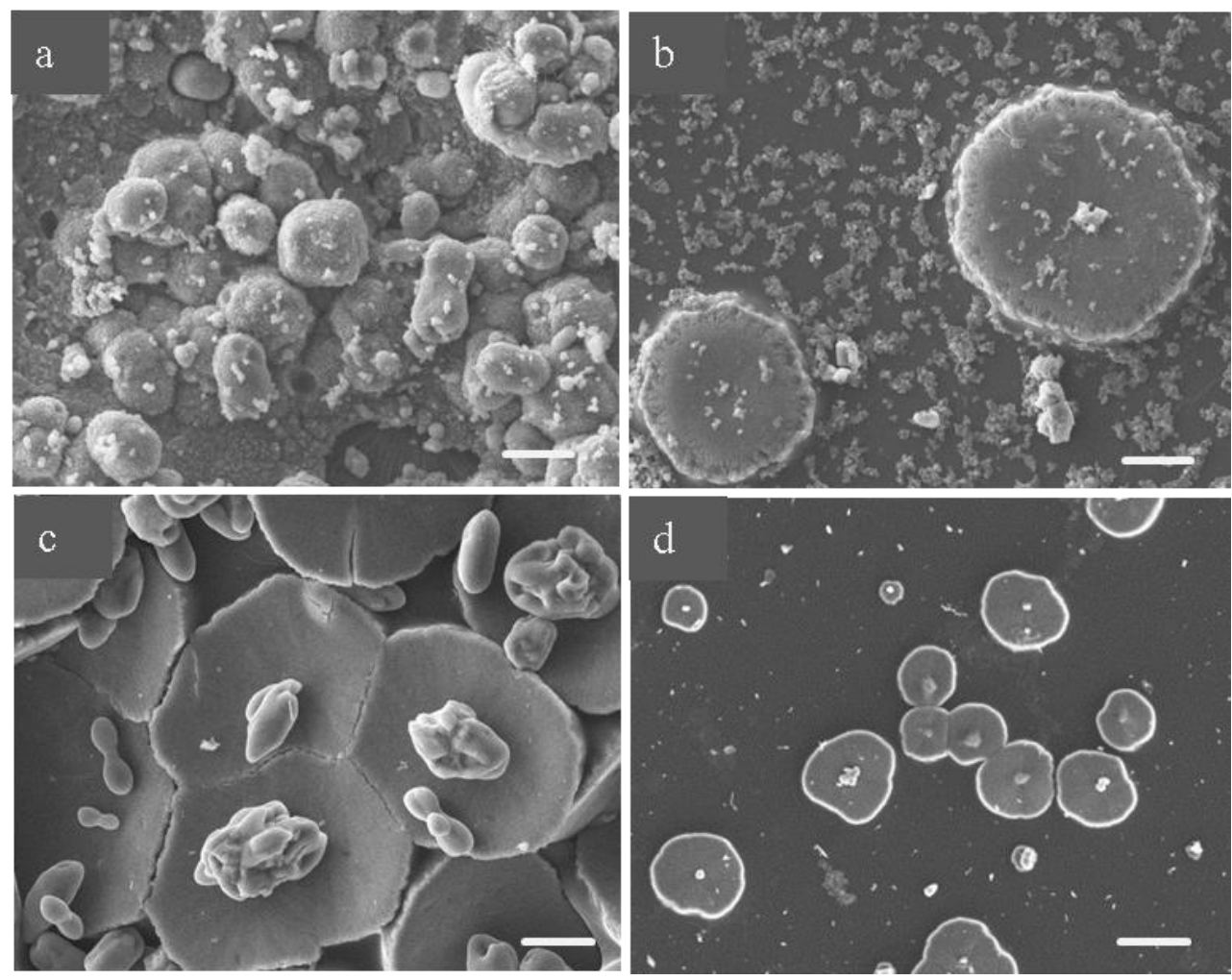

Figure 2-13: $\mathrm{SEM}$ images of $\mathrm{CaCO}_{3} /$ gelatin/PAA composites prepared using the four different mineralization methods: a) alternative soaking with $\mathrm{CaCl}_{2}$ and $\mathrm{NaHCO}_{3}$ solutions, b) alternative soaking of $\mathrm{CaCl}_{2}$ and saturated $\mathrm{CaCO}_{3}$ solutions, c) McGrath and d) Kitano methods. Scale bars: $10 \mu \mathrm{m}$. 


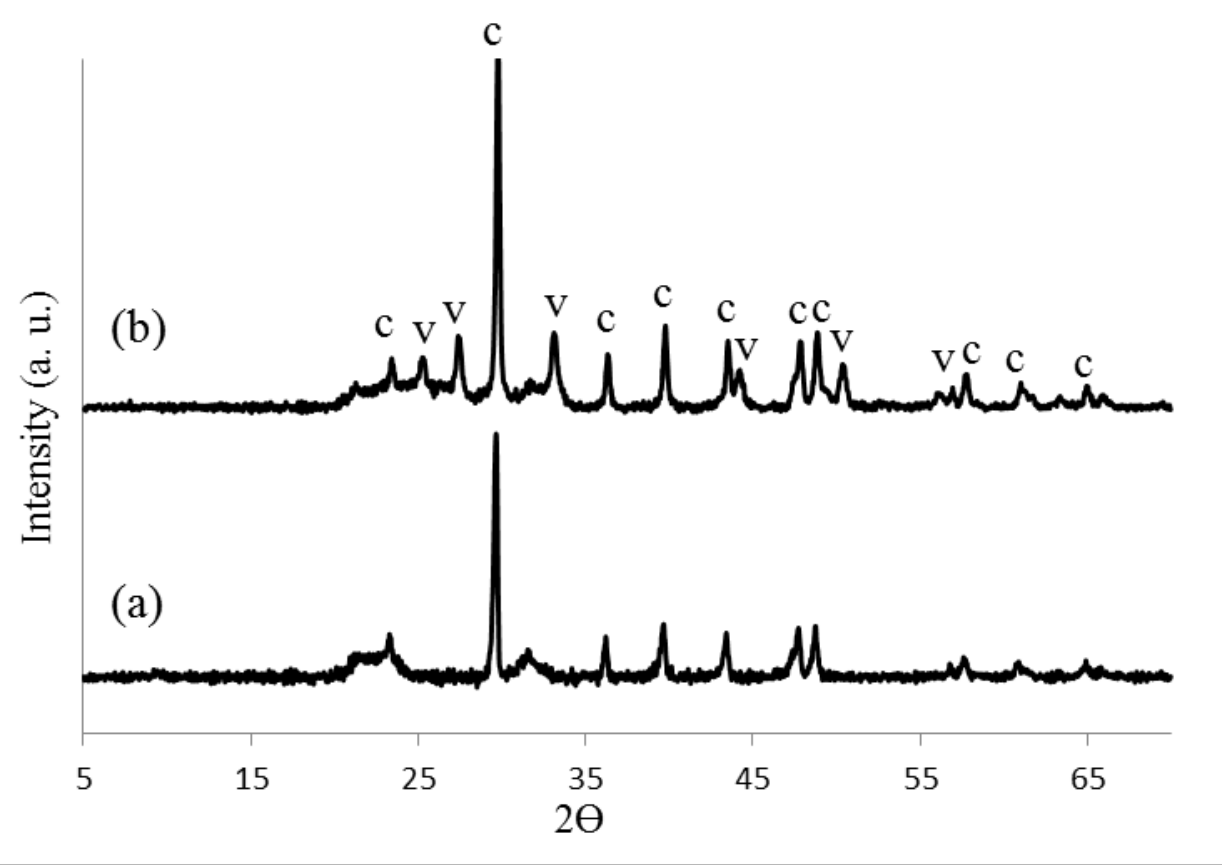

Figure 2-14: Powder XRD diffractograms of the $\mathrm{CaCO}_{3}$ /gelatin composites using the McGrath method (a) without any additives and (b) in the presence of $2 \mathrm{wt} \%$ PAA in each of the three crystallization solution. Labels $\mathrm{c}, \mathrm{v}$ and $\mathrm{g}$ indicate calcite, vaterite and gelatin respectively.

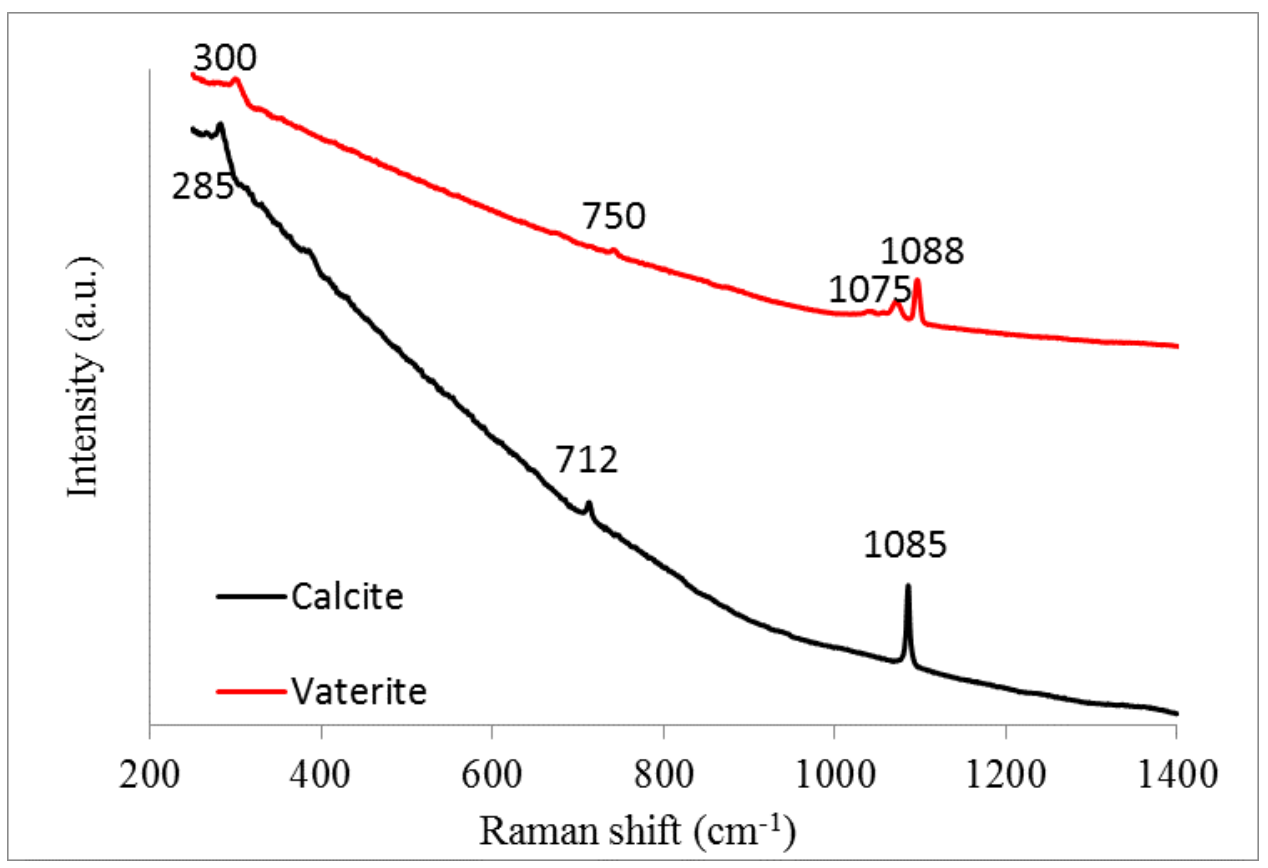

Figure 2-15: Micro-Raman spectroscopy of $\mathrm{CaCO}_{3} /$ gelatin/PAA using a near infrared laser diode $(785 \mathrm{~nm})$ confirmed the presence of vaterite (red) and calcite (black) in the $\mathrm{CaCO}_{3} /$ gelatin/PAA composites. 
It has been shown that the amount of mobile carboxylate anions provided by the PAA in the crystallization solution influences the lateral growth and polymorph selection of the $\mathrm{CaCO}_{3}$ crystals [42]. The degree of ionization of the carboxylic acid group in PAA and the base group in chitosan and gelatin is highly dependent on the $\mathrm{pH}$ of the solution. The $\mathrm{NH}_{2}$ group of chitosan and the $\mathrm{COOH}$ group of PAA are dissociated at $\mathrm{pH}$ values below 9.5 and over 3.2 respectively [42]. This range of $\mathrm{pH}$ values is correlated to the $\mathrm{pH}$ values of our crystallization solution used for calcium carbonate mineralization (Table 2).

The $\mathrm{pH}$ values of all crystallization solution in the absence of PAA and after adding $2 \mathrm{wt} \%$ of PAA were measured prior to addition to both the chitosan and gelatin hydrogel scaffolds (Table 4). All pH values were lower in the presence of PAA as expected due to the acidic nature of PAA. The data are summarized in Table 4. In the case of the $\mathrm{CaCl}_{2}$ solution the $\mathrm{pH}$ is 4.70. At this $\mathrm{pH}$ chitosan and PAA are in their respective cation and anion forms [47]. The $\mathrm{pH}$ of the $\mathrm{NaHCO}_{3}$ solution is reduced to 7.10 once PAA is added. At this $\mathrm{pH}$ value the PAA is charged but chitosan becomes natural. When the saturated $\mathrm{CaCO}_{3}$ solution was bubbled with $\mathrm{CO}_{2}$ the $\mathrm{pH}$ value dropped further to 6.01 from 9.46 and by adding the PAA it dropped to 5.84. In our study when the chitosan or gelatin film was alternatively soaked with $\mathrm{CaCl}_{2}$ and $\mathrm{NaHCO}_{3}$ no obvious lateral growth was observed. Presumably due to the higher $\mathrm{pH}$ of the $\mathrm{NaHCO}_{3}$ solution, chitosan is not as readily protonated, a polyelectrolyte complex does not form and as a result lateral growth of the calcium carbonate at the concentrations of PAA used here was not observed. Instead when the films were soaked with $\mathrm{CaCl}_{2}$ and $\mathrm{NaHCO}_{3}$ followed by saturated $\mathrm{CaCO}_{3}$ solution (McGrath method) lateral growth was achieved. Also alternative soaking of the chitosan film with $\mathrm{CaCl}_{2}$ and $\mathrm{CaCO}_{3}$ respectively led to lateral growth alone. This is because of the presence of protonated nitrogen cations on the chitosan and deprotonated carboxylic anions on the PAA.

\begin{tabular}{lll}
\hline \multicolumn{3}{l}{ Table 4: $\mathrm{pH}$ of crystallization solutions in the presence of PAA } \\
\hline Soaking solutions & $\mathrm{pH}$ of solution after bubbling with & $\mathrm{pH}$ of solution in the presence of 2 \\
& $\mathrm{CO}_{2}$ in the absence of PAA & wt\% of PAA and bubbling with \\
& 5.01 & $\mathrm{CO}_{2}$ \\
$\mathrm{CaCl}_{2}(500 \mathrm{mM})$ & 7.70 \\
$\mathrm{NaHCO}_{3}(500 \mathrm{mM})$ & 7.34 & 7.10 \\
$\mathrm{CaCO}_{3}(\mathrm{Kitano})$ & 6.01 & 5.84 \\
\hline
\end{tabular}




\subsubsection{4 $\mathrm{CaCO}_{3} /$ chitosan/AA and $\mathrm{CaCO}_{3} /$ gelatin/AA}

Calcium carbonate mineralization of chitosan vs. gelatin hydrogels in the presence of acrylic acid (AA), the monomer of polyacrylic acid was examined using the same crystallization conditions and approaches as above. SEM images showed the morphologies were less affected upon adding AA in both systems i.e. chitosan vs. gelatin compared to when PAA was added (Figure 2-16). Interestingly there was almost no crystal growth in the presence of AA in both the gelatin and chitosan template, when the Kitano method was used. When growth did occur it was not homogeneous and very large platelet polycrystalline calcite was formed for chitosan and stacked calcite in the case of gelatin when either the alternative soaking or McGrath methods were used. However significant crystallization occurred on the surface of chitosan using the McGrath method (Figure 2-16b) in comparison to gelatin (Figure 2-16e).

The XRD and micro-Raman analyses show that the observed crystals are calcite when either the alternative soaking or McGrath method is used which is similar to the data obtained when no additive was present in the gelatin and chitosan mineralization (data not shown here). In comparison with PAA the single carboxylic acid functional group per molecule has little ability to control the size and shape of the calcium carbonate crystals formed, which is consistent with literature [31]. The formation of a polyelectrolyte composite with the scaffold polymers appears to be critical to achieve lateral growth. Furthermore the variation of polymorph is evident when the PAA was used but in the presence of AA calcite was the only polymorph formed whether carbohydrate or protein substrates were used. 

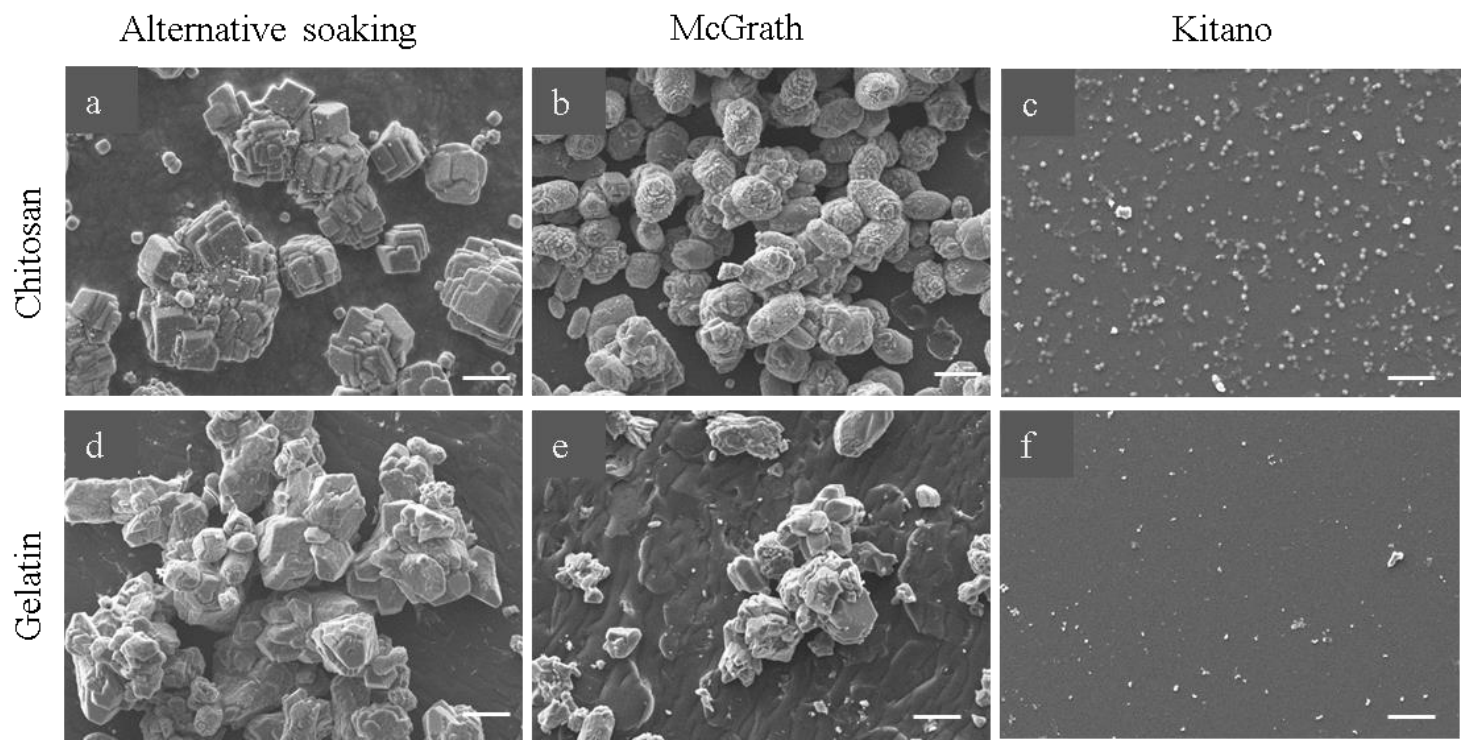

Figure 2-16: $\mathrm{SEM}$ images of $\mathrm{CaCO}_{3} /$ chitosan/AA (top row) and $\mathrm{CaCO}_{3} /$ gelatin/AA (bottom row) composites prepared with three different mineralization methods. For alternative soaking method the alternative soaking with $\mathrm{CaCl}_{2}$ and saturated $\mathrm{CaCO}_{3}$ solutions were used (images a, d). Scale bars: $10 \mu \mathrm{m}$.

In order to explore the calcium carbonate growth throughout the scaffold the cross-section of the $\mathrm{CaCO}_{3} /$ chitosan/PAA and $\mathrm{CaCO}_{3} /$ chitosan/AA composites (prepared via McGrath method) were investigated (Figure 2-17). The white arrow in Figure 2-17a shows the fractured cross-section of $\mathrm{CaCO}_{3} /$ chitosan/AA indicating little growth occurring within the film, the minerals grow just on the peripheral surface (black arrow represents the surface) which is consistent with EDS analysis (Figure 2-17b, calcium and carbon atoms are shown in blue and green respectively). The magnified view of the $\mathrm{CaCO}_{3} /$ chitosan/AA crosssection shows only a small amount of calcium carbonate growth within the film in the fractured region (Figure 2-17a inset).

However the backscatter image of a cross-section of the $\mathrm{CaCO}_{3} /$ chitosan/PAA shows appreciable calcium carbonate mineral growth within the chitosan hydrogel (see white arrow in Figure 2-17c). The lateral growth of calcium carbonate minerals at the surface as well as within the film is also evident in Figure 2-17c (white and black arrows demonstrate the fractured cross-section region and surface of $\mathrm{CaCO}_{3} /$ chitosan/PAA respectively). EDS mapping of a cross-section of a mineralized chitosan hydrogel template prepared via the McGrath method in the presence of PAA in all crystallization solutions confirmed the growth of calcium carbonate throughout the chitosan film (Figure 2-17D, calcium atoms are shown in blue). Moreover, the calcium carbonate crystallization on the underside of the 
porous chitosan template is evident indicating that the nanoscopic pores allows solvent diffusion throughout the chitosan template.

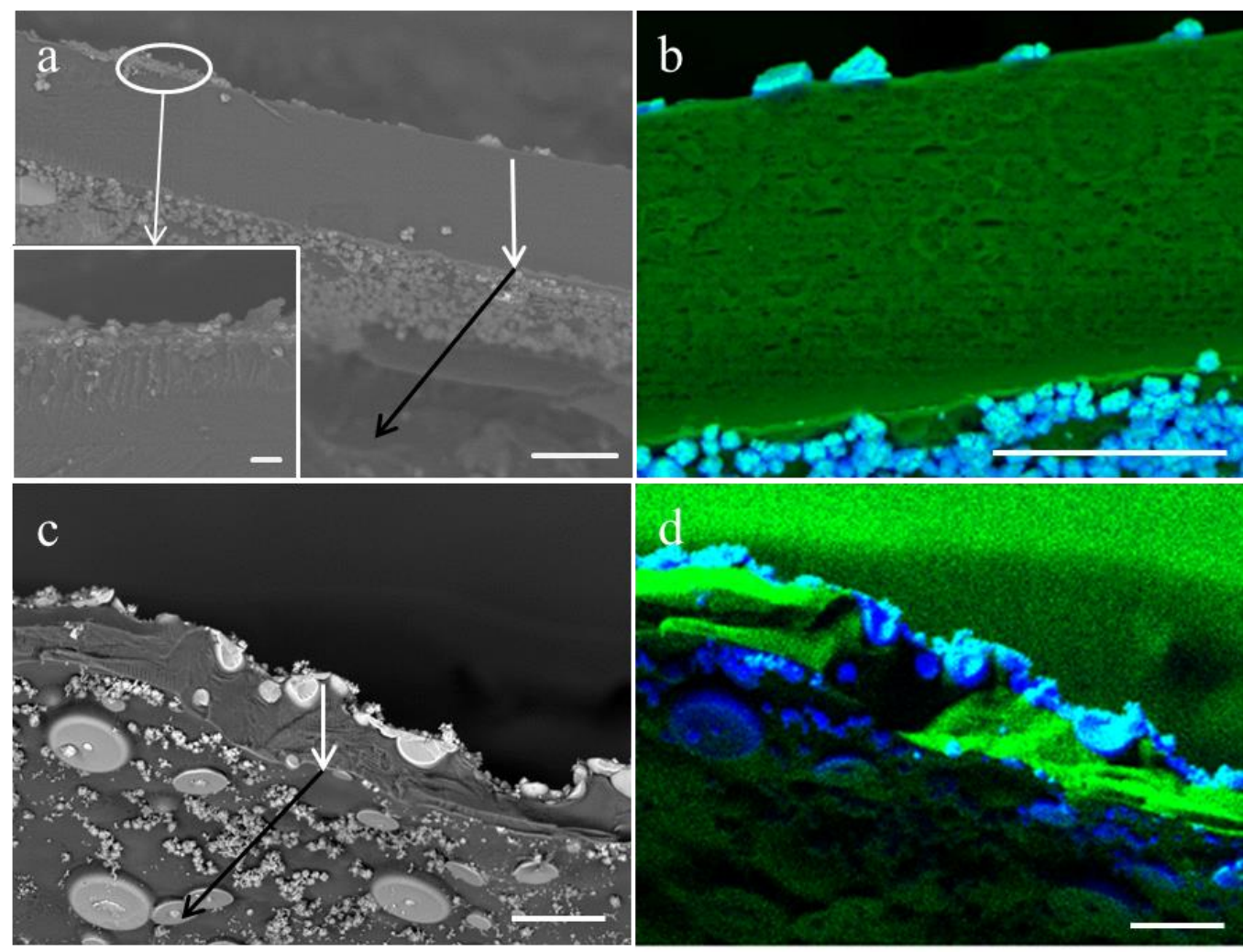

Figure 2-17: Cross-sections of (a) $\mathrm{CaCO}_{3} /$ chitosan/AA composite (white arrow shows the fractured surface and black arrow shows the surface), the magnified view shows the presence of calcium carbonate throughout the film in the peripheral fractured region, (b) EDS mapping of $\mathrm{CaCO}_{3} /$ chitosan/AA showing crystal growth on the surface of the chitosan film (calcium is shown in blue and carbon in green), (c) $\mathrm{CaCO}_{3} /$ chitosan/PAA showing the lateral calcium carbonate growth within the chitosan template in addition to the surface of the film, and (d) EDS mapping of $\mathrm{CaCO}_{3} /$ chitosan/PAA (calcium is shown in blue). All the presented composites were prepared using the McGrath method. Scale bars: $50 \mu \mathrm{m}$ (inset $10 \mu \mathrm{m}$ ).

Fractured cross-section of the $\mathrm{CaCO}_{3} /$ gelatin/PAA and $\mathrm{CaCO}_{3} /$ gelatin/AA composites were also investigated. Similar to $\mathrm{CaCO}_{3} /$ chitosan/AA there is no marked $\mathrm{CaCO}_{3}$ growth within the gelatin template. However a fractured cross-section of th $\mathrm{CaCO}_{3} /$ gelatin/PAA composite reveals that a small amount of $\mathrm{CaCO}_{3}$ growth within the gelatin template is evident, (circled area Figure 2-18b), but less so than for the $\mathrm{CaCO}_{3} /$ gelatin/PAA system. It seems the physically cross-linked chitosan can facilitated the solution transfer throughout the porous gel network more readily than the chemically cross-linked gelatin. The smaller pore size of the gelatin network plus the chemical linkages may not allow to the solution to diffuse within the template. 

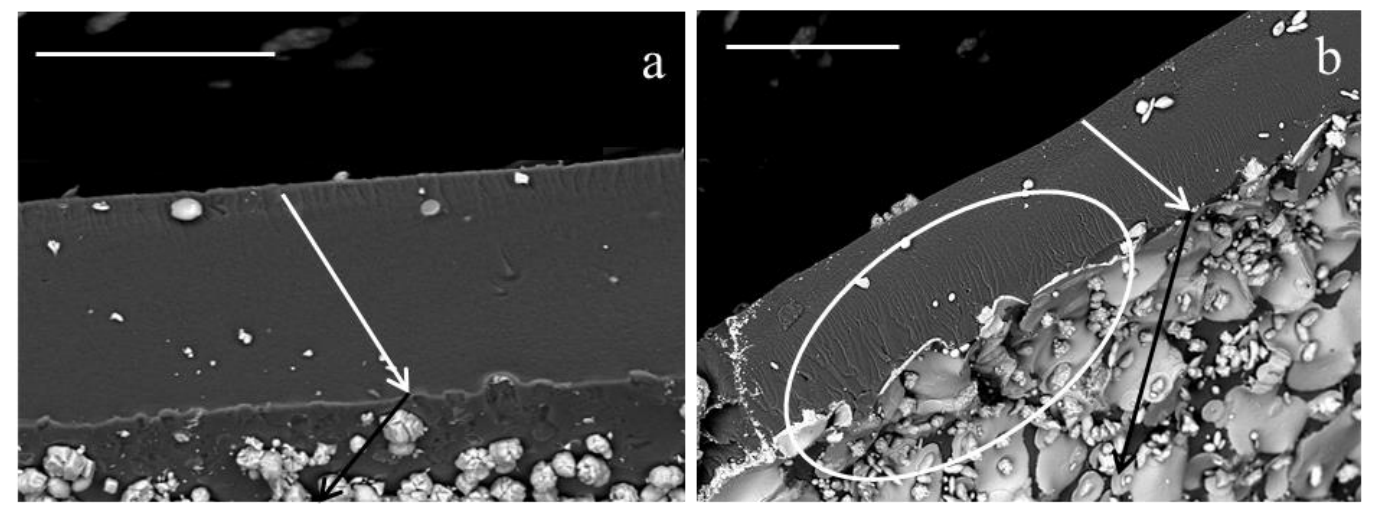

Figure 2-18: Cross-sections of (a) $\mathrm{CaCO} /$ gelatin/AA composite (white arrow shows the fractured surface and black arrow shows the surface) indicating the growth occurring in the surface, and (b) $\mathrm{CaCO} 3 /$ gelatin/PAA showing the lateral growth of calcium carbonate in the surface of chitosan template with a small amount growth within the film. All the presented composites were prepared via McGrath method. Scale bars: $100 \mu \mathrm{m}$.

\subsubsection{Glutamic acid/polyglutamic acid and aspartic acid/poly aspartic acid}

For the second series of additives; glutamic acid (GL), its polymeric form polyglutamic acid (PGL), and aspartic acid (AS) and its corresponding polymer, polyaspartic acid (PAS) were used. It is well-known that a small amount of acidic anionic macromolecules are present in the structure of organic-inorganic biominerals like bone and nacre [26, 48]. Are the same or different nucleation and growth outcomes obtained from, for example molecules like Laspartic acid and glutamic acid in controlling synthetic biomineralization? Do these monomers behave similarly or differently from their corresponding polymers?

These two amino acids both contain two carboxylic acid functional groups with GL having an additional methylene group. The different acidity of AS and GL comes from the side chain effect (see the structures in Table 2). This side chain may induce differences in the AS-controlled crystallization vs. the GL-controlled crystallization. These types of acidic additives are very common in controlled mineralization of synthetic bone and nacre [49] but a comprehensive study of this series of additives for the chitosan and gelatin hydrogels has not been undertaken previously in particular for the methods used in this study.

The $\mathrm{pH}$ of all solutions was measured in the presence and absence of additives prior to adding the film and the results were in the same range as measured for the PAA system described above (data not shown). 


\subsubsection{6 $\mathrm{CaCO}_{3} /$ Chitosan/GL, AS, PGL and PAS}

A summary of crystallization conditions, morphological and crystallinity analysis is compiled in Table 5. SEM studies of calcium carbonate grown within the chitosan scaffold using four additives (GL, AS, PGL and PAS) showed various morphologies (Figure 2-19). Each of the different crystallization methods was used. Faceted rhombohedral calcite crystals were occasionally formed in all three crystallization conditions, particularly in the case of the single molecule of glutamic acid and aspartic acid (Figure 2-19b, d). In the presence of GL and AS additives for the chitosan hydrogel system very large crystals are formed in the case of the alternative soaking method (Figure 2-19a, d). Elongated rhombohedral calcite crystals with polycrystalline structures were formed when GL was used in the alternative soaking mineralization method (Figure 2-19a). This elongated morphology seems larger than the typical rhombohedra $(30-50 \mu \mathrm{m})$. In contrast single and polycrystalline rhombohedral calcite are produced when AS was used in the case of the alternative soaking mineralization method (Figure 2-19d). Considerable crystallization was achieved when the McGrath method was used for both AS and GL additives. The growth is very homogeneous in the $\mathrm{CaCO}_{3} /$ chitosan/GL system. The higher load of calcium and carbonate ions led to high local concentrations of calcium due to the first stage of the McGrath method (alternatively soaking with calcium and carbonate ions). Once again smaller crystals are obtained for both $\mathrm{CaCO}_{3} /$ chitosan/GL and $\mathrm{CaCO}_{3} /$ chitosan/AS composites (size ranging from 3-5 $\mu \mathrm{m}$ in the case of GL and 4-10 $\mu \mathrm{m}$ in the case of AS) in comparison with the alternative soaking method. This is very similar to the observed morphology for the $\mathrm{CaCO}_{3}$ /chitosan system when no additive is present (Figure 2-2). Surprisingly the Kitano method leads to a significant amount of crystallization within the film in the presence of AS (Figure 2-19f). This is in contradiction with AA (Figure 2-16c) and GL (Figure 2-19f) results where there is almost no crystal growth on chitosan film. XRD and micro-Raman analysis confirmed that calcite was always nucleated for AS and GL additives no matter which crystallization method was used (data are not shown).

In order to compare the influence of the polymer and monomer additives, PGL and PAS were introduced into the $\mathrm{CaCO}_{3} /$ chitosan composite systems under the same crystallization conditions. Again more nucleation and growth occurred when the McGrath method was used (Figure 2-19h, k) but the morphologies created by each of the PGL and PAS additives are significantly different from PAA (Figure 2-9e). PGL generates the stacked multi-nucleation calcium carbonate while the PAS leads to aggregation of the calcium carbonate crystals. No 
lateral growth is evident in the presence of PGL and PAS (with the additive concentration used here $2 \mathrm{wt} \%$ ) when the McGrath method was used. In contrast lateral growth of calcium carbonate throughout the chitosan hydrogel scaffold is readily observed when using the Kitano and alternative soaking crystallization approaches (Figure 2-18g, i, 1, j). It can be seen in Figure 2-19g how the calcite laterally grows inside the chitosan.

For the small molecular additives the calcite crystals are elongated along the c-axis in contrast with the polymeric additives where lateral growth occurs, which is in good accordance with AA/PAA results. The polymer chains of the PGL and PAS induce a significant influence over the calcium carbonate nucleation and growth due to the possible interaction between the polymer and the hydrogel itself in addition to the association of the forming calcium carbonate with the polymer additives. The ability for PAS and PGL to induce lateral growth of calcium carbonate on chitosan hydrogel scaffolds is based on the same general mechanism as for PAA. Polyanionic PGL and PAS are able to interact with calcium ions and the chitosan scaffold which yields a higher local concentration of precursor ions close to the chitosan surface and polyelectrolyte complex formation [50]. Since lateral growth is not always observed it is assumed that in addition to functional group and local supersaturation in the microenvironment, the conformation of amino acids is an important factor for inducing specific growth in determining final morphology [13, 51]. The negatively charged groups of PGA and PAS that have an appropriate conformation interact with the amine group of chitosan resulting in lateral growth of calcite when the Kitano method was used. These data are in good agreement with the literature which confirm that the lateral growth of calcium carbonate on chitosan scaffolds in the presence of PAS and PGL [13, 50].

All the composites were analyzed by XRD and micro-Raman to determine the crystallinity and polymorphism. In the case of $\mathrm{CaCO}_{3} /$ chitosan/PGL a mixture of calcite and vaterite was formed when either the Kitano or alternative soaking methods of crystallization were used (Figure 2-20b and d). Calcite is formed using the McGrath method when PGL is present in all crystallization solutions (Figure 2-20f). These results show a different trend than when PAA was added to the crystallization solutions of both the Kitano and alternative soaking methods which lead to only calcite formation and in the case of McGrath method a mixture of calcite, aragonite and vaterite were formed. The XRD analysis of $\mathrm{CaCO}_{3} /$ chitosan/PGL system indicates the formation of calcite using both alternative soaking and McGrath (Figure 2-20c and f). However when Kitano solution with added, containing PAS, a mixture of calcite and vaterite results (Figure 2-20a). 


\begin{tabular}{|c|c|c|c|c|c|}
\hline Method & $\begin{array}{l}\text { Presoak } \\
\text { solution (1) }\end{array}$ & $\begin{array}{l}\text { Presoak solution } \\
\text { (2) }\end{array}$ & $\begin{array}{l}\text { Crystallization } \\
\text { solution (3) }\end{array}$ & Crystal morphology & Polymorph \\
\hline $\begin{array}{l}\text { Alternative } \\
\text { soaking }\end{array}$ & $\mathrm{CaCl}_{2}+\mathrm{GL}$ & - & $\mathrm{CaCO}_{3}+\mathrm{GL}$ & $\begin{array}{l}\text { Elongated rhombohedral } \\
\text { (Figure 2-19a) }\end{array}$ & Calcite \\
\hline $\begin{array}{l}\text { Alternative } \\
\text { soaking }\end{array}$ & $\mathrm{CaCl}_{2}+\mathrm{AS}$ & - & $\mathrm{CaCO}_{3}+\mathrm{AS}$ & $\begin{array}{l}\text { Polycrystalline/ } \\
\text { rhombohedra } \\
\text { (Figure 2-19d) }\end{array}$ & Calcite \\
\hline $\begin{array}{l}\text { Alternative } \\
\text { soaking }\end{array}$ & $\mathrm{CaCl}_{2}+\mathrm{PGL}$ & - & $\mathrm{CaCO}_{3}+\mathrm{PGL}$ & $\begin{array}{l}\text { Lateral growth } \\
\text { (Figure 2-19g) }\end{array}$ & $\begin{array}{l}\text { Calcite, } \\
\text { vaterite } \\
(52: 48)\end{array}$ \\
\hline $\begin{array}{l}\text { Alternative } \\
\text { soaking }\end{array}$ & $\mathrm{CaCl}_{2}+\mathrm{PAS}$ & - & $\mathrm{CaCO}_{3}+\mathrm{PAS}$ & $\begin{array}{l}\text { Lateral growth } \\
\text { (Figure 2-19j) }\end{array}$ & Calcite, \\
\hline McGrath & $\mathrm{CaCl}_{2}+\mathrm{GL}$ & $\mathrm{NaHCO}_{3}+\mathrm{GL}$ & $\mathrm{CaCO}_{3}+\mathrm{GL}$ & $\begin{array}{l}\text { Polycrystalline/ } \\
\text { rhombohedra } \\
\text { (Figure 2-19b) }\end{array}$ & Calcite \\
\hline McGrath & $\mathrm{CaCl}_{2}+\mathrm{AS}$ & $\mathrm{NaHCO}_{3}+\mathrm{AS}$ & $\mathrm{CaCO}_{3}+\mathrm{AS}$ & $\begin{array}{l}\text { Polycrystalline } \\
\text { (Figure 2-19e) }\end{array}$ & Calcite \\
\hline McGrath & $\mathrm{CaCl}_{2}+\mathrm{PGL}$ & $\mathrm{NaHCO}_{3}+\mathrm{PGL}$ & $\mathrm{CaCO}_{3}+\mathrm{PGL}$ & $\begin{array}{l}\text { Stacked/polycrystalline } \\
\text { (Figure 2-19h) }\end{array}$ & Calcite \\
\hline McGrath & $\mathrm{CaCl}_{2}+\mathrm{PAS}$ & $\mathrm{NaHCO}_{3}+\mathrm{PAS}$ & $\mathrm{CaCO}_{3}+\mathrm{PAS}$ & $\begin{array}{l}\text { Aggregated/polycrystalline } \\
\text { (Figure 2-19k) }\end{array}$ & $\begin{array}{l}\text { Calcite, } \\
\text { Vaterite } \\
(87: 13)\end{array}$ \\
\hline Kitano & - & - & $\mathrm{CaCO}_{3}+\mathrm{GL}$ & $\begin{array}{l}\text { Very small crystals (Figure } \\
2-19 c)\end{array}$ & Calcite \\
\hline Kitano & - & - & $\mathrm{CaCO}_{3}+\mathrm{AS}$ & $\begin{array}{l}\text { Polycrystalline } \\
\text { (Figure 2-19f) }\end{array}$ & Calcite \\
\hline Kitano & - & - & $\mathrm{CaCO}_{3}+\mathrm{PGL}$ & $\begin{array}{l}\text { Lateral growth } \\
\text { (Figure 2-19i) }\end{array}$ & $\begin{array}{l}\text { Calcite, } \\
\text { vaterite } \\
(22: 78)\end{array}$ \\
\hline Kitano & - & - & $\mathrm{CaCO}_{3}+\mathrm{PAS}$ & $\begin{array}{l}\text { Lateral growth } \\
\text { (Figure 2-191) }\end{array}$ & $\begin{array}{l}\text { Calcite, } \\
\text { Vaterite } \\
(62: 38)\end{array}$ \\
\hline
\end{tabular}




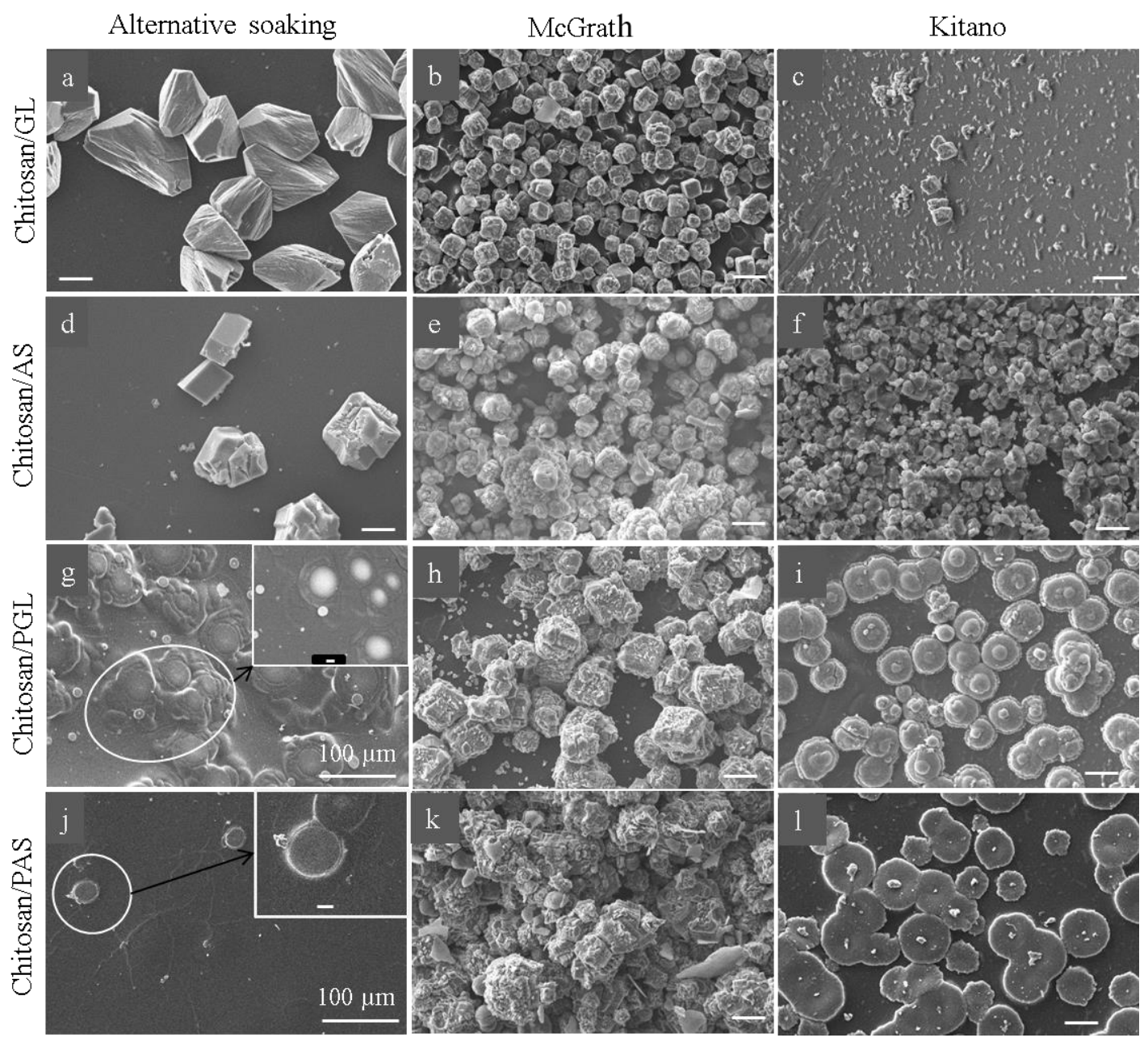

Figure 2-19: $\mathrm{SEM}$ images of $\mathrm{CaCO}_{3} /$ chitosan/GL (top row $\mathrm{a}, \mathrm{b}$ and c), $\mathrm{CaCO}_{3} / \mathrm{chitosan} \mathrm{AS}$ (second row $\mathrm{d}$, e and $\mathrm{f}$ ), $\mathrm{CaCO}_{3} /$ chitosan/PGL (third row $\mathrm{g}, \mathrm{h}$ and $\mathrm{i}$ ), and $\mathrm{CaCO}_{3} /$ chitosan/PAS (bottom row $\mathrm{j}$, $\mathrm{k}$ and $\mathrm{l}$ ) composites prepared with three different mineralization methods. Scale bars: $10 \mu \mathrm{m}$ (unless stated otherwise). 


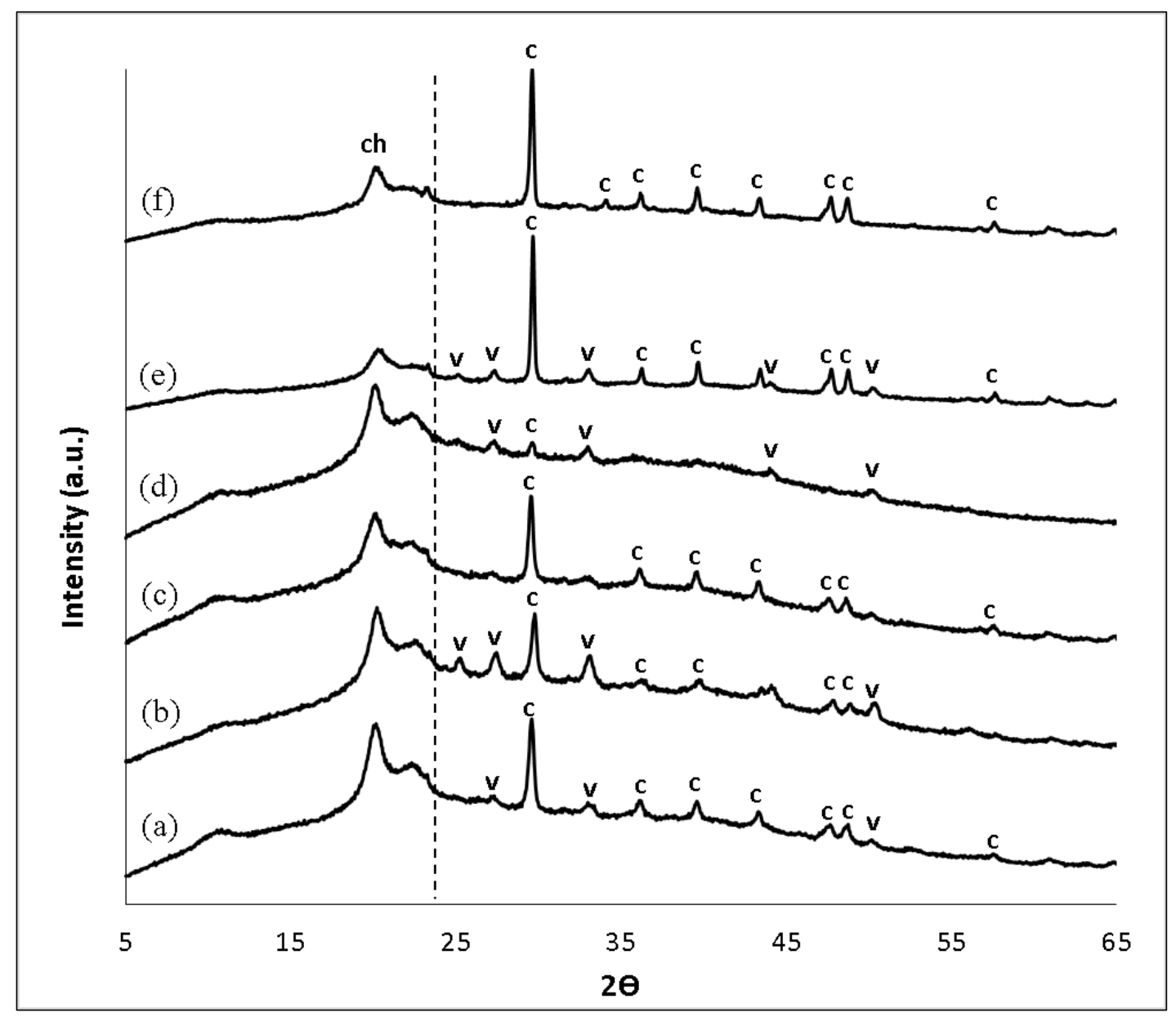

Figure 2-20: $\mathrm{XRD}$ patterns of $\mathrm{CaCO}_{3} /$ chitosan/PAS composites prepared via (a) Kitano, (c) alternative soaking, and (e) $\mathrm{McGrath}$ method and $\mathrm{CaCO}_{3} /$ chitosan/PGL composites prepared via (b) Kitano, (d) alternative soaking, (f) McGrath method. The peaks of the two calcium carbonate polymorphs are indicated with $\mathrm{c}$ and $\mathrm{v}$ for calcite and vaterite respectively. 


\subsubsection{7 $\mathrm{CaCO}_{3} /$ Gelatin/GL, AS, PGL and PAS}

The influence of this series of additives with the gelatin hydrogels was also investigated. Table 6 provides the information about the mineralization conditions, crystallinity, morphology and polymorph information for the $\mathrm{CaCO}_{3} /$ gelatin GL, PGL, AS and PAS systems.

A diverse range of morphologies of calcium carbonate crystals was grown within the gelatin matrix (see Figure 2-21). Rod shaped calcite crystals were produced in the presence of GL when both the alternative soaking and Kitano methods were used (Figure 2-21a, c) which indicates that the protein scaffold clearly modulates the crystallization process differently from the polysaccharide one (Figure 2-19a, c). In contrast polycrystalline rhombohedra formed in the case of when the alternative soaking with added AS was used (Figure 2-21d) and almost no crystal growth was observed in the case of when Kitano method was used (Figure 2-21f). Using the McGrath method in the presence of both GL and AS leads to the formation of polycrystalline rhombohedral calcium carbonate crystals (Figure 2-21b and e). Raman spectroscopy and XRD data show that the monomeric additives used in this study always lead to the nucleation of calcite for either the chitosan or gelatin scaffolds.

Again lateral growth of calcium carbonate crystals occurs in the presence of PGL and PAS (Figure 2-21g, i and 1). Compared to the chitosan scaffold the crystals are on average larger. A mixture of lateral growth and plate-like polycrystalline calcium carbonate crystals form when using the McGrath method in the presence of PAS (Figure 2-21h inset). The lateral growth of calcium carbonate was not evident for the same conditions for the chitosan scaffold which is consistent with the $\mathrm{CaCO}_{3} /$ chitosan/PAS results. It might be the significant aggregation that hides the lateral growth.

All the composites were analyzed by XRD and micro-Raman to determine the crystallinity and polymorphism. Polymorph growth is altered in comparison with calcium carbonate nucleation in chitosan scaffold. Although the dominant polymorph is calcite, a trace amount of vaterite is present (93:7) in the $\mathrm{CaCO}_{3} /$ chitosan/PAS system using the McGrath method, using PGL and PAS additives. The XRD data obtained from $\mathrm{CaCO}_{3} /$ gelatin/GL, AS, PGL and PAS samples prepared via the McGrath method are shown in Figure 2-22. Due to the dominant characteristic gelatin peak and the low peak intensity resulting for the calcite crystals for samples prepared via the alternative soaking and Kitano methods their data are not reported here. 


\begin{tabular}{|c|c|c|c|c|c|}
\hline Method & $\begin{array}{l}\text { Presoak } \\
\text { solution (1) }\end{array}$ & $\begin{array}{l}\text { Presoak solution } \\
\text { (2) }\end{array}$ & $\begin{array}{l}\text { Crystallization } \\
\text { solution (3) }\end{array}$ & Crystal morphology & Polymorph \\
\hline $\begin{array}{l}\text { Alternative } \\
\text { soaking }\end{array}$ & $\mathrm{CaCl}_{2}+\mathrm{GL}$ & - & $\mathrm{CaCO}_{3}+\mathrm{GL}$ & $\begin{array}{l}\text { Rod shaped } \\
\text { (Figure 2-21a) }\end{array}$ & Calcite \\
\hline $\begin{array}{l}\text { Alternative } \\
\text { soaking }\end{array}$ & $\mathrm{CaCl}_{2}+\mathrm{AS}$ & - & $\mathrm{CaCO}_{3}+\mathrm{AS}$ & $\begin{array}{l}\text { Poly crystalline } \\
\text { (Figure } 2-21 d \text { ) }\end{array}$ & Calcite \\
\hline $\begin{array}{l}\text { Alternative } \\
\text { soaking }\end{array}$ & $\mathrm{CaCl}_{2}+\mathrm{PGL}$ & - & $\mathrm{CaCO}_{3}+\mathrm{PGL}$ & $\begin{array}{l}\text { Lateral growth } \\
\text { (Figure 2-21g) }\end{array}$ & Calcite \\
\hline $\begin{array}{l}\text { Alternative } \\
\text { soaking }\end{array}$ & $\mathrm{CaCl}_{2}+\mathrm{PAS}$ & - & $\mathrm{CaCO}_{3}+\mathrm{PAS}$ & $\begin{array}{l}\text { Defected rhombohedra } \\
\text { (Figure } 2-21 \mathrm{j} \text { ) }\end{array}$ & Calcite \\
\hline McGrath & $\mathrm{CaCl}_{2}+\mathrm{GL}$ & $\mathrm{NaHCO}_{3}+\mathrm{GL}$ & $\mathrm{CaCO}_{3}+\mathrm{GL}$ & $\begin{array}{l}\text { Polycrystalline/ } \\
\text { rhombohedra } \\
\text { (Figure 2-21b) }\end{array}$ & Calcite \\
\hline McGrath & $\mathrm{CaCl}_{2}+\mathrm{AS}$ & $\mathrm{NaHCO}_{3}+\mathrm{AS}$ & $\mathrm{CaCO}_{3}+\mathrm{AS}$ & $\begin{array}{l}\text { Poly crystalline } \\
\text { (Figure } 2-21 \mathrm{e} \text { ) }\end{array}$ & Calcite \\
\hline McGrath & $\mathrm{CaCl}_{2}+\mathrm{PGL}$ & $\mathrm{NaHCO}_{3}+\mathrm{PGL}$ & $\mathrm{CaCO}_{3}+\mathrm{PGL}$ & $\begin{array}{l}\text { Stacked/polycrystalline } \\
\text { (Figure 2-21h) }\end{array}$ & Calcite \\
\hline McGrath & $\mathrm{CaCl}_{2}+\mathrm{PAS}$ & $\mathrm{NaHCO}_{3}+\mathrm{PAS}$ & $\mathrm{CaCO}_{3}+\mathrm{PAS}$ & $\begin{array}{l}\text { Polycrystalline/lateral } \\
\text { growth } \\
\text { (Figure 2-21k) }\end{array}$ & $\begin{array}{l}\text { Calcite, } \\
\text { vaterite }\end{array}$ \\
\hline Kitano & - & - & $\mathrm{CaCO}_{3}+\mathrm{GL}$ & $\begin{array}{l}\text { Rod shaped } \\
\text { (Figure 2-21c) }\end{array}$ & Calcite \\
\hline Kitano & - & - & $\mathrm{CaCO}_{3}+\mathrm{AS}$ & $\begin{array}{l}\text { Not Detected } \\
\text { (Figure 2-21f) }\end{array}$ & Calcite \\
\hline Kitano & - & - & $\mathrm{CaCO}_{3}+\mathrm{PGL}$ & $\begin{array}{l}\text { Lateral growth } \\
\text { (Figure 2-21i) }\end{array}$ & Calcite \\
\hline Kitano & - & - & $\mathrm{CaCO}_{3}+\mathrm{PAS}$ & $\begin{array}{l}\text { Lateral growth } \\
\text { (Figure 2-211) }\end{array}$ & Calcite \\
\hline
\end{tabular}




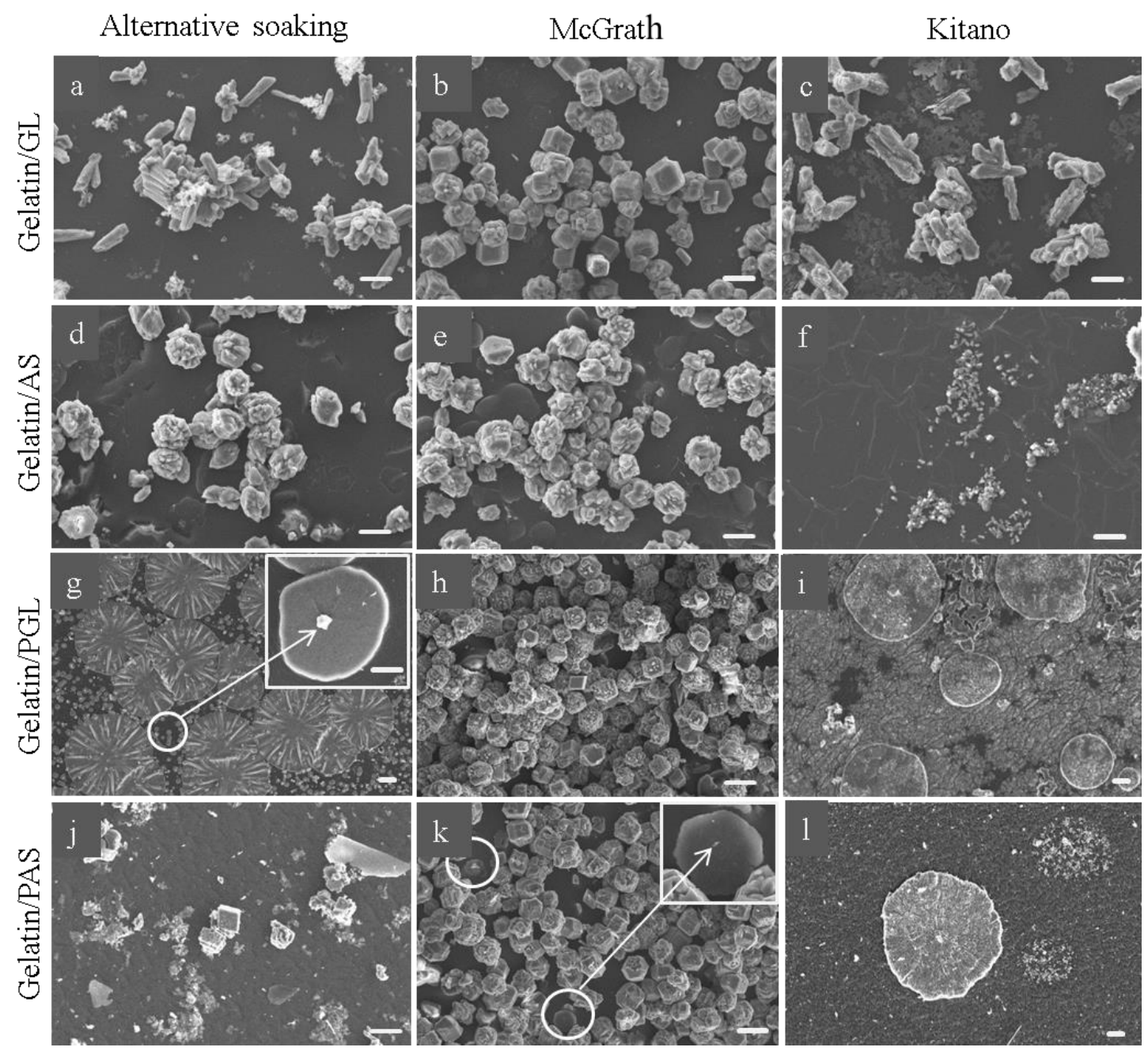

Figure 2-21: SEM images of $\mathrm{CaCO}_{3} /$ gelatin/GL (top row $\mathrm{a}$, b and c), $\mathrm{CaCO}_{3} /$ gelatin/AS (second row d, e and f), $\mathrm{CaCO}_{3}$ /gelatin/PGL (third row $\mathrm{g}$, $\mathrm{h}$ and i), and $\mathrm{CaCO}_{3} /$ gelatin/PAS (bottom row $\mathrm{j}, \mathrm{k}$ and $\mathrm{l}$ ) composites prepared with the three different mineralization methods. Scale bars: $10 \mu \mathrm{m}$ (unless stated otherwise). 


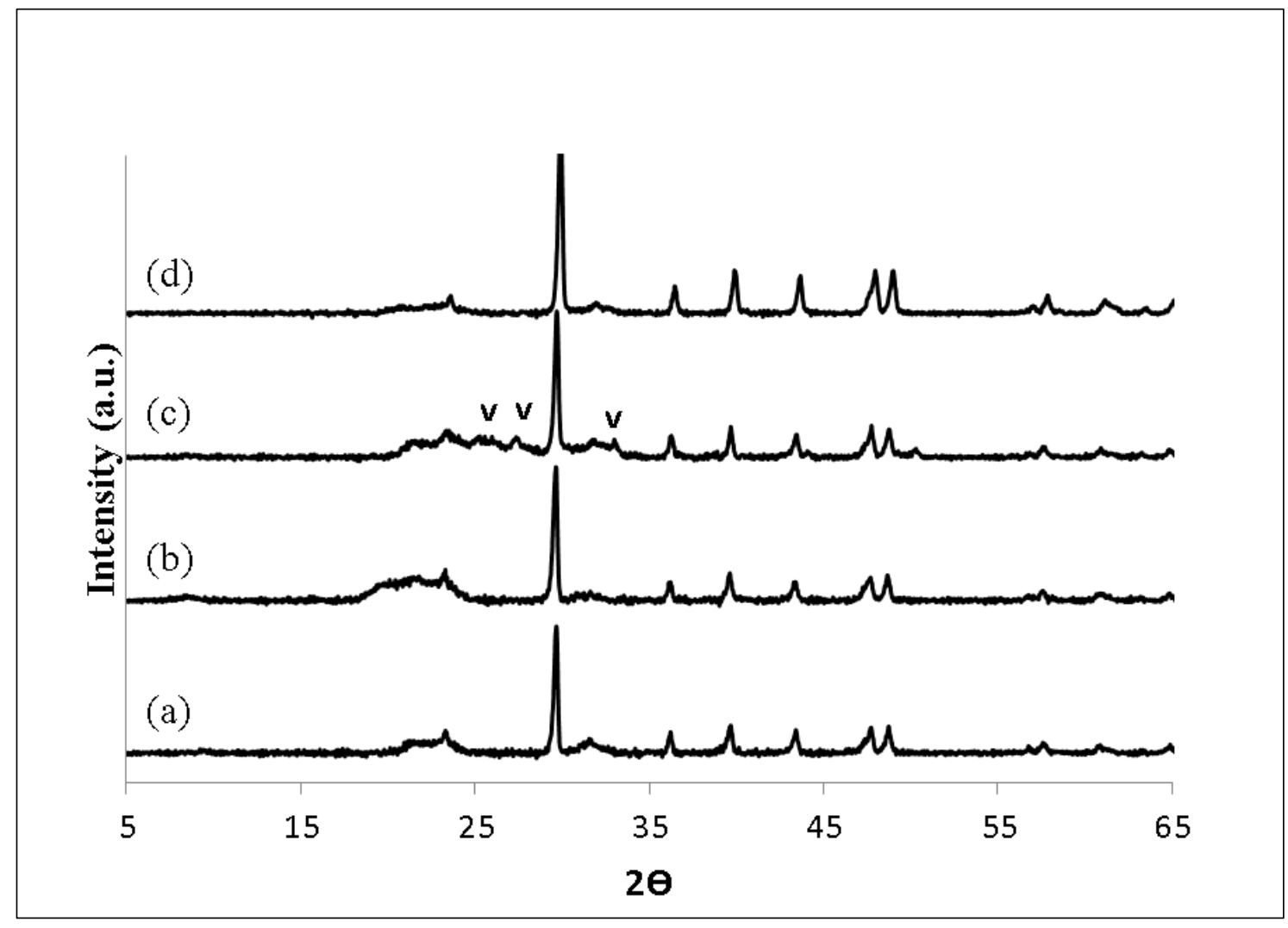

Figure 2-22: $\mathrm{XRD}$ pattern of (a) $\mathrm{CaCO}_{3} /$ Gelatin/AS, (b) $\mathrm{CaCO}_{3} /$ Gelatin/GL, (c) $\mathrm{CaCO}_{3} /$ Gelatin/PAS, and (d) $\mathrm{CaCO}_{3} /$ Gelatin/PGL composites prepared via McGrath methods. Vaterite peaks are shown with v letter.

The above data reveal that the conformations and size of the two amino acids are crucial in determining the crystal morphology and polymorph [52]. PAS and PGL exist as $\beta$-sheet and random coil conformations in calcium chloride solution, but they predominantly adsorb to an insoluble matrix in the $\beta$-sheet conformation [53]. A similar conformation of PAS and PGL may need to be adsorbed to the chitosan and gelatin matrices when they are interacting to initiate lateral growth of calcium carbonate and suppress the formation and/or development of stable faces of calcite (104) in the case of lateral growth. A strong electrostatic interaction at the interfaces between calcium carbonate/matrices/additive, such as PGL and PAS, is needed to form a polyelectrolyte composite material and then induce lateral growth of the mineral.

Our results reveal that a long polymer chain has a remarkable influence over $\mathrm{CaCO}_{3}$ growth. Furthermore polymeric additives led to strong growth modification of calcium carbonate crystals in comparison with their monomers which is in keeping with literature [28, 31]. It was observed PAS and PGL had the effect of inducing the formation of thin films and tablets of $\mathrm{CaCO}_{3}$ on a substrate, by the formation of a liquid-like amorphous precursor phase [4]. 
Later, it was discovered that a similar result could be obtained with the commercially cheaper PAA as well $[13,42]$. In our study we have found that PAA is more effective in lateral growth of calcium carbonate no matter which methods used. PGL and PAS are able to deposit a lateral growth on both chitosan and gelatin scaffolds, but depends which methods are used. The proposed mechanism for lateral growth of calcium carbonate can be through formation of polyelectrolyte composite where acidic macromolecules can adsorb to the surface of insoluble scaffold at the same time can bind to calcium ions on the surface of chitosan and gelatin. Adsorbed additives results in a local high ion concentration of the calcium ion on the surface of scaffolds, inducing nucleation of calcium carbonate. But nucleating phase is more likely to be that of amorphous calcium carbonate precursor due to having heterogeneous nucleation [4].

In this study, there was no evidence for lateral growth when monomeric additives were used irrespective of crystallization method, concentration of presoaking solution or concentration of additive. As the monomeric additives have a higher diffusion coefficient, they can interact with calcium ions rapidly and due to steric and chemical interactions cannot associate with the insoluble matrix. They also have a small number of functional groups compared with polymeric additives which restricts the lateral growth of calcium carbonate [31].

\subsubsection{Effect of concentration variation: McGrath method}

As mentioned in Chapter 1, one of the advantages of the McGrath method over the alternative soaking and Kitano methods is that it readily allows the concentrations of the ions to be changed in order to have better control over the size and shape of the crystal growth. Herein the gelatin and chitosan templates are mineralized in the presence of polymeric additives using the McGrath method by soaking the templates in lower concentrations of the presoaking solutions followed by saturated $\mathrm{CaCO}_{3}$ solution. The effect of lower presoaking ion concentration $\left(\mathrm{CaCl}_{2}\right.$ and $\left.\mathrm{NaHCO}_{3} 100 \mathrm{mM}\right)$ compared to that of a higher concentration $\left(\mathrm{CaCl}_{2}\right.$ and $\left.\mathrm{NaHCO}_{3} 500 \mathrm{mM}\right)$ is summarized in Table 7.

In the presence of $2 \mathrm{wt} \%$ of polymeric additives (PAA, PAS and PGL; present in all mineralization solutions) and low presoaking ion concentration, no significant changes in the size and shape of crystals were observed compared to samples which were mineralized with the high concentration presoaking solutions. Only the extent of calcification was decreased. However the morphology of crystals is dramatically altered in the presence of 1 wt $\%$ PGL, PAA and PAS irrespective of whether chitosan or gelatin scaffolds are used 
(Figure 2-23). The results suggest that a lower concentration of $\mathrm{CaCl}_{2}$ and $\mathrm{NaHCO}_{3}$ and the presence of $1 \mathrm{wt} \%$ of polymeric additives offer better control over the morphologies of obtained crystals for both chitosan and gelatin scaffolds. Lateral growth within and on the periphery of the hydrogel scaffold is evident and dominates for all samples (Figure 2-23a, $\mathrm{b}$, d, e, f) expect the $\mathrm{CaCO}_{3} /$ chitosan/PGL system (Figure 2-23c). In the $\mathrm{CaCO}_{3} /$ chitosan/PGL system, spherical calcium carbonate crystals (with the size ranging from $2-5 \mu \mathrm{m}$ ) were found in addition to the lateral growth (see white circles). This spherical growth of calcium carbonate with similar size is also obtained in the $\mathrm{CaCO}_{3}$ /gelatin/PGL system as well (Figure 2-23d).

Table 7: Crystallization conditions for calcium carbonate crystal growth with chitosan and gelatin hydrogel scaffolds in the presence of PAA, PAS and PGL.

\begin{tabular}{|c|c|c|c|c|c|c|}
\hline \multirow[t]{2}{*}{ Template } & \multirow{2}{*}{$\begin{array}{l}\text { Presoak } \\
\text { solution (1) }\end{array}$} & \multirow{2}{*}{$\begin{array}{l}\text { Presoak } \\
\text { solution (2) }\end{array}$} & \multirow{2}{*}{$\begin{array}{l}\text { Crystallization } \\
\text { solution (3) }\end{array}$} & \multirow[t]{2}{*}{ Crystal morphology } & \multicolumn{2}{|c|}{ Polymorph\% } \\
\hline & & & & & Calcite & Vaterite \\
\hline Chitosan & $\mathrm{CaCl}_{2}+\mathrm{PAS}$ & $\begin{array}{l}\mathrm{NaHCO}_{3}+ \\
\mathrm{PAS}\end{array}$ & $\mathrm{CaCO}_{3}+\mathrm{PAS}$ & $\begin{array}{l}\text { Lateral growth } \\
\text { (Figure 2-23a) }\end{array}$ & 29 & 71 \\
\hline Chitosan & $\mathrm{CaCl}_{2}+\mathrm{PGL}$ & $\begin{array}{l}\mathrm{NaHCO}_{3}+ \\
\mathrm{PGL}\end{array}$ & $\mathrm{CaCO}_{3}+\mathrm{PGL}$ & $\begin{array}{l}\text { Lateral growth/spherical } \\
\text { (Figure } 2-23 \mathrm{c} \text { ) }\end{array}$ & 56 & 44 \\
\hline Chitosan & $\mathrm{CaCl}_{2}+\mathrm{PAA}$ & $\begin{array}{l}\mathrm{NaHCO}_{3}+ \\
\text { PAA }\end{array}$ & $\mathrm{CaCO}_{3}+\mathrm{PAA}$ & $\begin{array}{l}\text { Lateral growth } \\
\text { (Figure 2-23e) }\end{array}$ & 63 & 37 \\
\hline Gelatin & $\mathrm{CaCl}_{2}+\mathrm{PAS}$ & $\begin{array}{l}\mathrm{NaHCO}_{3}+ \\
\mathrm{PAS}\end{array}$ & $\mathrm{CaCO}_{3}+\mathrm{PAS}$ & $\begin{array}{l}\text { Lateral growth } \\
\text { (Figure 2-23b) }\end{array}$ & 58 & 42 \\
\hline Gelatin & $\mathrm{CaCl}_{2}+\mathrm{PGL}$ & $\begin{array}{l}\mathrm{NaHCO}_{3}+ \\
\mathrm{PGL}\end{array}$ & $\mathrm{CaCO}_{3}+\mathrm{PGL}$ & $\begin{array}{l}\text { Lateral growth/spherical } \\
\text { (Figure 2-23d) }\end{array}$ & 62 & 38 \\
\hline Gelatin & $\mathrm{CaCl}_{2}+\mathrm{PAA}$ & $\begin{array}{l}\mathrm{NaHCO}_{3}+ \\
\text { PAA }\end{array}$ & $\mathrm{CaCO}_{3}+\mathrm{PAA}$ & $\begin{array}{l}\text { Lateral growth } \\
\text { (Figure 2-23f) }\end{array}$ & 30 & 70 \\
\hline
\end{tabular}

The concentration of all additives was $1 \mathrm{wt} \%$ with respect to the insoluble matrix mass and the presoaking solutions concentration was $100 \mathrm{mM}$. 

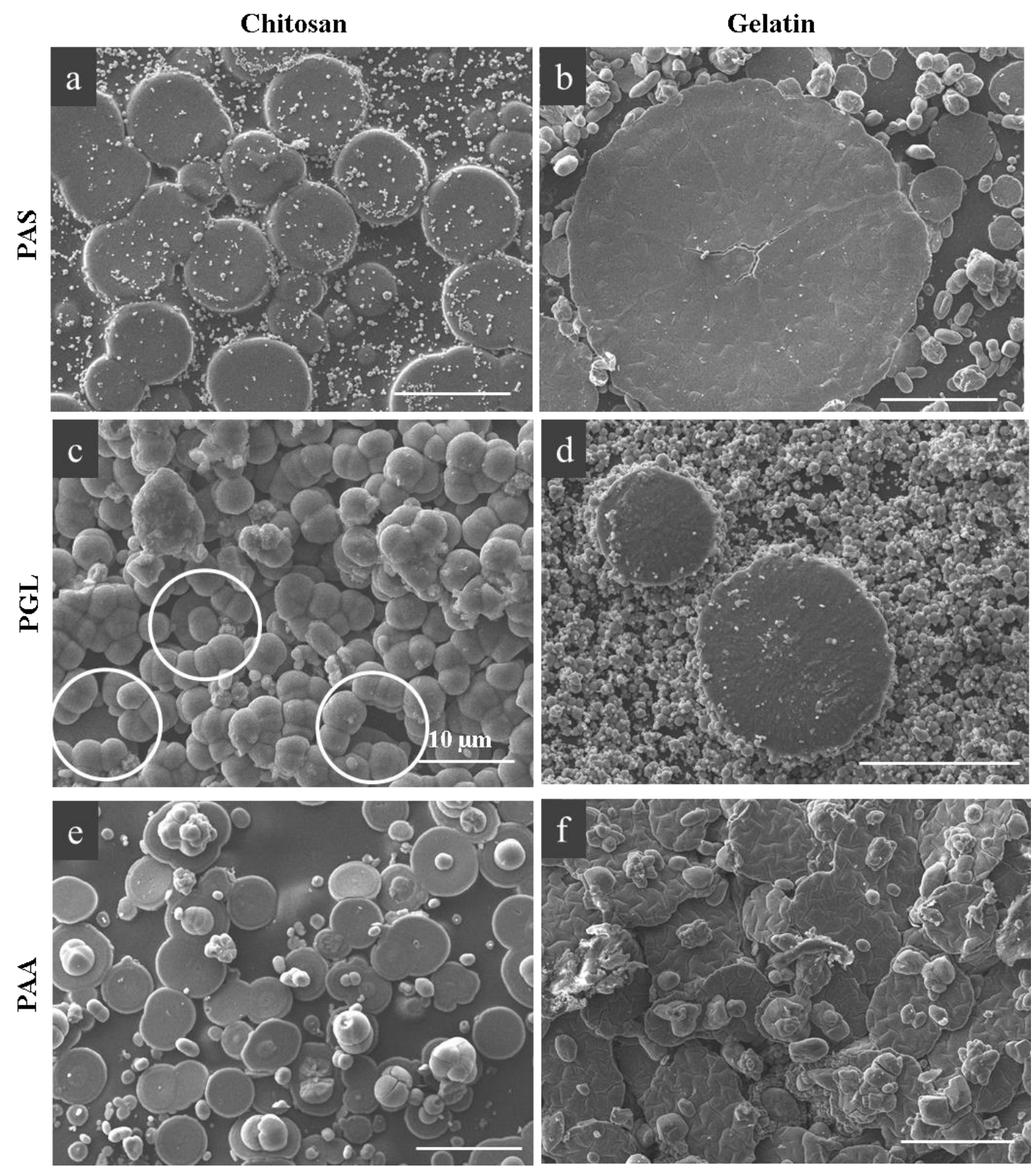

Figure 2-23: $\mathrm{SEM}$ images of $\mathrm{CaCO}_{3} /$ chitosan (left column) and $\mathrm{CaCO}_{3}$ /gelatin (right column) synthesized composite materials prepared via the McGrath method in the presence of (a), (b) PAS (c, d) PGL and (e, f) PAA. In (c) white circles are showing the somewhat hidden lateral growth crystals. Scale bars: $50 \mu \mathrm{m}$ (unless stated otherwise).

The variations in morphology are consistent with the XRD data (Figure 2-24). All obtained XRD diffractograms are similar and represent a mixture of calcite and vaterite polymorphs. No aragonite was nucleated.

When the concentration of the presoaking solutions is low, there appears to be sufficient polymeric additive to bind with both the calcium ions and the template with an appropriate conformation of amino acids in the case of PGL and PAS, hence facilitating polyelectrolyte 
complex formation, to result in a higher density of lateral growth. Based on the findings of Munro et al., the formation of a polyelectrolyte complex plays a key role in which polymorph is selected during mineralization [54]. It seems the formation of a polyelectrolyte complex promotes lateral growth of calcium carbonate polymorphs within and on the surface of the gelatin and chitosan scaffolds. The incorporation of PAA with the chitosan and gelatin scaffolds enhanced the nucleation of vaterite over calcite ( $70: 30$ vaterite to calcite) compared to when a high concentration of presoaking solutions was used. Upon switching from PAA to PGL and PAS, calcite nucleation is predominant (see Table 6). This can be attributed to the different charge density and conformation of PGL and PAS amino acids compared to PAA which changes the interaction with the chitosan and gelatin scaffolds and hence results in different morphology and polymorph selection. Our results suggest that there is also a relationship between lateral growth and vaterite formation; the more lateral growth the more vaterite nucleation is achieved.

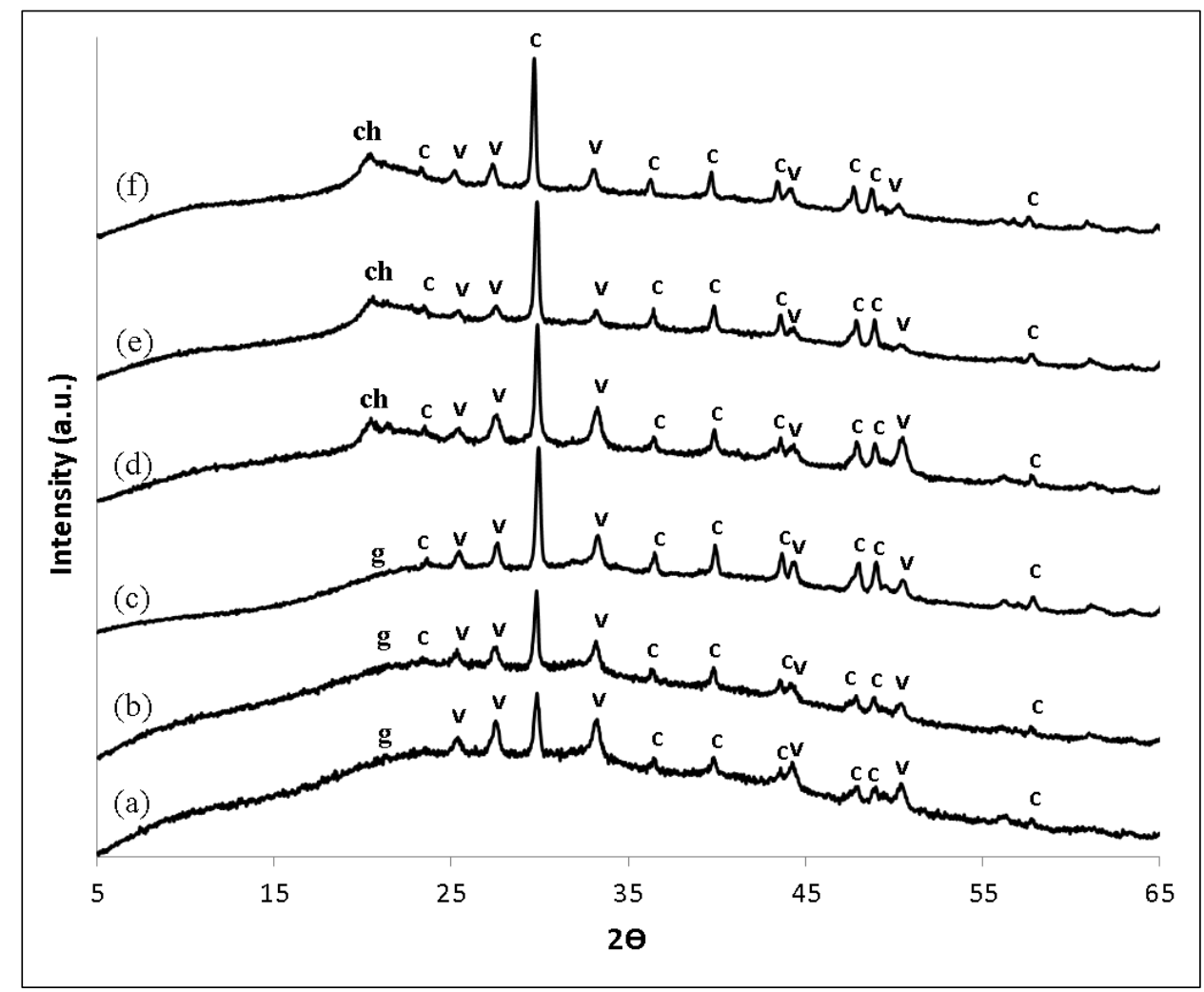

Figure 2-24: $\mathrm{XRD}$ pattern of (a) $\mathrm{CaCO}_{3} /$ gelatin/PAA, (b) $\mathrm{CaCO}_{3} /$ gelatin/PGL, (c) $\mathrm{CaCO}_{3} /$ gelatin/PAS, (d) $\mathrm{CaCO}_{3} /$ chitosan/PGL, (e) $\mathrm{CaCO}_{3} /$ chitosan/PGL and (f) $\mathrm{CaCO}_{3} /$ chitosan/PAS composites prepared via the McGrath method using a low concentration of presoaking solutions $(100 \mathrm{mM})$. Calcite and vaterite peaks are shown with $\mathrm{c}$ and $\mathrm{v}$ letters respectively. 


\subsubsection{TEM analysis}

Chitosan composites in the absence and presence of GL and PAA ( $2 \mathrm{wt} \%)$ prepared using the McGrath method were analyzed using TEM in order to gain information on the micro and nano-scale. These samples that have extensive crystallization in terms of the extent of calcification and crystals are homogenously distributed along the surface of the chitosan hydrogel scaffold.

The TEM micrographs of synthetic $\mathrm{CaCO}_{3} /$ chitosan and $\mathrm{CaCO}_{3} /$ chitosan/GL prepared via the McGrath method show polycrystalline $\mathrm{CaCO}_{3}$. No single crystals are observed, as was anticipated from the SEM analysis (Figure 2-25). The images also indicate the formation of very fine crystal structure down to $50 \mathrm{~nm}$ sub-grain size which is evident in both $\mathrm{CaCO}_{3} /$ chitosan (Figure 2-25E) and $\mathrm{CaCO}_{3} /$ chitosan/GL (Figure 2-25B) systems. This strongly offers that the final structure of the observed calcite is the result of the assembly of the nanoparticles.

In addition, the diffraction from several regions shows polycrystalline rings instead of single crystal spots (Figure 2-25C and F). Analysis of the diffraction rings confirms the formation of polycrystalline $\mathrm{CaCO}_{3}$ with a crystal structure of calcite in both $\mathrm{CaCO}_{3} /$ chitosan and $\mathrm{CaCO}_{3} /$ chitosan/GL systems which confirms the previous XRD results. Low-energy (104) planes of calcite structure are observed in the SAED pattern in both systems.

The corresponding high-resolution TEM (HRTEM) images of the $\mathrm{CaCO}_{3} /$ chitosan system (Figure 2-25G) indicate that there are significant defect-free areas showing lattice spacing of $0.307 \mathrm{~nm}$ which is attributed to (104) lattice planes of calcite (Figure 2-25H). The atomic packing that is evident (Figure 2-25I) may imply the presence of single crystals of calcite within the internal structure of the polycrystalline calcium carbonate crystals [55]. However in some regions the continuity of the lattice planes disappears representing the presence of disordered regions (Figure 2-25I). Despite the existence of orientated polycrystalline nanoparticles (Figure 2-25I), randomly oriented polycrystallinity and disordered regions are evident (Figure 2-25G yellow rectangle). The disordered region can be attributed to the presence of amorphous calcium carbonate which is occluded within calcite nanoparticles (Figure 2-25G orange circle and its corresponding FFT Figure 2-25G' inset Figure 2-25G). The HRTEM results for $\mathrm{CaCO}_{3} /$ chitosan/GL are not shown but they give similar data. 


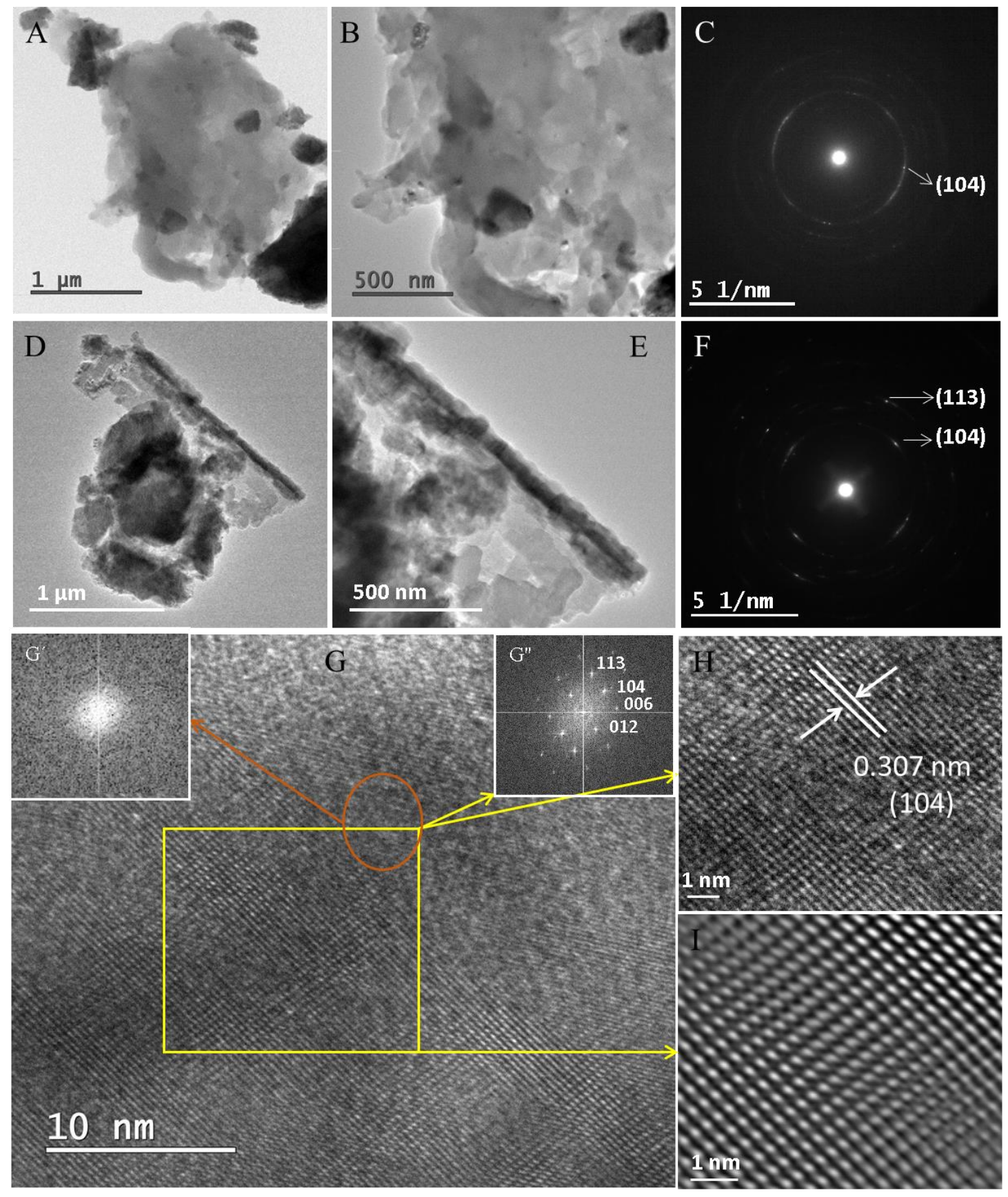

Figure 2-25: TEM micrographs $\mathrm{CaCO}_{3} /$ chitosan/GL (Top row), $\mathrm{CaCO}_{3} / \mathrm{chitosan}_{\text {(second }}$ row) and corresponding HRTEM image of $\mathrm{CaCO}_{3} /$ chitosan (bottom row). Fast Fourier transformation (FFT) analysis of HRTEM image (G) reveals the presence of amorphous calcium carbonate $\left(\mathrm{G}^{\prime}\right)$ and pseudo-single crystal of calcite $\left(\mathrm{G}^{\prime \prime}\right)$. The rhombohedral crystal arrangement in some regions is evident (I). 
TEM analysis of $\mathrm{CaCO}_{3} /$ chitosan/PAA systems clearly reveals the nanoparticle building units in the final structure of either calcite or vaterite. The polycrystalline calcite and vaterite are observed (calcite is not shown here). Low-magnification SEM images show the individual polycrystalline vaterite with the size of $1 \mu \mathrm{m}$ in diameter (Figure 2-26A and B) is composed of aggregations of nanoparticles down to $10 \mathrm{~nm}$ in size (Figure 2-26C). Corresponding SAED of the $\mathrm{CaCO}_{3} /$ chitosan/PAA systems shows two rings which are attributed to the (112) and (300) planes of vaterite (Figure 2-26F). HRTEM examination suggests a range of observations from highly orientated crystals, randomly positioned ((Figure 2-26C) to defined atoms in a hexagonal packing arrangement of vaterite crystals (Figure 2-26E). 


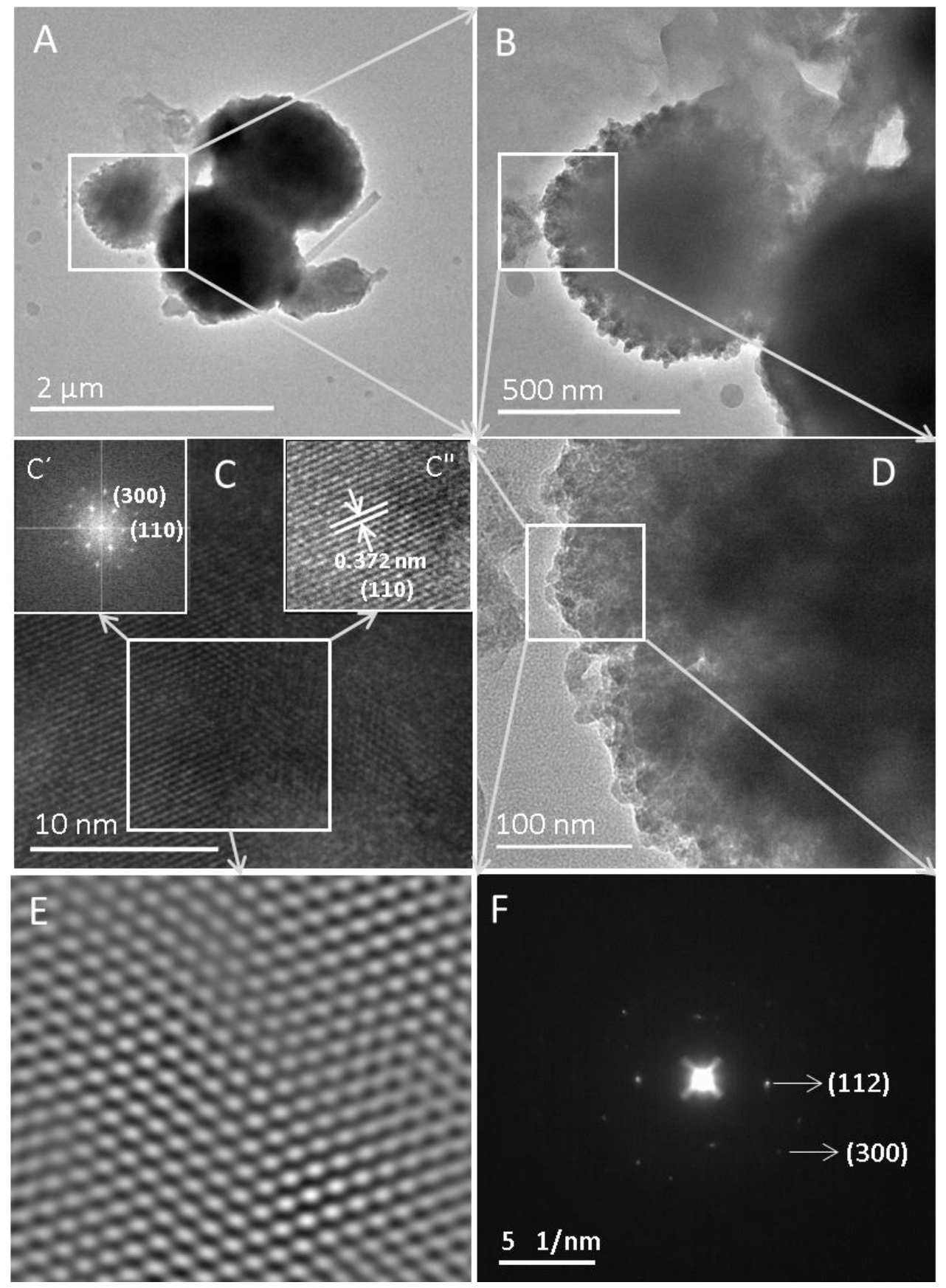

Figure 2-26: TEM analysis of $\mathrm{CaCO}_{3} /$ chitosan/PAA (A) and (B) showing the lowmagnification view of laterally growing calcium carbonate, (C) HRTEM image of the white box region in (D), (D) zoomed area of (B) indicating each individual vaterite is composed of thousands of nanoparticles, (E) IFFT pattern showing the hexagonal crystal package of vaterite is evident in some region, (F) the corresponding SAED of (D) indicating the polycrystallinity nature of $\mathrm{CaCO}_{3} /$ chitosan/PAA. FFT analysis of HRTEM image (C) reveals the polycrystalline vaterite $\left(\mathrm{C}^{\prime}\right.$ inset $\left.\mathrm{C}\right)$ and lattice planes with $0.372 \mathrm{~nm}$ fringes (C") which correspond to (110) lattice planes of vaterite. 


\subsection{Conclusion}

Mineralization of chitosan and gelatin hydrogel scaffolds in the absence and presence of monomers and their corresponding polymer additives, using four crystallization methods (alternate soaking, McGrath and Kitano) was investigated. This study demonstrates the similar behaviour of carbohydrate-based and protein-based hydrogels as scaffolds in modulating calcium carbonate crystallization in the absence of additives. Despite the different chemistry of chitosan and gelatin few morphological variations of calcite crystals were obtained in the absence of additives irrespective of which mineralization method was used. Using the McGrath method, as compared to the other two methods, induced mineralization uniformly throughout the hydrogel scaffolds rather than only partially at the surface. Previously the ubiquity of McGrath method with respect to the chemical and physical attributes of the hydrogel scaffold and calcium carbonate mineralization was shown. Here again the McGrath method showed that it is applicable to a range of templated crystallization systems, in particular gelatin a protein-based hydrogel well adapted to biomimetic biomineralization.

The crystallization conditions with the effect of monomeric acrylic acid, glutamic acid, aspartic acid and their corresponding polymers ( $2 \mathrm{wt} \%)$ were examined. The morphology created by each additive in combination with chitosan and gelatin is different and is different again as the mineralization method is changed. AA, GL and AS had weaker control over calcium carbonate crystal size compared to polymeric additives in both media in particular when the alternative soaking and Kitano methods of crystallization were used. This means the binding between the small monomeric molecules and the calcium ions is not sufficiently strong to modulate the growth event. Similar to samples mineralized with no additive, calcite was the only polymorph in the presence of monomeric additives.

In contrast a large degree of control over crystal size and morphology and polymorph was achieved when polymeric additives were used. Addition of $2 \mathrm{wt} \%$ PAA, PGL and PAS to all crystallization solutions almost always led to lateral growth of calcium carbonate with calcite polymorph in both chitosan and gelatin hydrogel when the alternative soaking and Kitano methods were used. Lateral growth was only observed in the case of the McGrath method, by adding $2 \mathrm{wt} \%$ PAA to all the crystallization solutions, no lateral growth was seen for PGL and PAS. However lateral growth dominated upon lowering the concentration of the presoaking ion solutions. In the presence of $1 \mathrm{wt} \%$ polymeric additives in the McGrath 
method better control over the morphologies of the obtained crystals in both chitosan and gelatin templates was achieved. In both chitosan and gelatin scaffolds in the presence of polymeric additives mixtures of polymorphs, mostly vaterite and calcite, were formed compared to when monomers were used especially in the case of the McGrath method. Polymeric additives have been shown to influence more strongly the morphology of $\mathrm{CaCO}_{3}$, due to the formation of a polyelectrolyte complex within and on the surface of the chitosan and gelatin scaffolds, they enhanced lateral growth of the calcium carbonate crystals within the chitosan template compared to when the templates are mineralized in the presence of monomers or without additives.

In the presence and absence of additives, no matter which method or scaffold was used, all produced crystals are polycrystalline which form via assembly of nanoparticles. However, the atomic packing of calcite and vaterite is evident within the internal structure of the polycrystalline calcium carbonate crystals when examined by HRTEM.

The results can provide new biomimetic ways to manipulate a new hard nacre-like material with applications in various areas such as synthetic implantable materials. Potentially combining a suitable scaffold with a suitable mineral component and using a specific mineralization technique will allow us to build tailored materials. However synthesizing the required size and morphology of the crystals with the desired mechanical properties remains a big challenge. 


\section{References}

1. Sommerdijk, N.A.J.M. and G. de With, ChemInform Abstract: Biomimetic $\mathrm{CaCO}_{3}$ Mineralization Using Designer Molecules and Interfaces. ChemInform, 2009. 40(5): p. no-no.

2. Wegst, U.G.K., H. Bai, E. Saiz, A.P. Tomsia and R.O. Ritchie, Bioinspired structural materials. Nat Mater, 2015. 14(1): p. 23-36.

3. Weiner, S. and P.M. Dove, An Overview of Biomineralization Processes and the Problem of the Vital Effect. Reviews in Mineralogy and Geochemistry, 2003. 54(1): p. 1-29.

4. Gower, L.B., Biomimetic Model Systems for Investigating the Amorphous Precursor Pathway and Its Role in Biomineralization. Chemical Reviews, 2008. 108(11): p. 4551-4627.

5. Ratner, B.D., A.S. Hoffman, F.J. Schoen and J.E. Lemons, Biomaterials Science: An Introduction to Materials in Medicine. 2012: Elsevier Science.

6. Sun, J. and B. Bhushan, Hierarchical structure and mechanical properties of nacre: a review. RSC Advances, 2012. 2(20): p. 7617-7632.

7. Meldrum, F.C., Calcium carbonate in biomineralisation and biomimetic chemistry. International Materials Reviews, 2003. 48(3): p. 187-224.

8. Asenath-Smith, E., H. Li, E.C. Keene, Z.W. Seh and L.A. Estroff, Crystal Growth of Calcium Carbonate in Hydrogels as a Model of Biomineralization. Advanced Functional Materials, 2012. 22(14): p. 2891-2914.

9. McGrath, N.H.M.K.M., Hydrogels as biomimetic mineralisation scaffolds. Bioinspired, Biomimetic and Nanobiomaterials, 2011. 1(1): p. 26-37.

10. Kopeček, J., Hydrogel biomaterials: A smart future? Biomaterials, 2007. 28(34): p. 5185-5192.

11. Barbucci, R., Hydrogels. 2009: Springer.

12. Keene, E.C., J.S. Evans and L.A. Estroff, Silk Fibroin Hydrogels Coupled with the $n 16 N-\beta$ Chitin Complex: An in Vitro Organic Matrix for Controlling Calcium Carbonate Mineralization. Crystal Growth \& Design, 2010. 10(12): p. 5169-5175.

13. Kato, T., T. Suzuki, T. Amamiya, T. Irie, M. Komiyama and H. Yui, Effects of macromolecules on the crystallization of $\mathrm{CaCO}_{3}$ the Formation of Organic/Inorganic Composites. Supramolecular Science, 1998. 5(3-4): p. 411-415.

14. Munro, N.H., D.W. Green, A. Dangerfield and K.M. McGrath, Biomimetic mineralisation of polymeric scaffolds using a combined soaking and Kitano approach. Dalton Transactions, 2011. 40(36): p. 9259-9268.

15. Wu, Y., C. Cheng, J. Yao, X. Chen and Z. Shao, Crystallization of Calcium Carbonate on Chitosan Substrates in the Presence of Regenerated Silk Fibroin. Langmuir, 2011. 27(6): p. 28042810.

16. Falini, G., M. Gazzano and A. Ripamonti, Calcite crystallization on gelatin films containing polyelectrolytes. Advanced Materials, 1994. 6(1): p. 46-48. 
17. Hosoda, N., A. Sugawara and T. Kato, Template Effect of Crystalline Poly(vinyl alcohol) for Selective Formation of Aragonite and Vaterite $\mathrm{CaCO}_{3}$ Thin Films. Macromolecules, 2003. 36(17): p. 6449-6452.

18. Nindiyasari, F., L. Fernández-Díaz, E. Griesshaber, J.M. Astilleros, N. Sánchez-Pastor and W.W. Schmahl, Influence of Gelatin Hydrogel Porosity on the Crystallization of $\mathrm{CaCO}_{3}$. Crystal Growth \& Design, 2014. 14(4): p. 1531-1542.

19. Munro, N.H., D.W. Green and K.M. McGrath, In situ continuous growth formation of synthetic biominerals. Chemical Communications, 2013. 49(33): p. 3407-3409.

20. Hosoda, N. and T. Kato, Thin-Film Formation of Calcium Carbonate Crystals: Effects of Functional Groups of Matrix Polymers. Chemistry of Materials, 2001. 13(2): p. 688-693.

21. Colfen, H., Biomineralization: A crystal-clear view. Nat Mater, 2010. 9(12): p. 960-961.

22. Gebauer, D., H. Cölfen, A. Verch and M. Antonietti, The Multiple Roles of Additives in $\mathrm{CaCO}_{3}$ Crystallization: A Quantitative Case Study. Advanced Materials, 2009. 21(4): p. 435-439.

23. Meldrum, F.C. and H. Cölfen, Controlling Mineral Morphologies and Structures in Biological and Synthetic Systems. Chemical Reviews, 2008. 108(11): p. 4332-4432.

24. Suzuki, M., K. Saruwatari, T. Kogure, Y. Yamamoto, T. Nishimura, T. Kato and H. Nagasawa, An Acidic Matrix Protein, Pif, Is a Key Macromolecule for Nacre Formation. Science, 2009. 325(5946): p. 1388-1390.

25. Ren, D., Q. Feng and X. Bourrat, Effects of additives and templates on calcium carbonate mineralization in vitro. Micron, 2011. 42(3): p. 228-245.

26. Addadi, L., D. Joester, F. Nudelman and S. Weiner, Mollusk Shell Formation: A Source of New Concepts for Understanding Biomineralization Processes. Chemistry - A European Journal, 2006. 12(4): p. 980-987.

27. Pereira-Mouriès, L., M.-J. Almeida, C. Ribeiro, J. Peduzzi, M. Barthélemy, C. Milet and E. Lopez, Soluble silk-like organic matrix in the nacreous layer of the bivalve Pinctada maxima. European Journal of Biochemistry, 2002. 269(20): p. 4994-5003.

28. Schenk, A.S., B. Cantaert, Y.-Y. Kim, Y. Li, E.S. Read, M. Semsarilar, S.P. Armes and F.C. Meldrum, Systematic Study of the Effects of Polyamines on Calcium Carbonate Precipitation. Chemistry of Materials, 2014. 26(8): p. 2703-2711.

29. Falini, G., S. Albeck, S. Weiner and L. Addadi, Control of Aragonite or Calcite Polymorphism by Mollusk Shell Macromolecules. Science, 1996. 271(5245): p. 67-69.

30. Wada, N., K. Kanamura and T. Umegaki, Effects of Carboxylic Acids on the Crystallization of Calcium Carbonate. Journal of Colloid and Interface Science, 2001. 233(1): p. 65-72.

31. Aschauer, U., J. Ebert, A. Aimable and P. Bowen, Growth Modification of Seeded Calcite by Carboxylic Acid Oligomers and Polymers: Toward an Understanding of Complex Growth Mechanisms. Crystal Growth \& Design, 2010. 10(9): p. 3956-3963.

32. Munro, N.H. and K.M. McGrath, Biomimetic mineralisation of polymeric scaffolds using a combined soaking approach: adaptation with various mineral salts. Dalton Transactions, 2011. 40(36): p. 9269-9275. 
33. Sowoidnich, K. and H.-D. Kronfeldt, Fluorescence Rejection by Shifted Excitation Raman Difference Spectroscopy at Multiple Wavelengths for the Investigation of Biological Samples. ISRN Spectroscopy, 2012. 2012: p. 11.

34. Demers, J.-L.H., S.C. Davis, B.W. Pogue and M.D. Morris, Multichannel diffuse optical Raman tomography for bone characterization in vivo: a phantom study. Biomedical Optics Express, 2012. 3(9): p. 2299-2305.

35. Zhou, J., M. Zhou and R.A. Caruso, Agarose Template for the Fabrication of Macroporous Metal Oxide Structures. Langmuir, 2006. 22(7): p. 3332-3336.

36. Wang, X., C.E. Egan, M. Zhou, K. Prince, D.R.G. Mitchell and R.A. Caruso, Effective gel for gold nanoparticle formation, support and metal oxide templating. Chemical Communications, 2007(29): p. 3060-3062.

37. Liu, X. and P.X. Ma, Phase separation, pore structure, and properties of nanofibrous gelatin scaffolds. Biomaterials, 2009. 30(25): p. 4094-4103.

38. Dutta, P.K., Chitin and Chitosan for Regenerative Medicine. 2015: Springer India.

39. Kumagai, H., R. Matsunaga, T. Nishimura, Y. Yamamoto, S. Kajiyama, Y. Oaki, K. Akaiwa, H. Inoue, $\mathrm{H}$. Nagasawa, $\mathrm{K}$. Tsumoto, and $\mathrm{T}$. Kato, $\mathrm{CaCO}_{3} /$ Chitin hybrids: recombinant acidic peptides based on a peptide extracted from the exoskeleton of a crayfish controls the structures of the hybrids. Faraday Discussions, 2012. 159(0): p. 483-494.

40. Munro, N.H. and K.M. McGrath, Biomimetic approach to forming chitin/aragonite composites. Chemical Communications, 2012. 48(39): p. 4716-4718.

41. Wada, N., N. Horiuchi, M. Nakamura, K. Nozaki, T. Hiyama, A. Nagai and K. Yamashita, Controlled calcite nucleation on polarized calcite single crystal substrates in the presence of polyacrylic acid. Journal of Crystal Growth, 2015. 415: p. 7-14.

42. Wada, N., S. Suda, K. Kanamura and T. Umegaki, Formation of thin calcium carbonate films with aragonite and vaterite forms coexisting with polyacrylic acids and chitosan membranes. Journal of Colloid and Interface Science, 2004. 279(1): p. 167-174.

43. Wada, N., N. Horiuchi, M. Nakamura, T. Hiyama, A. Nagai and K. Yamashita, Effect of Polyacrylic acid and Polarization on the Controlled Crystallization of Calcium Carbonate on Single-Phase Calcite Substrates. Crystal Growth \& Design, 2013. 13(7): p. 2928-2937.

44. Arakaki, A., K. Shimizu, M. Oda, T. Sakamoto, T. Nishimura and T. Kato, Biomineralizationinspired synthesis of functional organic/inorganic hybrid materials: organic molecular control of self-organization of hybrids. Organic \& Biomolecular Chemistry, 2015. 13(4): p. 974-989.

45. Kato, T., T. Suzuki and T. Irie, Layered Thin-Film Composite Consisting of Polymers and Calcium Carbonate: A Novel Organic/Inorganic Material with an Organized Structure. Chemistry Letters, 2000. 29(2): p. 186-187.

46. Dickinson, S.R. and K.M. McGrath, Quantitative determination of binary and tertiary calcium carbonate mixtures using powder X-ray diffraction. Analyst, 2001. 126(7): p. 1118-1121.

47. Zhang, S. and K.E. Gonsalves, Influence of the Chitosan Surface Profile on the Nucleation and Growth of Calcium Carbonate Films. Langmuir, 1998. 14(23): p. 6761-6766. 
48. Beniash, E., Biominerals-hierarchical nanocomposites: the example of bone. Wiley Interdisciplinary Reviews: Nanomedicine and Nanobiotechnology, 2011. 3(1): p. 47-69.

49. Tong, H., W. Ma, L. Wang, P. Wan, J. Hu and L. Cao, Control over the crystal phase, shape, size and aggregation of calcium carbonate via a l-aspartic acid inducing process. Biomaterials, 2004. 25(17): p. 3923-3929.

50. Sugawara, A., A. Oichi, H. Suzuki, Y. Shigesato, T. Kogure and T. Kato, Assembled structures of nanocrystals in polymer/calcium carbonate thin-film composites formed by the cooperation of chitosan and poly(aspartate). Journal of Polymer Science Part A: Polymer Chemistry, 2006. 44(17): p. 5153-5160.

51. Falini, G., S. Fermani, M. Gazzano and A. Ripamonti, Oriented Crystallization of Vaterite in Collagenous Matrices. Chemistry - A European Journal, 1998. 4(6): p. 1048-1052.

52. Nudelman, F., Nacre biomineralisation: A review on the mechanisms of crystal nucleation. Seminars in Cell \& Developmental Biology.

53. Addadi, L., J. Moradian, E. Shay, N.G. Maroudas and S. Weiner, A chemical model for the cooperation of sulfates and carboxylates in calcite crystal nucleation: Relevance to biomineralization. Proceedings of the National Academy of Sciences of the United States of America, 1987. 84(9): p. 2732-2736.

54. Munro, N.H. and K.M. McGrath, How important is polyelectrolyte complex formation in biomimetic mineralisation? Manipulation via alcohol addition. Dalton Transactions, 2013. 42(23): p. 8259-8269.

55. Seto, J., Y. Ma, S.A. Davis, F. Meldrum, A. Gourrier, Y.-Y. Kim, U. Schilde, M. Sztucki, M. Burghammer, S. Maltsev, C. Jäger, and H. Cölfen, Structure-property relationships of a biological mesocrystal in the adult sea urchin spine. Proceedings of the National Academy of Sciences, 2012. 109(10): p. 3699-3704. 


\section{Chapter 3}

\section{Calcium phosphate mineralization within chitosan vs. gelatin hydrogel scaffolds with and without additives}

\subsection{Introduction}

The development of biominerals through the mimicking of natural material structures and functions is a fast growing research area particularly in the tissue engineering and biomineralization fields [1-4]. Living organisms have almost complete control over all aspects of the mineralization process from nucleation to crystal growth, shape to size and from composition to polymorph selection [5]. In biological systems, calcified hard tissues such as bone and nacre are highly complex materials. Nacre and bone are beautiful examples of the exquisite control that is exerted over mineral formation in biological systems, with the initial control occurring at the nanoscale $[6,7]$. Therefore understanding the principals involved in the nanoscale arrangement of the base building blocks of biomineral formation is crucial for designing and synthesizing new advanced materials.

Similar to nacre, natural bone is also a combination of hard and soft tissues arranged into hierarchical architectures $[8,9]$. The intimate association of inorganic calcium phosphate and organic collagen enables bone to support and protect the organism. The detail of bone structure was described in Chapter 1; the interaction of a hard mineral with an organic component at the interface is influenced by many parameters such as the mineral phase itself, its shape and size, the insoluble matrix and the soluble acid-rich proteins that are intimately associated with each other [10].

Calcium phosphate exists in various polymorphic forms such as amorphous calcium phosphate (ACP), brushite (dicalcium phosphate dihydrate, $\mathrm{CaHPO}_{4} .2 \mathrm{H}_{2} \mathrm{O}, \mathrm{DCPD}$ ), and hydroxylapatite $\left(\mathrm{Ca}_{5}\left(\mathrm{PO}_{4}\right)_{3} \mathrm{OH}, \mathrm{HAp}\right)$. In living organisms especially in vertebrates, ACP, poorly crystalline HAp and crystalline HAp are mostly found [11]. The carbonated hydroxylapatite (HAp) polymorph of calcium phosphate is the most common inorganic phase of bone [12] comprising up to $70 \%$ of bone dry weight [13]. Despite HAp having hexagonal crystal symmetry, bone minerals are mostly nonstoichiometric; poorly crystalline thin plate-like shapes with only two of the six symmetry related (100) faces [5]. It is believed 
that HAp crystals are formed from the subsequent phase transition of ACP or octacalcium phosphate (OCP) precursor $[12,14,15]$. The presence of ACP in the surface of bone crystals was first demonstrated through an NMR study [16]. The thickness of the plate-like crystals is reported in the ranges of 1.5-4 $\mathrm{nm}$ [14, 17-19], therefore a large proportion of the atoms lie in very close proximity to the surface of the crystals. The substitution of the hydroxyl ions by carbonate ions in the HAp structure also impacts on the disorder of the HAp crystallinity [5]. The c-axes of the nanosize HAp crystals are aligned and oriented parallel to the organic collagen fibrils [20]. The collagen, which has a hydrogel nature, is a major organic constituent in bone and serves as the insoluble 3D framework to initiate the calcium phosphate nucleation and growth [21-23]. Another organic phase of bone is non-collagenous soluble acidic macromolecules which represents less than $10 \%$ of the organic matrix. Soluble acidic additives such as glutamic and aspartic acid residues are thought to be vital in controlling inorganic crystal phase [8]. Many in vivo experiments have been done to elucidate the role of soluble and insoluble organic compartments in bone in order to understand the possible mechanisms involved in HAp crystallization. These in vivo experiments have then been corroborated through synthetic reproduction in order to show the feasibility of achieving effective mineralization in vitro [9, 14, 17, 24-26]. Therefore recreating inorganic-organic bone-like composites, comprising insoluble hydrogels as scaffolds and calcium phosphate in the presence of soluble organic acidic additives, through biomimetic synthesis at ambient conditions may be particularly suitable for development of bone tissue regeneration. This combination may provide good biocompability and mechanical performance similar to bone [2].

Hydrogels have been used as a popular platform for modelling biomineralization pathways in bone tissue engineering due to their 3D porous, fibrous, and water-swollen scaffolds. In matrix-mediated biomineralization, crystal nucleation and growth is often mediated, initiated and/or controlled by (bio)organic molecules and/or self-assembled templates. The main (bio)organic components are proteins, carbohydrates and lipids and the final materials are inherently inorganic/organic composites. For example in the formation of nacre, chitin provides the nucleation sites for the formation and growth of aragonite crystals. In vertebrates, collagen type 1 is the responsive scaffold for HAp mineralization processes. The charged groups on the surface of the organic matrix are believed to direct the nucleation and growth events. Often the intimate association between the inorganic crystals and the organic matrix constituents is assisted by soluble acidic additives, therefore creating composite 
materials with unique structural properties. Such additives are able to modulate crystal sizes and shapes under experimental conditions. Agarose hydrogel [27], regenerated cellulose [28], chitosan [29-31] and gelatin [32] have been used as in vitro models of frameworks for calcium phosphate crystal growth with a potential application in bone-graft material.

Many in vivo and in vitro studies have been undertaken to elucidate the combination of soluble and insoluble organic matrices and water soluble organic protein is required to achieve effective mineralization [19]. Therefore the soluble acidic additives (noncollagenous proteins in bone mineralization for example which comprise less than $10 \%$ of the organic matrix in bone) are the other important factors in both in vivo and in vitro mineralization experiments [33]. These soluble acids are capable of binding to free ions such as calcium and phosphate, due to their high charge density, as well as the matrix and thereby regulating/inhibiting the growth processes by transporting ions to the mineralization front. In calcium phosphate mineralization these additives are negatively charged due to the high quantities of aspartic and glutamic acid which can stabilize metastable inorganic phases and control crystal sizes and shapes.

In order to fabricate bone-like material with similar properties to native bone and dentin a number of in vitro experiments have been carried out using additives similar to those found in bone and teeth. The involvement of amino acids such as glutamic acid, aspartic acid and their corresponding polymers in calcium phosphate mineralization in solution and matrix are successfully shown in literature [34-36]. Amino acids are able to interact with inorganic ions with their side terminal amine and carboxyl groups. Both glutamic acid and aspartic acid inhibit the rate of calcium phosphate nucleation and growth [37] however, aspartic acid significantly increases the amount of calcium phosphate crystals formed within the collagen matrix [35].

As mentioned in Chapter 2 in the case of calcium carbonate mineralization, using carbohydrate-based matrix, such as chitosan a composite that closely resemble (chemically and structurally) nacre can be formed but other substrates are also successful in generating calcium carbonate mineral composites. In similarity, to mimic the nanoscale structures of bone the combination of HAp and collagen might be considered to be a strong candidate. Other natural polymers such as chitosan and gelatin, with incorporated acidic polypeptides, have also been widely used as the scaffolds in in vitro biomineralization due to their low cost abundance and biocompatibility. 
In this Chapter the focus is switched from calcium carbonate to calcium phosphate precipitation within chitosan vs. gelatin hydrogel scaffolds in the presence of the same additives as explored in Chapter 2. Gelatin is used in order to directly mimic the role of collagen in bone mineralization however chitosan is investigated as a comparator. The effect of the different mineralization techniques used for calcium carbonate mineralization is also considered for calcium phosphate mineralization.

\subsection{Materials and methods}

The materials and methods used for the calcium phosphate mineralization are the same as described in Chapter 2. Chitosan (2 wt \%) and gelatin (5 wt\%) hydrogel scaffolds were prepared and used for mineralization.

\subsubsection{Calcium phosphate crystal growth experiments}

Chitosan and gelatin hydrogel films were first treated with $\mathrm{NaOH}(1.00 \mathrm{M}, 30 \mathrm{~mL})$ and glutaraldehyde (1\% v/v in phosphate buffer $(100 \mathrm{mM}$ at $\mathrm{pH}=7), 30 \mathrm{~mL})$ solutions for $1 \mathrm{~h}$ and overnight respectively prior to mineralization. The films were subsequently washed by M.Q. water until neutral $\mathrm{pH}$ was achieved. Chitosan and gelatin hydrogel templates were mineralized using the same three crystallization methods used for the calcium carbonate precipitation by switching the anion from carbonate to phosphate with the same source of calcium. Calcium phosphate was precipitated in both chitosan and gelatin hydrogels using:

1- Calcium phosphate Kitano solution: a saturated calcium hydrogen phosphate solution was prepared as follows: $1.74 \mathrm{~g}$ of the $\mathrm{CaCl}_{2} \cdot 2 \mathrm{H}_{2} \mathrm{O}$ and $1.78 \mathrm{~g} \mathrm{Na} 2 \mathrm{HPO}_{4}$ were separately dissolved in $500 \mathrm{~mL}$ of M.Q. water. The two solutions were mixed and a saturated $\mathrm{CaHPO}_{4}$ solution was achieved. The saturated $\mathrm{CaHPO}_{4}$ solution was bubbled with $\mathrm{CO}_{2}$ gas at approximately $3 \mathrm{~L} \mathrm{~h}^{-1}$ for about $6 \mathrm{~h}$ then filtered. The filtrate was then bubbled with $\mathrm{CO}_{2}$ for another $30 \mathrm{~min}$ at $3 \mathrm{~L} \mathrm{~h}^{-1}$ prior to introducing the wet hydrogel films. The chitosan and gelatin scaffolds were immersed and generally left to mineralize for at least one week at room temperature.

2- Alternative soaking: two variants on the alternative soaking system were used a) aqueous solutions of $10 \mathrm{mM} \mathrm{CaCl}_{2} \cdot 2 \mathrm{H}_{2} \mathrm{O}$ and $10 \mathrm{mM} \mathrm{Na}_{2} \mathrm{HPO}_{4}$ (2 cycles) and b) $10 \mathrm{mM}$ $\mathrm{CaCl}_{2} \cdot 2 \mathrm{H}_{2} \mathrm{O}$ and saturated $\mathrm{CaHPO}_{4}$ (one cycle). Wet hydrogel films were soaked in $30 \mathrm{~mL}$ of $\mathrm{CaCl}_{2} .2 \mathrm{H}_{2} \mathrm{O}(10 \mathrm{mM})$ and $30 \mathrm{~mL}$ of $\mathrm{Na}_{2} \mathrm{HPO}_{4}(10 \mathrm{mM})$ solutions for $24 \mathrm{~h}$ respectively. 
After 2 cycles of alternative soaking, the films were left in the last mineralization solution $\left(\mathrm{Na}_{2} \mathrm{HPO}_{4}\right)$ for at least one week.

3. McGrath method: after alternatively soaking the hydrogel film in $30 \mathrm{~mL}$ of the $10 \mathrm{mM}$ $\mathrm{CaCl}_{2} \cdot 2 \mathrm{H}_{2} \mathrm{O}$ and $10 \mathrm{mM} \mathrm{Na} 2 \mathrm{HPO}_{4}$ solutions for $24 \mathrm{~h}$ each respectively, Kitano solution (saturated calcium hydrogen phosphate solution) was then introduced and the films left for at least one week. All samples were gently washed after mineralization and air dried prior to characterization. 


\subsection{Results and Discussion}

\subsubsection{Calcium phosphate/chitosan and calcium phosphate/gelatin composites: No additive}

The formation of calcium phosphate $(\mathrm{CaP})$ minerals was investigated in the absence of monomeric and polymeric additives using three crystallization methods. Various concentrations of the presoaking solutions $(10,50,100$ and $500 \mathrm{mM})$ of $\mathrm{CaCl}_{2}$ and $\mathrm{Na}_{2} \mathrm{HPO}_{4}$ were used in the case of the alternative soaking and McGrath methods. Higher concentrations of the presoaking solutions led to aggregated $\mathrm{CaP}$ formation. While in the $\mathrm{CaCO}_{3}$ precipitation investigation described in Chapter 2, enhancing the concentrations of the presoaking solutions leads to extensive mineralization of $\mathrm{CaCO}_{3}$, in $\mathrm{CaP}$ mineralization, due to the lower solubility of $\mathrm{CaP}$ compared with $\mathrm{CaCO}_{3}$, extensive calcification of the chitosan and gelatin hydrogel scaffolds was achieved at lower concentrations of presoaking solution. In particular $10 \mathrm{mM}$ was found to yield sufficient nucleation and growth. Therefore in this study $10 \mathrm{mM} \mathrm{CaCl}_{2}$ and $10 \mathrm{mM} \mathrm{Na}_{2} \mathrm{HPO}_{4}$ presoaking solutions were used for both the alternative soaking and McGrath methods for the chitosan and gelatin hydrogel scaffolds.

In Table 1 are given the initial and final $\mathrm{pH}$ values of crystallization solutions used in the $\mathrm{CaP}$ mineralization using the McGrath method. The final $\mathrm{pH}$ values in the case of $\mathrm{CaCl}_{2}$ and $\mathrm{Na}_{2} \mathrm{HPO}_{4}$ were measured after overnight presoaking and for $\mathrm{CaHPO}_{4}$ after one week post the crystallization process. The trend in the $\mathrm{pH}$ values for the $\mathrm{CaP}$ precipitation is similar to that seen for $\mathrm{CaCO}_{3}$. The $\mathrm{pH}$ starts from a lower initial $\mathrm{pH}$ and reaches higher values upon degassing of $\mathrm{CO}_{2}$. The increasing $\mathrm{pH}$ ensures that crystallization occurs. Indeed the $\mathrm{pH}$ rise is the key factor which defines which polymorph of $\mathrm{CaP}$ forms. For this range of $\mathrm{pH}$, various $\mathrm{CaP}$ polymorphs such as brushite (mildly acidic favourable $\mathrm{pH} \sim 5-6.5$ ) and HAp (mildly basic favourable $\mathrm{pH} \sim 7-8$ especially $\mathrm{pH}=7.4$ ) can be deposited [38].

Table 1: Initial and final $\mathrm{pH}$ of presoaking $\left(\mathrm{CaCl}_{2}\right.$ and $\left.\mathrm{Na}_{2} \mathrm{HPO}_{4}\right)$ and post-crystallization $\left(\mathrm{CaHPO}_{4}\right)$ solutions for the McGrath method.

\begin{tabular}{llll}
\hline Solution & Initial $\mathrm{pH}$ & Final $\mathrm{pH}$ (chitosan film) & Final pH (gelatin film) \\
$\mathrm{CaCl}_{2}(10 \mathrm{mM})$ & 5.72 & 6.70 & 6.91 \\
$\mathrm{Na}_{2} \mathrm{HPO}_{4}(10 \mathrm{mM})$ & 8.00 & 8.10 & 8.80 \\
$\mathrm{CaHPO}_{4}$ (Saturated) & 5.82 & 6.81 & 7.24 \\
\hline
\end{tabular}


The influence of the different crystallization methods and the two hydrogel scaffolds were explored (Figure 3-1). Considering first the chitosan scaffold, it can be seen that for the samples prepared using the two alternative soaking methods, so-called spherical morphology $\mathrm{CaP}$ crystals ranging in size from 1-3 $\mu \mathrm{m}$ in diameter form, growth is not homogeneous throughout and over the scaffold (Figure 3-1a, c). In comparison, with the McGrath and Kitano methods mineralization is uniform (Figure 3-1e, g).

A magnified view of the spherical growth morphology formed for the alternative soaking with $\mathrm{CaCl}_{2}$ and saturated $\mathrm{CaHPO}_{4}$ solutions (Figure 3-1b), is shown in Figure 3-2a. This more clearly indicates that the spherical $\mathrm{CaP}$ crystals have a porous and spongy-like morphology. Clusters of these same porous spherical CaP crystals $(1-3 \mu \mathrm{m}$ in diameter for individual spherical crystals) are obtained when the Kitano method is used (Figure 3-1g).

A second morphology is also observed with chitosan. Flower-like platelet clusters (10-20 $\mu \mathrm{m}$ (Figure 3-1e)) are observed when the McGrath method is used. A magnified view of this morphology is shown in Figure 3-2c. Hence it can be seen that the clusters result from aggregation of the platelets and that the original platelet growth is the result of uniform nucleation throughout and on chitosan scaffold. Full blanket coverage of the scaffold is evident underneath the clusters.

In the case of the gelatin scaffolds more homogenous growth occurs irrespective of which crystallization method is used compared with the chitosan scaffolds. This is particularly evident when the alternative soaking methods are used. For the alternative soaking method with $\mathrm{CaCl}_{2}$ and $\mathrm{Na}_{2} \mathrm{HPO}_{4}$ (2 cycles) the $\mathrm{CaP}$ crystals, which are roughly spherical, range in size from $500 \mathrm{~nm}$ to $2 \mu \mathrm{m}$ in diameter (Figure $3-1 \mathrm{~b}$ ). The CaP crystals grown more closely resemble the flower-like platelet clusters observed for the chitosan scaffold. The so-called porous spherical morphology is not observed with the gelatin scaffold. It should be noted though that for the gelatin scaffold the aggregation of the $\mathrm{CaP}$ platelet is not identical to that for the chitosan scaffold (see magnified images in Figure 3-2), but more closely resemble an interconnected network of platelet CaP crystals (see magnified image Figure 3-2b). When the alternative soaking with $\mathrm{CaCl}_{2}$ and saturated $\mathrm{CaHPO}_{4}$ (Figure 3-1d) and the Kitano method (Figure 3-1h) are used the result is the formation of very small aggregated $\mathrm{CaP}$ particles, platelet formation is minimal. That is in difference to when chitosan hydrogels are used. When the McGrath method is used flower-like platelet crystals also form, which are 5-10 $\mu \mathrm{m}$ in size (Figure 3-1f). 

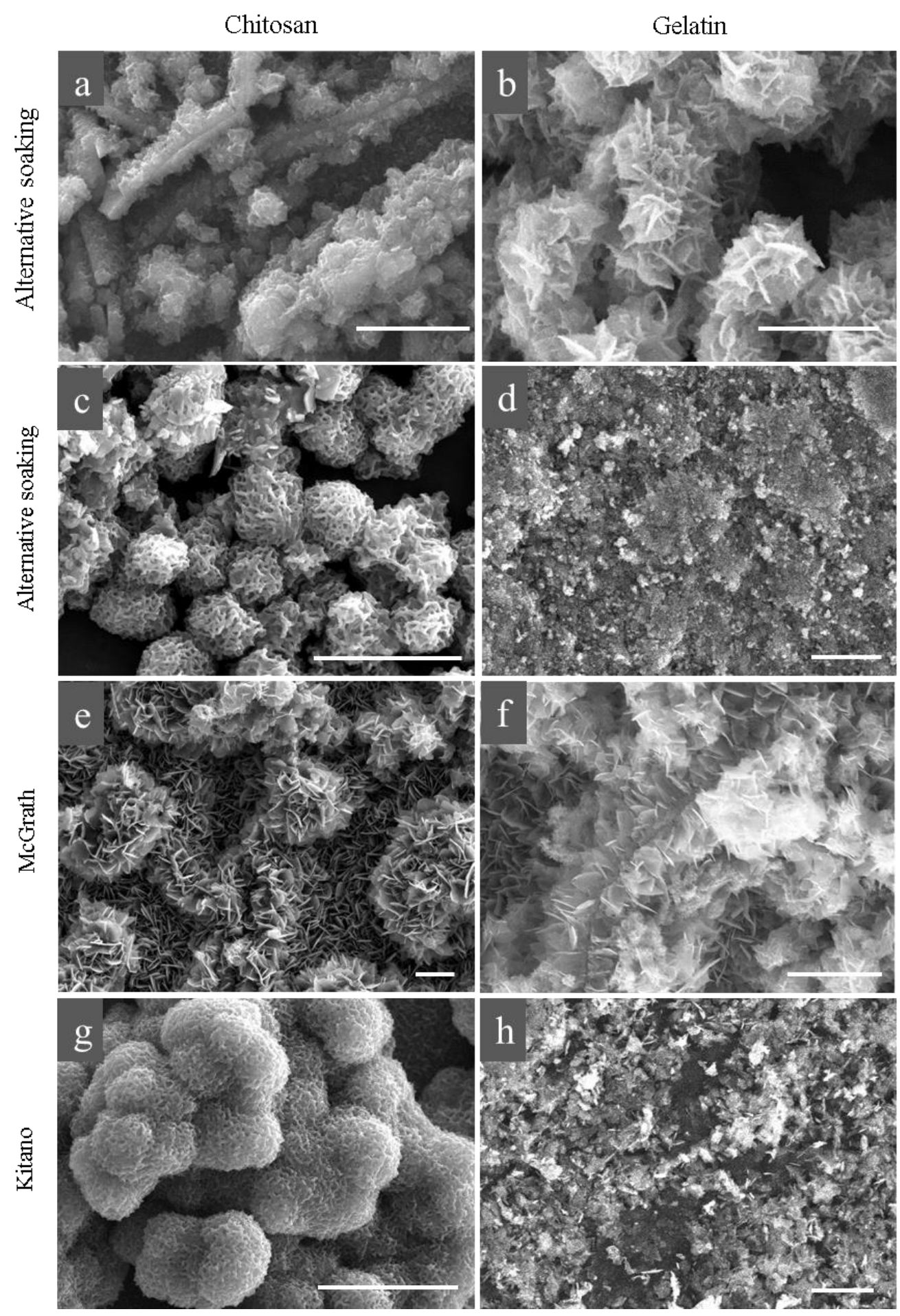

Figure 3-1: CaP minerals grown using chitosan and gelatin films using the four different mineralization techniques, with composites prepared using $(\mathrm{a}, \mathrm{e})$ alternative soaking with $\mathrm{CaCl}_{2}$ and $\mathrm{Na}_{2} \mathrm{HPO}_{4}$, (b, f) alternative soaking with $\mathrm{CaCl}_{2}$ and saturated $\mathrm{CaHPO}_{4}$, (c, g) the McGrath method, and (d, f) the Kitano method. Scale bars: $5 \mu \mathrm{m}$. 


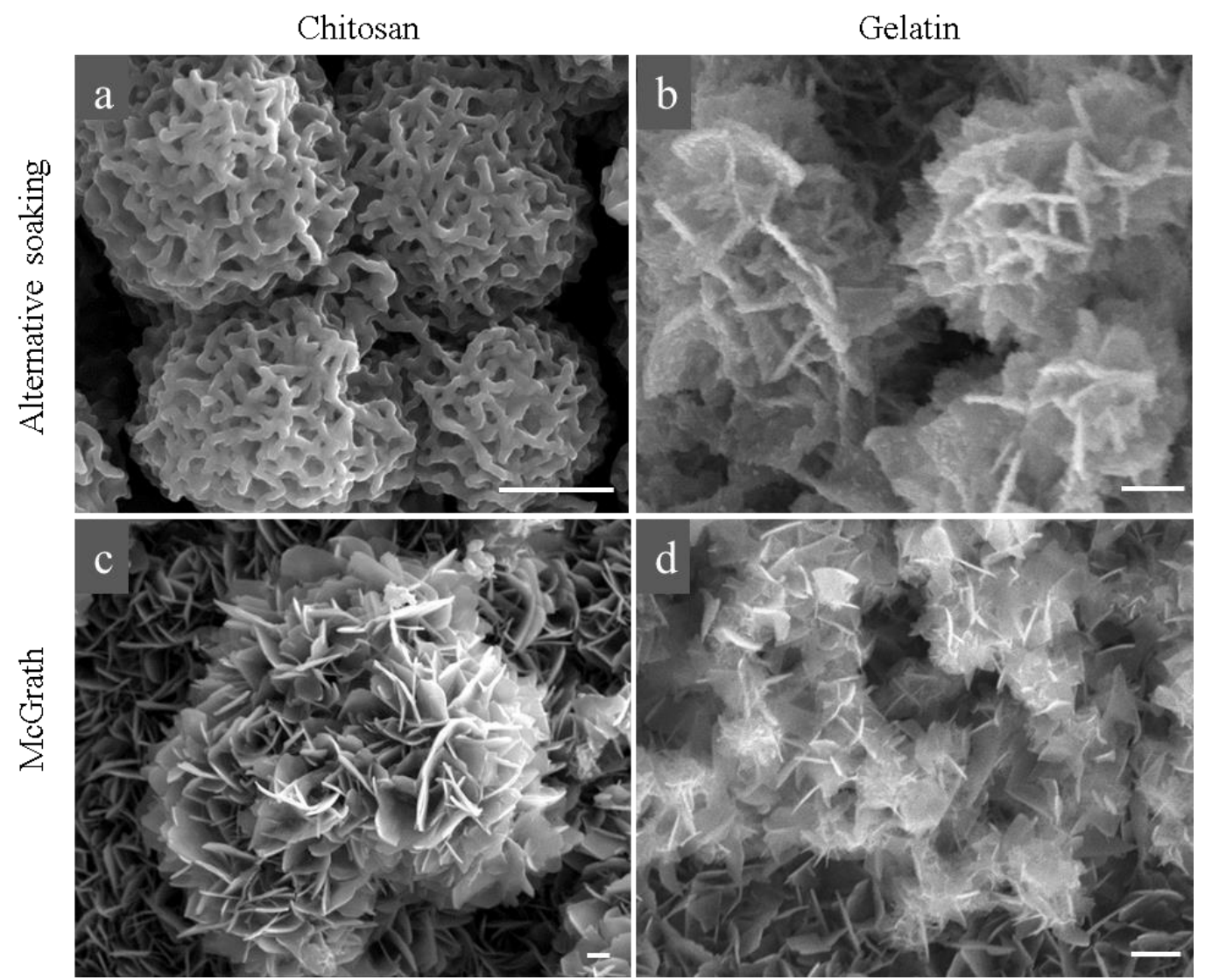

Figure 3-2: Magnified view of $\mathrm{CaP} /$ chitosan composites prepared via (a) alternative soaking using $\mathrm{CaCl}_{2} \cdot 2 \mathrm{H}_{2} \mathrm{O}$ and saturated $\mathrm{CaHPO}_{4}$ (Figure 3-1c), and (c) the $\mathrm{McGrath}$ method (Figure 3-1e) and $\mathrm{CaP} /$ gelatin composites prepared via (b) alternative soaking with $\mathrm{CaCl}_{2}$ and $\mathrm{Na}_{2} \mathrm{HPO}_{4}$ (Figure 3-1e), and (d) the McGrath method (Figure 3-1f). Scale bars: $1 \mu \mathrm{m}$.

Powder XRD analysis performed on $\mathrm{CaP}$ which was immediately precipitated from saturated $\mathrm{CaHPO}_{4}$ (after bubbling the solution with $\mathrm{CO}_{2}$ ) showed brushite formation (Figure 3-3). If the solution is left to crystallize for at least one week the resulting precipitate was confirmed to be HAp (Figure 3-4). This difference with regard to which form dominates as a function of crystallization time is not surprising since bubbling the solution with $\mathrm{CO}_{2}$ drops the $\mathrm{pH}$ of the saturated $\mathrm{CaHPO}_{4}$ solution until it becomes mildly acidic, which favours brushite formation. However by the time degassing is complete, the $\mathrm{pH}$ of the solution has increased and it is then mildly basic and hence HAp precipitates. Furthermore, and more importantly, over time the metastable brushite converts to HAp which is the thermodynamically favorable polymorph of $\mathrm{CaP}[39,40]$. 


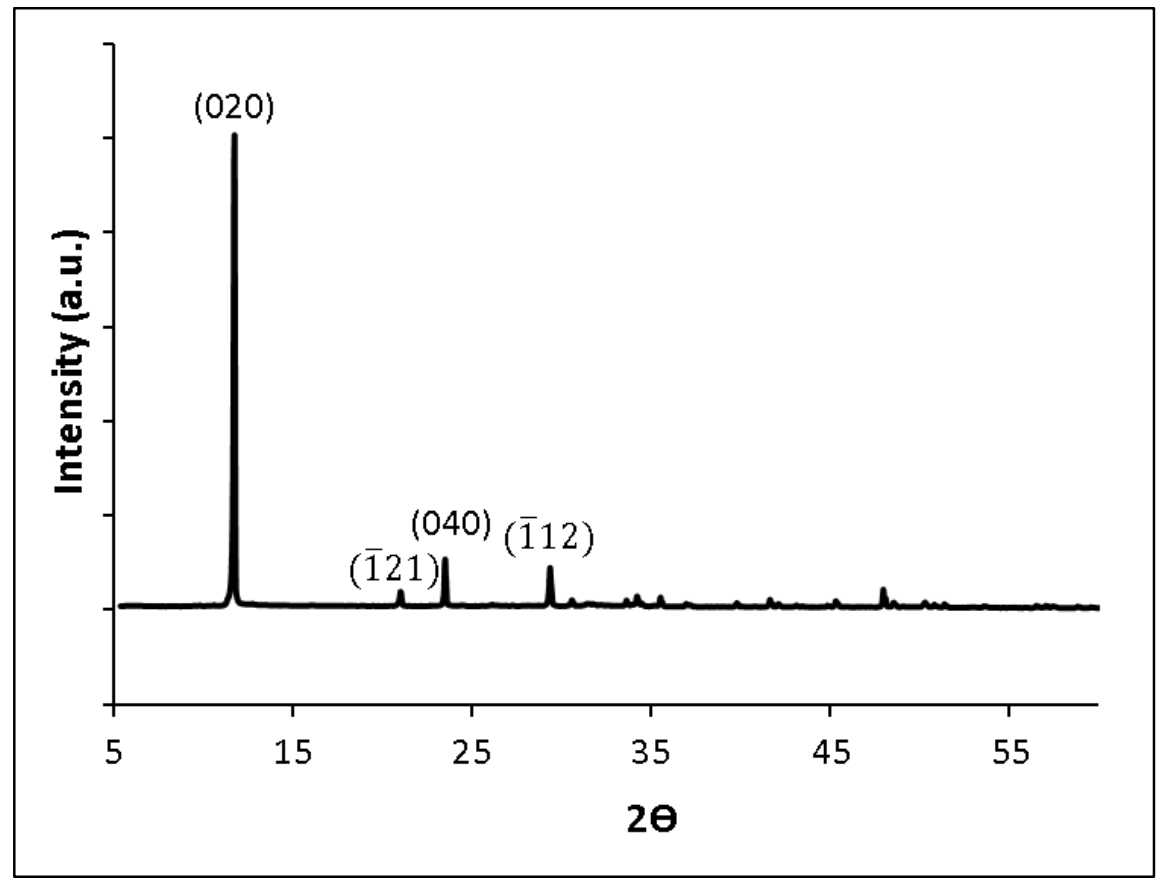

Figure 3-3: Powder XRD pattern of $\mathrm{CaP}$ immediately precipitated from a $\mathrm{CO}_{2}$ bubbled saturated $\mathrm{CaHPO}_{4}$ solution. The peak assignments correspond with brushite: $11.74^{\circ}(020)$, $21.02^{\circ}(\overline{\mathbf{1}} \mathbf{2 1}), 23.51^{\circ}(040)$ and $29.36^{\circ}(\overline{\mathbf{1} 12})$.

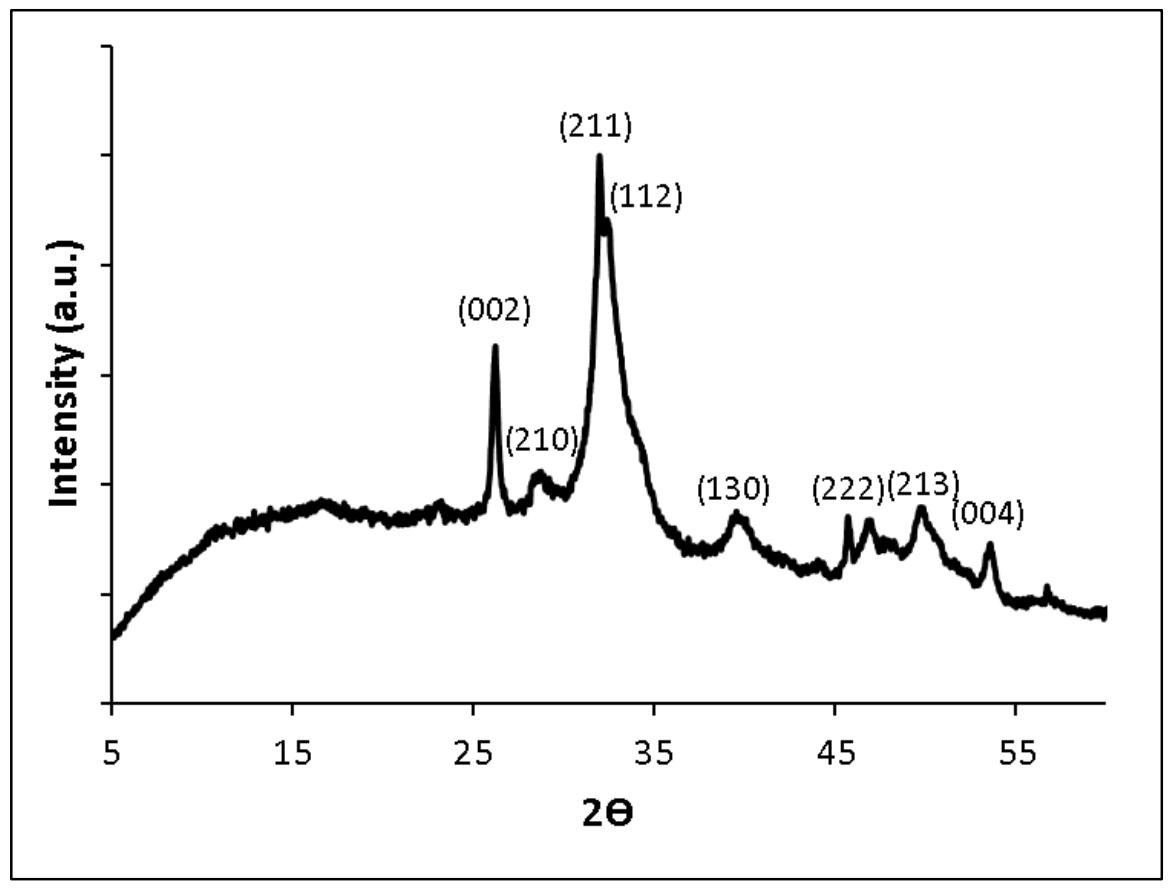

Figure 3-4: Powder XRD pattern of $\mathrm{CaP}$ formed after one week of crystallization from a $\mathrm{CO}_{2}$ bubbled saturated $\mathrm{CaHPO}_{4}$ solution. The peak assignments correspond to HAp: $26.0^{\circ}$

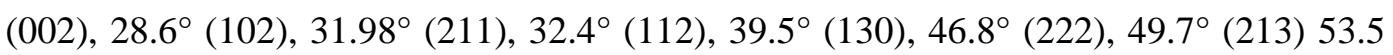
(004) $47.5^{\circ}(018)$ and $48.6^{\circ}(116)$. 
The mineral phase of $\mathrm{CaP}$ within chitosan and gelatin hydrogel scaffolds was also investigated by XRD (Figure 3-5). The diffractogarms for the pure cross-linked gelatin (Figure 3-5a) and chitosan films (Figure 3-5e) are repeated here for easier comparison. In all mineralized samples irrespective of which crystallization method was used, similar XRD patterns were measured. These data indicate that while the scaffolds are heavily mineralized, the extent of crystalline $\mathrm{CaP}$ is small, what crystalline $\mathrm{CaP}$ is formed is $\mathrm{HAp}$. Hence the $\mathrm{CaP}$ mix is ACP and HAp. The broad background peaks at $\sim 2 \theta=20^{\circ}$ in the mineralized gelatin hydrogel corresponds to the amorphous nature of the gelatin hydrogel film (Figure 3-5a, b, c and d). While for the chitosan system the peaks at $2 \theta=10^{\circ}, 19^{\circ}$ and $21^{\circ}$ correspond to microcrystalline regions within the chitosan hydrogel scaffold itself (Figure 3-5e, f, g and h), as mentioned in Chapter 2. A very small broad peak at $32.0^{\circ}$ (211) is evident in the gelatin mineralized scaffold for all crystallization methods confirming that the crystalline form of $\mathrm{CaP}$ that is formed is HAp and not brushite. The significant broadening of the diffraction lines in HAp crystals is attributed to the formation of fine crystals. In the case of $\mathrm{CaP}$ formed within the chitosan scaffold the most intense HAp peaks at $2 \theta=26.2^{\circ}(002)$ and $32.0^{\circ}(211)$ are evident when the McGrath method is used (Figure 3-5h). However, the peak at $32.0^{\circ}$ appears to be broadened when using the alternative soaking and Kitano methods which may indicate that the individual HAp crystal sizes are in the nanoscale.

The micro-Raman spectrum corresponding to HAp crystallization from bulk $\mathrm{CaHPO}_{4}$ solution after one week is shown in Figure 3-6. The observed peaks are comparable with literature $[41,42]$. A prominent peak at $\sim 960 \mathrm{~cm}^{-1}$, is attributed to the stretching mode $\left(v_{1}\right)$ of the $\mathrm{P}-\mathrm{O}$ bond of the tetrahedral $\mathrm{PO}_{4}$ group. Apart from this strong peak, other peaks at 585,430 and $1040 \mathrm{~cm}^{-1}$ are resolved which are attributed to the bending mode $\left(v_{4}\right)$ of the $\mathrm{PO}_{4}$ group $(\mathrm{O}-\mathrm{P}-\mathrm{O}$ bond $)$, the degenerate bending mode $\left(v_{2}\right)$ of the $\mathrm{PO}_{4}$ group $(\mathrm{O}-\mathrm{P}-\mathrm{O}$ bond), and the asymmetric stretching mode $\left(v_{3}\right)$ of the $\mathrm{PO}_{4}$ group $(\mathrm{P}-\mathrm{O}$ bond) respectively. $\mathrm{CaP}$ mineralization of either the chitosan or gelatin hydrogel scaffolds in the absence of any additives and regardless of the crystallization method, leads to the formation of HAp (with a characteristic very strong $\mathrm{PO}_{4}$ peak at $\sim 960 \mathrm{~cm}^{-1}$ ) as determined by Raman spectroscopy (data are not shown). 


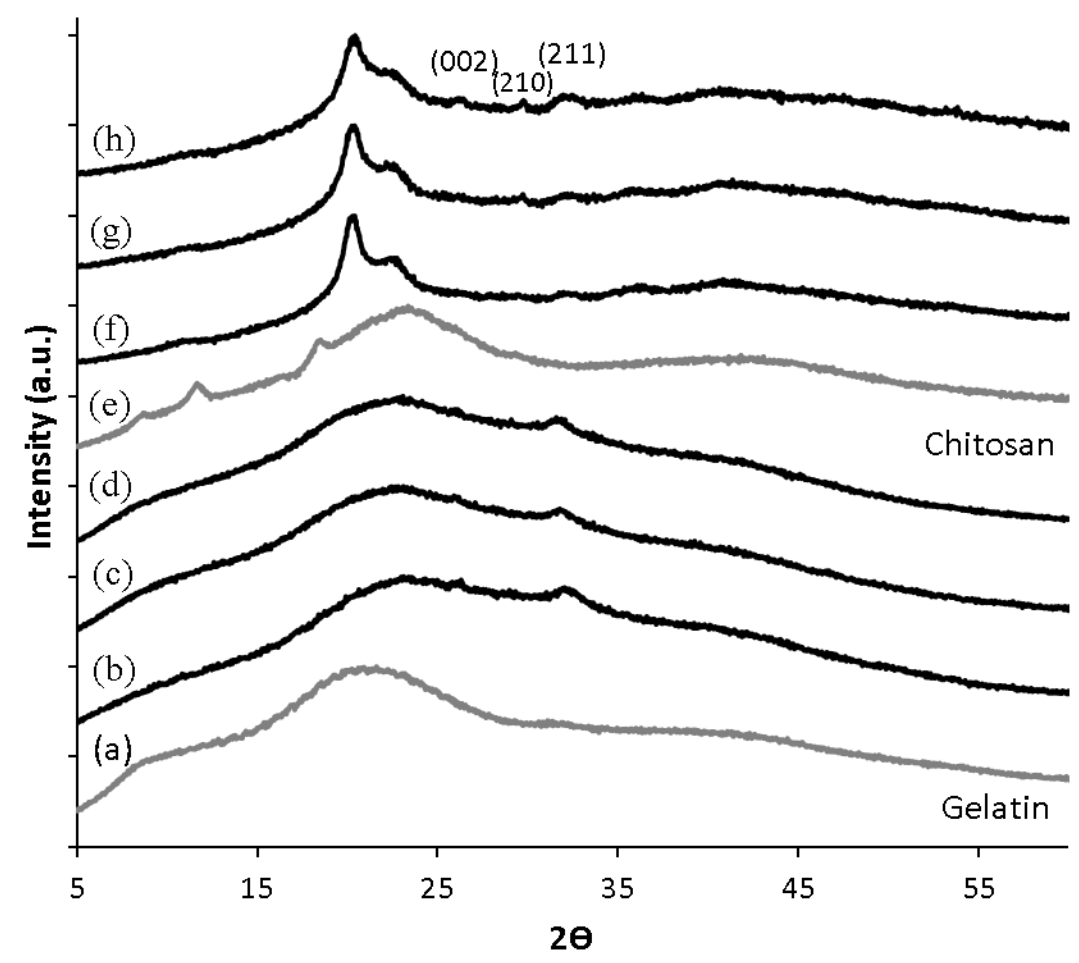

Figure 3-5: Powder XRD pattern of (a) pure cross-linked gelatin film, (b, c, d) CaP/gelatin composites prepared via Kitano, alternative soaking and McGrath methods respectively, (e) pure chitosan film, and (f, g, h) CaP/chitosan composites prepared via Kitano, alternative soaking and McGrath methods respectively.

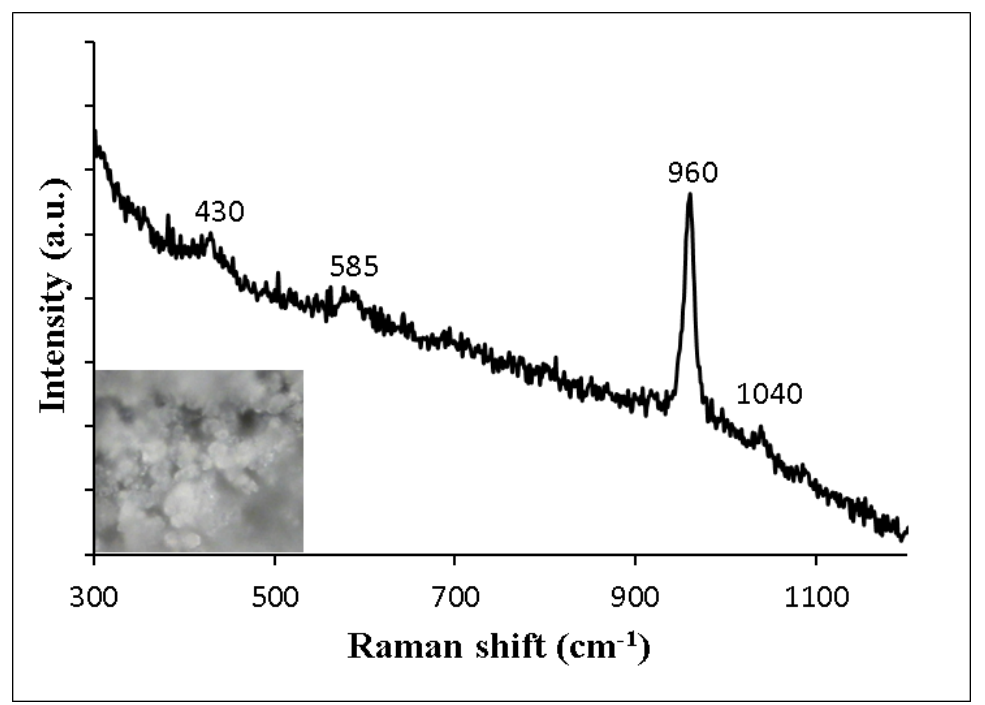

Figure 3-6: Micro-Raman spectrum of $\mathrm{CaP}$ precipitate formed after one week from bulk $\mathrm{CaHPO}_{4}$ solution. The crystals correspond to the HAp polymorph. The inset shows the corresponding optical image of the crystals. 


\subsubsection{Chitosan and gelatin hydrogel scaffold mineralization: with additives}

In Chapter 2 we demonstrated the fabrication of $\mathrm{CaCO}_{3}$-based biominerals through the addition of monomeric and polymeric additives to chitosan and gelatin hydrogel scaffolds. The acidic additives are considered to be similar to the acidic residue rich polypeptides present in biominerals. In this chapter the same additives (monomeric acrylic acid, Lglutamic acid, L-aspartic acid and their corresponding polymers) are used for the CaP-based mineralization chitosan and gelatin hydrogel scaffolds.

\subsubsection{CaP/chitosan and CaP/gelatin: AA/PAA}

The addition of AA and PAA to the CaP crystallization solution was investigated. Based on the results from the $\mathrm{CaCO}_{3}$-based mineralization experiments, the addition of additive to all of the crystallization solutions leads to the best control over the $\mathrm{CaCO}_{3}$ crystallization. Therefore in the case of $\mathrm{CaP}$ the additives were added to all crystallization solutions.

SEM images show that the addition of PAA/AA to the crystallization solutions had a marked effect on the $\mathrm{CaP}$ precipitation in comparison with when no additive is present for both chitosan and gelatin scaffolds (Figure 3-7). Interestingly there is no crystal growth when AA or PAA is present, for both gelatin and chitosan scaffolds, when the Kitano method and alternative soaking with $\mathrm{CaCl}_{2}$ and saturated $\mathrm{CaHPO}_{4}$ are used (data not shown). Also in the case of using the alternative soaking method with $\mathrm{CaCl}_{2}$ and $\mathrm{NaHPO}_{4}$ there is almost no growth for the chitosan hydrogel scaffold (Figure 3-7a).

In the presence of AA, partially aggregated spherical (2-5 $\mu \mathrm{m}$ in diameter) crystals form on the surface of the gelatin for samples prepared using the alternative soaking method with $\mathrm{CaCl}_{2}$ and $\mathrm{NaHPO}_{4}$ (Figure 3-7b). In contrast, in the case of AA combined with the McGrath method, fairly homogeneous and densely packed $\mathrm{CaP}$ nanoparticles, which is more easily observable in back scattered images (Figure 3-7 c, d insets), are produced throughout both gelatin and chitosan hydrogel scaffolds (Figure 3-7c, d).

A low degree of mineralization occurs when PAA is used in the case of alternative soaking with $\mathrm{CaCl}_{2}$ and $\mathrm{NaHPO}_{4}$ for both chitosan and gelatin scaffolds (Figure 3-7e, f). Interestingly, in the presence of PAA, a mixture of flat $\mathrm{CaCO}_{3}$ and $\mathrm{CaP}$ minerals are generated for chitosan scaffolds when using the McGrath method (Figure 3-7g) while using the same conditions but with gelatin only aggregated $\mathrm{CaP}$ forms (3-7h). 
The results suggest that the first stages of crystallization may involve the lateral growth of $\mathrm{CaCO}_{3}$ (calcite or vaterite based on the data presented in Chapter 2 results) due to the addition of PAA to the $\mathrm{CaCl}_{2}$ solution which promotes $\mathrm{CaCO}_{3}$ formation. Upon the addition of the $\mathrm{Na}_{2} \mathrm{HPO}_{4}$ solution followed by saturated $\mathrm{CaHPO}_{4}$ solution, the $\mathrm{CaP}$ is thought to be nucleated on the surface of both the $\mathrm{CaCO}_{3}$ and chitosan due to the lower solubility of $\mathrm{CaP}$, hence preventing further $\mathrm{CaCO}_{3}$ formation. The resulting complex material formation is commonly found in pathological biomineralization such as urinary stones. This indicates that when there is a choice of soluble salts it is possible to lead to selective overgrowth of one mineral phase on another [43, 44].

$\mathrm{XRD}$ analyses of the $\mathrm{CaP} /$ chitosan and $\mathrm{CaP} /$ gelatin composites, formed using AA/PAA additives and the alternative soaking with $\mathrm{CaCl}_{2}$ and $\mathrm{Na}_{2} \mathrm{HPO}_{4}$, and $\mathrm{McGrath}$ methods show that $\mathrm{ACP}$ is the only $\mathrm{CaP}$ formed (data are similar to Figure 3-5f). However XRD analysis of the $\mathrm{CaP} /$ chitosan/PAA system using the McGrath method indicates a mixture of calcite and HAP and/or ACP forms (Figure 3-8). Micro-Raman analyses show that the observed crystals are calcite (as shown in Figure 2-6, Chapter 2). This domination of the calcite peaks is because the substrate is covered with very large $\mathrm{CaCO}_{3}$ crystals. This polymorph dominates the area of investigation for Raman analysis and $\mathrm{CaP}$ cannot be detected. 


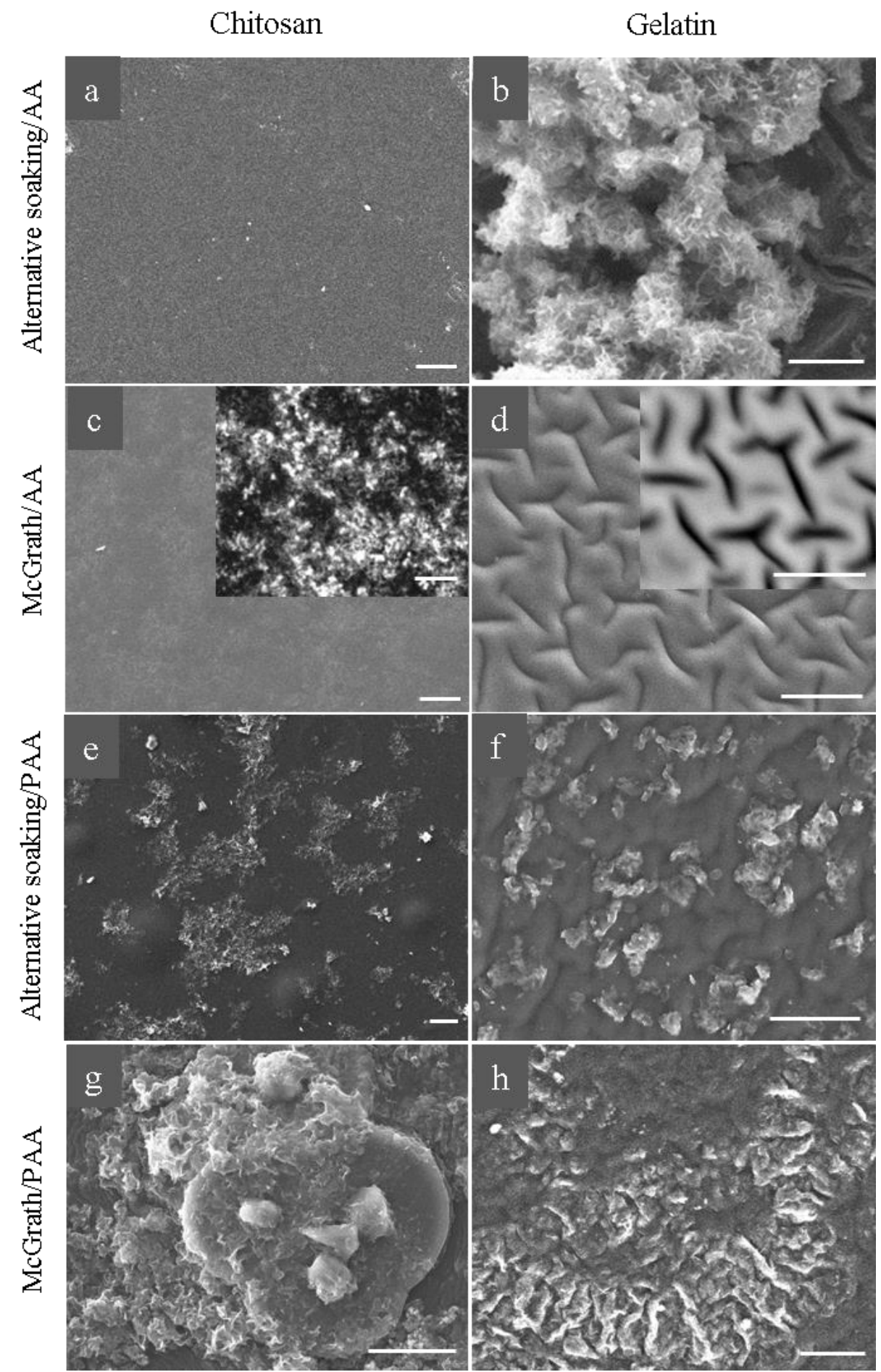

Figure 3-7: $\mathrm{CaP} /$ chitosan/AA, $\mathrm{CaP} /$ gelatin/AA $\mathrm{CaP} /$ chitosan/PAA and

$\mathrm{CaP} /$ gelatin/PAA composites prepared via $(\mathrm{a}, \mathrm{b}, \mathrm{e}, \mathrm{f})$ alternative soaking with $\mathrm{CaCl}_{2}$ and $\mathrm{Na}_{2} \mathrm{HPO}_{4}$, and (c, d, g, h) McGrath methods. Scale bars: $10 \mu \mathrm{m}$. 


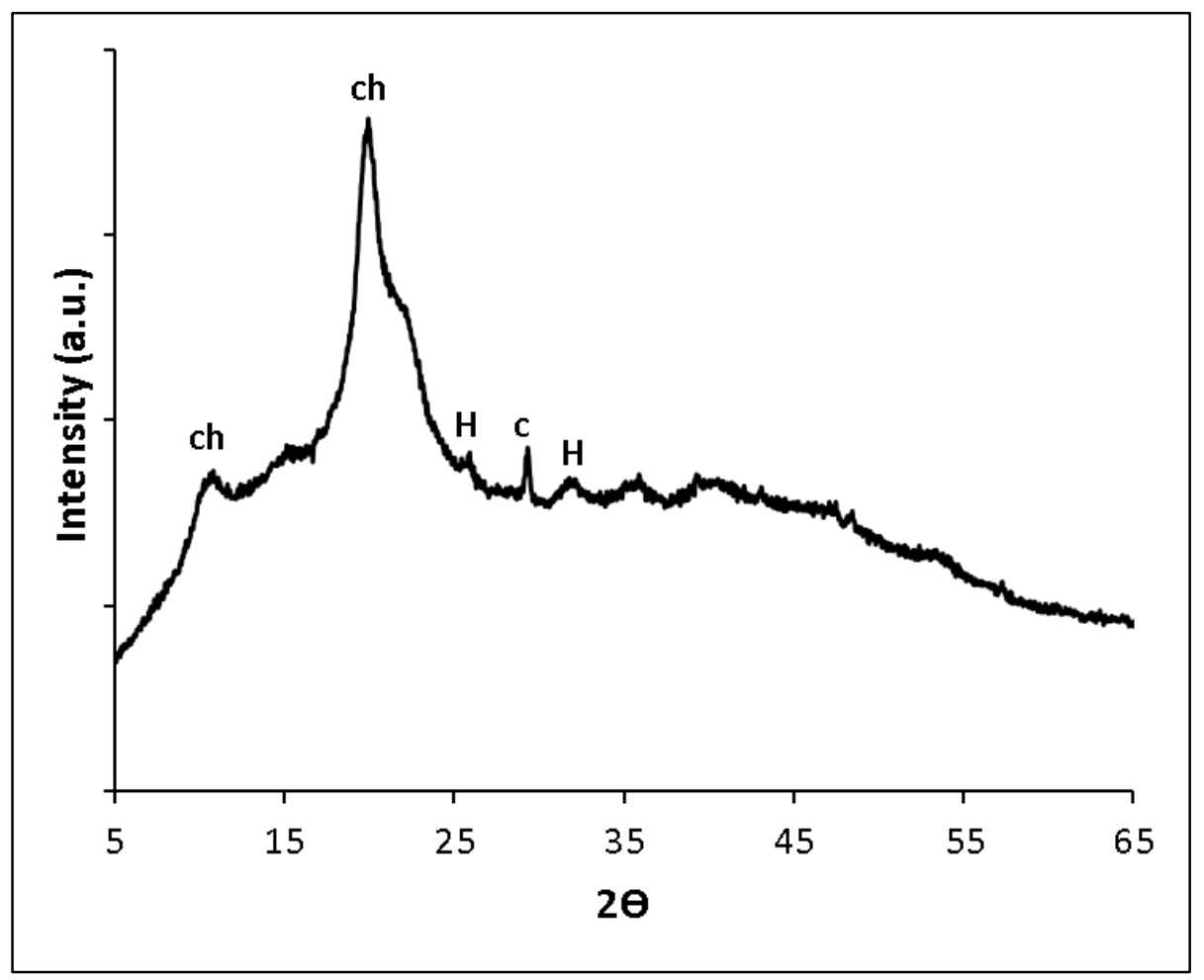

Figure 3-8: Powder XRD pattern of a CaP/chitosan/PAA composite synthesized via the McGrath method in the presence of $2 \mathrm{wt} \%$ PAA indicating the formation of a mixture of calcite and HAp on the surface of chitosan. H, c and ch show HAp, calcite, chitosan peaks respectively.

\subsubsection{CaP/chitosan/GL, AS, PGL and PAS composite}

A summary of the crystallization conditions, morphology, and crystallinity analysis of $\mathrm{CaP} /$ chitosan/GL, AS, PGL and PAS composites is presented in Table 2. SEM images of $\mathrm{CaP}$ grown within the chitosan scaffold using four additives (GL, AS, PGL and PAS) showed various morphologies (Figures 3-9 and 3-10). The four different crystallization methods were used. Porous spherical $\mathrm{CaP}(\sim 1.5-3 \mu \mathrm{m}$ in diameter $)$ similar to those shown in Figure 3-2a formed in the case of $\mathrm{CaP} /$ chitosan/GL, for all the crystallization methods except alternative soaking with $\mathrm{CaCl}_{2}$ and $\mathrm{Na}_{2} \mathrm{HPO}_{4}$ solutions (Figure 3-9c, e, g). The alternative soaking with $\mathrm{CaCl}_{2}$ and $\mathrm{Na}_{2} \mathrm{HPO}_{4}$ solutions induces the precipitation of the flower-like platelet $\mathrm{CaP}$ morphology $(\sim 1-1.5 \mu \mathrm{m}$ in length) in addition to the flower-like clusters with almost complete coverage of minerals throughout and on the hydrogel scaffold compared to the other three methods (Figure 3-9a). Similar results were also obtained in the case of $\mathrm{CaP} / \mathrm{Chitosan} / \mathrm{AS}$ for the McGrath method where platelet-like crystals are formed (Figure 3-10c). In the case of the Kitano method with added AS almost no crystal growth 
occurs with chitosan films (Figure 3-10g) and both alternative soaking methods lead to aggregated $\mathrm{CaP}$ crystal formation.

When PGL and PAS were introduced into the $\mathrm{CaP} /$ chitosan composite systems under the same crystallization conditions significant changes in morphology are evident. The differences between GL/PGL and PGL/PAS are more remarkable than for AS/PAS. However platelet-like (Figure 3-9d, h and Figure 3-10d, f) and spherical structures (Figure 3-9a, d and Figure 3-10b, f), which are the very common morphologies are achieved once again. Compared to the GL/AS additives in the case of PGL/PAS the crystals are on average smaller. For example the spherical CaP minerals are $\sim 100-300 \mathrm{~nm}$ in diameter in the $\mathrm{CaP} /$ chitosan/PGL and $\mathrm{CaP} /$ chitosan/PAS systems when the alternative soaking with $\mathrm{CaCl}_{2}$ and $\mathrm{Na}_{2} \mathrm{HPO}_{4}$ solutions are used. The size of the $\mathrm{CaP}$ minerals is influenced by the density of nucleating sites. More nucleation sites lead to more crystal nucleation and smaller crystals and vice versa. All four methods lead to extensive nucleation and growth along the chitosan scaffold in the case of PGL and PAS. Interestingly a very thin film of $\mathrm{CaP}$ forms parallel to the chitosan scaffold in the CaP/chitosan/PAS composite when the Kitano method is used (Figure 3-10g).

All the composites were analyzed by XRD and micro-Raman to determine the crystallinity and polymorphism. In the case of $\mathrm{CaCO}_{3} /$ chitosan/GL, ACP (with XRD pattern similar to Figure 3-5f) forms irrespective of which crystallization method is used. This indicates that the samples with porous spherical morphology may be amorphous. The same behaviour is observed for the $\mathrm{CaP} /$ chitosan/PGL system when alternative soaking with $\mathrm{CaCl}_{2}$ and saturated $\mathrm{CaHPO}_{4}$ solution is used. However for the $\mathrm{CaP} /$ chitosan/PGL system using alternative soaking with $\mathrm{CaCl}_{2}$ and $\mathrm{Na}_{2} \mathrm{HPO}_{4}, \mathrm{HAp}$ peaks are detected (Figure 3-11a). The intensity of the peaks for the same system increases when the Kitano method is used (Figure 3-11b). These XRD results for AS/PAS additives show a different trend than when PGL was added to the crystallization solutions. HAp is formed using the McGrath method for $\mathrm{CaP} /$ chitosan/AS or CaP/chitosan/PAS composites (Figure 3-11c and d). Those samples that are platelet-shaped are more highly crystalline compared to those where predominately the spherical $\mathrm{CaP}$ morphology is observed. Interestingly brushite is produced when the alternative soaking with $\mathrm{CaCl}_{2}$ and $\mathrm{Na}_{2} \mathrm{HPO}_{4}$ with added PAS is used. The rest of the $\mathrm{CaP} /$ chitosan/AS and $\mathrm{CaP} /$ chitosan/PAS samples provided evidence for the formation of most likely amorphous CaP. Micro-Raman spectroscopy confirmed that HAp (spectrum similar to Figure 3-6) and ACP are the only polymorphs formed for all crystallization 
methods used for $\mathrm{CaP} /$ chitosan composites in the presence of GL, AS, PGL and PAS. Also it is again noted that the formation of platelet structures result in the appearance of HAp peaks whereas spherical CaP crystals do not and are most likely ACP.

These results suggest that besides $\mathrm{pH}$, which has been shown to be a key factor with regard to which form of $\mathrm{CaP}$ precipitates, additives influence precipitation of calcium phosphates and interconversion between different polymorphs. The transformation of $\mathrm{CaP}$ polymorphs in the range of $\mathrm{pH}$ used here is highly likely. For instance brushite formed under mild acidic conditions converts over time and may occur only transiently prior to HAp formation. Moreover additives also play a key role in defining crystal size. The presence of the polymeric form of an additive generally favours smaller crystal formation. Depending on the conditions that mineralization takes place under it can be determinant whether healthy mineralization or pathological mineralization occurs. 
Table 2: Crystallization conditions for calcium phosphate crystal growth using chitosan hydrogel scaffolds in the presence of GL, PGL, AS and PAS.

\begin{tabular}{|c|c|c|c|c|c|}
\hline Method & $\begin{array}{l}\text { Presoak } \\
\text { solution (1) }\end{array}$ & $\begin{array}{l}\text { Presoak } \\
\text { solution (2) }\end{array}$ & $\begin{array}{l}\text { Crystallization } \\
\text { solution (3) }\end{array}$ & Crystal morphology & Polymorph \\
\hline $\begin{array}{l}\text { Alternative } \\
\text { soaking }\end{array}$ & $\mathrm{CaCl}_{2} / \mathrm{GL}$ & $\mathrm{Na}_{2} \mathrm{HPO}_{4} / \mathrm{GL}$ & - & $\begin{array}{l}\text { Platelet } \\
\text { (Figure 3-9a) }\end{array}$ & HAp, ACP \\
\hline $\begin{array}{l}\text { Alternative } \\
\text { soaking }\end{array}$ & $\mathrm{CaCl}_{2} / \mathrm{AS}$ & $\mathrm{Na}_{2} \mathrm{HPO}_{4} / \mathrm{AS}$ & - & $\begin{array}{l}\text { Aggregated } \\
\text { (Figure 3-10a) }\end{array}$ & HAp, ACP \\
\hline $\begin{array}{l}\text { Alternative } \\
\text { soaking }\end{array}$ & $\mathrm{CaCl}_{2} / \mathrm{PGL}$ & $\mathrm{Na}_{2} \mathrm{HPO}_{4} / \mathrm{PGL}$ & - & $\begin{array}{l}\text { Spherical } \\
\text { (Figure 3-9b) }\end{array}$ & HAp \\
\hline $\begin{array}{l}\text { Alternative } \\
\text { soaking }\end{array}$ & $\mathrm{CaCl}_{2} / \mathrm{PAS}$ & $\mathrm{Na}_{2} \mathrm{HPO}_{4} / \mathrm{PAS}$ & - & $\begin{array}{l}\text { Spherical } \\
\text { (Figure 3-10b) }\end{array}$ & brushite \\
\hline $\begin{array}{l}\text { Alternative } \\
\text { soaking }\end{array}$ & $\mathrm{CaCl}_{2} / \mathrm{GL}$ & - & $\mathrm{CaHPO}_{4} / \mathrm{GL}$ & $\begin{array}{l}\text { Spherical } \\
\text { (Figure 3-9b) }\end{array}$ & ACP \\
\hline $\begin{array}{l}\text { Alternative } \\
\text { soaking }\end{array}$ & $\mathrm{CaCl}_{2} / \mathrm{AS}$ & - & $\mathrm{CaHPO}_{4} / \mathrm{AS}$ & $\begin{array}{l}\text { Aggregated/platelet } \\
\text { (Figure 3-10c) }\end{array}$ & HAp, ACP \\
\hline $\begin{array}{l}\text { Alternative } \\
\text { soaking }\end{array}$ & $\mathrm{CaCl}_{2} / \mathrm{PGL}$ & - & $\mathrm{CaHPO}_{4} / \mathrm{PGL}$ & $\begin{array}{l}\text { Spherical, Platelet } \\
\text { (Figure 3-9d) }\end{array}$ & HAp, ACP \\
\hline $\begin{array}{l}\text { Alternative } \\
\text { soaking }\end{array}$ & $\mathrm{CaCl}_{2} / \mathrm{PAS}$ & - & $\mathrm{CaHPO}_{4} / \mathrm{PAS}$ & $\begin{array}{l}\text { Platelet } \\
\text { (Figure 3-10d) }\end{array}$ & HAp, ACP \\
\hline McGrath & $\mathrm{CaCl}_{2} / \mathrm{GL}$ & $\mathrm{Na}_{2} \mathrm{HPO}_{4} / \mathrm{GL}$ & $\mathrm{CaHPO}_{4} / \mathrm{GL}$ & Spherical (Figure 3-9e) & $\mathrm{ACP}$ \\
\hline McGrath & $\mathrm{CaCl}_{2} / \mathrm{AS}$ & $\mathrm{Na}_{2} \mathrm{HPO}_{4} / \mathrm{AS}$ & $\mathrm{CaHPO}_{4} / \mathrm{AS}$ & $\begin{array}{l}\text { Platelet } \\
\text { (Figure 3-10e) }\end{array}$ & HAp \\
\hline McGrath & $\mathrm{CaCl}_{2} / \mathrm{PGL}$ & $\mathrm{Na}_{2} \mathrm{HPO}_{4} / \mathrm{PGL}$ & $\mathrm{CaHPO}_{4} / \mathrm{PGL}$ & Aggregated (Figure 3-9f) & $\mathrm{ACP}$ \\
\hline McGrath & $\mathrm{CaCl}_{2} / \mathrm{PAS}$ & $\mathrm{Na}_{2} \mathrm{HPO}_{4} / \mathrm{PAS}$ & $\mathrm{CaHPO}_{4} / \mathrm{PAS}$ & $\begin{array}{l}\text { Spherical/platelet } \\
\text { (Figure 3-10f) }\end{array}$ & HAP \\
\hline Kitano & - & - & $\mathrm{CaHPO}_{4} / \mathrm{GL}$ & Spherical (Figure 3-9g) & $\mathrm{ACP}$ \\
\hline Kitano & - & - & $\mathrm{CaHPO}_{4} / \mathrm{AS}$ & $-($ Figure $3-10 \mathrm{~g})$ & - \\
\hline Kitano & - & - & $\mathrm{CaHPO}_{4} / \mathrm{PGL}$ & Platelet (Figure 3-9h) & HAp \\
\hline Kitano & - & - & $\mathrm{CaHPO}_{4} / \mathrm{PAS}$ & Thin film (Figure 3-10h) & HAp, ACP \\
\hline
\end{tabular}


Chitosan/GL
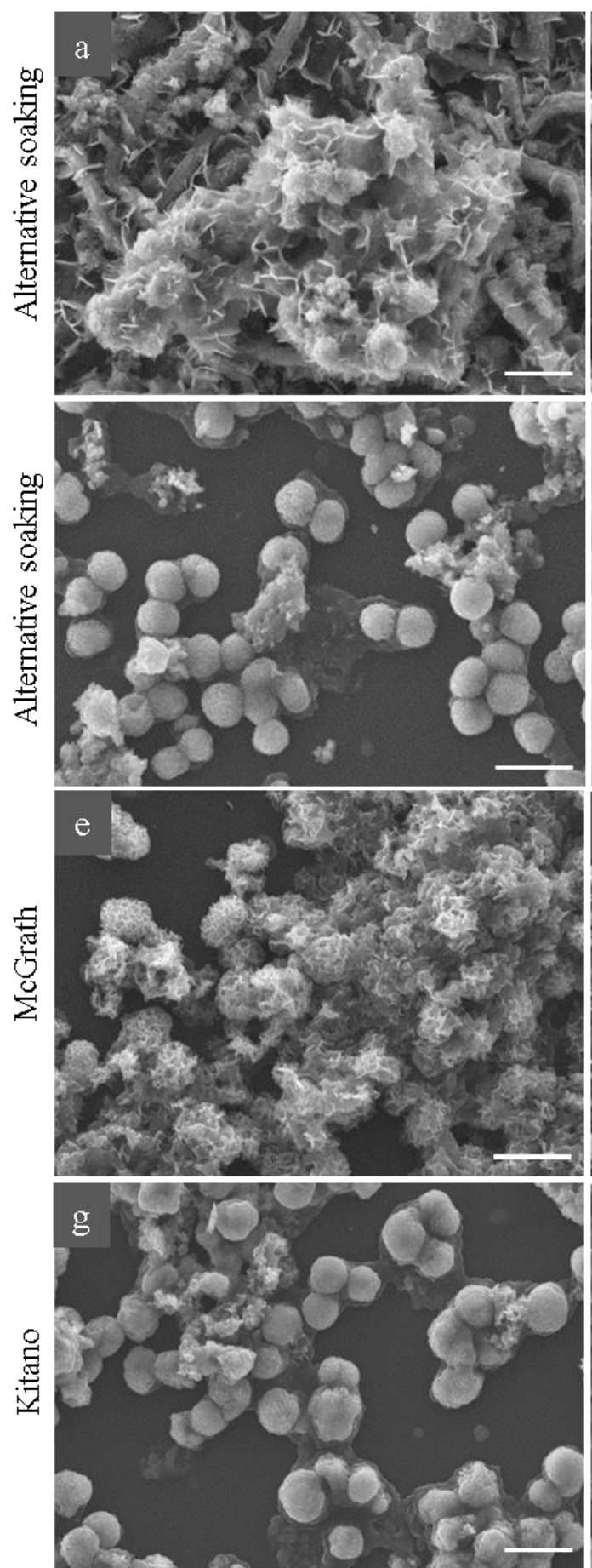

Chitosan/PGL
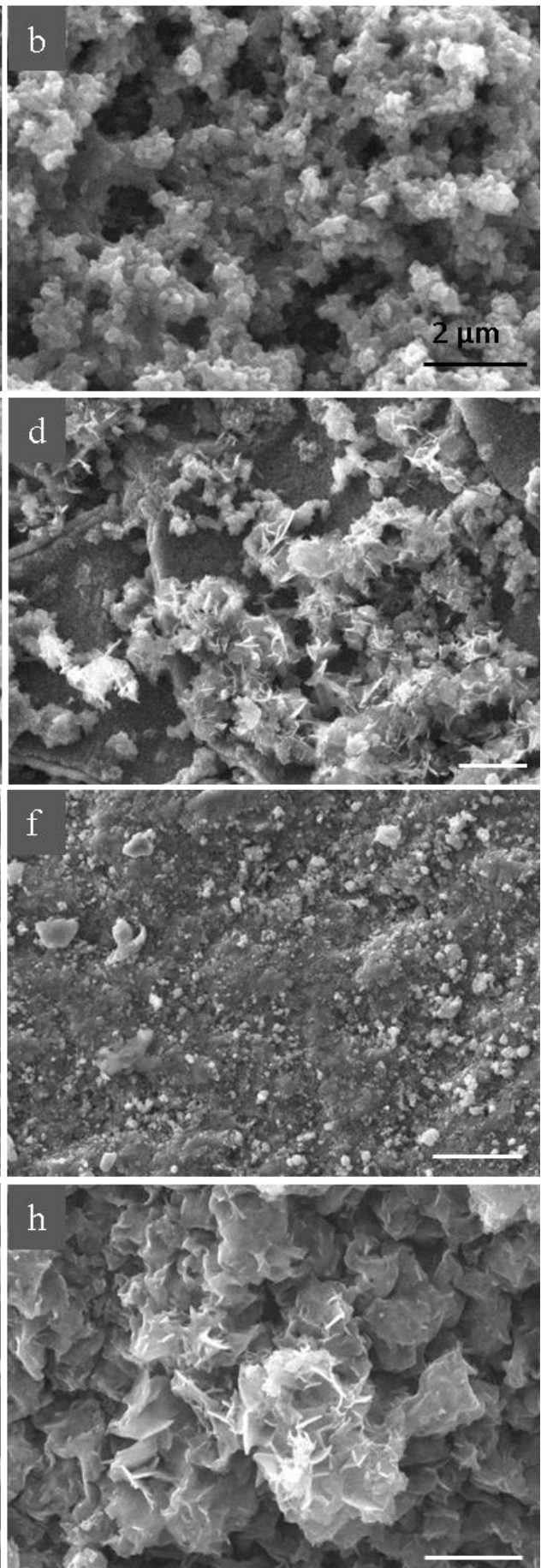

Figure 3-9: $\mathrm{SEM}$ images of $\mathrm{CaP} /$ chitosan/GL (left a, $\mathrm{c}$, e and g) and $\mathrm{CaP} / \mathrm{chitosan} / \mathrm{PGL}$

(right $\mathrm{b}, \mathrm{d}, \mathrm{f}$ and $\mathrm{h}$ ) composites prepared with the four different mineralization methods from top to bottom: alternative soaking with $\mathrm{CaCl}_{2}$ and $\mathrm{Na}_{2} \mathrm{HPO}_{4}$, alternative soaking with $\mathrm{CaCl}_{2}$ and saturated $\mathrm{CaHPO}_{4}, \mathrm{McGrath}$ method, and Kitano method. Scale bars: $5 \mu \mathrm{m}$ (unless stated otherwise). 


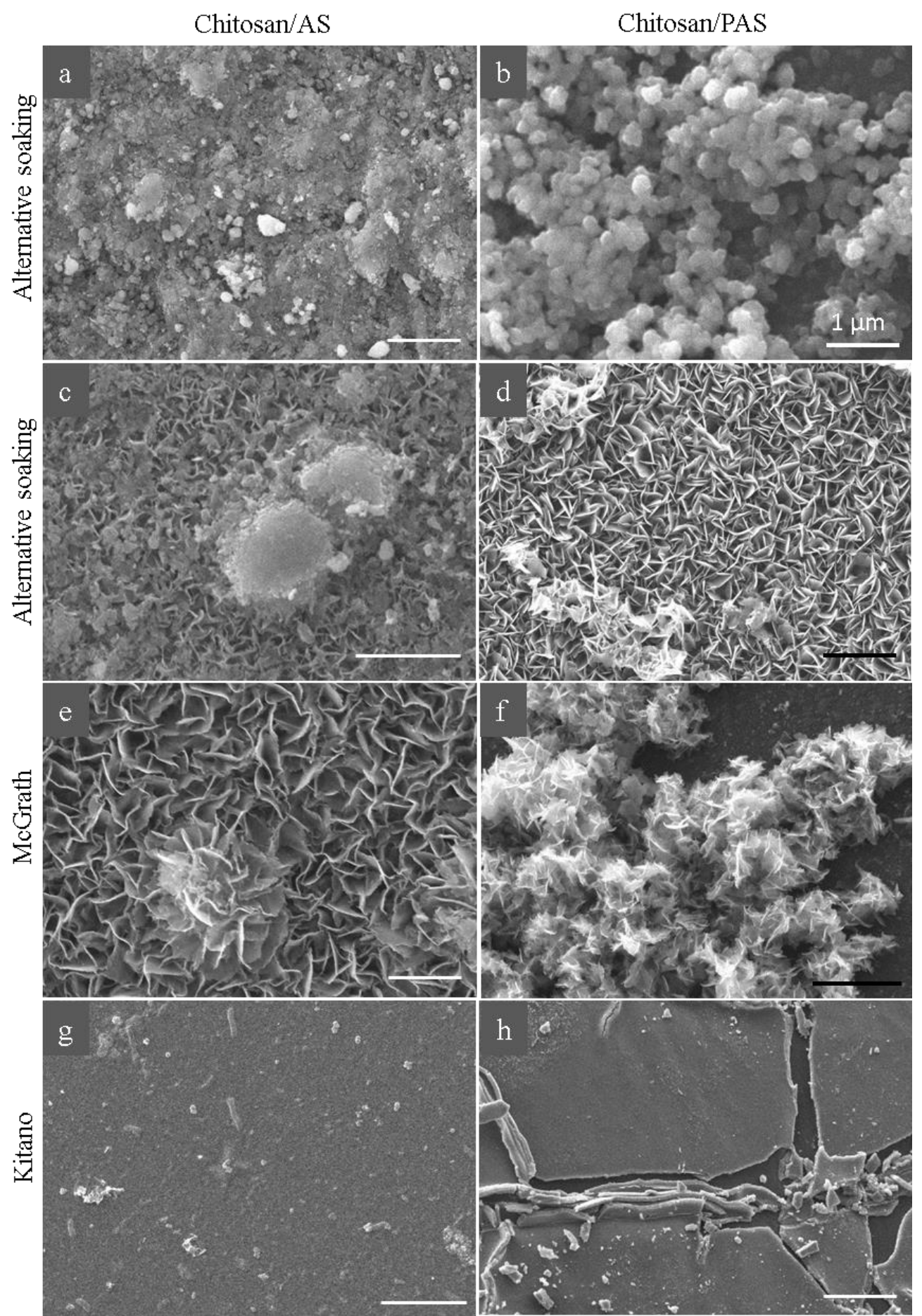

Figure 3-10: SEM images of CaP/chitosan/AS (left a, c, e and g) and CaP/chitosan/PAS (right $\mathrm{b}, \mathrm{d}, \mathrm{f}$ and $\mathrm{h}$ ) composites prepared with the four different mineralization methods from top to bottom: alternative soaking with $\mathrm{CaCl}_{2}$ and $\mathrm{Na}_{2} \mathrm{HPO}_{4}$, alternative soaking with $\mathrm{CaCl}_{2}$ and saturated $\mathrm{CaHPO}_{4}, \mathrm{McGrath}$ method, and Kitano Method. Scale bars: $10 \mu \mathrm{m}$ (inset $1 \mu \mathrm{m}$ ). 


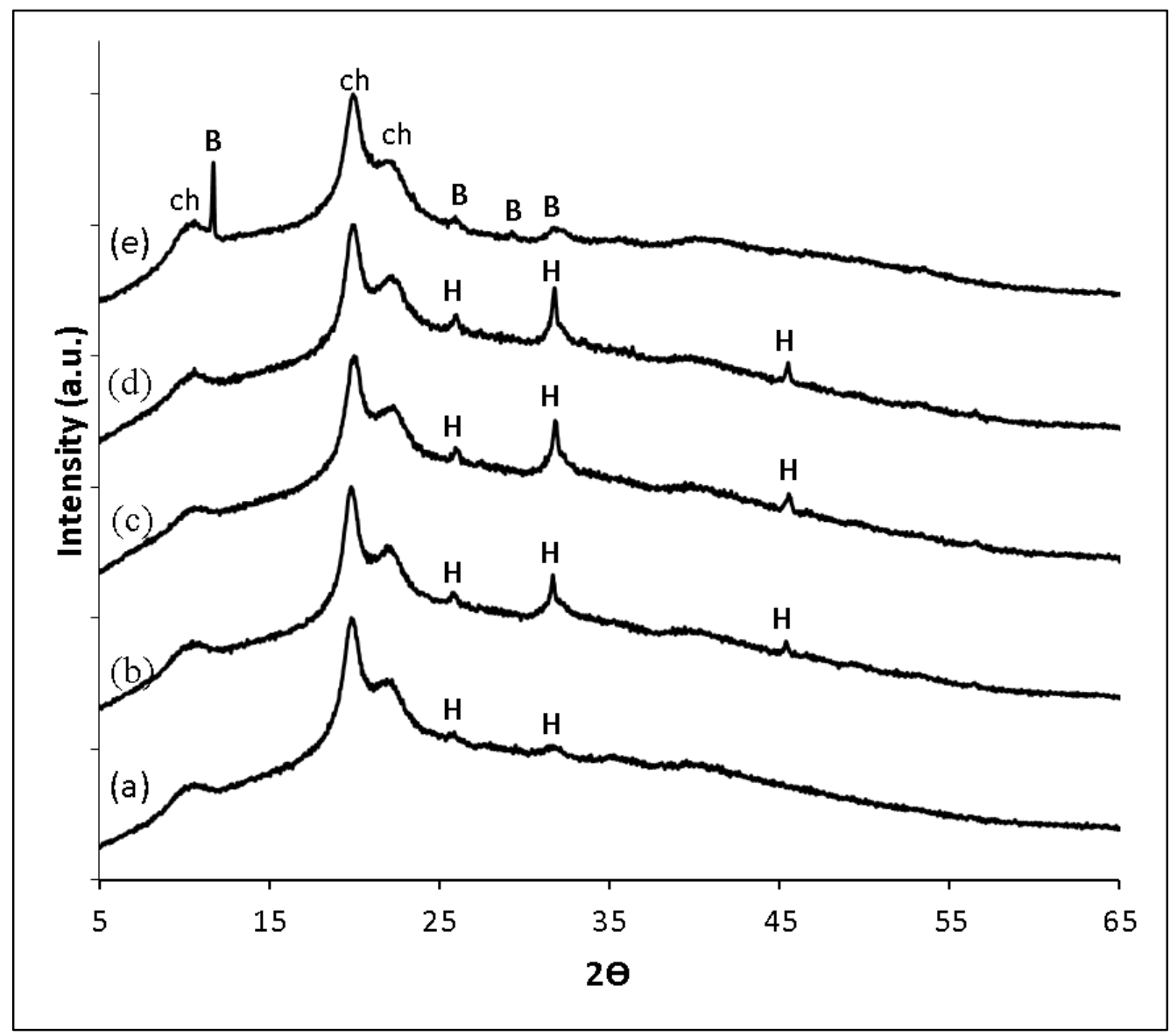

Figure 3-11: XRD patterns of $\mathrm{CaP} /$ chitosan/PGL composites prepared via (a) alternative soaking with $\mathrm{CaCl}_{2}$ and $\mathrm{Na}_{2} \mathrm{HPO}_{4}$, and (b) the Kitano method; CaP/chitosan/PAS composites prepared via (c) the McGrath method, and (e) the alternative soaking with $\mathrm{CaCl}_{2}$ and $\mathrm{Na}_{2} \mathrm{HPO}_{4}$; and $\mathrm{CaP} /$ chitosan/AS composites prepared via (d) alternative soaking with $\mathrm{CaCl}_{2}$ and $\mathrm{Na}_{2} \mathrm{HPO}_{4}$. The peaks of the two calcium phosphate polymorphs formed are indicated with $\mathrm{H}$ and B for HAp and brushite respectively and ch shows chitosan itself. 


\subsubsection{CaP/gelatin/GL, AS, PGL and PAS composites}

The influence of GL, AS, PGL and PAS additives with respect to calcium phosphate growth in gelatin hydrogels was also investigated. Table 3 provides the information about the mineralization conditions, crystallinity, morphology and polymorph information for the CaP/gelatin GL, PGL, AS and PAS systems.

The common platelet-shaped and spherical-like morphologies of $\mathrm{CaP}$ minerals grew within the gelatin matrix (see Figure 3-12 and 3-13). Flower-like platelet clusters comprising platelet-shaped $\mathrm{CaP}$ crystals are produced in the presence of GL and AS when both the alternative soaking with $\mathrm{CaCl}_{2}$ and $\mathrm{Na}_{2} \mathrm{HPO}_{4}$ and $\mathrm{McGrath}$ methods are used (Figure 3-12a, c and 3-13e). The alternative soaking with $\mathrm{CaCl}_{2}$ and saturated $\mathrm{CaHPO}_{4}$ solution with added GL (Figure 3-12c) and AS (Figure 3-13c) produces platelets, whereas under the same conditions but with added PGL and PAS aggregated CaP particles are formed (Figure 3-12d and $3-13 d$ respectively). In contrast assembled nanoparticles (where the nanoparticles are on average spherical), which homogenously cover the entire surface of the gelatin scaffold are observed in the case of when the alternative soaking with $\mathrm{CaCl}_{2}$ and $\mathrm{Na}_{2} \mathrm{HPO}_{4}$ and McGrath methods are used in the presence of PGL (Figure 3-12b, f) and PAS (Figure 3-13b, f). In the case of $\mathrm{CaP} /$ gelatin/GL the plate-shaped minerals form when using the Kiatno method (Figure 3-12g). Once again similar to $\mathrm{CaP} /$ chitosan/AS and $\mathrm{CaP} /$ chitosan/AA no crystal growth is observed in the case of CaP/gelatin/AS when the Kitano method is used (Figure 3-13g). This indicates that compared to the other three methods used here, in the presence of monomeric additives such as AS and GL, the Kitano method clearly does not induce mineralization within the gelatin or chitosan scaffolds due to a lower local concentration of ions with fewer nucleation sites being initiated. In contrast plate-shape and aggregated $\mathrm{CaP}$ formation throughout the gelatin hydrogel scaffold is readily observed in the presence of PGL (Figure 3-12h) and PAS (Figure 3-13h) when using the Kitano crystallization approach.

Powder XRD and micro-Raman spectroscopy provide evidence for HAp precipitation (with the most intense peaks at $\sim 2 \theta=32.0^{\circ}$ (211) for XRD and $\sim 960 \mathrm{~cm}^{-1}$ for Raman) throughout the gelatin hydrogel scaffold for almost all CaP/gelatin with GL, AS, PGL and PAS additives using all crystallization methods (Figures 3-14 and 3-15). The remaining samples are comprised of ACP. 


\begin{tabular}{|c|c|c|c|c|c|}
\hline Method & $\begin{array}{l}\text { Presoak } \\
\text { solution (1) }\end{array}$ & $\begin{array}{l}\text { Presoak } \\
\text { solution (2) }\end{array}$ & $\begin{array}{l}\text { Crystallization } \\
\text { solution (3) }\end{array}$ & Crystal morphology & Polymorph \\
\hline $\begin{array}{l}\text { Alternative } \\
\text { soaking }\end{array}$ & $\mathrm{CaCl}_{2} / \mathrm{GL}$ & $\mathrm{Na}_{2} \mathrm{HPO}_{4} / \mathrm{GL}$ & - & $\begin{array}{l}\text { Spherical/platelet } \\
\text { (Figure 3-12a) }\end{array}$ & HAp \\
\hline $\begin{array}{l}\text { Alternative } \\
\text { soaking }\end{array}$ & $\mathrm{CaCl}_{2} / \mathrm{AS}$ & $\mathrm{Na}_{2} \mathrm{HPO}_{4} / \mathrm{AS}$ & - & $\begin{array}{l}\text { Platelet } \\
\text { (Figure 3-13a) }\end{array}$ & HAp, ACP \\
\hline $\begin{array}{l}\text { Alternative } \\
\text { soaking }\end{array}$ & $\mathrm{CaCl}_{2} / \mathrm{PGL}$ & $\mathrm{Na}_{2} \mathrm{HPO}_{4} / \mathrm{PGL}$ & - & (Figure 3-12b) & HAp \\
\hline $\begin{array}{l}\text { Alternative } \\
\text { soaking }\end{array}$ & $\mathrm{CaCl}_{2} / \mathrm{PAS}$ & $\mathrm{Na}_{2} \mathrm{HPO}_{4} / \mathrm{PAS}$ & - & $\begin{array}{l}\text { Spherical } \\
\text { (Figure 3-13b) }\end{array}$ & \\
\hline $\begin{array}{l}\text { Alternative } \\
\text { soaking }\end{array}$ & $\mathrm{CaCl}_{2} / \mathrm{GL}$ & - & $\mathrm{CaHPO}_{4} / \mathrm{GL}$ & $\begin{array}{l}\text { platelet } \\
\text { (Figure 3-12b) }\end{array}$ & HAp \\
\hline $\begin{array}{l}\text { Alternative } \\
\text { soaking }\end{array}$ & $\mathrm{CaCl}_{2} / \mathrm{AS}$ & - & $\mathrm{CaHPO}_{4} / \mathrm{AS}$ & $\begin{array}{l}\text { pletlet } \\
\text { (Figure 3-13c) }\end{array}$ & HAp, ACP \\
\hline $\begin{array}{l}\text { Alternative } \\
\text { soaking }\end{array}$ & $\mathrm{CaCl}_{2} / \mathrm{PGL}$ & - & $\mathrm{CaHPO}_{4} / \mathrm{PGL}$ & $\begin{array}{l}\text { Aggregated } \\
\text { (Figure 3-12d) }\end{array}$ & HAp, ACP \\
\hline $\begin{array}{l}\text { Alternative } \\
\text { soaking }\end{array}$ & $\mathrm{CaCl}_{2} / \mathrm{PAS}$ & - & $\mathrm{CaHPO}_{4} / \mathrm{PAS}$ & $\begin{array}{l}\text { Aggregated } \\
\text { (Figure 3-13d) }\end{array}$ & ACP \\
\hline McGrath & $\mathrm{CaCl}_{2} / \mathrm{GL}$ & $\mathrm{Na}_{2} \mathrm{HPO}_{4} / \mathrm{GL}$ & $\mathrm{CaHPO}_{4} / \mathrm{GL}$ & Spherical (Figure 3-12e) & $\mathrm{ACP}$ \\
\hline McGrath & $\mathrm{CaCl}_{2} / \mathrm{AS}$ & $\mathrm{Na}_{2} \mathrm{HPO}_{4} / \mathrm{AS}$ & $\mathrm{CaHPO}_{4} / \mathrm{AS}$ & Platelet (Figure 3-13e) & HAp \\
\hline McGrath & $\mathrm{CaCl}_{2} / \mathrm{PGL}$ & $\mathrm{Na}_{2} \mathrm{HPO}_{4} / \mathrm{PGL}$ & $\mathrm{CaHPO}_{4} / \mathrm{PGL}$ & $\begin{array}{l}\text { Spherical nanoparticles } \\
\text { (Figure 3-12f) }\end{array}$ & $\mathrm{ACP}$ \\
\hline McGrath & $\mathrm{CaCl}_{2} / \mathrm{PAS}$ & $\mathrm{Na}_{2} \mathrm{HPO}_{4} / \mathrm{PAS}$ & $\mathrm{CaHPO}_{4} / \mathrm{PAS}$ & $\begin{array}{l}\text { Spherical nanoparticles } \\
\text { (Figure 3-13f) }\end{array}$ & HAP \\
\hline Kitano & - & - & $\mathrm{CaHPO}_{4} / \mathrm{GL}$ & platelet (Figure 3-12g) & HAp \\
\hline Kitano & - & - & $\mathrm{CaHPO}_{4} / \mathrm{AS}$ & - (Figure 3-13g) & - \\
\hline Kitano & - & - & $\mathrm{CaHPO}_{4} / \mathrm{PGL}$ & $\begin{array}{l}\text { Aggregated/spherical } \\
\text { (Figure 3-12h) }\end{array}$ & HAp \\
\hline Kitano & - & - & $\mathrm{CaHPO}_{4} / \mathrm{PAS}$ & platelet (Figure 3-13h) & HAp \\
\hline
\end{tabular}




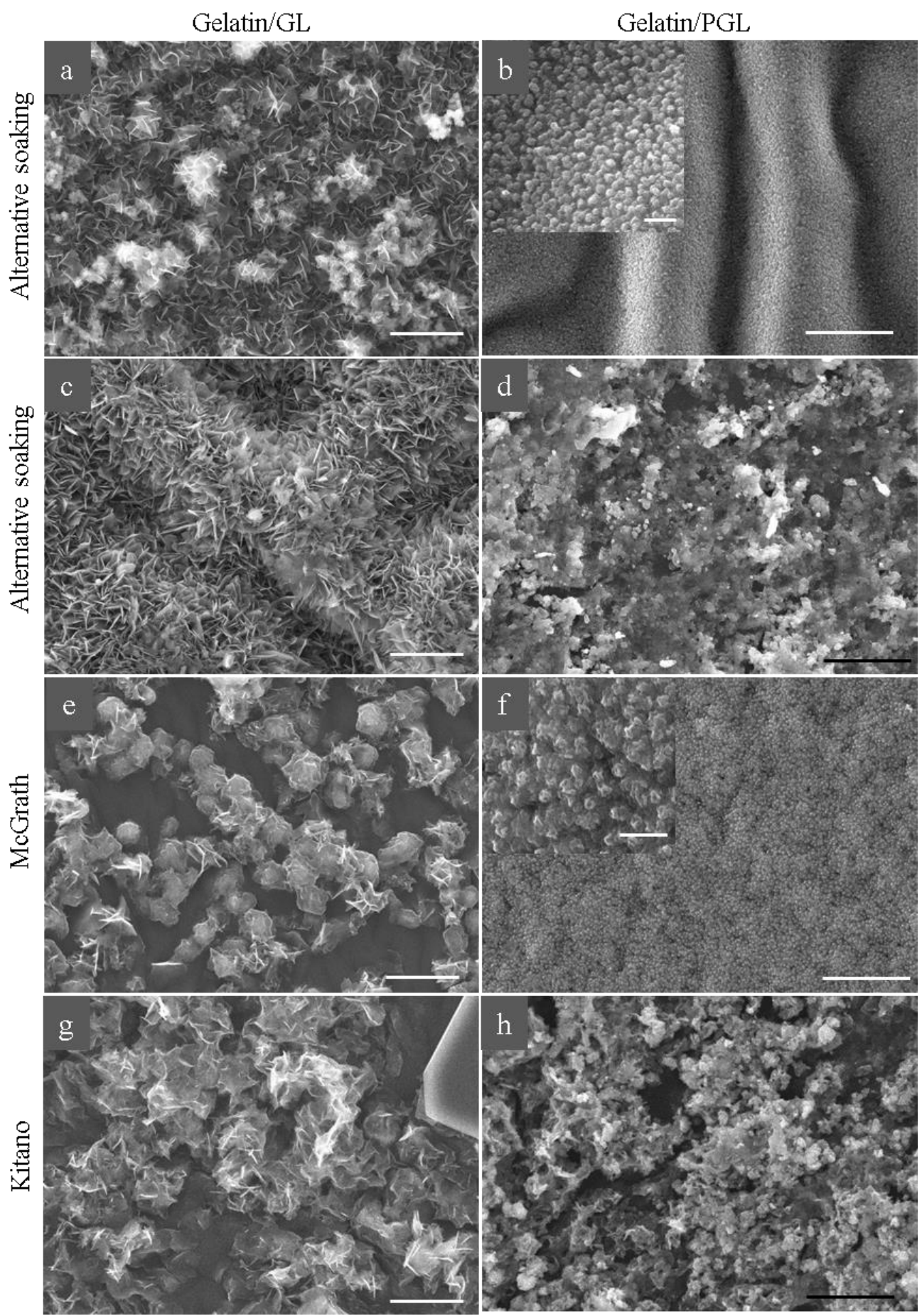

Figure 3-12: SEM images of CaP/gelatin/GL (left a, c, e and g) and CaP/gelatin/PGL (right $b, d, f$ and $h$ ) composites prepared with the four different mineralization methods from top to bottom: alternative soaking with $\mathrm{CaCl}_{2}$ and $\mathrm{Na}_{2} \mathrm{HPO}_{4}$, alternative soaking with $\mathrm{CaCl}_{2}$ and saturated $\mathrm{CaHPO}_{4}$, McGrath method, and Kitano Method. Scale bars: $10 \mu \mathrm{m}$ (insets $1 \mu \mathrm{m}$ ). 


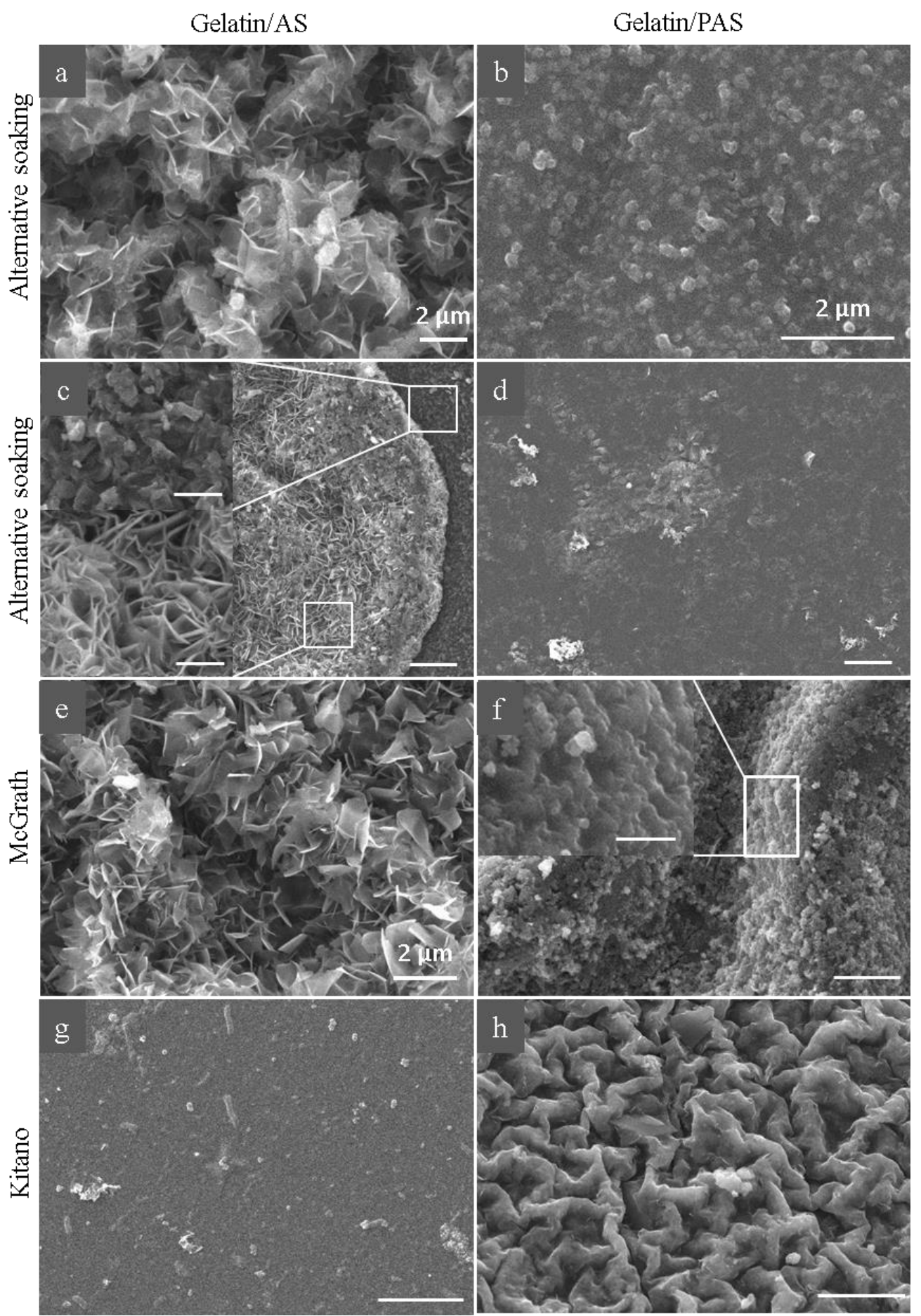

Figure 3-13: SEM images of CaP/gelatin/GL (left a, c, e and g) and CaP/gelatin/PGL (right $b, d, f$ and $h$ ) composites prepared with the four different mineralization methods from top to bottom: alternative soaking with $\mathrm{CaCl}_{2}$ and $\mathrm{Na}_{2} \mathrm{HPO}_{4}$, alternative soaking with $\mathrm{CaCl}_{2}$ and saturated $\mathrm{CaHPO}_{4}, \mathrm{McGrath}$ method, and Kitano method. Scale bars: $10 \mu \mathrm{m}$ (otherwise stated unless) (inset $1 \mu \mathrm{m}$ ). 


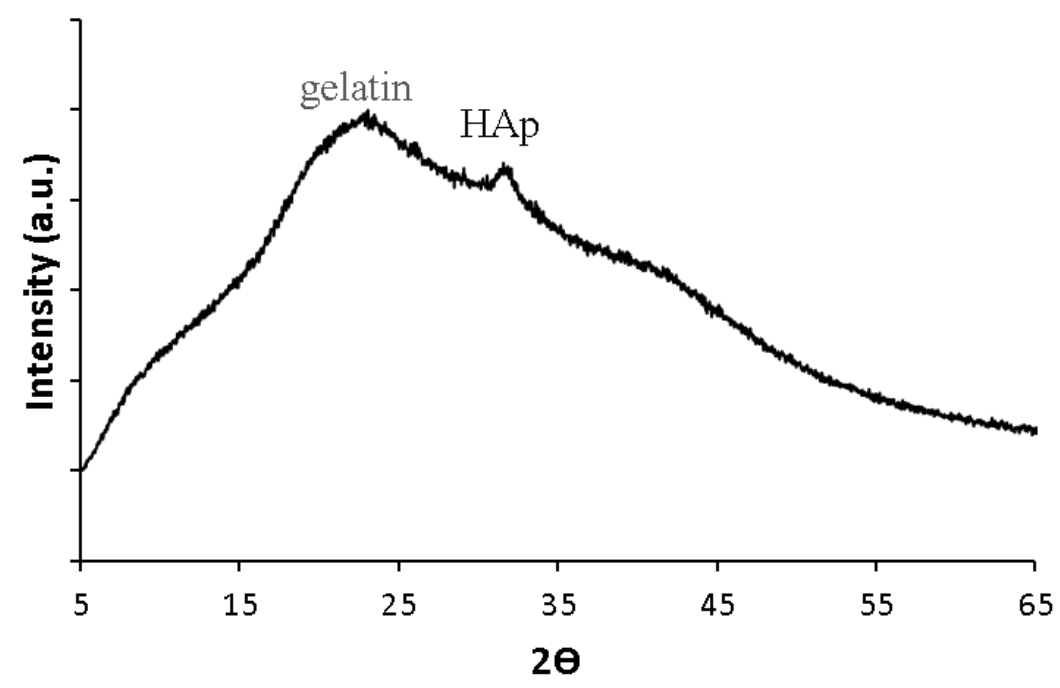

Figure 3-14: Representative XRD diffractogram of $\mathrm{CaP} /$ gelatin composites in the presence of GL, AS, PGL and PAS additives.

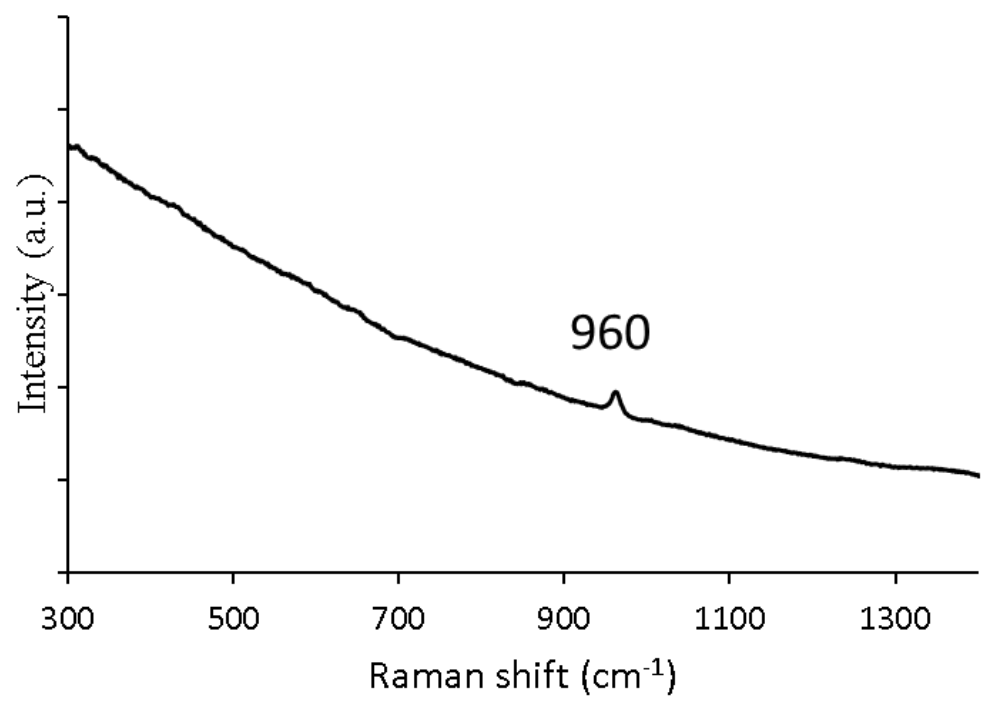

Figure 3-15: Representative micro-Raman spectrum of CaP/gelatin composites in the presence of GL, AS, PGL and PAS additives.

It was shown previously in Chapter 2 that PAA plays a significant role in controlling the morphology and mineralization process of $\mathrm{CaCO}_{3}$. In the case of CaP PAA does not appear to be a good candidate for modulating the mineralization process. In contrast monomeric inexpensive additives such as AS and GL reasonably control CaP mineralization compared to AA or PAA and can be considered to be good replacements for the more expensive PGL/PAS additives. But it should be noted that both PGL and PAS added into the gelatin matrix system, which is mimicking the real native system such as bone, leads to the 
formation of finer HAp crystals (nanoscale) compared with the monomeric additives and the chitosan hydrogel scaffold itself (see Figure 3-12b, f and Figure 3-13f). The mechanism of interaction between $\mathrm{CaP} /$ hydrogel scaffold/additive obeys the same mechanism that was described in Chapter 2 where the negatively charged acidic additives associate with the precursor ions and carry them to the chitosan and gelatin hydrogel scaffolds inhibiting or /promoting interactions during crystal nucleation and growth of $\mathrm{CaP}$.

\subsubsection{CaP/Gelatin and CaP/Gelatin /PAS}

It is noted that using the McGrath and alternative soaking with $\mathrm{CaCl}_{2}$ and $\mathrm{Na}_{2} \mathrm{HPO}_{4}$ ( 2 cycle) methods in the case of PGL and PAS results in extensive mineralization of the scaffold as shown in Figure 3-12b, $f$ and Figure 3-13f). Since the McGrath method is a facile and flexible method, the method readily allows the cycle of pre-soaking solutions increased to two or more before exposure to Kitano solution for producing extensive mineralized hydrogels. Therefore in order to achieve more nucleation events with an enhanced amount of crystal growth on hydrogel scaffold, two cycles of alternative soaking with $\mathrm{CaCl}_{2}$ and $\mathrm{Na}_{2} \mathrm{HPO}_{4}$ plus saturated $\mathrm{CaHPO}_{4}$ solution were combined. The crystal morphology was investigated with and without PAS additive $(1 \mathrm{wt} \%)$ as a representative system to explore the effect of additive and crystallization method in crystal formation. Extensive mineralization of spherical shaped $\mathrm{CaP}$ minerals ( $\sim 2 \mu \mathrm{m}$ in diameter) occurs throughout the gelatin scaffold in the absence of additive (Figure 3-16a). Each of the spherical CaP minerals is formed via aggregation of plate-shaped crystals (inset Figure 3-16a). EDS analysis shows that the $\mathrm{Ca} / \mathrm{P}$ ratio is $\sim 1.52$ which indexes to HAp or ACP formation. The fractured crosssection of the $\mathrm{CaP} /$ chitosan indicates that growth occurs predominantly on the peripheral surface with little penetration throughout the film.

Addition of PAS to the CaP/gelatin system shows an identical effect on the crystallization as that observed for the $\mathrm{CaP} /$ gelatin system, but with a reduction in the size of the mineral aggregates that are formed which fully cover the gelatin surface (Figure 3-16c). The presence of PAS in the $\mathrm{CaP} /$ gelatin system also leads to a marked increase in the $\mathrm{Ca} / \mathrm{P}$ ratio to $\sim 1.64$ which is closer to that expected for HAp crystals (1.67) indicating a reduction in the amount of ACP formation. At higher magnification it can be seen that the plate-shaped $\mathrm{CaP}$ nanoparticles are highly connected to each other which resembles the morphology reported for apatite minerals that are seen in the rostrum of whales (Figure $1 \mathrm{H}$ reference [26]). In Figure 3-17 are shown images to provide a better comparison between Figure 3- 
16c and Figure $1 \mathrm{H}$ taken from reference 26 (shown here as Figure 3-17d). The layered stacked platelet structure in rostrum is evident in Figure 3-17d where the blade-like edges of the platelets are nearly parallel (Figure 3-17d inset) [26]. Our results show that the platelet-like HAp crystals of the CaP/gelatin/PAS system (Figure 3-17a) are well-aligned in some regions and are connected together (Figure 3-17c). It is noted that the stacked layers of the HAp aggregates may be due to drying processes (Figure 3-17b). The results for the lower concentration of additive suggest that the same morphology, similar to that for $2 \mathrm{wt} \%$ PAS, results indicating the reproducibility and reliability of the modified McGrath method.

The fractured cross-section of CaP/gelatin/PAS composites shows that the growth of $\mathrm{CaP}$ occurs at the surface as well as throughout the film (Figure 3-16d). EDS mapping of a crosssection of a mineralized gelatin hydrogel scaffold in the presence of $1 \mathrm{wt} \%$ PAS in all crystallization solutions confirmed the growth of calcium phosphate throughout the gelatin film (Figure 3-16e calcium atoms are shown in green, phosphorous in blue and carbon in purple). The inset to Figure 3-16e confirms the homogeneous distribution of $\mathrm{CaP}$ particles throughout the gelatin hydrogel scaffold. The combination of the gelatin scaffold with PAS and $\mathrm{CaP}$ results in the formation of synthetic intercalated composite material when the McGrath method is used (Figure 3-16f).

Further internal structure investigation of $\mathrm{CaP} /$ gelatin/PAS using TEM shows that the CaP crystals are composed of needle-shaped nanoparticles of around 80-200 nm in length (Figure 3-18A). The corresponding selected area electron diffraction (SAED) data consist of a broad diffraction pattern indicating the diffraction pattern is completely polycrystalline (Figure 318A inset) and identified as HAp. The broad diffraction peak could be attributed to small calcium phosphate crystals forming within the gelatin pores, however HRTEM analysis reveals the existence of amorphous calcium carbonate (Figure 3-18B inset IFFT) in addition to randomly orientated polycrystalline HAp (Figure 3-18B). The distance between the lattice fringes $(0.34 \mathrm{~nm})$ confirms that the mineral is HAP, with those fringes corresponding to (002) lattice planes ((Figure 3-18B inset). 

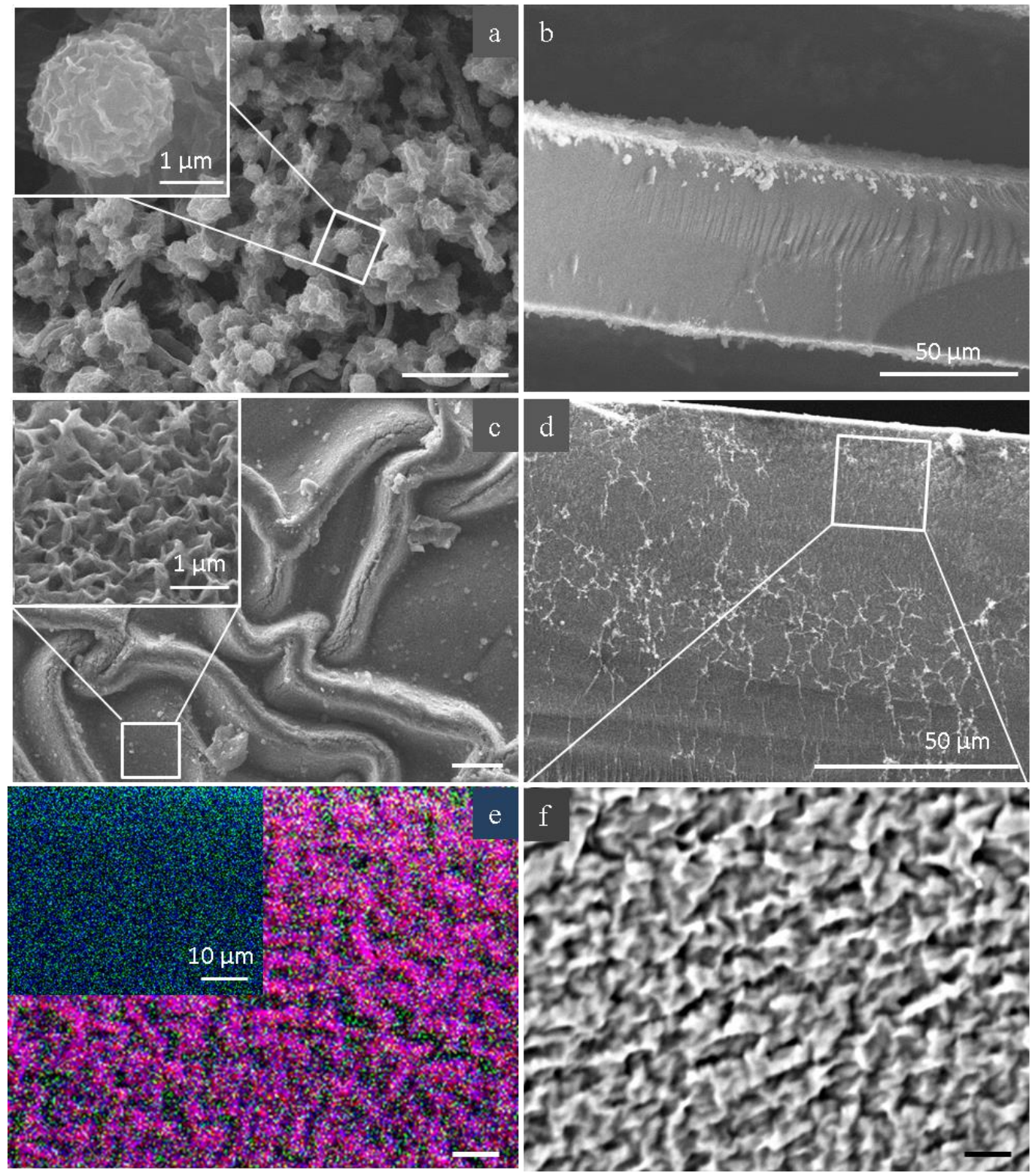

Figure 3-16: SEM images of (a) CaP/gelatin composite, and (b) the corresponding crosssection, (c) CaP/gelatin/PAS (inset shows the magnified view indicating plate-shaped HAp formation within the gelatin hydrogel scaffold), and (d) corresponding cross-section, (f) back scattered magnified view of the white rectangle shown in (d) and (e) EDS mapping of $\mathrm{CaP} /$ gelatin/PAS showing crystal growth within the film (calcium is shown in green, phosphorous in blue and carbon in purple) and inset shows just calcium (green), phosphorous (blue) ensuring the presence of $\mathrm{CaP}$ within the hydrogel. All samples were prepared via the McGrath method with two presoaking cycles. Scale bars: $10 \mu \mathrm{m}$ (unless stated otherwise). 

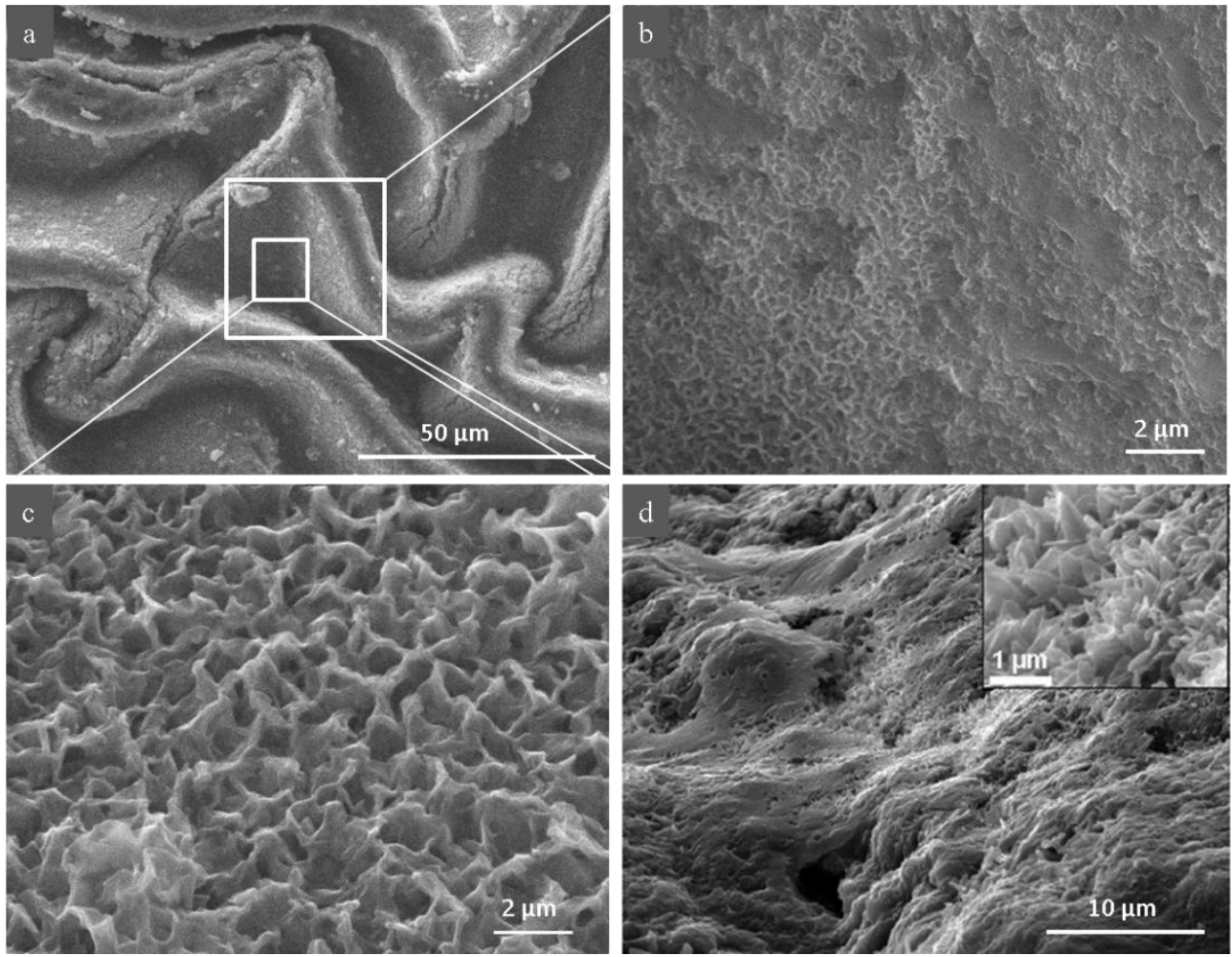

Figure 3-17: SEM images of (a) low magnification fully mineralized CaP/gelatin/PAS composite, (b) magnified view of the large white rectangle indicating the presence of platelets and aggregated HAp, (c) magnified view of the small white rectangle indicating well-organized plate-shaped HAp formation within the gelatin hydrogel scaffold, and (d) transverse section of whale rostrum showing sharp corners of the platelets-like minerals, taken from reference [26].
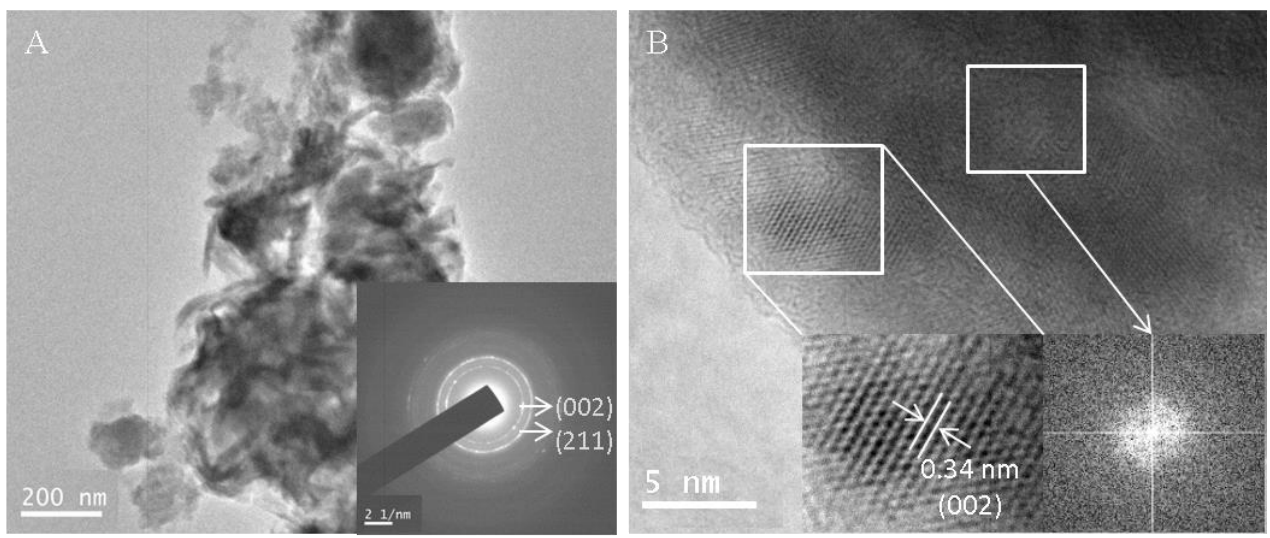

Figure 3-18: TEM micrographs of (A) CaP/gelatin/PAS compared with the corresponding SAED data (inset) showing the polycrystalline nature of the synthesized HAp and (B) corresponding HRTEM image indicating the random orientation of the polycrystalline HAp. Fast Fourier transformation (FFT) analysis of the HRTEM image reveals the presence of amorphous calcium phosphate (bottom right) and lattice planes with $0.34 \mathrm{~nm}$ fringes which correspond to the (002) lattice planes of HAp. 


\subsection{Conclusion}

Calcium phosphate growth within gelatin and chitosan hydrogel scaffolds in the absence and presence of monomers and their corresponding polymer additives, using the same crystallization methods for the $\mathrm{CaCO}_{3}$ reported in Chapter 2 was investigated. In the absence of additives the results suggest that despite no remarkable differences in the morphology of the obtained $\mathrm{CaP}$ crystals, upon switching from the carbohydrate-based chitosan to the protein-based gelatin scaffolds the size of the $\mathrm{CaP}$ minerals growth decreases irrespective of the mineralization method used. Spherical and plate-shaped morphologies composed of ACP and poorly crystalline HAp respectively were always formed. The lower peak intensities in XRD data of $\mathrm{CaP}$ can be attributed to $\mathrm{ACP}$ or the finer grain of the $\mathrm{CaP}$ crystals formation. TEM analysis confirmed the existence of both ACP and polycrystalline HAP.

When using alternative soaking with $\mathrm{CaCl}_{2}$ and $\mathrm{Na}_{2} \mathrm{HPO}_{4}$ and the McGrath method, as compared to the other two methods, extensive mineralization was induced throughout the hydrogel scaffolds rather than only partially at the peripheral surface.

Introducing monomeric acrylic acid, L-glutamic acid, L-aspartic acid and their corresponding polymers $(2 \mathrm{wt} \%)$ to $\mathrm{CaP} /$ chitosan and $\mathrm{CaP} /$ gelatin systems leads to remarkable morphology differences. In comparison with the $\mathrm{CaCO}_{3}$ system where monomeric additives showed weaker control over calcium carbonate crystal size and shape and always led to calcite formation compared to polymeric additives in both chitosan and gelatin, predictable changes to morphology and crystallinity upon addition of additives cannot be readily achieved for CaP. Furthermore, PAA which can be successfully used to control calcium carbonate mineralization is essentially ineffective for calcium phosphate.

PAS and PGL, along with their corresponding monomers have been found to exhibit similar behaviour. AS and GL are less expensive compared to PGL and PAS, and can be used as good candidates in controlling $\mathrm{CaP}$ mineralization. However using the McGrath and alternative soaking with $\mathrm{CaCl}_{2}$ and $\mathrm{Na}_{2} \mathrm{HPO}_{4}$ methods with added PGL and PAS additives in protein-based hydrogel scaffold results in the formation of assembled-nanoparticles compared with their monomeric additives. Moreover the presence of the polymeric form of an additive generally favours smaller crystal formation.

Homogeneous and extensive mineralization throughout the gelatin scaffold was achieved when the number of presoaking cycles were increased in the McGrath method to two in the 
absence and presence of $1 \mathrm{wt} \%$ PAS. TEM analysis of the internal structure of $\mathrm{CaP} /$ gelatin/PAS shows that the CaP crystals are polycrystalline and correspond to HAp. The polycrystalline HAp forms via assembly of needle-shaped nanoparticles. However $\mathrm{ACP}$ is also evident within the internal structure of the polycrystalline HAp crystals in the $\mathrm{CaP} /$ gelatin/PAS system when sample was examined by HRTEM analysis.

$\mathrm{pH}$ was also found to play a vital role in determining of which polymorph of $\mathrm{CaP}$ precipitates. Brushite forms under mild acidic conditions whereas thermodynamically stable HAp favours mild basic conditions. Depending on the conditions under which mineralization occurs either healthy or pathological mineralization occurs. The interconversion between of $\mathrm{CaP}$ polymorphs in the range of $\mathrm{pH}$ used in this study is highly likely.

In the next chapter calcium phosphate precipitation using both chitosan and gelatin hydrogel scaffolds and the McGrath method with two presoaking cycles is reported. Herein the focus is switched to understanding the role of citrate ions on calcium phosphate mineralization due to the importance of citrate on hydroxylapatite growth in bone biomineralization. 


\section{References}

1. Yao, H.-B., J. Ge, L.-B. Mao, Y.-X. Yan and S.-H. Yu, 25th Anniversary Article: Artificial Carbonate Nanocrystals and Layered Structural Nanocomposites Inspired by Nacre: Synthesis, Fabrication and Applications. Advanced Materials, 2014. 26(1): p. 163-188.

2. He, C., G. Xiao, X. Jin, C. Sun and P.X. Ma, Electrodeposition on nanofibrous polymer scaffolds: Rapid mineralization, tunable calcium phosphate composition and topography. Advanced Functional Materials, 2010. 20(20): p. 3568-3576.

3. Koev, S.T., P.H. Dykstra, X. Luo, G.W. Rubloff, W.E. Bentley, G.F. Payne and R. Ghodssi, Chitosan: an integrative biomaterial for lab-on-a-chip devices. Lab on a Chip, 2010. 10(22): p. 3026-3042.

4. Smith, L.A., X. Liu and P.X. Ma, Tissue Engineering with Nano-Fibrous Scaffolds. Soft Matter, 2008. 4(11): p. 2144-2149.

5. Addadi, L., A. Gal, D. Faivre, A. Scheffel and S. Weiner, Control of Biogenic Nanocrystal Formation in Biomineralization. Israel Journal of Chemistry, 2015: p. n/a-n/a.

6. Mann, S., Biomineralization: Principles and Concepts in Bioinorganic Materials Chemistry. 2001: Oxford University Press.

7. Wang, R. and H.S. Gupta, Deformation and Fracture Mechanisms of Bone and Nacre. Annual Review of Materials Research, 2011. 41(1): p. 41-73.

8. Beniash, E., Biominerals-hierarchical nanocomposites: the example of bone. Wiley Interdisciplinary Reviews: Nanomedicine and Nanobiotechnology, 2011. 3(1): p. 47-69.

9. Weiner, S. and H.D. Wagner, THE MATERIAL BONE: Structure-Mechanical Function Relations. Annual Review of Materials Science, 1998. 28(1): p. 271-298.

10. Weiner, S. and L. Addadi, Design strategies in mineralized biological materials. Journal of Materials Chemistry, 1997. 7(5): p. 689-702.

11. Cazalbou, S., C. Combes, D. Eichert and C. Rey, Adaptative physico-chemistry of bio-related calcium phosphates. Journal of Materials Chemistry, 2004. 14(14): p. 2148-2153.

12. Mahamid, J., A. Sharir, L. Addadi and S. Weiner, Amorphous calcium phosphate is a major component of the forming fin bones of zebrafish: Indications for an amorphous precursor phase. Proceedings of the National Academy of Sciences, 2008. 105(35): p. 12748-12753.

13. Stanishevsky, A., S. Chowdhury, P. Chinoda and V. Thomas, Hydroxyapatite nanoparticle loaded collagen fiber composites: Microarchitecture and nanoindentation study. Journal of Biomedical Materials Research Part A, 2008. 86A(4): p. 873-882.

14. Olszta, M.J., X. Cheng, S.S. Jee, R. Kumar, Y.-Y. Kim, M.J. Kaufman, E.P. Douglas and L.B. Gower, Bone structure and formation: A new perspective. Materials Science and Engineering: R: Reports, 2007. 58(3-5): p. 77-116.

15. Wang, L. and G.H. Nancollas, Pathways to biomineralization and biodemineralization of calcium phosphates: the thermodynamic and kinetic controls. Dalton Transactions, 2009(15): p. 2665-2672. 
16. Wang, Y., S. Von Euw, F.M. Fernandes, S. Cassaignon, M. Selmane, G. Laurent, G. PehauArnaudet, C. Coelho, L. Bonhomme-Coury, M.-M. Giraud-Guille, F. Babonneau, T. Azaïs, and N. Nassif, Water-mediated structuring of bone apatite. Nat Mater, 2013. 12(12): p. 1144-1153.

17. Veis, A., Mineral-matrix interactions in bone and dentin. Journal of Bone and Mineral Research, 1993. 8(S2): p. S493-S497.

18. Weiner, S. and P. Zaslansky, Structure-Mechanical Function Relations in Bones and Teeth, in Learning from Nature How to Design New Implantable Biomaterialsis: From Biomineralization Fundamentals to Biomimetic Materials and Processing Routes, R.L. Reis and S. Weiner, Editors. 2005, Springer Netherlands. p. 3-13.

19. Cantaert, B., E. Beniash and F.C. Meldrum, The role of poly(aspartic acid) in the precipitation of calcium phosphate in confinement. Journal of Materials Chemistry B, 2013. 1(48): p. 6586-6595.

20. Traub, W., T. Arad and S. Weiner, Three-dimensional ordered distribution of crystals in turkey tendon collagen fibers. Proceedings of the National Academy of Sciences, 1989. 86(24): p. 98229826.

21. Deshpande, A.S., P.-A. Fang, J.P. Simmer, H.C. Margolis and E. Beniash, Amelogenin-Collagen Interactions Regulate Calcium Phosphate Mineralization in Vitro. Journal of Biological Chemistry, 2010. 285(25): p. 19277-19287.

22. Ozawa, H., K. Hoshi and N. Amizuka, Current Concepts of Bone Biomineralization. Journal of Oral Biosciences, 2008. 50(1): p. 1-14.

23. Colfen, H., Biomineralization: A crystal-clear view. Nat Mater, 2010. 9(12): p. 960-961.

24. Lowenstam, H.A.W., S, on biomineralization. 1989, Oxford University Press.

25. Nudelman, F., K. Pieterse, A. George, P.H.H. Bomans, H. Friedrich, L.J. Brylka, P.A.J. Hilbers, G. de With and N.A.J.M. Sommerdijk, The role of collagen in bone apatite formation in the presence of hydroxyapatite nucleation inhibitors. Nat Mater, 2010. 9(12): p. 1004-1009.

26. Li, Z., M. Ai-Jawad, S. Siddiqui and J.D. Pasteris, A mineralogical study in contrasts: highly mineralized whale rostrum and human enamel. Scientific Reports, 2015. 5: p. 16511.

27. Tabata, M., T. Shimoda, K. Sugihara, D. Ogomi, T. Serizawa and M. Akashi, Osteoconductive and hemostatic properties of apatite formed on/in agarose gel as a bone-grafting material. Journal of Biomedical Materials Research Part B: Applied Biomaterials, 2003. 67B(2): p. 680-688.

28. Granja, P.L., C.C. Ribeiro, B. De Jéso, C. Baquey and M.A. Barbosa, Mineralization of regenerated cellulose hydrogels. Journal of Materials Science: Materials in Medicine, 2001. 12(9): p. 785-791.

29. Caridade, S.G., E.G. Merino, N.M. Alves and J.F. Mano, Bioactivity and Viscoelastic Characterization of Chitosan/Bioglass ${ }^{\circledR}$ Composite Membranes. Macromolecular Bioscience, 2012. 12(8): p. 1106-1113.

30. Ehrlich, H., B. Krajewska, T. Hanke, R. Born, S. Heinemann, C. Knieb and H. Worch, Chitosan membrane as a template for hydroxyapatite crystal growth in a model dual membrane diffusion system. Journal of Membrane Science, 2006. 273(1-2): p. 124-128.

31. Kumar, R., K.H. Prakash, P. Cheang, L. Gower and K.A. Khor, Chitosan-mediated crystallization and assembly of hydroxyapatite nanoparticles into hybrid nanostructured films. Journal of the Royal Society Interface, 2008. 5(21): p. 427-439. 
32. Bigi, A., E. Boanini, S. Panzavolta and N. Roveri, Biomimetic Growth of Hydroxyapatite on Gelatin Films Doped with Sodium Polyacrylate. Biomacromolecules, 2000. 1(4): p. 752-756.

33. Deshpande, A.S., P.-A. Fang, X. Zhang, T. Jayaraman, C. Sfeir and E. Beniash, Primary Structure and Phosphorylation of Dentin Matrix Protein 1 (DMP1) and Dentin Phosphophoryn (DPP) Uniquely Determine Their Role in Biomineralization. Biomacromolecules, 2011. 12(8): p. 2933-2945.

34. Palmer, L.C., C.J. Newcomb, S.R. Kaltz, E.D. Spoerke and S.I. Stupp, Biomimetic Systems for Hydroxyapatite Mineralization Inspired By Bone and Enamel. Chemical Reviews, 2008. 108(11): p. 4754-4783.

35. Olszta, M.J., E.P. Douglas and L.B. Gower, Scanning Electron Microscopic Analysis of the Mineralization of Type I Collagen via a Polymer-Induced Liquid-Precursor (PILP) Process. Calcified Tissue International, 2003. 72(5): p. 583-591.

36. Ndao, M., J.T. Ash, N.F. Breen, G. Goobes, P.S. Stayton and G.P. Drobny, $A{ }^{13} C\left\{{ }^{31} P\right\}$ REDOR NMR Investigation of the Role of Glutamic Acid Residues in Statherin- Hydroxyapatite Recognition. Langmuir, 2009. 25(20): p. 12136-12143.

37. Koutsopoulos, S. and E. Dalas, The effect of acidic amino acids on hydroxyapatite crystallization. Journal of Crystal Growth, 2000. 217(4): p. 410-415.

38. Wang, L. and G.H. Nancollas, Calcium Orthophosphates: Crystallization and Dissolution. Chemical Reviews, 2008. 108(11): p. 4628-4669.

39. Reis, R.L. and S. Weiner, Learning from Nature How to Design New Implantable Biomaterials: From Biomineralization Fundamentals to Biomimetic Materials and Processing Routes: Proceedings of the NATO Advanced Study Institute, held in Alvor, Algarve, Portugal, 13-24 October 2003. 2005: Springer Netherlands.

40. Grover, L.M., J.C. Knowles, G.J.P. Fleming and J.E. Barralet, In vitro ageing of brushite calcium phosphate cement. Biomaterials, 2003. 24(23): p. 4133-4141.

41. Pasteris, J.D., B. Wopenka, J.J. Freeman, K. Rogers, E. Valsami-Jones, J.A.M. van der Houwen and M.J. Silva, Lack of $\mathrm{OH}$ in nanocrystalline apatite as a function of degree of atomic order: implications for bone and biomaterials. Biomaterials, 2004. 25(2): p. 229-238.

42. Koutsopoulos, S., Synthesis and characterization of hydroxyapatite crystals: A review study on the analytical methods. Journal of Biomedical Materials Research, 2002. 62(4): p. 600-612.

43. Rokidi, S., C. Combes and P.G. Koutsoukos, The Calcium Phosphate-Calcium Carbonate System: Growth of Octacalcium Phosphate on Calcium Carbonates. Crystal Growth \& Design, 2011. 11(5): p. 1683-1688.

44. Lonsdale, K., Epitaxy as a Growth Factor in Urinary Calculi and Gallstones. Nature, 1968. 217(5123): p. 56-58. 


\section{Chapter 4}

\section{Citrate controlled hydroxylapatite formation}

\subsection{Introduction}

Hydroxylapatite (HAp) crystallization is important in healthy and pathological mineralization and has been the subject of extensive research in the field of biomineralization. Bone is one of the most well-studied biominerals because of its ready accessibility and its importance in human health. Bone is also center of attention due to its excellent mechanical properties with different functions on the macro, micro and nanoscopic levels. Advancement in our knowledge and understanding of bone crystallization is required in order to successfully produce synthetic bone-like materials for medical treatments as well as for designing new advanced functional materials.

Bone is a very complex material with a large number of hierarchical levels. On the molecular level it mainly comprises organic collagen, inorganic HAp and water. The mineral phase, HAp, associated with the collagen fibrils provides unique mechanical properties to the calcified tissue. The integration of organic and inorganic materials in bone, where the HAp nanocrystals, having an approximate length of $30-50 \mathrm{~nm}$, width $15-30 \mathrm{~nm}$ and thickness $\sim 2-$ $5 \mathrm{~nm}$, run in parallel with, and are imbedded into the organic collagen matrix, in the presence of non-collagenous molecules, ensure that bone is an incredible load-bearing material. The size and the morphology of bone HAp nanoparticles have been elucidated using scanning and transmission electron microscopy examination (SEM and TEM). Analysis of the TEM data revealed the needle, or plate-like shapes of HAp nanocrystals [1].

XRD offers clues for understanding the amorphous or crystalline composition of bone. XRD data reveals the poorly crystalline nature of bone minerals. Despite HAp having a hexagonal unit-cell symmetry, XRD data do not reflect the perfect hexagonal symmetry but rather a highly disordered structure [2-4]. Additional investigation to find a reason for this poor crystallinity of bone was performed using FTIR spectroscopy. FTIR studies showed that the hydroxyl ions are substituted by carbonate ions in the HAp structure $[5,6]$. Such a model is in good agreement with the XRD data and for a while the substitution of carbonate ions was taken to account for bone's mineral structure. However, this new view of the structure of 
bone was quickly rejected because the experimentally determined $\mathrm{Ca} / \mathrm{P}$ ratios found in bone are in contradiction with the HAp structure even when the substitution is considered.

Solid-state nuclear magnetic resonance (SS-NMR) is a feasible technique and well placed to allow examination of the molecular features of bone. Fortunately in bone, the NMR active isotope ${ }^{13} \mathrm{C}$ is present within the organic scaffold controlling and aiding nucleation and growth of the inorganic mineral phase which contains the NMR active ${ }^{31} \mathrm{P}$. The mineral and organic components can be investigated separately only by altering which nucleus is observed. Molecular level chemical information can be directly acquired from the final solid products with very little sample preparation compared to techniques such as TEM. In particular this technique is able to uncover the buried interface of the collagen and HAp mineral phase using ${ }^{1} \mathrm{H}-{ }^{31} \mathrm{P}$ heteronuclear correlation (HetCor) spectroscopy [7-11].

Recently, the role of small organic molecules such as citrate ions have been emphasized, in addition to the role of macromolecules (as discussed in Chapter 3 ) in bone biomineralization through quantitative advanced SS-NMR analysis. The presence of citrate in bone was confirmed several decades ago at a level of 2-5 wt $\%$ but its location within the bone structure at that time was unknown. Surprisingly since the in-vivo and in-vitro studies in 1975 until recent years the role and place of citrate within the structure of bone has not featured in the literature. A recent study using advanced multi-NMR spectroscopy revealed the adsorption of citrate on the HAp crystals. It was hypothesized that the citrate regulates the mineralization process of the HAp by limiting further growth of HAp crystals (2-3 nm in thickness). Essentially the way that the citrate molecules, with their three carboxylic acid groups incorporate into the apatite crystals is different from very small ions like fluoride or hydroxide. Citrate anions bind to the surface of the apatite crystals and cover approximately $1 / 6$ of the available apatite surface area in bone. Therefore it seems as though the carboxylate groups of the citrate anions have a crucial role in bone mineral nucleation and growth, particularly in order to stabilize the nanoscopic sized apatite crystals. These new insights into the citrate-apatite binding allow greater understanding to be gained particularly pertaining to some intriguing unresolved questions such as: why the plate-like apatite crystal morphology is formed in bone whereas the shape of tooth enamel is rod-like [12].

There is however ongoing debate about the role of citrate anions in bone and pathological biomineralization [13]. Through use of the SS-NMR dipolar dephasing technique healthy bone and pathological urinary stones were recently investigated in order to determine 
whether citrate is present or not in the different samples. The three expected signals for citrate in ${ }^{13} \mathrm{C}$-NMR arise from the carboxylate groups ( $\left.180 \mathrm{ppm}\right)$; quaternary carbon atom ( 76 ppm), and the methylene carbons ( 46 ppm). The dipolar dephasing technique enables the quaternary carbon of citrate to be distinguished from those carbon atoms directly bound to hydrogen. It was found that citrate ions exist in healthy bone and also some unfavourable calcified tissues. Beside its ability to modify the $\mathrm{pH}$, which is a very important factor in deposition of apatite, it seems citrate itself has a pivotal role in biomineralization mechanisms in health and disease.

In the new model of the organic-inorganic structure of bone, the active role of citrate ions in bone biomineralization is indicated. This has resulted in citrate ions being introduced into biomimetic syntheses of bone-like materials. Citrate-apatite [14, 15], citrate-functionalized carbonate-apatite [16] powders and self-assembled pluronic/HAp/citrate inorganic/organic composites $[14,17,18]$ are a few examples of recent successfully synthesized bone-related materials inspired using the most recent view of the structure of bone.

In this Chapter biomimetic synthesis of bone-like biocomposites in the presence of citrate ions, as inspired by citrate-apatite-collagen in vivo is presented. We consider gelatin vs. chitosan as the insoluble hydrogel matrix providing the HAp crystal growth scaffold environment. Citrate ions were introduced $(0,1,2$ and $2.5 \mathrm{wt} \%$ with respect to the chitosan and gelatin mass) in order to mimic and control the growth of HAp crystals within the gelatin or chitosan templates. Gelatin was used to directly mimic the collagen scaffold. It is a partial derivative of collagen but is significantly cheaper, and is widely used for collagen bone grafts and as a scaffold for tissue engineering [19, 20]. Chitosan was also used as a comparator scaffold. 


\subsection{Material and methods}

Chitosan and gelatin films were formed as described in Chapter 2.

\subsubsection{HAp-citrate formation on chitosan and gelatin hydrogels}

HAp composites were prepared via the McGrath method as follows: the hydrogel templates were twice presoaked with first $30 \mathrm{~mL}$ of $\mathrm{CaCl}_{2}(10 \mathrm{mM})$ and then $30 \mathrm{~mL}$ of $\mathrm{Na}_{2} \mathrm{HPO}_{4}(6$ $\mathrm{mM}$ ) solutions prior to addition of $\mathrm{CO}_{2}$ bubbled saturated $\mathrm{CaHPO}_{4}$ solution. Saturated calcium phosphate was achieved by mixing $500 \mathrm{~mL}$ of $\mathrm{CaCl}_{2}(20 \mathrm{mM})$ with $500 \mathrm{~mL}$ of $\mathrm{Na}_{2} \mathrm{HPO}_{4}(12 \mathrm{mM})$. The solution was stirred and the $\mathrm{pH}$ was checked and adjusted to be in the range of 7.4-8 using $\mathrm{NaOH}(1 \mathrm{M})$ and $\mathrm{HCl}(1 \mathrm{M})$. The solution was bubbled with $\mathrm{CO}_{2}$ gas at approximately $3 \mathrm{~L} \mathrm{~h}^{-1}$ for about $6 \mathrm{~h}$ then filtered. The filtrate was bubbled with $\mathrm{CO}_{2}$ for another $30 \mathrm{~min}$ at $3 \mathrm{~L} \mathrm{~h}^{-1}$ then $30 \mathrm{~mL}$ of filtered solution was introduced to the wet hydrogel films. The crystallization solutions contained either no additives or 1, 2 and $2.5 \mathrm{wt}$. $\%$ sodium citrate with reference to the mass of chitosan $(0.004,0.008$ and $0.01 \mathrm{~g})$ or gelatin $(0.01,0.02$ and $0.025 \mathrm{~g})$ templates in all crystallization solutions.

After adding the final crystallization solution the hydrogel templates were left to mineralize for up to 10 days at room temperature, after which the films were gently washed and the excess solution removed. The films were then dried in a covered container for two days at room temperature.

Pure HAp was precipitated by combining $500 \mathrm{~mL}$ of $\mathrm{CaCl}_{2}(20 \mathrm{mM})$ with $500 \mathrm{~mL}$ of $\mathrm{Na}_{2} \mathrm{HPO}_{4}(12 \mathrm{mM})$ and adjusting the $\mathrm{pH}$ to 7.4 using $\mathrm{NaOH}$ and $\mathrm{HCl}(1 \mathrm{M})$. The mixture was gently stirred for $4 \mathrm{~h}$, centrifuged and the precipitate was air dried before analysis. HApcitrate was formed by addition of $0.05 \mathrm{~g}$ sodium citrate into $150 \mathrm{~mL}$ of each of the solutions of $\mathrm{CaCl}_{2}$ and $\mathrm{Na}_{2} \mathrm{HPO}_{4}$, the solutions were mixed and stirred for $\sim 4 \mathrm{~h}$, centrifuged and the precipitate was then air dried.

\subsubsection{Characterization techniques}

All prepared samples were examined using the same techniques as described in Chapter 2 including XRD, SEM and TEM. In addition to the mentioned techniques solid-state NMR was used. 


\subsubsection{Solid-State NMR technique}

In solid-state NMR spectroscopy a powder sample is used, which consists of many crystallites with random orientations. The nuclear spin interactions are anisotropic and dependent on the crystallite orientations. Anisotropic interactions between the nuclei lead to line broadening yielding a powder pattern. Interpretation of solid state NMR data may therefore provide useful information about the chemistry of a system. However, due to inequivalent nuclear sites within a sample the resulting spectrum may include overlapping peaks making interpretation difficult. Several techniques have been developed to mitigate this problem and therefore deliver more direct information about the systems being investigated [21].

\subsection{Cross-polarization}

Cross-polarization $(\mathrm{CP})$ can significantly increase the sensitivity of solid-state NMR for solids containing protons. Cross-polarization pulse sequences are used to transfer magnetic polarization from an abundant proton source such as ${ }^{1} \mathrm{H}$ to a dilute nucleus such as ${ }^{13} \mathrm{C}$ during a contact period which causes an enhancement of the NMR signal from the dilute nucleus. $\mathrm{CP}$ is normally used to aid in the observation of dilute spins [22].

\subsection{Magic-angle spinning}

Magic-angle spinning (MAS) is widely used in solid-state NMR experiments. It aids in removing both the effects of chemical shift anisotropy and heteronuclear dipolar-coupling. It is also utilized to narrow lines from quadrupolar nuclei and can remove the effects of homonuclear dipolar coupling from NMR spectra. The latter application requires very high spinning speeds however, and so is not widely available. Anisotropic interactions between nuclei, which are usually averaged by Brownian motion in liquid samples, lead to remarkable line broadening in solid state NMR, but can be averaged to zero by spinning the sample very rapidly at the magic angle $\left(54.74^{\circ}\right.$ with respect to the direction of the magnetic field) which results in liquid-like spectra with narrow line widths [22].

\subsection{Cross-polarization magic angle spinning}

The combination of cross-polarization and magic-angle spinning is called cross-polarization magic angle spinning (CPMAS). This technique enables very high resolution solid-state NMR data to be obtained. Through the CPMAS technique high sensitivity is achieved from the $\mathrm{CP}$ and high chemical shift resolution is provided from the MAS. In addition more scans can be collected per unit time because the scan repetition rate depends on the shorter 
relaxation time of the protons rather than the longer relaxation time of the spin $I=1 / 2$ nuclide [23].

\subsection{Dipolar dephasing method}

Dipolar dephasing has traditionally been used as a standard spectral assignment tool in solidstate NMR in order to monitor the ${ }^{13} \mathrm{C}-{ }^{1} \mathrm{H}$ dipolar-dipolar interactions [24]. The technique allows the selective differentiation of non-protonated carbon signals from protonated carbon atoms. The strength of ${ }^{13} \mathrm{C}-{ }^{1} \mathrm{H}$ dipole-dipole interactions is a function of the internuclear distances and molecular motion of the ${ }^{13} \mathrm{C}-{ }^{1} \mathrm{H}$ and drops rapidly when the distances between the carbons and hydrogen increase [25]. As such dipolar dephasing experiments can be used to differentiate between protonated carbon with strong dipolar coupling to protons $(\mathrm{CH}$ and $\mathrm{CH}_{2}$ ) and nonprotonated carbon atoms with a weak dipolar coupling to protons. $\mathrm{CH}_{3}$ signals are exceptional and behave like nonprotonated carbon atoms and never disappear entirely due to the unique atomic motional properties of the methyl group. Dipolar dephasing experiments are normally carried out in two parts: 1) a reference spectrum is acquired using standard CPMAS without applying dipolar dephasing; 2) before the CPMAS, with dipolar dephasing signal acquisition, the high power ${ }^{1} \mathrm{H}$ decoupler is briefly turned off for a period of time. During this delay period the ${ }^{13} \mathrm{C}-{ }^{1} \mathrm{H}$ dipolar-dipolar interactions are averaged just by MAS. Then the experiment is performed and the weakly dipolar dephasing nonprotonated carbon atoms and methyl carbons signals appear [13].

The NMR experiments were performed at the University of Queensland Centre for Advanced Imaging using a Bruker Avance III spectrometer at operating frequencies of 300.13 MHz for ${ }^{1} \mathrm{H}, 75 \mathrm{MHz}$ for ${ }^{13} \mathrm{C}$, and $57 \mathrm{MHz}$ for ${ }^{31} \mathrm{P}$. The magic-angle spinning probe spinning frequency was $5 \mathrm{kHz}$. The $90^{\circ}$ pulse lengths were $4.5 \mu \mathrm{s}$ for both ${ }^{13} \mathrm{C}$ and ${ }^{31} \mathrm{P}$ and $2.5 \mu$ s for ${ }^{1} \mathrm{H}$. All samples were first ground using liquid nitrogen and the powder was then packed into a $4 \mathrm{~mm}$ zirconia rotor. All samples were first characterized using the standard cross-polarization magic angle spinning (CPMAS) technique where the cross polarization contact time was 1-4 ms and the recycle delay was $3 \mathrm{~s}$. To select for the different signals of carbons with weak ${ }^{13} \mathrm{C}-{ }^{1} \mathrm{H}$ dipolar couplings, spectra were also acquired with an additional $80 \mu$ s of gated decoupling before signal detection. High-power decoupling at a ${ }^{1} \mathrm{H}$ field strength of $100 \mathrm{kHz}$ using the tppm15 (two-pulse phase modulated) scheme was used. The repetition time was $3 \mathrm{~s}$ in all ${ }^{13} \mathrm{C}$ and ${ }^{1} \mathrm{H}$ experiments and for ${ }^{31} \mathrm{P}$ it was $30 \mathrm{~s}$. 


\subsection{Results and Discussion}

The properties of synthetic bone-like materials depend on the size of the mineral crystals and the interaction of the minerals and the organic matrix at the interface. The integration of mineral into the organic matrix at the molecular level and its subsequent growth with extreme precision is achieved by the assistance of multiple organic additives. It is strongly believed that citrate ions as a small organic molecule can control the morphology and size of calcium phosphate precipitation in bone [26].

The work presented herein is a detailed study of the effect of citrate ions on HAp/chitosan and HAp/gelatin composite formation. The main goal of this investigation is understanding the role of, and incorporation of, citrate ions on HAp nucleation and growth within chitosan or gelatin hydrogel templates in order to fabricate HAp/chitosan/citrate and HAp/gelatin/citrate composites with structure similarity to bone. XRD, SSNMR, SEM and TEM were used to characterize the materials. HAp and HAp/citrate powders, in addition to the synthesized composites generated in vitro via the McGrath process, were synthesized and characterized for comparison. Information was obtained about the size and shape of the crystals formed, the presence of any citrate ions in the final structure and, the crystallinity of the final material.

\subsubsection{XRD analysis of prepared composites}

The mineral phase of the prepared composite samples was probed using XRD (Figure 4-1). In the case of $\mathrm{CaP}$ formed directly from aqueous salt solution the most intense peaks at $2 \theta$ $=26.17^{\circ}$ (correspond to the (002) planes) and $2 \theta=31.97^{\circ}$ (the (121) planes) indicate the formation of HAp crystals (Figure 4-1h). The introduction of citrate ions affects precipitation of the HAp from solution, this is evident by the observed line broadening of all of the peaks (Figure 4-1g). Such broadening is typical of a decreasing particle size indicating that the presence of citrate ions has inhibited the growth of the HAp (see confirmation from TEM images Figure 4-13A).

Consider now the $\mathrm{CaP} /$ chitosan composite system, with no added citrate ions. The XRD pattern shows the main peak representative of HAp crystals (Figure 4-1e). In the presence of $2.5 \mathrm{wt} \%$ sodium citrate, the observed peaks once again become broader, indicating the inhibitory effect of the citrate ions with respect to growth of HAp yeilds smaller crystals (Figure 4-1f). The peaks at $2 \theta=10^{\circ}, 19^{\circ}$ and $21^{\circ}$ are attributed to microcrystalline regions 
within the chitosan template. The chitosan hydrogel XRD diffractogram is shown for straightforward comparison (Figure 4-1d). (XRD peaks for $1 \mathrm{wt} \%$ citrate and $2 \mathrm{wt} \%$ citrate are not shown here as the peaks were similar to when $2.5 \mathrm{wt} \%$ was present).

For the gelatin mineralized hydrogel the major HAp peaks are obscured by the gelatin background scattering indicating either the low level of mineralization and/or crystallinity in the final composite (Figure 4-1a, b and c). The most intense peak at $31.97^{\circ}$ corresponding to the (121) planes of HAp is observed in the absence and presence of citrate ions (Figure $4-1 b$ and c). Significant broadening of the peaks again indicates that the mineral within the gelatin scaffold consists of fine-grained crystals. The very broad peak at $\sim 2 \theta=20$ in the mineralized gelatin hydrogel diffractograms corresponds to the amorphous nature of the gelatin hydrogel film itself (Figure 4-1a). 


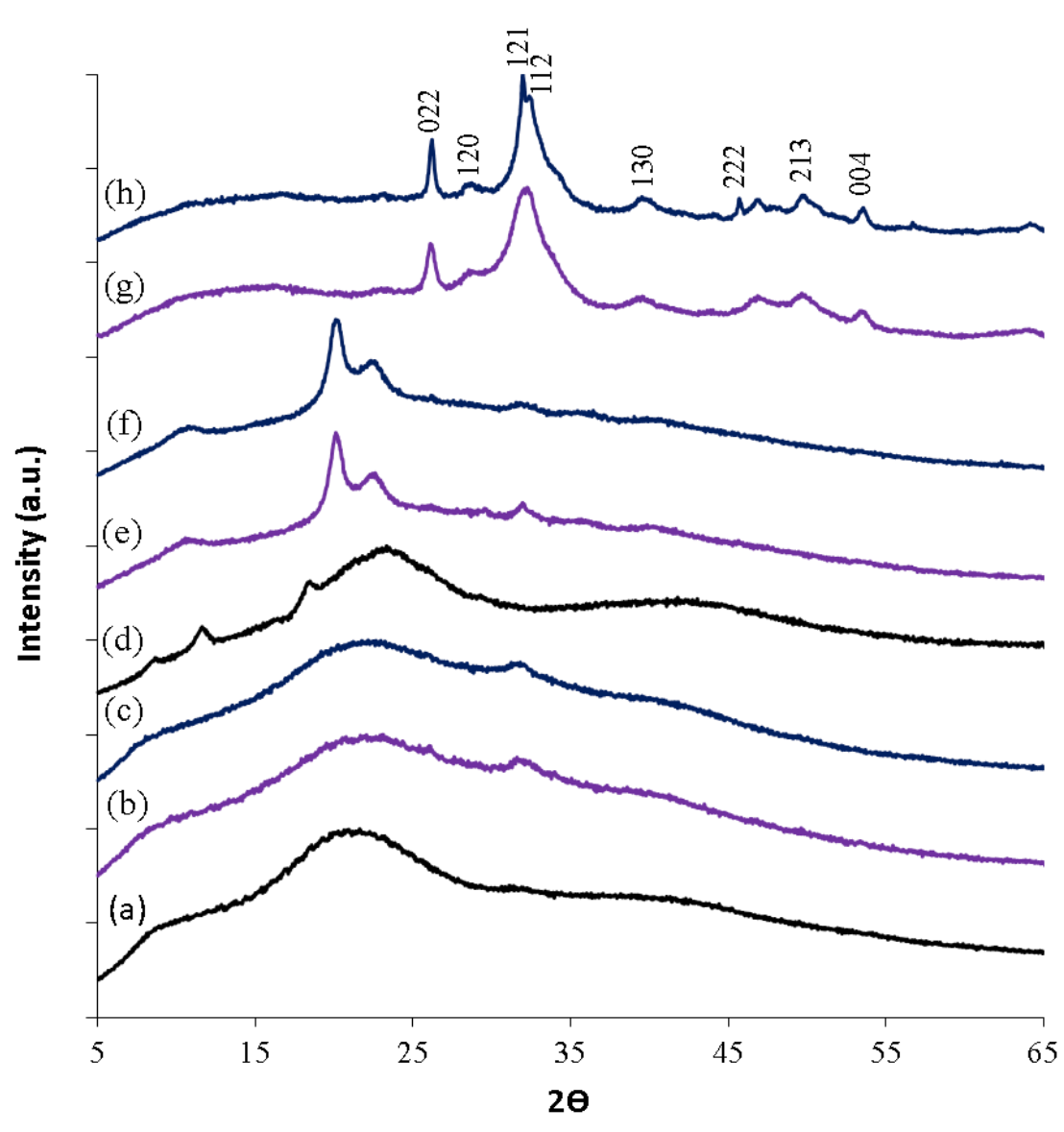

Figure 4-1: XRD diffractgrams of: (a) untreated cross-linked gelatin hydrogel, (b) CaP/gelatin, (c) CaP/gelatin/citrate, (d) untreated chitosan hydrogel, (e) $\mathrm{CaP} /$ chitosan, (f) $\mathrm{CaP} /$ chitosan/citrate (g) $\mathrm{CaP} /$ citrate precipitate obtained from bulk solution and (h) $\mathrm{CaP}$ (directly obtained from solution precipitation) which correspond to HAp crystals. (The concentration of sodium citrate reported here is $2.5 \mathrm{wt} \%)$. 


\subsubsection{Solid-state NMR (SS-NMR) characterization}

Both the gelatin and chitosan substrates and the phosphate minerals are NMR active. Based on the XRD results described above, it is evident that the HAp/citrate crystals, $\mathrm{HAp} /$ gelatin/citrate and HAp/chitosan/citrate nanocomposites were poorly crystalline HAp. SS-NMR spectroscopy is one of the best techniques to investigate disordered materials and gain atomic-level insights into the structure of samples [10]. Herein it has been applied in order to determine how citrate ions integrate with HAp crystals.

In Figure 4-2 are compared the ${ }^{13} \mathrm{C}$-CPMAS solid-state NMR spectra of the pure sodium citrate versus, sodium citrate-HAp, and, the dipolar dephasing (DD) ${ }^{13} \mathrm{C}-\mathrm{CPMAS}$ of the sodium citrate-HAp. Initially as a reference the ${ }^{13} \mathrm{C}$-CPMAS solid-state NMR spectrum of sodium citrate with no dipolar dephasing (DD) was acquired. The obtained ${ }^{13} \mathrm{C}$-CPMAS spectrum is similar to a solution ${ }^{13} \mathrm{C}-\mathrm{NMR}$ spectrum since pure sodium citrate was used. As expected three signals are evident, a two peaks at approximately 43 and 47 ppm resulting from the two $\mathrm{CH}_{2}$ groups, a three peaks at 177,181 and $185 \mathrm{ppm}$ from the three carboxylate carbons and an intense sharp peak from the single quaternary carbon at approximately 76 ppm (see Figure 4-2 blue spectrum).

Similar peak positions were observed for the as-synthesized HAp/citrate sample in the ${ }^{13} \mathrm{C}$ CPMAS solid-state NMR spectrum (Figure 4-2 black). Hence the formation of HAp/citrate was confirmed. The only difference was the significant peak broadening (the width of the HAp/citrate peaks is almost 4 times wider than for pure sodium citrate) furthermore the individual methylene and carboxylate signals is no longer able to be resolved. These results are not surprising given the small amount of citrate anions, present in the samples since only $2.5 \mathrm{wt} \%$ citrate was used in the synthesis. The two methylene groups give a signal at 46 ppm, and the three carboxylate carbons give a signal at $\sim 180 \mathrm{ppm}$. The quaternary carbon gives a peak in approximately the same position but the peak is significantly broader (76 ppm).

Using the dipolar dephasing method, the differentiation of the signals of the quaternary carbon of citrate from those carbon atoms directly bound to hydrogen i.e. the $\mathrm{CH}_{2}$ groups (see Figure 4-2 purple spectrum) was possible. The methylene carbon signal (46 ppm) disappears entirely, while the signals from the non-protonated carbon (76 ppm) and carboxylate carbons (180 ppm) are retained as expected when DD is used. 


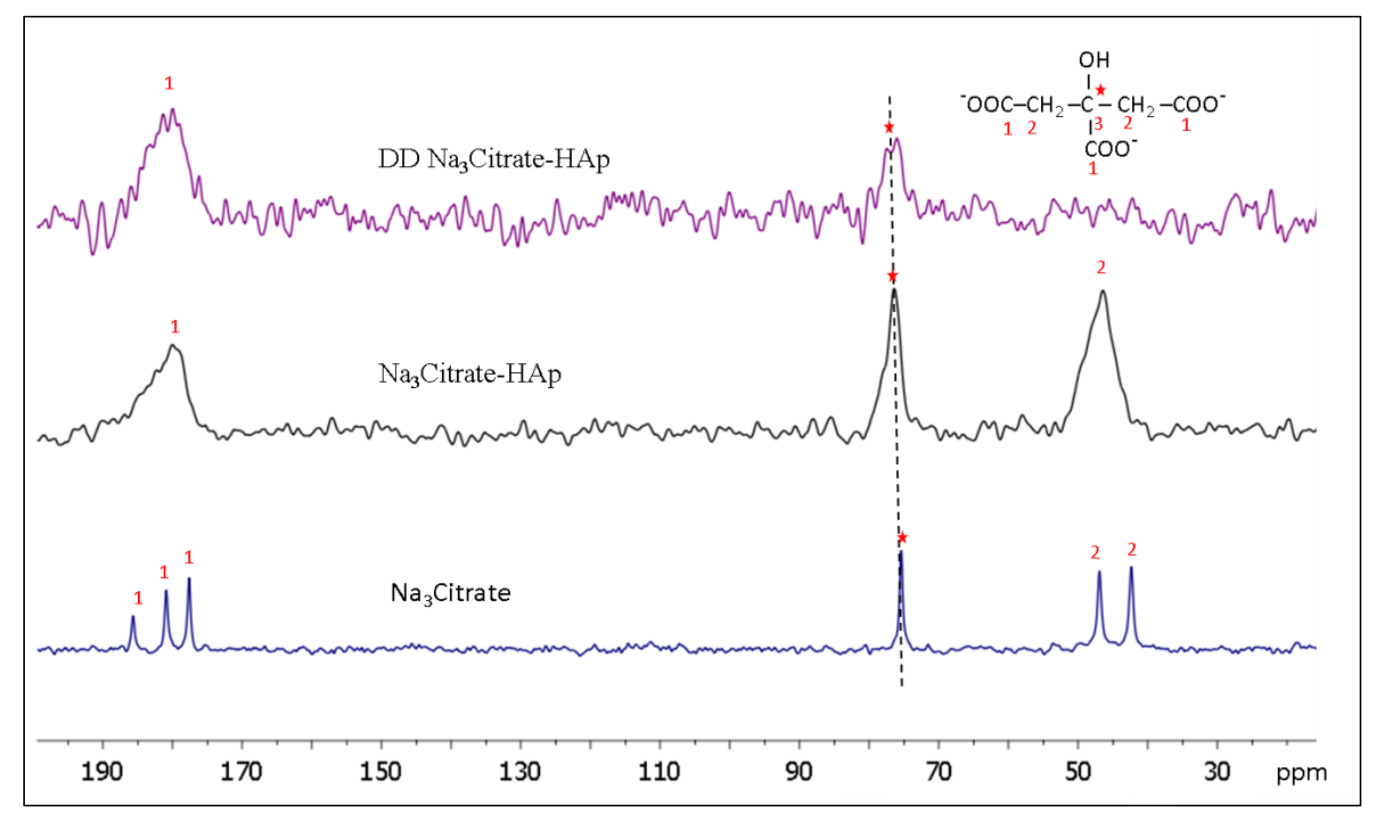

Figure 4-2: ${ }^{13} \mathrm{C}-\mathrm{CPMAS}$ solid-state NMR of pure tri-sodium citrate, and tri-sodium citrateHAp (cross polarization contact time of $1 \mathrm{~ms}$ ) and DD-CPMAS spectrum of tri-citrate-HAp (DD period was $80 \mu$ s). Peaks are labelled according to the shown structure.

\subsubsection{HAp/chitosan}

The regular ${ }^{13} \mathrm{C}-\mathrm{SSNMR}$ data of the pure chitosan film prior to mineralization is shown in Figure 4-3 and labelled as per the reference chemical structure shown in the figure. The weak peaks at 173.64 and $23.20 \mathrm{ppm}$ are attributed to the carbonyl (C7) and methyl (C8) groups respectively due to the acetylation of $\mathrm{NH}_{2}$ group by acetic acid. The shoulder at 96.69 ppm in the $\mathrm{C} 1$ peak arises due to the acetylglucosamine unit C2 [27].

The CPMAS ${ }^{13} \mathrm{C}$ SSNMR of mineralized chitosan films, prepared using the McGrath method, in the presence and absence of citrate were also explored, with $1 \mathrm{~ms}$ contact time (data not shown). Due to the small amount of citrate ions present in the final solid structure (initial concentrations were 1, 2 and $5 \mathrm{wt} \%$ ) the peaks arising due to the presence of citrate were not visible being swamped by those peaks arising due to chitosan. Hence the spectra of all samples were directly comparable to the spectrum that is shown in Figure 4-3. As can be seen in Figure 4-2 when citrate ions are attached to the surface of the HAp crystal, the peaks become very broad and weak. Furthermore the most intensive quaternary carbon atom of citrate at $76 \mathrm{ppm}$, is located at same position as the most intense peak arising from the chitosan, therefore the peak due to the non-protonated carbon is hidden by the strong peak of chitosan. 
Citrate peaks were only detected when $2.5 \mathrm{wt} \%$ sodium citrate was added. A very small peak at $\sim 47$ ppm (see Figure 4-4 black spectrum labelled C2) and a small shoulder in the carbonyl peak of chitosan at $\sim 177 \mathrm{ppm}$. In order to resolve the citrate peaks from those of HAp mineralized chitosan, first the contact time was increased from $1 \mathrm{~ms}$ to $4 \mathrm{~ms}$ in the ${ }^{13} \mathrm{C}$ CPMAS measurement then the DD condition was applied (Figure 4-4). Increasing the contact time enhanced the detection of the citrate signals. A very narrow shoulder was observed on the chitosan peak at $\sim 78 \mathrm{ppm}$ which is attributable to the quaternary carbon of citrate (Figure 4-4 purple spectrum (asterisk)). This latter peak was not present in the HAp/chitosan films with no citrate or when 1 or $2 \mathrm{wt} \%$ of citrate was added to the synthesized solutions. By applying the DD condition, the signals from the nonprotonated carbons of the citrate ions at $\sim 76 \mathrm{ppm}$ and a shoulder at $\sim 78 \mathrm{ppm}$ in addition to the methyl and carboxylate groups from chitosan were detected (Figure 4-4 blue spectrum). The signals from the $\mathrm{C} 1, \mathrm{C} 2, \mathrm{C} 3$ and $\mathrm{C} 4$ carbons of chitosan were no longer evident as expected. The most intense peak of chitosan did not completely dephase however a shoulder clearly arises which is quite likely from the nonprotonated $\mathrm{sp}^{3}$ carbon of the citrate ion. 


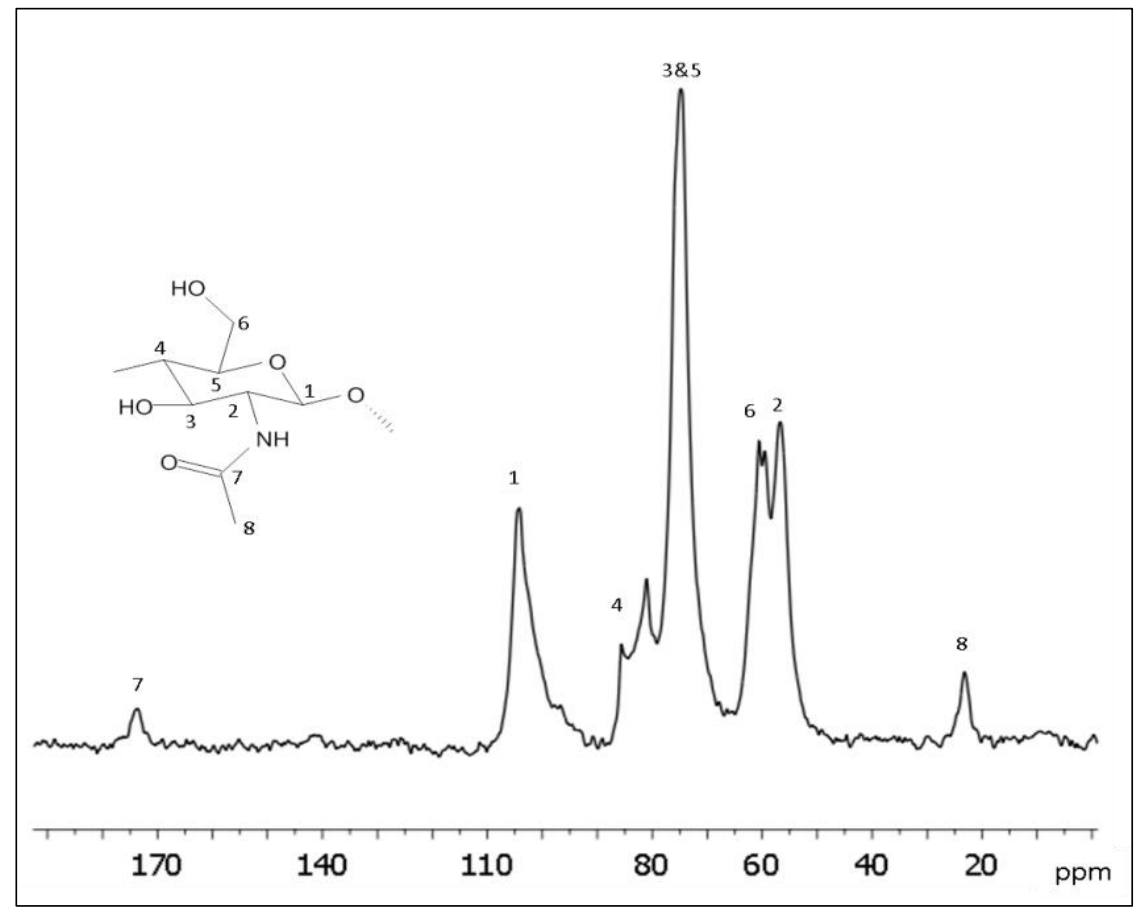

Figure 4-3: ${ }^{13} \mathrm{C}-\mathrm{CPMAS}$ solid-state NMR spectrum acquired from a pure chitosan film (contact time is $1 \mathrm{~ms}$ ).

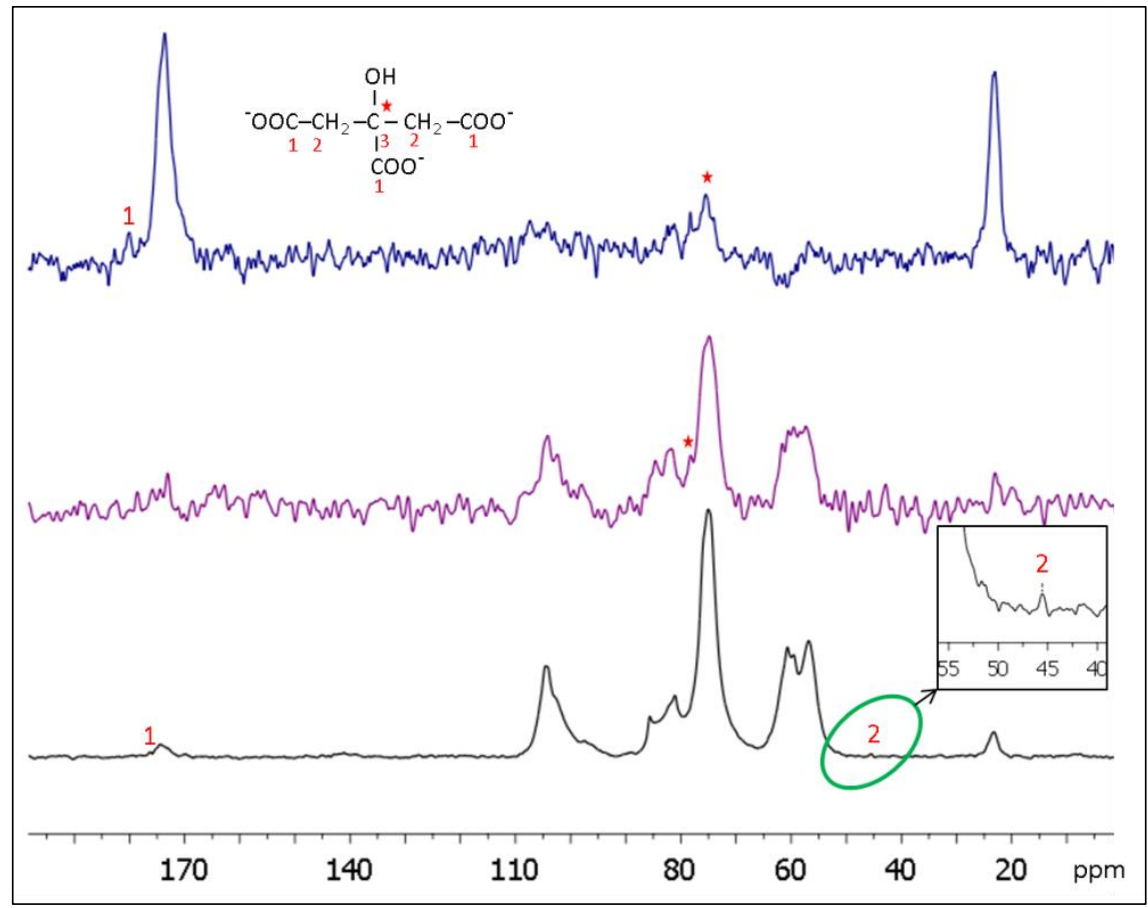

Figure 4-4: ${ }^{13} \mathrm{C}-\mathrm{CPMAS}$ solid-state NMR spectra of HAp/chitosan prepared in the presence of $2.5 \mathrm{wt} \%$ sodium citrate with a $1 \mathrm{~ms}$ contact time (black and the box in the corner shows the blown up peak at $\sim 47 \mathrm{ppm}$ ) and $4 \mathrm{~ms}$ contact time (purple). The corresponding DD-CPMAS spectrum is also shown in blue. (DD period was $80 \mu$ s). 


\subsubsection{HAp/gelatin}

The ${ }^{13} \mathrm{C}$-CPMAS, SSNMR spectrum of the cross-linked gelatin films closely resembles that of collagen SSNMR spectra in the literature $[26,28]$ in terms of peak positions and amino acid residues (Figure 4-5). The signal in the range of 100-115 ppm corresponds to the spinning sidebands (ssb) arising from carbonyl carbons. The region from 160-185 ppm contains carbonyl and carboxylic carbons of amino acid residues [29]. The aliphatic region of gelatin is in the range of 10-80 which is indicated by those peaks below the dashline in Figure 4-5.

In Figure 4-6 are compared the ${ }^{13} \mathrm{C}-\mathrm{CPMAS}$, SSNMR spectra of mineralized gelatin in the absence of citrate and the dipolar data acquired from mineralized gelatin films with 2 and $2.5 \mathrm{wt} \%$ sodium citrate additive. The spectra are very similar to those of bone reported in the literature. Citrate $\mathrm{CH}_{2}$ methylene carbons are possibly hidden in the aliphatic region and the carboxylate groups overlap with the carbonyl region of the gelatin spectrum. The only signal expected to see is the citrate quaternary carbon signal at $\sim 76 \mathrm{ppm}$. From the CPMAS data no significant signal was observed even by increasing the contact time to $4 \mathrm{~ms}$ but there was a shoulder near to $76 \mathrm{ppm}$ that appeared in the $2.5 \mathrm{wt} \%$ sodium citrate samples (Figure 4-6 blue peak) which can be related to the integration of citrate ions to HAp through the gelatin matrix. The results of the dipolar dephasing experiments conducted on HAp/gelatin in the presence of 2 and $2.5 \mathrm{wt} \%$ citrate ion revealed a nondephased citrate ion peak at 76 ppm especially for the sample containing $2.5 \mathrm{wt} \%$ citrate (Figure 4-6 black spectrum peak). Again the resonance frequencies of the gelatin protein $\mathrm{CH}_{3}$ group signal is only partially dephased. In the presence of $2 \mathrm{wt} \%$ of citrate anions the dephasing of nonprotonated carbon is partially indicated ((Figure 4-6 purple spectrum peak). For clarity and better comparison CPMAS and DD NMR data were obtained from the HAp/gelatin composite is shown in Figure 4-7.

The results of CPMAS and DD ${ }^{13} \mathrm{C}$ SSNMR of mineralized gelatin and chitosan in the presence of citrate ions showed that the amount of citrate ions present during synthesis is crucial to fabricate biomimetic HAp/gelatin/citrate and HAp/chitosan/citrate composite. The DD results of both systems provide evidence that at least $2.5 \mathrm{wt} \%$ citrate must be present for sufficient citrate to be incorporated into the final material and detected via SSNMR when only 1 or $2 \mathrm{wt} \%$ citrate was added no dephasing occurred in the chitosan system while in the gelatin system in the presence of $2 \mathrm{wt} \%$ citrate a very weak peak was able to be detected. 


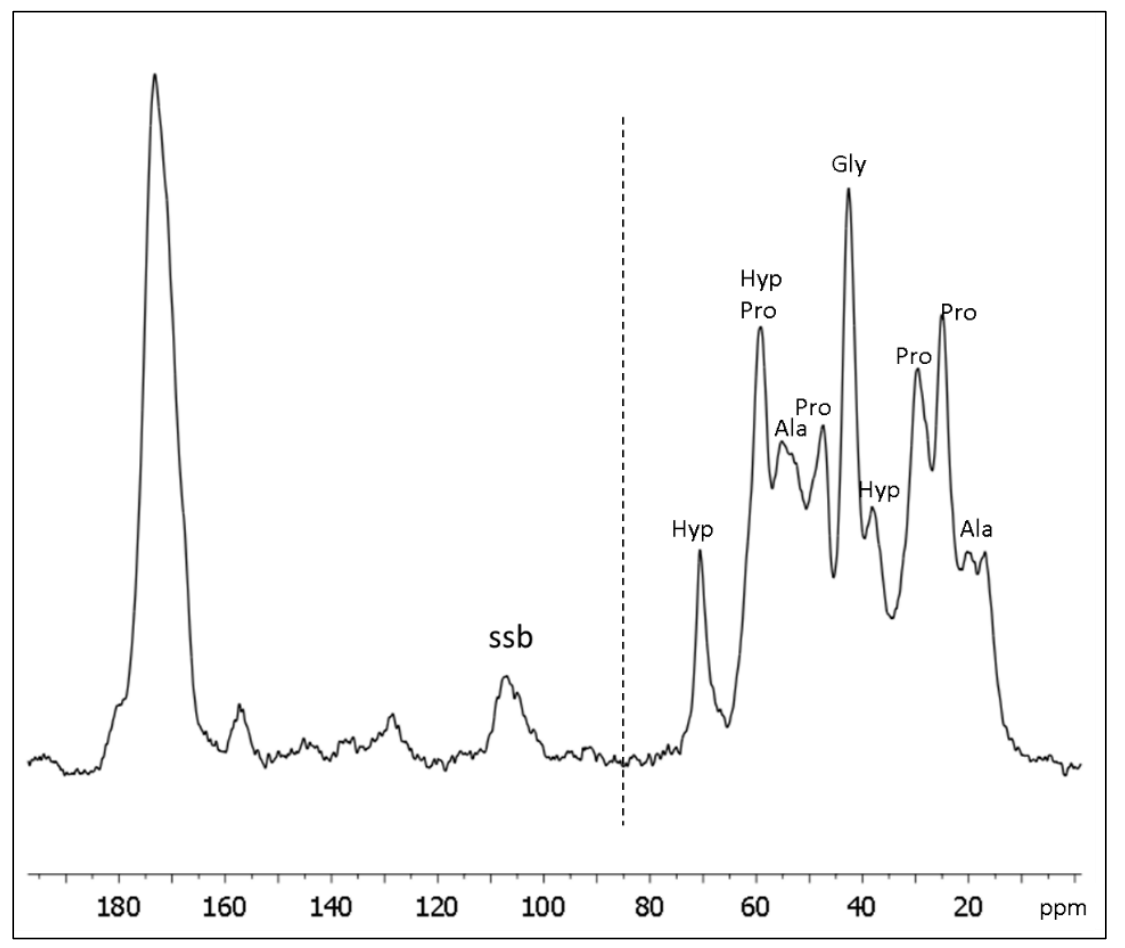

Figure 4-5: ${ }^{13} \mathrm{C}-\mathrm{CPMAS}$ solid-state NMR spectrum of the cross-linked gelatin film. Spinning sidebands are labelled as ssb.

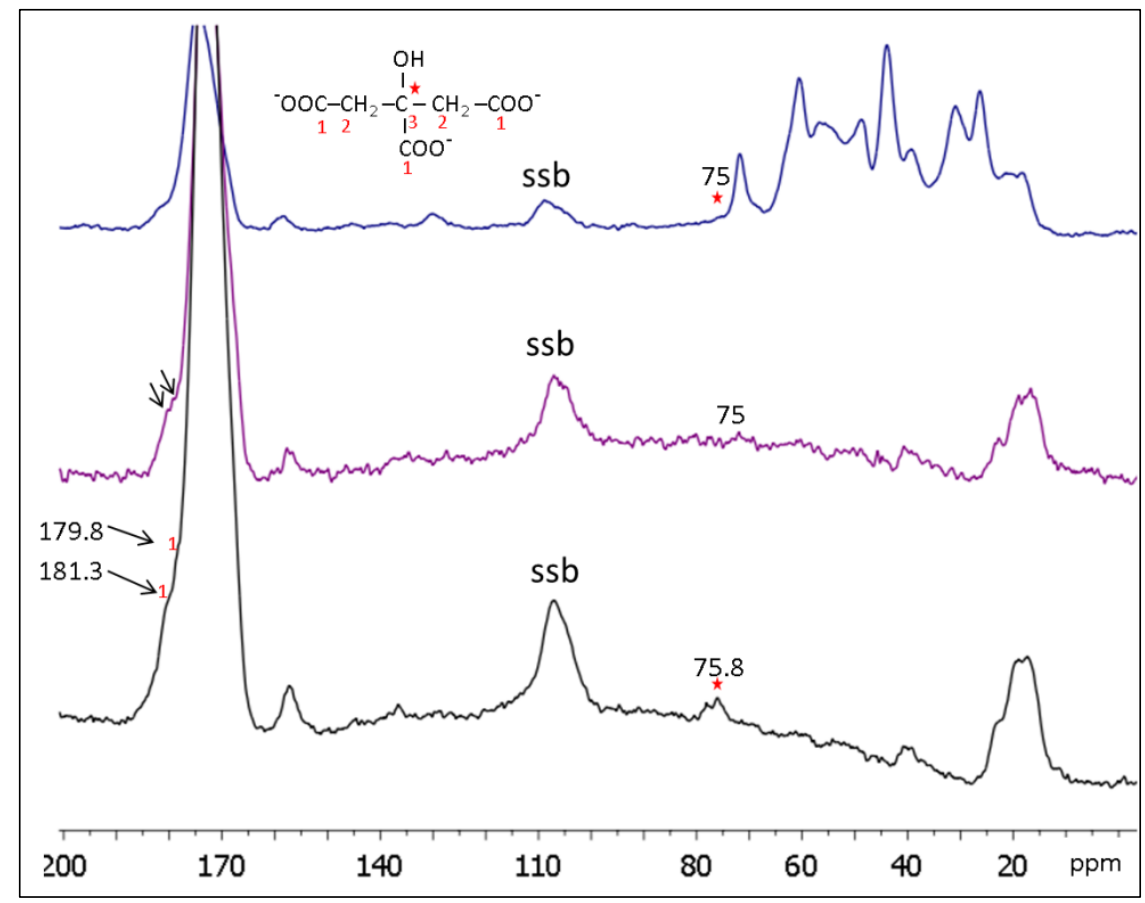

Figure 4-6: ${ }^{13} \mathrm{C}-\mathrm{CPMAS}$ solid-state NMR of HAp/gelatin film formed in the presence of $2.5 \mathrm{wt} \%$ sodium citrate with a $1 \mathrm{~ms}$ contact time (black) and $4 \mathrm{~ms}$ contact time (purple). Corresponding DD-CPMAS spectra is also shown (DD period was $80 \mu \mathrm{s}$ ). Spinning sidebands are labelled as ssb. 


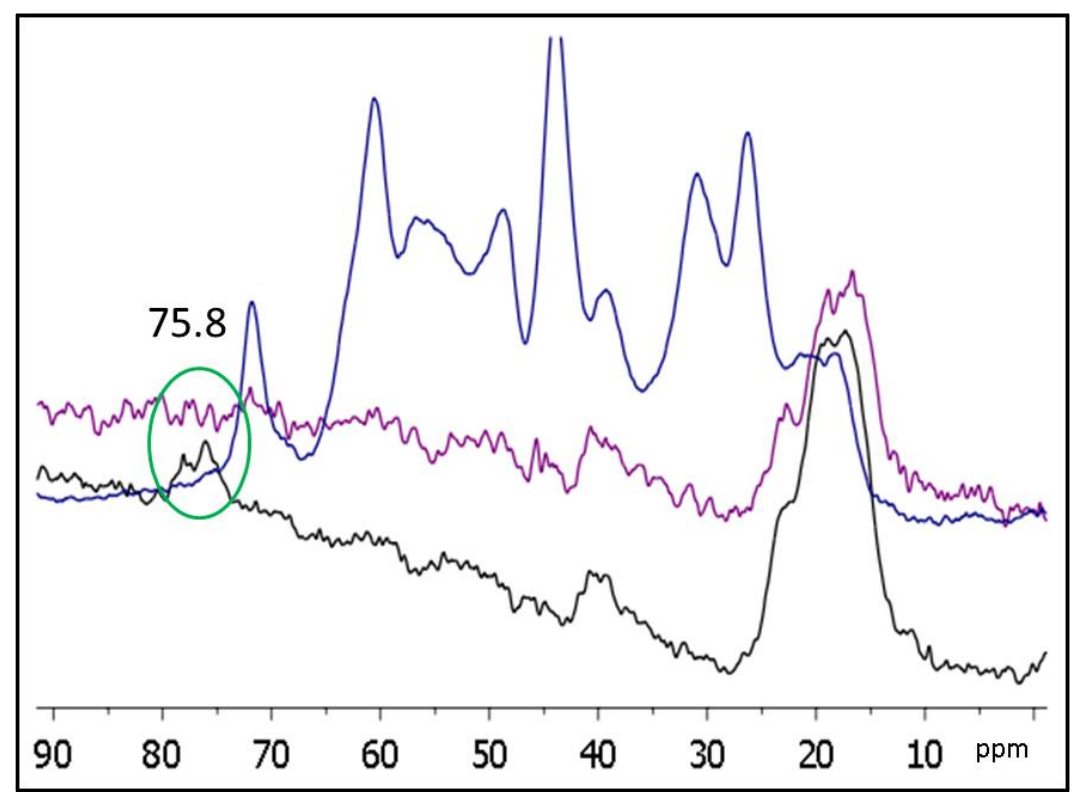

Figure 4-7: Comparison of CPMAS and DD data for the region where the most intensive citrate signal occurs. The dephasing signal when $2.5 \mathrm{wt} \%$ citrate was added in the synthetic protocol is apparent at $75.8 \mathrm{ppm}$ (black spectrum).

Additional evidence of $\mathrm{HAp} /$ gelatin/citrate and HAp/chitosan/citrate formation can be achieved from ${ }^{1} \mathrm{H}$ SSNMR. In Figure 4-8 are compared the ${ }^{1} \mathrm{H}$ MAS spectra from HAp/gelatin (Figure 4-8A) and HAp/chitosan (Figure 4-8B) composite materials in the absence and presence of citrate ions. The results show a broad signal at $\sim 5.1$ due to the presence of water in the solid structure which possibly hide or mask the citrate ${ }^{1} \mathrm{H}$ signals. In both gelatin and chitosan systems synthesized in the presence of either 2 or $2.5 \mathrm{wt} \%$ sodium citrate the ${ }^{1} \mathrm{H}$ signal is significantly broader than the ${ }^{1} \mathrm{H}$ signal of samples containing no citrate, indicating the inhibitory effect of citrate ions on HAp growth or the formation of amorphous calcium phosphate. The ${ }^{1} \mathrm{H}$ HAp/citrate spectra show two additional small peaks at approximately 2.16 and $0.20 \mathrm{ppm}$ which index to the $\mathrm{OH}$ group from HAp (Figure 4-8C). Interestingly in the HAp/gelatin and HAp/chitosan composites with no citrate ions these small peaks are not present (Figure 4-8A and B purple peaks) but in the HAp/gelatin and HAp/chitosan samples with either 2 or $2.5 \mathrm{wt} \%$ of citrate ions the $\mathrm{OH}$ signal is observed, presumably arising from the $\mathrm{OH}$ groups of the citrate ions (Figure 4-8A and B blue and green spectra for 2 and $2.5 \mathrm{wt} \%$ citrate respectively). These results suggest the inclusion of citrate ions in the synthesized composites. ${ }^{1} \mathrm{H}$ MAS data for gelatin-HAp with $2.5 \mathrm{wt} \%$ citrate mirrors the ${ }^{1} \mathrm{H}$ MAS data obtained for HAp/chitosan, only the intensity of the ${ }^{1} \mathrm{H}$ MAS peak of the HAp/gelatin material is higher (Figure 4-8D). 

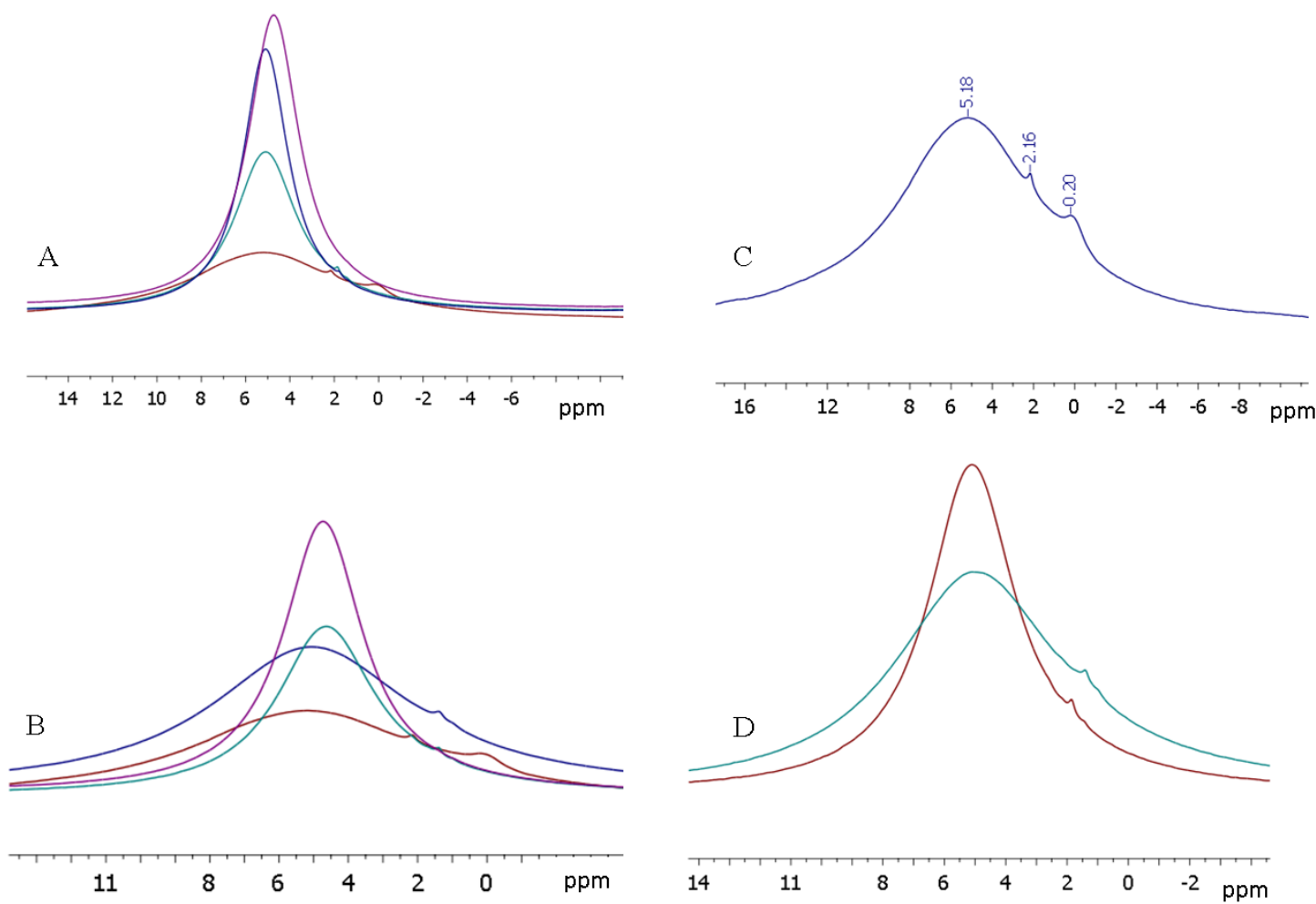

Figure 4-8: Comparison of ${ }^{1} \mathrm{H}$ NMR spectra of (A) HAp/gelatin, (B) HAp/chitosan material are shown as follows: purple: no citrate, blue: $2 \mathrm{wt} \%$ citrate, green $2.5 \mathrm{wt} \%$ and red: HAp/citrate. The individual spectrum of HAp-citrate is shown in (C) and (D) shows the comparison of HAp/gelatin and HAp/chitosan containing $2.5 \mathrm{wt} \%$ of citrate ions which mirror each other except the lower intensity in the case of chitosan.

${ }^{31} \mathrm{P}$ CP-MAS data from Hap/citrate crystals shows an intense signal at $3.2 \mathrm{ppm}$ indicating the presence of poorly crystalline HAp mineral with a similar chemical shift distribution to that of bone (Figure 4-9 blue spectrum sharp peak). The same result was obtained for biomimetic synthesized HAp/gelatin (Figure 4-9 purple spectrum peak) and HAp/chitosan (Figure 4-9 green peak) with $2.5 \mathrm{wt} \%$ sodium citrate, except the intensity of the signal at 3.2 ppm has drastically decreased and peak broadening was observed in both systems. This suggests that both ACP and HAp are present in the synthesized composites.

From the SS-NMR data, shown above it was found that HAp precipitation could be stabilized with $2.5 \mathrm{wt} \%$ sodium citrate. As such only samples with $2.5 \mathrm{wt} \%$ sodium citrate were examined for SEM and TEM. 


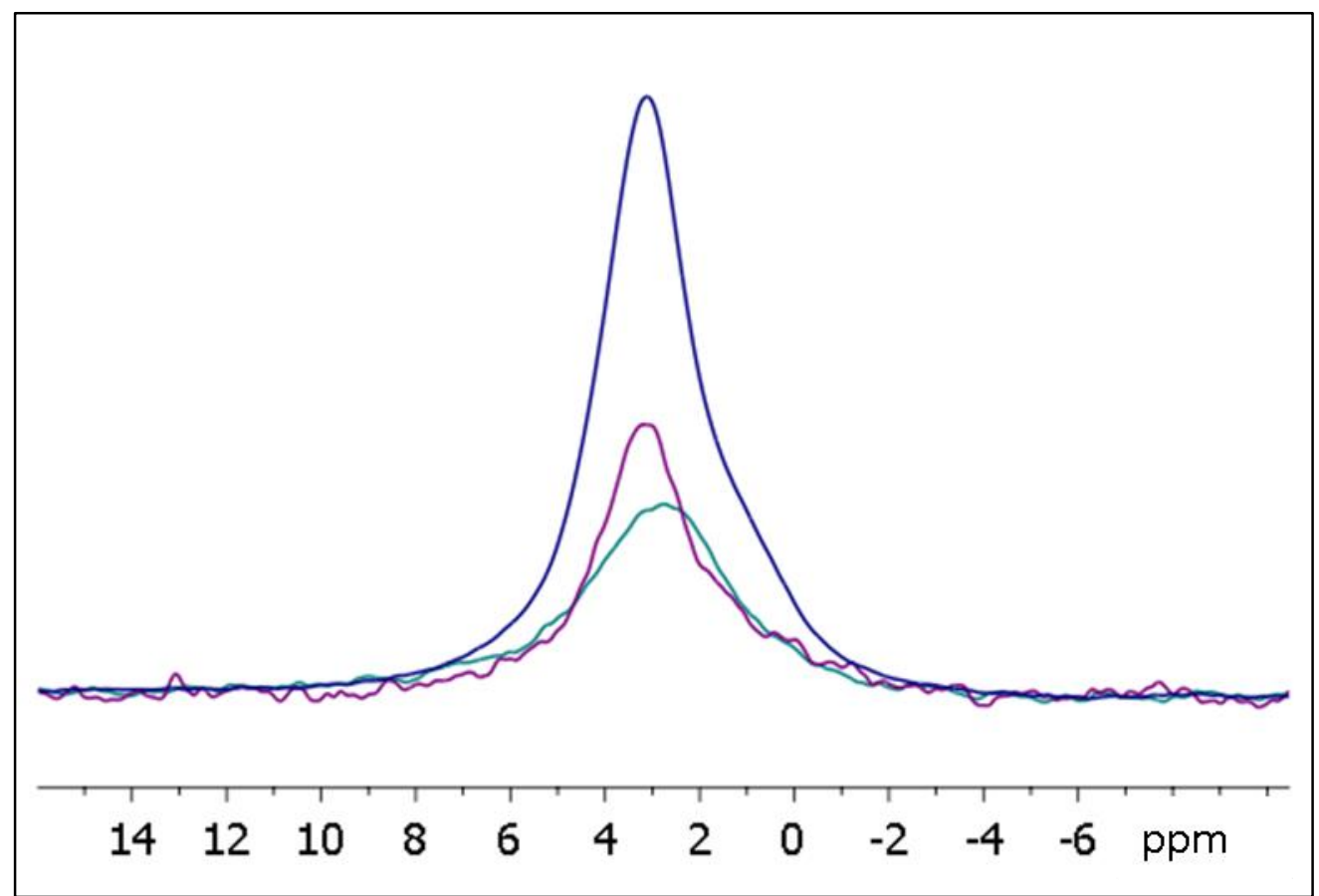

Figure 4-9: Comparison of ${ }^{31} \mathrm{P}$ CPMAS NMR spectra of HAp/citrate (blue), HAp/gelatin (purple) and HAp/chitosan (green) all synthesized with $2.5 \mathrm{wt} \%$ sodium citrate.

\subsubsection{Morphological analysis of prepared composites}

The influence of sodium citrate additive on HAp nucleation and growth in chitosan and gelatin hydrogel scaffolds was explored. SEM was used to investigate four systems: HAp/chitosan, HAp/chitosan/citrate, HAp/gelatin and HAp/gelatin/citrate.

In Figure 4-10 is shown a series of representative SEM micrographs from the four systems: HAp/chitosan (Figure 4-11A), HAp/chitosan/citrate (Figure 4-10B), HAp/gelatin (Figure 410C) and HAp/gelatin/citrate (Figure 4-10D) composites. Similar HAp morphologies with different sizes are formed for both hydrogel systems in the absence and presence of citrate ions. The spherical flower-like clusters of HAp are present throughout the scaffolds. These morphologies are themselves composed of plate-like crystallites (for example see insets in Figure 4-11). This is a typical morphology for HAp grown on polymeric substrates such as collagen [30]. The individual flowers in HAp/chitosan composites have diameters in the range of 1.30-2.5 $\mu \mathrm{m}$ which become smaller $(1.2-1.8 \mu \mathrm{m})$ when citrate ions are added to the synthesis system. In the case of HAp/gelatin composites the size of the individual flower diameters is in the range of 1.8-2.5 $\mu \mathrm{m}$ which once again becomes smaller when citrate ions are added to the crystallization system $(1.04-1.5 \mu \mathrm{m})$. The size of the crystals becomes smaller upon addition of the citrate ions in both the chitosan and gelatin systems which 
clearly show the inhibitory effect of the citrate ions on the growth of HAp crystals. Due to the precipitation of fine crystals in the chitosan and gelatin matrices XRD data does not provide resolved peaks and indicates that the samples which are heavily mineralized are poorly crystalline and hence XRD data do not fully represent the mineralized state of the composite. In the presence of citrate anions greater mineralization is achieved compared to when no additive is present in the case of chitosan. Hence citrate enhances nucleation but inhibits the growth of individual crystals. For the gelatin matrix hydrogels regardless of the presence or absence of citrate ions a similar extent of mineralization was obtained. The extent of crystallization was similar for the HAp/chitosan/citrate, HAp/gelatin and HAp/gelatin/citrate composites compared with the HAp/chitosan composite.

EDS data of the synthesized composites indicates that the samples contain both calcium and phosphate. The $\mathrm{Ca} / \mathrm{P}$ ratios were in the range of $1.5-1.73$ which confirms that the mineral form throughout the chitosan and gelatin hydrogel composites is HAp [31]. 

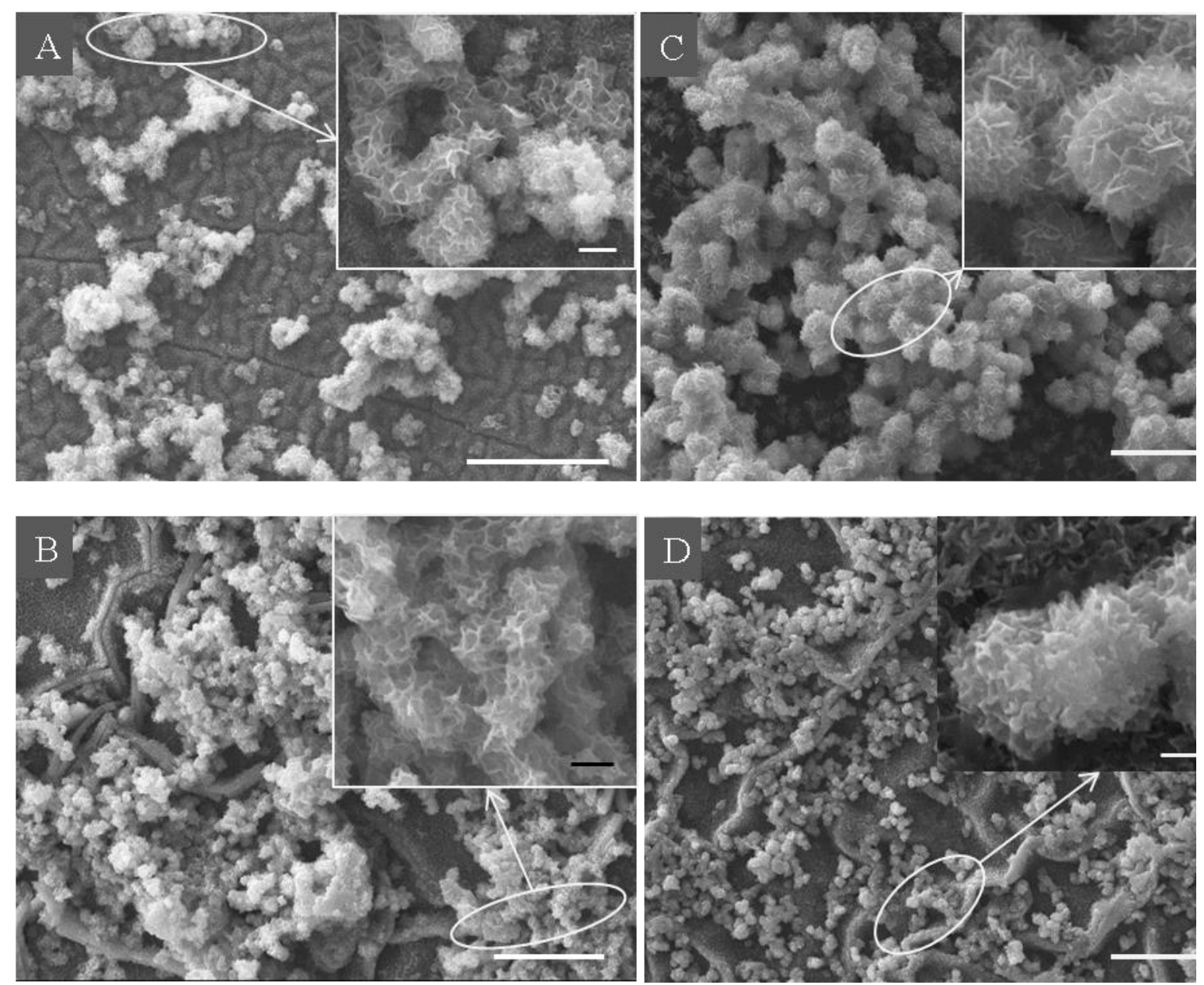

Figure 4-10: SEM micrographs of (A) HAp/chitosan, (B) HAp/chitosan/citrate, (C) HAp/gelatin and (D) HAp/gelatin/citrate composites. The inset images show the magnified view of the flower-like HAp crystals grown within the chitosan and gelatin hydrogel films which indicate the plate or flake-like morphology of the HAp minerals. Scale bars are 10 $\mu \mathrm{m}$ and insets are $1 \mu \mathrm{m}$. 


\subsubsection{TEM Analysis of composites}

\subsubsection{HAp}

In Figure 4-11 is shown TEM data for the synthesized HAp crystals from bulk solution. STEM-EDS measurements of the HAp show a $\mathrm{Ca} / \mathrm{P}$ ratio of $\sim 1.72$ which is approximately within the stoichiometric value of pure HAp crystals with a $\mathrm{Ca} / \mathrm{P}$ ratio of 1.67 (Figure 4-12). Low resolution electron micrographs of HAp crystals clearly indicate that closely randomly packed thin elongated plate-like agglomerate (dashed white in Figure 4-11B) and needlelike (dashed black rectangle in Figure 4-11B) HAp structures are formed. In literature it is proposed that the needle-like morphology is probably due to on-edge viewing of the curled plate-like HAp minerals [32]. It is noted that here there is no evidence of curling. The individual needle-like crystals have a length of about 50-250 nm and width of about 10-30 nm. The selected area electron diffraction (SAED) pattern (Figure 4-11C) shows that the sample is polycrystalline. The rings in Figure 4-11C correspond to the (002), (121), (112) and (222) planes of hexagonal HAp which is in accordance with the XRD results (see Figure 4-1h).

HRTEM was used to further explore the symmetry of the crystals. HAp is electron beam sensitive. Charging leads to random movements of HAp crystals and therefore it is a challenge to capture HRTEM images [33]. HRTEM images of the HAp crystals highlighted in Figure 4-11D show the crystal lattice planes are randomly aligned. An atomic packing arrangement can be observed but it does not represent a continuous crystal packing (see inset Figure 4-11D). The lattice spacing of $0.23 \mathrm{~nm}$ is attributed to the (212) planes of HAp crystals (see inset Figure 4-11D). 

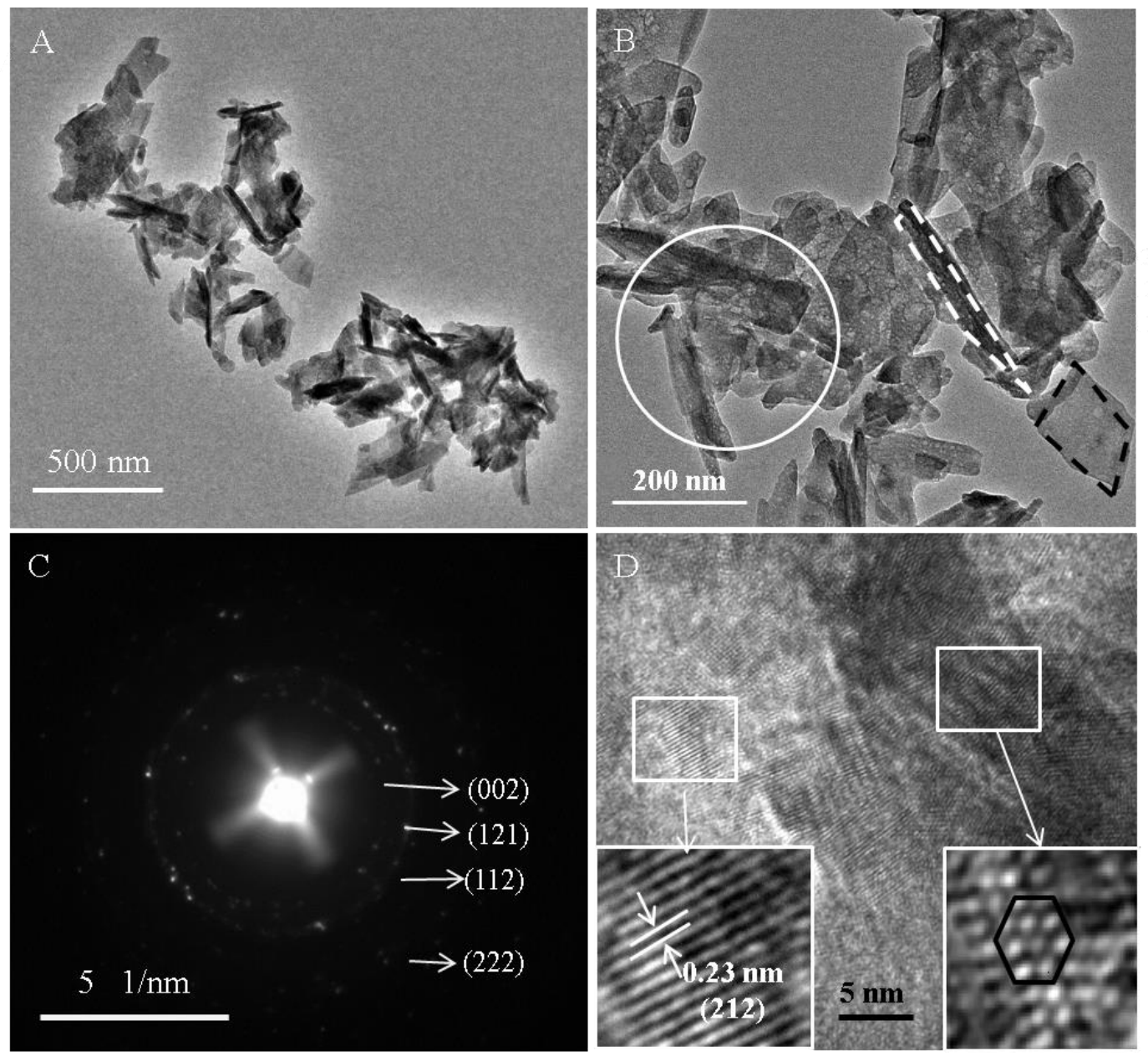

Figure 4-11: Electron micrographs of HAp crystals: (A) and (B) low resolution TEM images showing the plate and needle-like structure of HAp, (B) circle shows the region used for SAED analysis, the white dashline rectangle shows the needle-like HAp structure while the black dashline indicates the plate-like HAp structure, (C) SAED pattern indexed to HAp crystal structure and (D) HRTEM image of the white circle region in (B). Insets show the IFFT images of the highlighted encircled regions shown in D. 


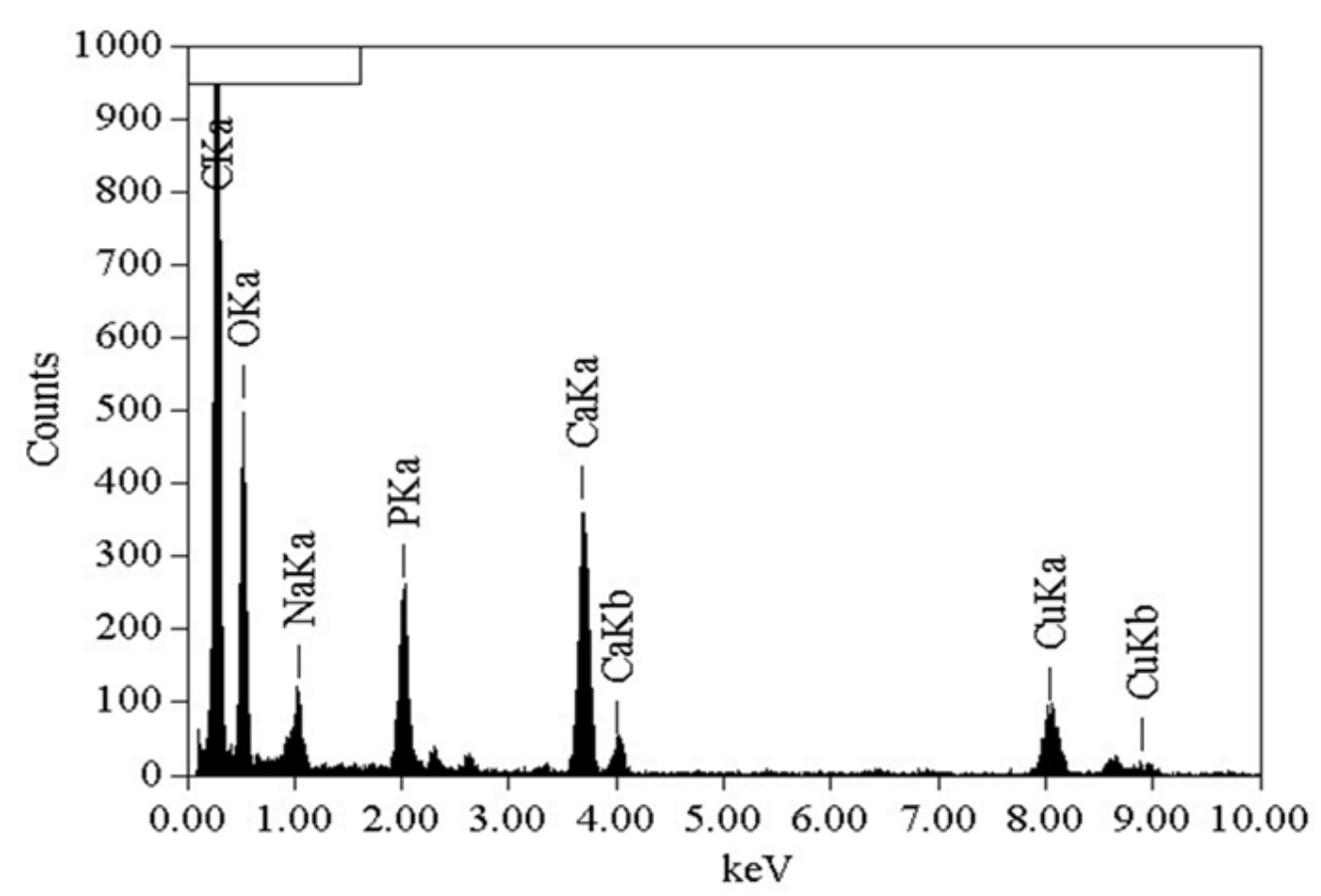

Figure 4-12: EDS spectrum of the synthesized HAp crystals indicating a $\mathrm{Ca} / \mathrm{P}$ ratio of 1.72 .

\subsubsection{HAp/citrate}

In Figure 4-13 are shown electron micrographs of the synthesized HAp/citrate crystals. Low resolution images of HAp-citrate clearly show the drastic decrease of the HAp crystal size (Figure 4-13A and B) and the thin needle structure with a length of $\sim 20-50$ and width $\sim 5$ $15 \mathrm{~nm}$ (Figure 4-13A and B). The SAED of HAp/citrate shows very different peaks from the pure HAp confirming nanoscopic dimensions and fine-grained HAp crystal formation (Figure 4-13C). This agrees with the observed broadening of the peaks in the XRD results (Figure 4-1g). Further planes such as 300 and 212 were observed which shows the merits of using electron beams rather than X-rays. The strong interaction of electrons and atoms enables the imaging of individual crystals and provides bulk information which is not possible with X-ray techniques. HRTEM analysis revealed that the distance between the lattice fringes is $0.269 \mathrm{~nm}$ corresponding to (112) planes which confirm the existence of HAp crystals (inset Figure 4-13D). 

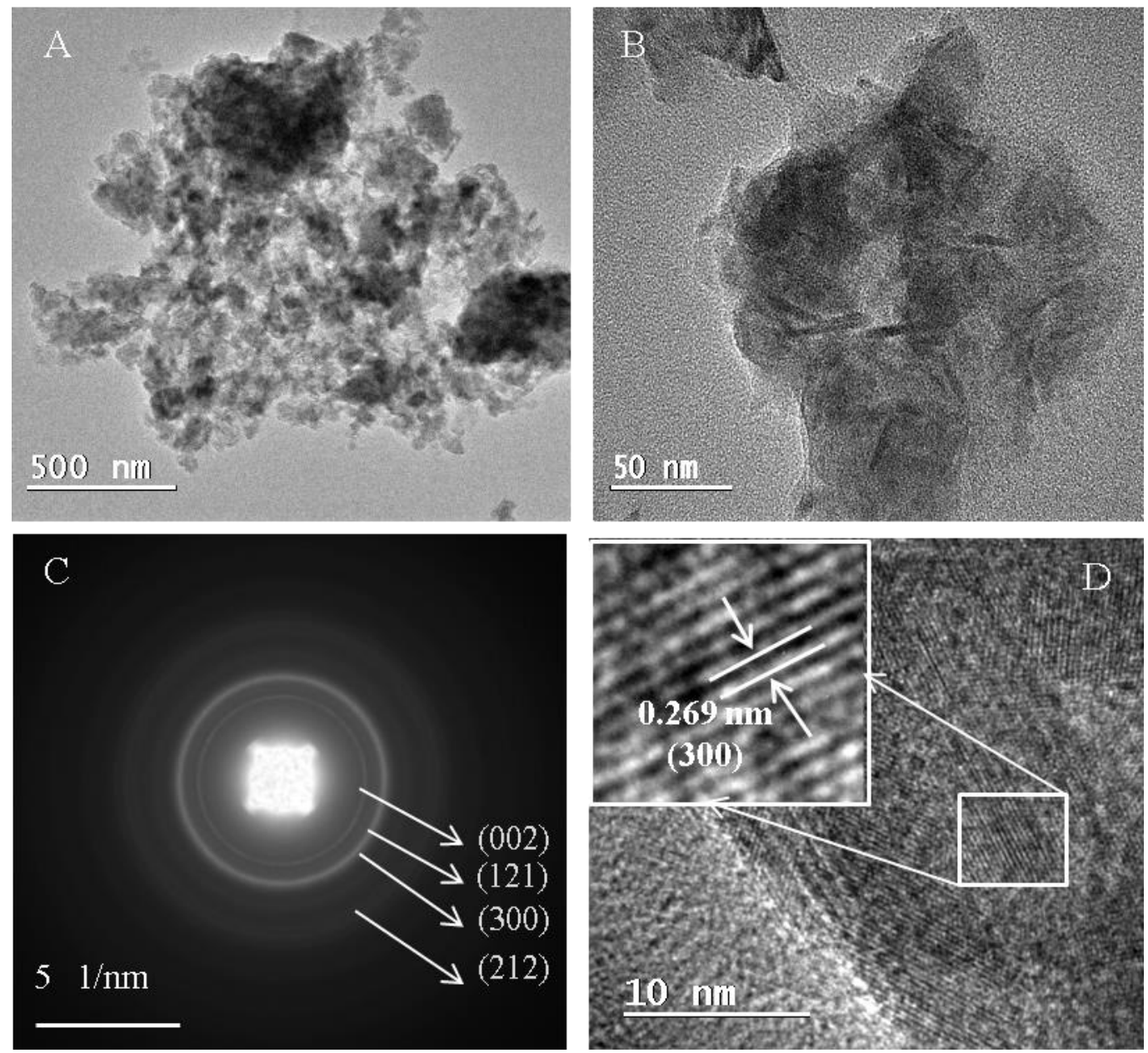

Figure 4-13: TEM micrographs of citrate-HAp: (A), and (B) show low resolution images, (C) SAED which indexed the low crystallinity and fine-grained citrate-HAp formation and (D) HRTEM image shows the high resolution image of the lattice fringes corresponding to the (112) plane of the HAp/citrate crystals (inset IFFT results). 


\subsubsection{HAp/chitosan and HAp/chitosan/citrate}

TEM micrograph of the as-synthesized HAp/chitosan and HAp/chitosan/citrate composites (the corresponding SEM data are shown in Figure 4-11A and B) are shown in Figure 4-14 and Figure 4-15 respectively. Low resolution images of HAp/chitosan show regular needlelike HAp mineralized within the chitosan scaffold which is different from the synthesized HAp crystals in terms of size (Figure 4-14A and B). Compared to synthesized HAp crystals the dimensions of the needles decreased by almost three times, to a length of $40-80 \mathrm{~nm}$ (average size $65 \mathrm{~nm}$ ) and 4-8 $\mathrm{nm}$ (average size $4.9 \mathrm{~nm}$ ) width. A SAED pattern (shown in inset Figure 4-14B) and HRTEM (shown in Figure 4-14D) indexed to the more defined reflection of (121) HAp plane. In addition the presence of amorphous calcium phosphate (ACP) mineral is evident (see Figure 4-15C FFT analysis in inset). $\mathrm{Ca} / \mathrm{P}$ ratios of 1.26 obtained from EDS also confirmed the formation of amorphous calcium phosphate [34].

In Figure 4-15 TEM data depicting crystal growth of HAp/chitosan/citrate composites are given. Addition of citrate ions does not induce a significant change in the morphology of the HAp minerals grown (Figure 4-15A and B). The HAp minerals have a needle-like shape and are 40-120 nm in length (average size $79 \mathrm{~nm}$ ) and 4-12 nm (average size $6.4 \mathrm{~nm}$ ) in width. The SAED of HAp/chitosan/citrate composites presents diffusive polycrystalline diffraction rings and shows a typical intensive plane of HAp mineral expected second-order (004) HAp reflections such as (213) (Figure 4-15D). HRTEM images indicate that the needles are crystalline and the distance between the lattice fringes is $0.278 \mathrm{~nm}$ corresponding to the (112) plane, confirming HAp formation (Figure 4-15C). 

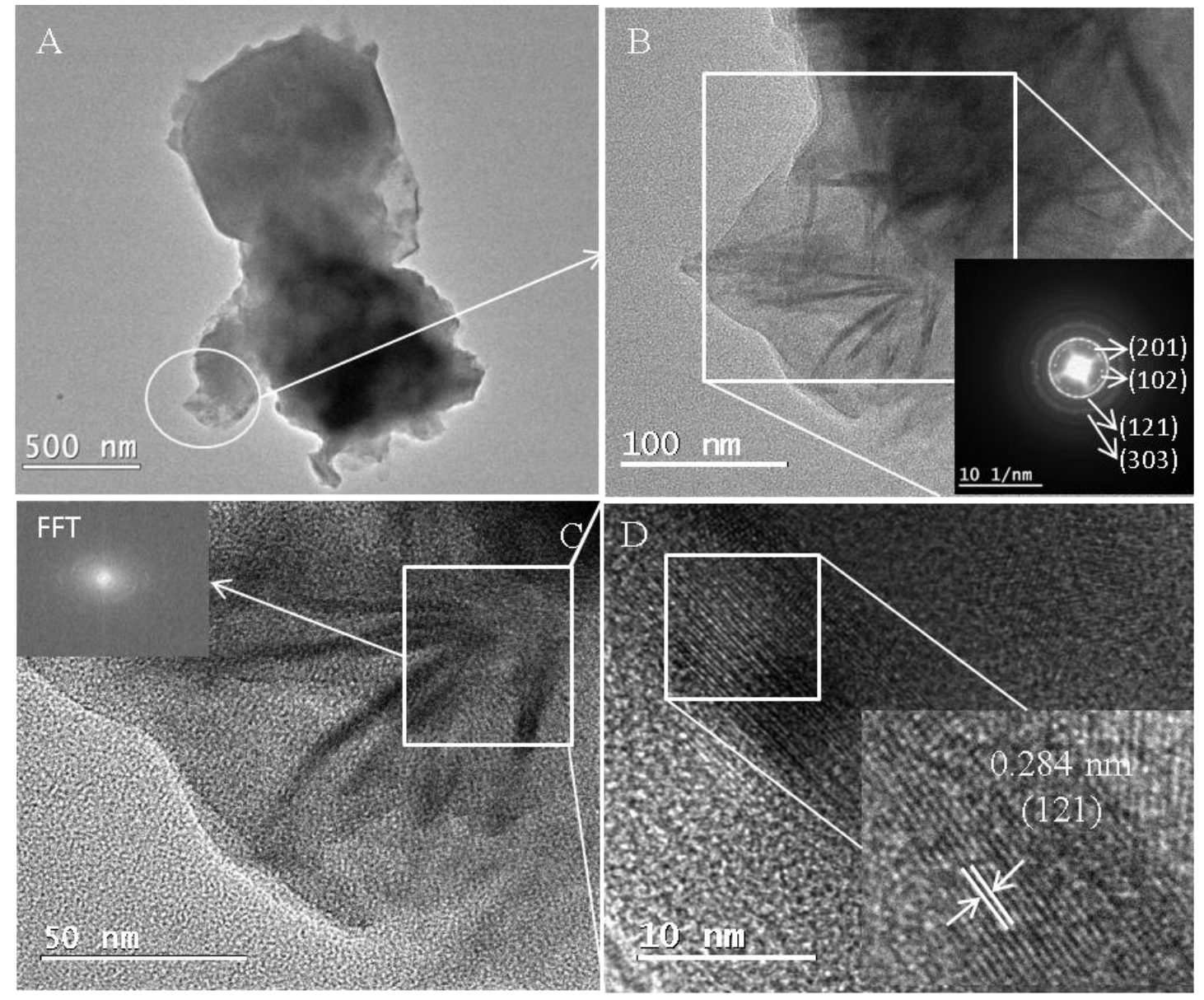

Figure 4-14: TEM micrographs of HAp/chitosan composites: (A) shows low resolution image of HAp/chitosan, (B) high magnification view of white circle in A showing needle structure of HAp, (C) high-resolution micrograph of the same sample with the corresponding SAED and FFT indicating the presence of ACP in synthesized HAp/chitosan and (D) HRTEM image showing the most intense HAp plane (121). 

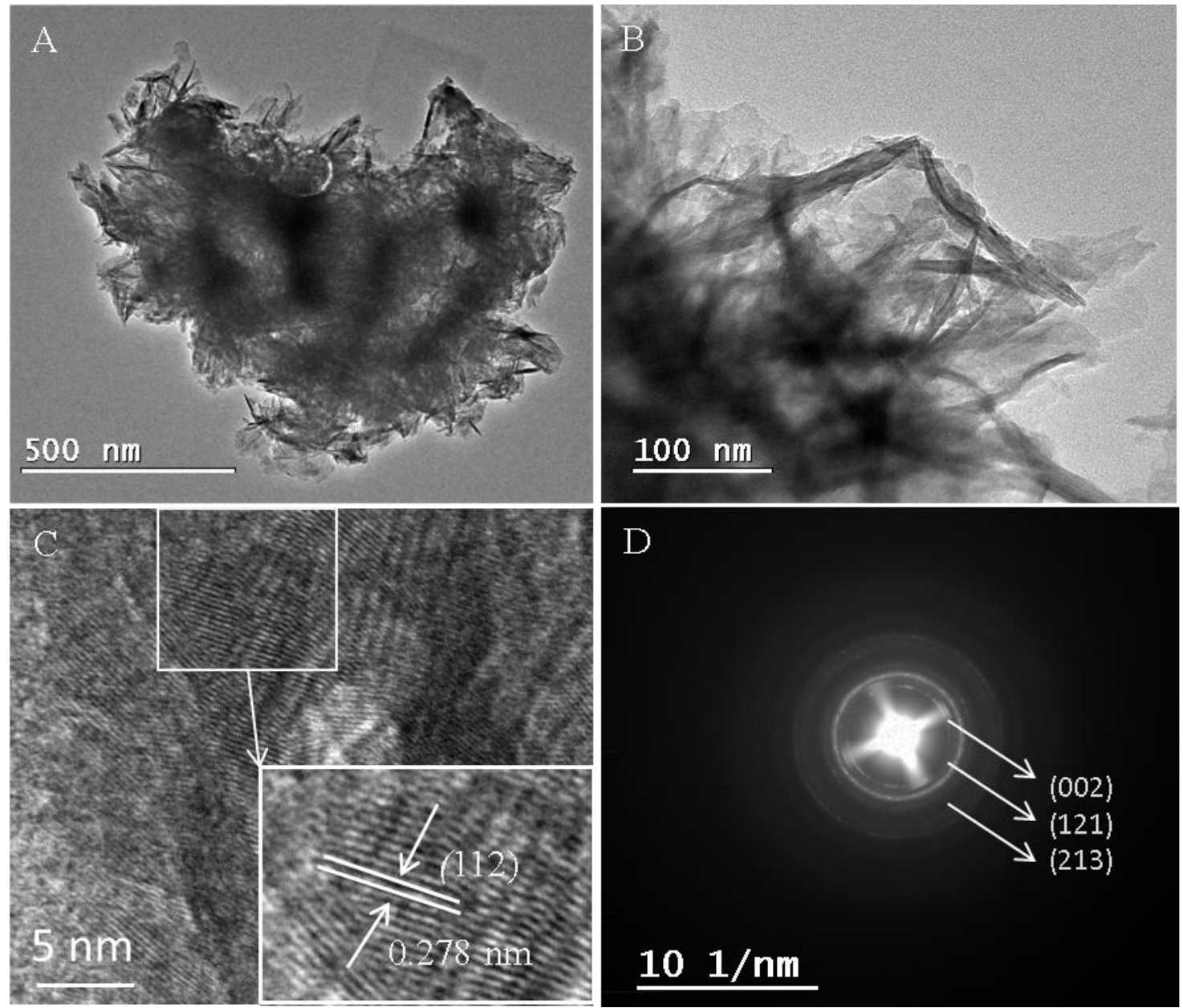

Figure 4-15: TEM micrographs of HAp/chitosan/citrate composites: (A) and (B) show low resolution images, (C) high-resolution micrograph of the same sample and (D) the corresponding SAED. 


\subsubsection{HAp/gelatin and HAp/gelatin/citrate}

TEM micrographs for the HAp/gelatin and HAp/gelatin/citrate composites (SEM images given in Figure 4-11C, D) are shown in Figure 4-16 and 4-17 respectively. Low magnification TEM analysis of HAp/gelatin composites shows the spherical structure of HAp (Figure 4-16A). The spherical HAp is composed of thousands of needle-like structures (Figure 4-16B). From the morphology point of view no distinguishable differences were observed except the very long needles (for example $350 \mathrm{~nm}$ in length) and wider width (25 $\mathrm{nm}$ in some cases) are seen in the system compared with both HAp/chitosan and HAp/chitosan/citrate nanocomposites. The inset (Figure 4-16B) shows a SAED that is indexed to the reflections of the most detected plane (121), in addition to other planes such as (120) and (002). HRTEM analysis through FFT reveals more defined reflections of the (112), (121), and (300) (Figure 4-16D inset). In Figure 4-16D it can be seen that the needlelike structures are surrounded by plate-like randomly oriented HAp crystals.

TEM analysis of HAp/gelatin/citrate composites is shown in Figure 4-17. Compared to the HAp/gelatin samples the needle size is decreased to $80-250 \mathrm{~nm}$ in length and 3-8 $\mathrm{nm}$ in width. Introducing citrate ions leads to marked thinning of the width of the needles. SAED broadening and diffusive diffraction patterns indicate presence of polycrystalline structures with fine HAp crystal formation (Figure 4-17C). The presence of ACP is also evident (Figure 4-18D inset top left). The HRTEM image once again shows the needles are crystalline and the distance between the lattice fringes is $0.282 \mathrm{~nm}$ corresponding to (121) plane (Figure 4-17d inset bottom right). 

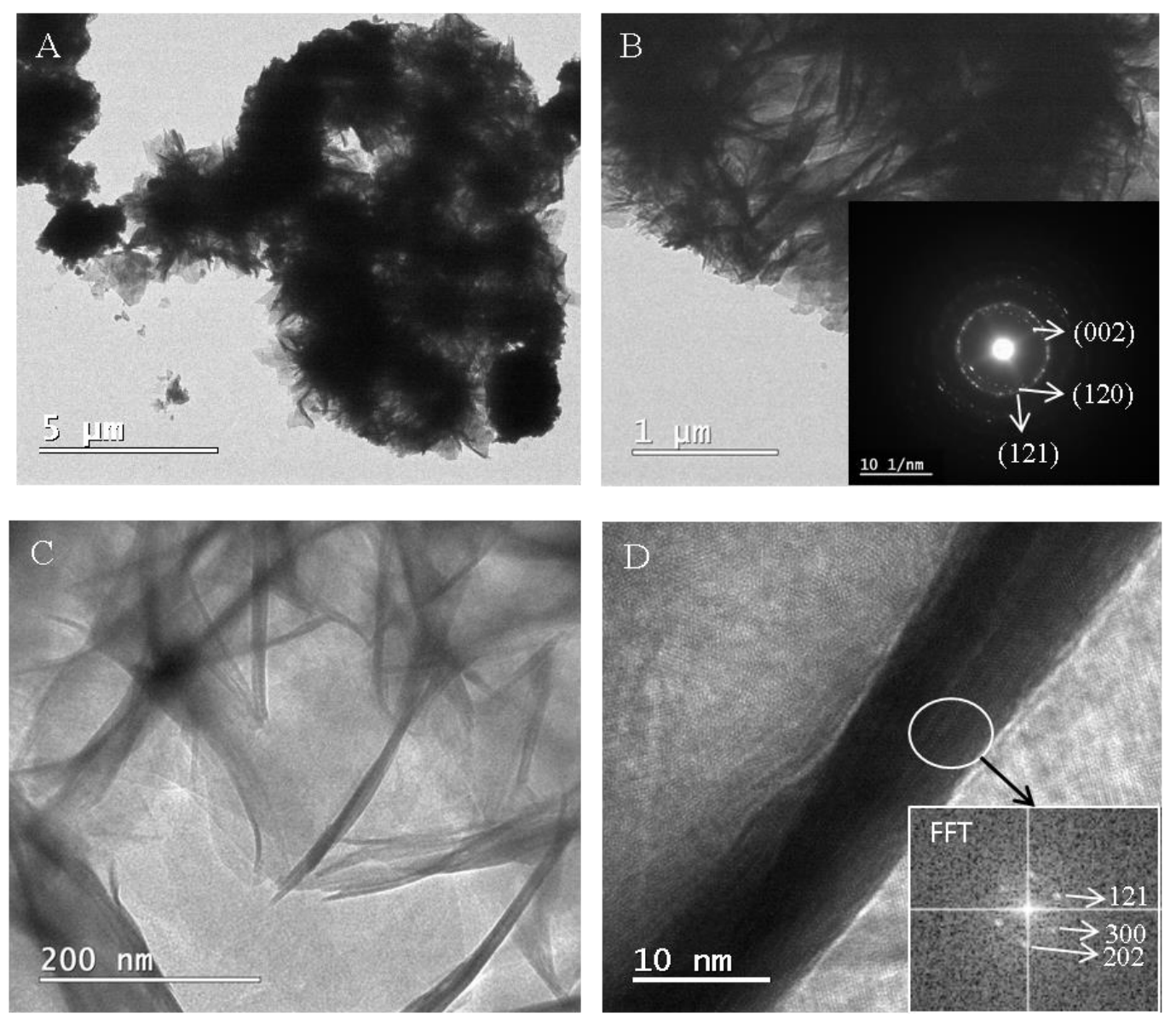

Figure 4-16: TEM micrographs of HAp/gelatin composites: (A) low resolution TEM image showing aggregated spherical structure of the HAp similar to the corresponding SEM image Figure 4-11C (B) low resolution micrograph indicating the needle-like structure and inset shows corresponding SAED with the detected planes. (C) Needle-like structure is evident and (D) HRTEM image showing the most identified HAp plane such as (121) and (300) (inset FFT). 

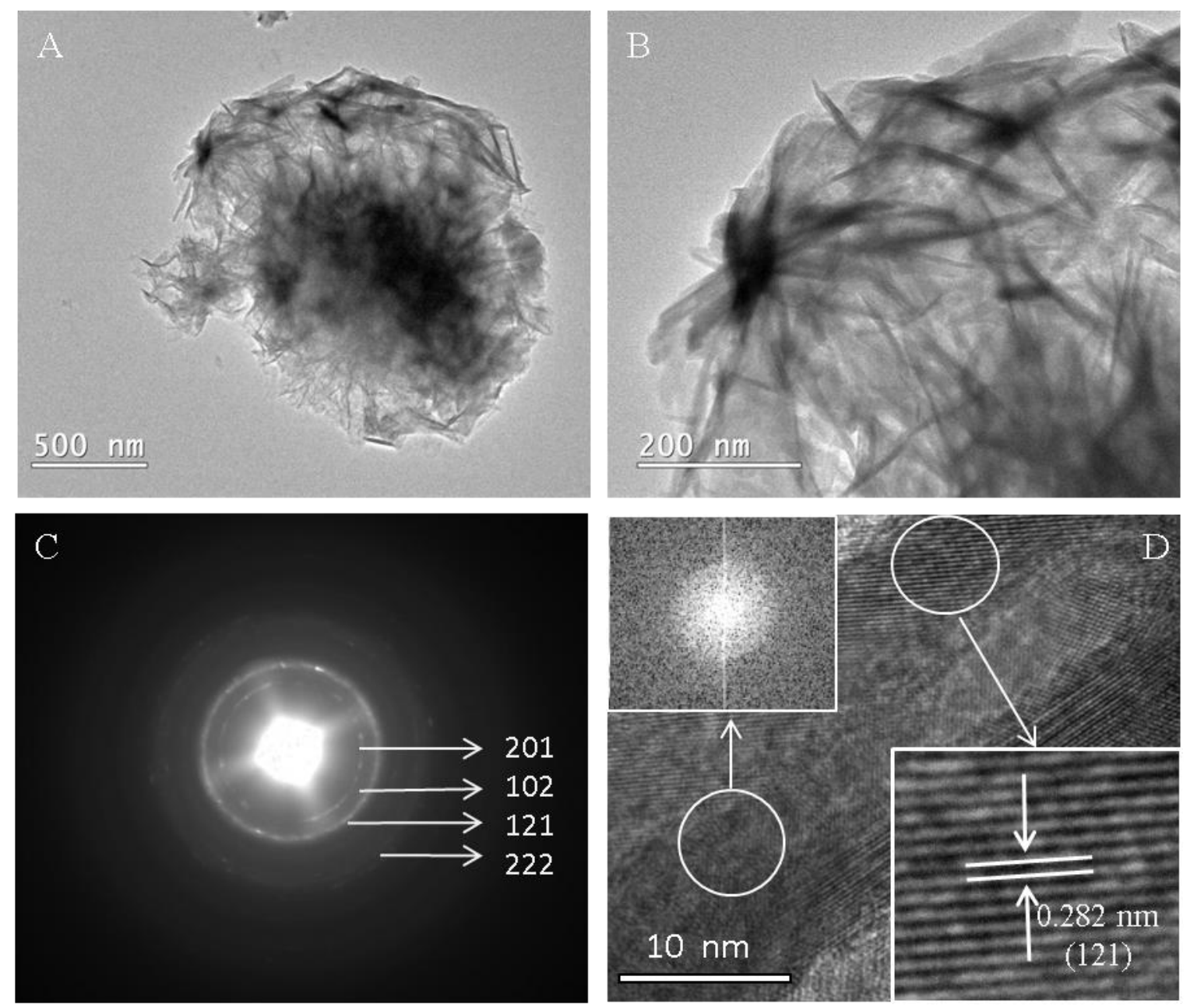

Figure 4-17: TEM micrographs of HAp/gelatin/citrate composites: (A), and (B) show low resolution images, (B) indicating the thin needles in the presence of citrate compared to when no sodium citrate was added, (C) SAED showing the diffusive pattern indicating finegrained HAp mineral formation, and (D) HRTEM analysis showing the lattice fringes about $0.282 \mathrm{~nm}$ corresponding to the (121) plane, and an amorphous halo (inset top left), suggesting the combination of fine crystals of HAp and ACP are precipitated within the gelatin matrix when $2.5 \mathrm{wt} \%$ sodium citrate is present in the synthesis protocol.

The TEM morphological examinations are summarized in Table 1 and Figure 4-18. From this analysis it appears that the morphology of synthesized HAp crystals from bulk solution are significantly different from those precipitated within organic hydrogel matrices irrespective of whether protein or carbohydrate is used (see Figure 4-18 top row). HAp crystals show a long length and wide width needle structure $(80-250 \mathrm{~nm})$ compared to the other specimens except for the gelatin/HAp system ( same range) while the HAp/citrate system presents crystals with the short length needle-like structure $(20-50 \mathrm{~nm})$. The deposition of HAp in both chitosan (second row) and gelatin (botton row) matrices with no 
citrate or $2.5 \mathrm{wt} \%$ sodium citrate additive display the same needle morphology. The organic matrix has an active role in regulation of the HAp crystal growth as it can be seen from images when no sodium citrate is present. The thinnest needles were formed in the HAp/gelatin/citrate with a 3-8 $\mathrm{nm}$ size.

The crystallinity of HAp decreased when citrate ions were added to the crystallization solution which is consistent with the XRD results. This decrease is more affected when the HAp precipitates in organic matrices (diffusive SAED pattern in the case of $\mathrm{HAp} /$ gelatin/citrate and HAp/chitosan/citrate). Moreover the presence of ACP in additional to poorly-crystalline and fine-grained HAp is clearly evident.

Table 1: Summary of the TEM data analysis of HAp, HAp/citrate powders and their composites with chitosan and gelatin. The averaged values and standard deviation were obtained from at least 10 crystals per image.

\begin{tabular}{|c|c|c|c|c|c|}
\hline Sample & $\begin{array}{l}\text { Length } \\
(\mathrm{nm})\end{array}$ & Width (nm) & $\begin{array}{l}\mathrm{Ca} / \mathrm{P} \text { ratio } \\
(\mathrm{EDS})\end{array}$ & $\begin{array}{l}\text { Mineral Phase } \\
\text { (XRD and SAED) }\end{array}$ & $\begin{array}{l}\text { Mineral shape and } \\
\text { orientation }\end{array}$ \\
\hline HAp & $\begin{array}{l}50-250 \\
160 \pm 83\end{array}$ & $\begin{array}{l}10-30 \\
27 \pm 7.3\end{array}$ & $1.64,1.72$ & $\begin{array}{l}\text { Polycrystalline } \\
\text { HAp }\end{array}$ & $\begin{array}{l}\text { Needle and plate-like, } \\
\text { random orientation }\end{array}$ \\
\hline HAp/citrate & $\begin{array}{l}20-50 \\
29 \pm 7.3\end{array}$ & $\begin{array}{l}3-10 \\
4.3 \pm 1.5\end{array}$ & $1.52,1.50$ & $\begin{array}{l}\text { Poorly crystalline } \\
\text { HAp }\end{array}$ & $\begin{array}{l}\text { Needle-like, random } \\
\text { orientation }\end{array}$ \\
\hline HAp/chitosan & $\begin{array}{l}40-80 \\
65 \pm 15\end{array}$ & $\begin{array}{l}4-8 \\
4.9 \pm 0.30\end{array}$ & $1.56,1.28$ & $\begin{array}{l}\text { Poorly crystalline } \\
\text { HAp/ACP }\end{array}$ & $\begin{array}{l}\text { Needle-like, } \\
\text { orientation }\end{array}$ \\
\hline HAp/gelatin & $\begin{array}{l}70-350 \\
100 \pm 38\end{array}$ & $\begin{array}{l}10-25 \\
7.2 \pm 2.2\end{array}$ & $1.58,1.40$ & $\begin{array}{l}\text { Poorly crystalline } \\
\text { HAp/ACP }\end{array}$ & $\begin{array}{l}\text { Needle-like, random } \\
\text { orientation }\end{array}$ \\
\hline $\begin{array}{l}\text { HAp/chitosan } \\
\text { /citrate }\end{array}$ & $\begin{array}{l}40-120 \\
79 \pm 37\end{array}$ & $\begin{array}{l}4-12 \\
6.4 \pm 3.9\end{array}$ & $1.52,1.36$ & $\begin{array}{l}\text { Poorly crystalline } \\
\text { HAp }\end{array}$ & $\begin{array}{l}\text { Needle-like, random } \\
\text { orientation }\end{array}$ \\
\hline $\begin{array}{l}\text { HAp/gelatin/ } \\
\text { citrate }\end{array}$ & $\begin{array}{l}80-250 \\
120 \pm 53\end{array}$ & $\begin{array}{l}3-12 \\
6.6 \pm 2.0\end{array}$ & $1.56,1.33$ & crystalline & $\begin{array}{l}\text { Needle-like, random } \\
\text { orientation }\end{array}$ \\
\hline
\end{tabular}



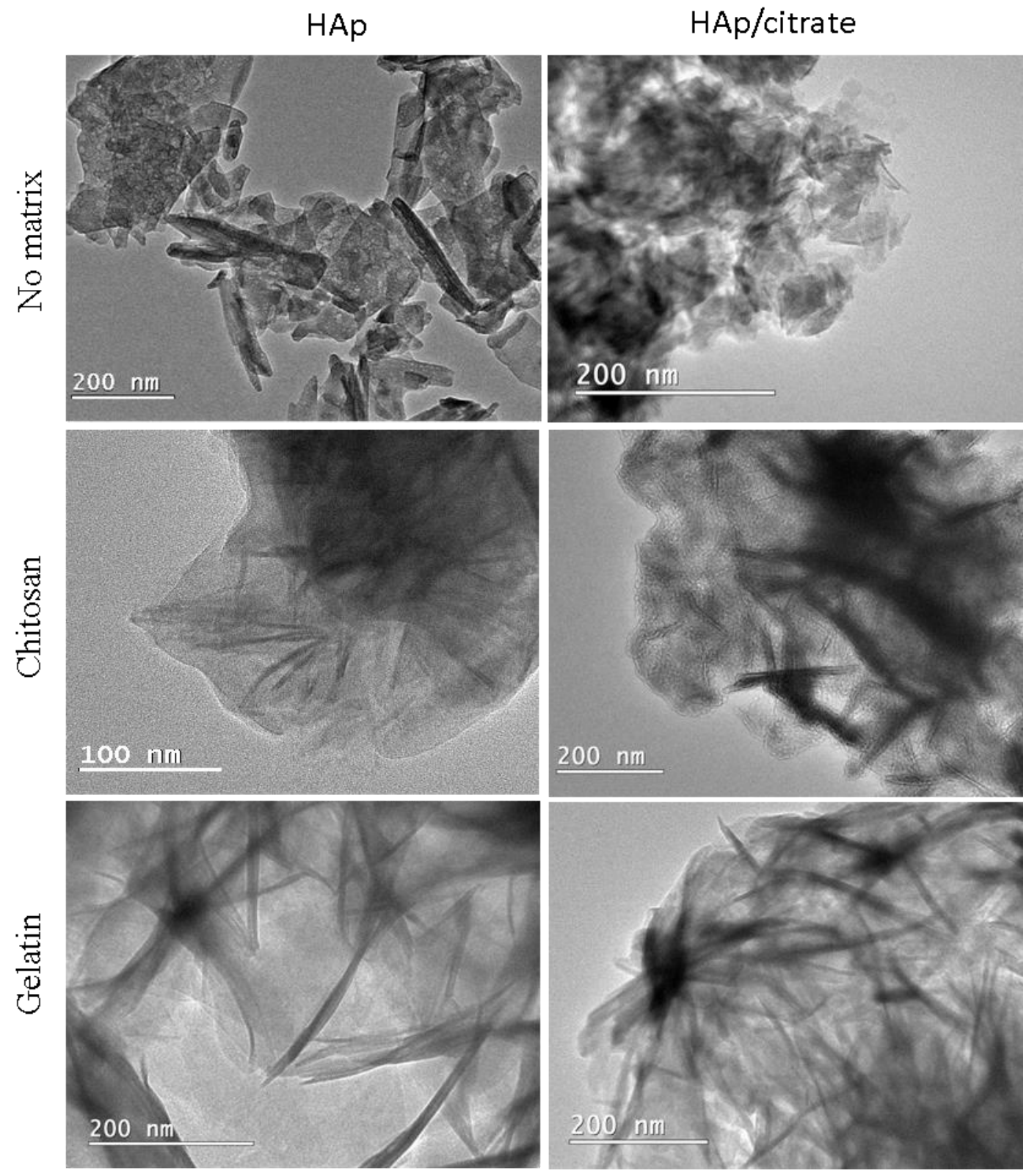

Figure 4-18: Comparison of the TEM morphological analysis of HAp grown from bulk solution and chitosan and gelatin hydrogel matrices with no citrate or $2.5 \mathrm{wt} \%$ sodium citrate present. 


\subsection{Conclusion}

It has been known for long that citrate is a major component of bone; comprising 1-2\% weight of bone. Applying multinuclear SSNMR $\left({ }^{13} \mathrm{C}-{ }^{31} \mathrm{P}\right.$ internuclear distance $)$ reveals that the nanocrystal surface of bone mineral makes intimate atomic-scale molecular connections with organic matrix macromolecules $[10,12]$ and citrate [26]. This new concept of bone formation should be considered in developing new material for bone replacement material and bone repair. We have shown biomimetic synthesis of bone-like biocomposites in the presence of citrate ions, as inspired by the new model of citrate/apatite/collagen in vivo was successfully achieved. Gelatin vs. chitosan as insoluble hydrogel matrices were used as the scaffold environment for HAp crystal growth. The results suggest that the McGrath method has potential in controlling HAp crystal growth throughout gelatin and chitosan hydrogel scaffolds in the absence and presence of citrate ions resulting in materials with HAp crystals with similar morphology to those found in bone. The poorly crystalline HAp is the dominant mineral phase formed in the nanocomposites when no citrate or $2.5 \mathrm{wt} \%$ sodium citrate is added.

SSNMR dipolar dephasing condition studies reveal that HAp precipitation could be stabilized with $2.5 \mathrm{wt} \%$ sodium citrate with respect to the chitosan and gelatin mass. The signals from the quaternary carbon atom and carboxylate groups are dephased successfully in both HAp/chitosan/citrate and HAp/gelatin/citrate composites when $2.5 \mathrm{wt} \%$ sodium citrate was used. It shows that citrate is present in our synthetic composite materials.

TEM data demonstrates that the crystal size of HAp can be tuned at nanoscale by addition of citrate additive similar to those concentration present in bone (2-5 wt \%). Needle-like morphology with a polycrystalline structure are mostly formed. The size of the HAp crystals within the gelatin and chitosan matrices is decreased upon adding citrate ions into the crystallization solution. Our results discussed in this Chapter for HAp/chitosan/citrate and HAp/gelatin/citrate composites have a great structural match and resemblance to bone structure and could result in better biocompatibility of HAp/citrate composites with a potential application in artificial bone grafted materials. 


\section{References}

1. Dorozhkin, S.V. and M. Epple, Biological and Medical Significance of Calcium Phosphates. Angewandte Chemie International Edition, 2002. 41(17): p. 3130-3146.

2. Neuman, W.F. and M.W. Neuman, The Nature of the Mineral Phase of Bone. Chemical Reviews, 1953. 53(1): p. 1-45.

3. Olszta, M.J., X. Cheng, S.S. Jee, R. Kumar, Y.-Y. Kim, M.J. Kaufman, E.P. Douglas and L.B. Gower, Bone structure and formation: A new perspective. Materials Science and Engineering: R: Reports, 2007. 58(3-5): p. 77-116.

4. Addadi, L., A. Gal, D. Faivre, A. Scheffel and S. Weiner, Control of Biogenic Nanocrystal Formation in Biomineralization. Israel Journal of Chemistry, 2015: p. n/a-n/a.

5. Rey, C., C. Combes, C. Drouet and M.J. Glimcher, Bone mineral: update on chemical composition and structure. Osteoporosis International, 2009. 20(6): p. 1013-1021.

6. Glimcher, M.J., Bone: Nature of the Calcium Phosphate Crystals and Cellular, Structural, and Physical Chemical Mechanisms in Their Formation. Reviews in Mineralogy and Geochemistry, 2006. 64(1): p. 223-282.

7. Jäger, C., T. Welzel, W. Meyer-Zaika and M. Epple, A solid-state NMR investigation of the structure of nanocrystalline hydroxyapatite. Magnetic Resonance in Chemistry, 2006. 44(6): p. 573580.

8. Wang, Y., S. Von Euw, F.M. Fernandes, S. Cassaignon, M. Selmane, G. Laurent, G. PehauArnaudet, C. Coelho, L. Bonhomme-Coury, M.-M. Giraud-Guille, F. Babonneau, T. Azaïs, and N. Nassif, Water-mediated structuring of bone apatite. Nat Mater, 2013. 12(12): p. 1144-1153.

9. Duer, M.J., The contribution of solid-state NMR spectroscopy to understanding biomineralization: Atomic and molecular structure of bone. Journal of Magnetic Resonance, 2015. 253: p. 98-110.

10. DiMasi, E. and L.B. Gower, Biomineralization Sourcebook: Characterization of Biominerals and Biomimetic Materials. 2014: Taylor \& Francis.

11. Cho, G., Y. Wu and J.L. Ackerman, Detection of Hydroxyl Ions in Bone Mineral by Solid-State NMR Spectroscopy. Science, 2003. 300(5622): p. 1123-1127.

12. Xie, B. and G.H. Nancollas, How to control the size and morphology of apatite nanocrystals in bone. Proceedings of the National Academy of Sciences, 2010. 107(52): p. 22369-22370.

13. Reid, D., M. Duer, G. Jackson, R. Murray, A. Rodgers and C. Shanahan, Citrate Occurs Widely in Healthy and Pathological Apatitic Biomineral: Mineralized Articular Cartilage, and Intimal Atherosclerotic Plaque and Apatitic Kidney Stones. Calcified Tissue International, 2013. 93(3): p. 253-260.

14. Davies, E., K.H. Müller, W.C. Wong, C.J. Pickard, D.G. Reid, J.N. Skepper and M.J. Duer, Citrate bridges between mineral platelets in bone. Proceedings of the National Academy of Sciences, 2014. 111(14): p. E1354-E1363.

15. Iafisco, M., G.B. Ramirez-Rodriguez, Y. Sakhno, A. Tampieri, G. Martra, J. Gomez-Morales and J.M. Delgado-Lopez, The growth mechanism of apatite nanocrystals assisted by citrate: relevance to bone biomineralization. CrystEngComm, 2015. 17(3): p. 507-511. 
16. Delgado-López, J.M., M. Iafisco, I. Rodríguez, A. Tampieri, M. Prat and J. Gómez-Morales, Crystallization of bioinspired citrate-functionalized nanoapatite with tailored carbonate content. Acta Biomaterialia, 2012. 8(9): p. 3491-3499.

17. Hu, Y.Y., X.P. Liu, X. Ma, A. Rawal, T. Prozorov, M. Akinc, S.K. Mallapragada and K. SchmidtRohr, Biomimetic Self-Assembling Copolymer-Hydroxyapatite Nanocomposites with the Nanocrystal Size Controlled by Citrate. Chemistry of Materials, 2011. 23(9): p. 2481-2490.

18. Leeuwenburgh, S.C.G., I.D. Ana and J.A. Jansen, Sodium citrate as an effective dispersant for the synthesis of inorganic-organic composites with a nanodispersed mineral phase. Acta Biomaterialia, 2010. 6(3): p. 836-844.

19. Lien, S.-M., L.-Y. Ko and T.-J. Huang, Effect of pore size on ECM secretion and cell growth in gelatin scaffold for articular cartilage tissue engineering. Acta Biomaterialia, 2009. 5(2): p. 670679.

20. Xia, W., W. Liu, L. Cui, Y. Liu, W. Zhong, D. Liu, J. Wu, K. Chua and Y. Cao, Tissue engineering of cartilage with the use of chitosan-gelatin complex scaffolds. Journal of Biomedical Materials Research Part B: Applied Biomaterials, 2004. 71B(2): p. 373-380.

21. Duer, M.J., The Basics of Solid-State NMR, in Solid-State NMR Spectroscopy Principles and Applications. 2007, Blackwell Science Ltd. p. 1-72.

22. Duer, M.J., Essential Techniques for Spin-1/2 Nuclei, in Solid-State NMR Spectroscopy Principles and Applications. 2007, Blackwell Science Ltd. p. 73-110.

23. McDermott, A.E. and T. Polenova, Solid State NMR Studies of Biopolymers. 2012: Wiley.

24. Opella, S.J. and M.H. Frey, Selection of nonprotonated carbon resonances in solid-state nuclear magnetic resonance. Journal of the American Chemical Society, 1979. 101(19): p. 5854-5856.

25. Komatsu, T. and J. Kikuchi, Selective Signal Detection in Solid-State NMR Using RotorSynchronized Dipolar Dephasing for the Analysis of Hemicellulose in Lignocellulosic Biomass. The Journal of Physical Chemistry Letters, 2013. 4(14): p. 2279-2283.

26. Hu, Y.-Y., A. Rawal and K. Schmidt-Rohr, Strongly bound citrate stabilizes the apatite nanocrystals in bone. Proceedings of the National Academy of Sciences, 2010. 107(52): p. 2242522429.

27. De Angelis, A.A., D. Capitani and V. Crescenzi, Synthesis and ${ }^{13} C$ CP-MAS NMR Characterization of a New Chitosan-Based Polymeric Network. Macromolecules, 1998. 31(5): p. 1595-1601.

28. Nikel, O., D. Laurencin, C. Bonhomme, G.E. Sroga, S. Besdo, A. Lorenz and D. Vashishth, Solid State NMR Investigation of Intact Human Bone Quality: Balancing Issues and Insight into the Structure at the Organic-Mineral Interface. The Journal of Physical Chemistry C, 2012. 116(10): p. 6320-6331.

29. Aliev, A.E., Solid-state NMR studies of collagen-based parchments and gelatin. Biopolymers, 2005. 77(4): p. 230-245.

30. Song, J., E. Saiz and C.R. Bertozzi, A New Approach to Mineralization of Biocompatible Hydrogel Scaffolds: An Efficient Process toward 3-Dimensional Bonelike Composites. Journal of the American Chemical Society, 2003. 125(5): p. 1236-1243. 
31. Reis, R.L. and J.S. Román, Biodegradable Systems in Tissue Engineering and Regenerative Medicine. 2004: CRC Press.

32. Hu, Y.-Y., Y. Yusufoglu, M. Kanapathipillai, C.-Y. Yang, Y. Wu, P. Thiyagarajan, T. Deming, M. Akinc, K. Schmidt-Rohr and S. Mallapragada, Self-assembled calcium phosphate nanocomposites using block copolypeptide templates. Soft Matter, 2009. 5(21): p. 4311-4320.

33. Suvorova and Buffat, Electron diffraction from micro- and nanoparticles of hydroxyapatite. Journal of Microscopy, 1999. 196(1): p. 46-58.

34. Mahamid, J., A. Sharir, L. Addadi and S. Weiner, Amorphous calcium phosphate is a major component of the forming fin bones of zebrafish: Indications for an amorphous precursor phase. Proceedings of the National Academy of Sciences, 2008. 105(35): p. 12748-12753. 


\section{Chapter 5}

\section{Conclusion}

The content of this thesis dealt with the fabrication of specialized organic-inorganic composite materials by understanding and mimicking the processes involved in natural materials. Bone and nacre are excellent examples of biominerals that combine strength with toughness, making them superior materials with respect to mechanical behaviour. Mimicking features of a bone and nacre which are formed under ambient laboratory conditions is not a trivial task. However being able to mimic natural material formation would allow us to create complex nanoscale structures under ambient conditions using simple crystallization methods.

In this thesis, calcium carbonate vs. calcium phosphate mineralization using carbohydratebased vs. protein-based hydrogel scaffolds were investigated. The effect of acidic anionic monomeric and their corresponding polymeric additives, mimicking molecules used in nature in the fabrication of biominerals was also investigated. Three different crystallization methods including the alternative soaking (two variants), McGrath and Kitano methods and various characterization techniques including SEM, HRTEM, XRD, Raman spectroscopy and SSNMR were used to analyze the as-synthesized materials. The major outcomes of this thesis are presented below followed by some ideas for possible future research direction.

The production of calcium carbonate was examined by nucleation within chitosan and gelatin scaffolds in the absence of any additive in order to understand the contribution of the scaffolds themselves on calcium carbonate mineralization. The results suggest that despite the different chemistry of the chitosan and gelatin hydrogel scaffolds, morphologically similar calcite crystals were obtained irrespective of which mineralization method was used. A greater amount of mineralization, and also a more uniform distribution, was achieved throughout the hydrogel scaffolds rather than only partially at the peripheral surface was achieved using the McGrath method, as compared to the other two methods.

Through the addition of the negatively charged monomeric AA, GL and AS additives and their corresponding polymers the morphology created by each additive in combination with chitosan vs. gelatin is different, and it is different again as the mineralization method is 
changed. Despite different morphologies being formed, similar to the case when no additive was present, calcite was the only polymorph formed.

In contrast, polymeric additives gave rise to a remarkable influence over $\mathrm{CaCO}_{3}$ growth within both chitosan and gelatin hydrogel scaffolds due to the formation of a polyelectrolyte complex between the added polymer molecules in the chitosan and gelatin scaffolds. These complexes enhance lateral growth of the calcium carbonate crystals within the scaffolds compared to when the scaffolds are mineralized in the presence of monomeric or without additives. X-Ray diffraction data showed that the crystallinity and polymorphism is altered by the different crystallization methods and also by each additive themselves. In both chitosan and gelatin scaffolds in the presence of polymeric additives, mixtures of polymorphs mostly vaterite and calcite, were formed compared to when monomers were used especially in the case of the McGrath method. Moreover HRTEM data analysis demonstrate that with and without additives, no matter which crystallization method or scaffold was used, all produced crystals are polycrystalline formed via assembly of nanoparticles. In the case of PGL and PAS the conformation of amino acids is a key in determination of calcium carbonate crystal morphology. Hence no lateral growth was seen for PGL and PAS when the McGrath method used. In contrast upon lowering the concentration of the presoaking ion solutions and also reducing the PGL and PAS additives to $1 \mathrm{wt} \%$ in the McGrath method a large degree of control over crystal morphology and polymorph was achieved.

The focus was then switched from calcium carbonate to calcium phosphate growth. The same crystallization conditions and additives were applied. In the absence of additives socalled spherical and platelet-shaped morphologies composed of ACP and poorly crystalline HAp respectively were always formed within both chitosan and gelatin hydrogel scaffolds. However in the case of chitosan scaffold the spherical-shaped CaP crystals are porous and mostly amorphous whereas for gelatin the spherical-shaped $\mathrm{CaP}$ crystals consist of an interconnected network of crystalline HAp platelet crystals. Furthermore, more homogenous growth occurs for the gelatin scaffold irrespective of which crystallization method is used compared with the chitosan scaffolds. In addition when the alternative soaking with $\mathrm{CaCl}_{2}$ and $\mathrm{Na}_{2} \mathrm{HPO}_{4}$ and the McGrath method were used extensive mineralization was induced throughout the hydrogel scaffolds rather than only partially at the peripheral surface as compared to the other two methods. 
The effect of the negatively charged acidic, monomeric vs. polymeric additives, on the crystallization of calcium phosphate was also investigated. In the series of additives AA and PAA showed weaker control over calcium phosphate mineralization in both chitosan and gelatin hydrogel scaffolds. This result is not consistent with the results observed for calcium carbonate mineralization in the presence of particularly PAA. In contrast, upon introducing AS and GL and their corresponding polymeric additives differences in both morphology and crystallinity were realized. Once again the same morphologies (spherical and platelet) were observed in the presence of AS and GL irrespective of the mineralization method used. However the using alternative soaking with $\mathrm{CaCl}_{2}$ and $\mathrm{Na}_{2} \mathrm{HPO}_{4}$ and the $\mathrm{McGrath}$ method with added PAS and PGL, resulted in nanoparticle formation, these nanoparticles subsequently assembled yielding on average spherical particles of $\mathrm{CaP}$ which homogeneously covered the hydrogel scaffold surface. Samples that are platelet-shaped were formed to be more highly crystalline compared to those where predominately the porous spherical CaP morphology was observed.

The size of $\mathrm{CaP}$ minerals is altered upon changing the hydrogel scaffold. Switching from the carbohydrate-based chitosan to the protein-based gelatin scaffolds results in a decrease of crystal size irrespective of the mineralization method used.

Investigation of the crystals using HRTEM analysis of CaP/gelatin/PAS revealed that the $\mathrm{CaP}$ crystals are polycrystalline HAp. The base growth unit is needle-shaped nanoparticles. These nanoparticles assemble yielding the large polycrystalline HAp.

$\mathrm{pH}$ was also found to be a key factor in controlling which polymorph of $\mathrm{CaP}$ precipitates. Depending on the conditions under which mineralization occurs either healthy or pathological mineralization occurs.

Finally, as inspired by case of bone formation, the effect of citrate as an additive in calcium phosphate growth using the McGrath method was investigated. Again gelatins vs. chitosan hydrogel scaffolds were used. Poorly crystalline HAp is produced when no citrate or 2.5 wt \% sodium citrate is added. The results of CPMAS and DD ${ }^{13} \mathrm{C}$ SSNMR of mineralized gelatin and chitosan reveal that the HAp precipitate can be stabilized with $2.5 \mathrm{wt} \%$ sodium citrate with respect to the chitosan and gelatin mass. An intense signal at $3.2 \mathrm{ppm}$ in the ${ }^{31} \mathrm{P}$ CP-MAS data for HAp-citrate crystals further confirmed the presence of poorly crystalline HAp mineral with a similar chemical shift distribution to that of bone. Furthermore the crystal size of HAp can be nano-tuned by changing the concentration of citrate ions in a 
range similar to that present in bone $(2-5 \mathrm{wt} \%)$. TEM data reveal that the needle-like morphology with a polycrystalline structure is mostly formed on chitosan and gelatin scaffolds in the absence and presence of citrate ions. This emphasizes the role of the hydrogel scaffold itself in controlling HAp crystal formation. However upon addition of citrate ions into the crystallization solution the size of the HAp crystals within the gelatin and chitosan matrices is decreased more closely mimicking the structural features of bone.

\section{Overall comparison}

Considering the results collectively it is possible to make an overall comparison between the crystallization of calcium carbonate (marine biomineral) and calcium phosphate (mammalian biomineral) in the carbohydrate-based (marine scaffold) vs. protein-based (mammalian scaffold) hydrogel scaffolds. First of all the crystal sizes and morphologies of calcium carbonate and calcium phosphate are very different. A diverse range of morphologies of calcium carbonate crystals with very large crystal size were grown within the both scaffolds, whereas calcium phosphate mostly forms very small platelet-shaped crystals. Secondly, both $\mathrm{CaCO}_{3}$ and $\mathrm{CaP}$ have a common polycrystalline nature where the final material is composed of aggregations of nanoparticles. However in the case of $\mathrm{CaCO}_{3}$ highly crystalline calcite or vaterite dominates whereas for CaP poorly crystalline HAp and ACP are mostly formed. This result is comparable to that found in invertebrate biominerals such as nacre which have a high degree of crystallinity and vertebrate biominerals such as bone with a poorly-crystalline HAp is found in bone. Physically cross-linked chitosan and chemically cross-linked gelatin, despite the different chemistry and pore size, display the similar behaviour in modulating $\mathrm{CaCO}_{3}$ and $\mathrm{CaP}$ crystallization. However gelatin scaffolds yield smaller crystals compared to the chitosan hydrogel, especially in the case of CaP mineralization.

The presence of acidic protein is a common feature of both vertebrate and invertebrate biominerals. In $\mathrm{CaCO}_{3}$ biomineralization acidic protein is responsible for morphological control and determines which polymorphs forms while in $\mathrm{CaP}$ biomineralization the acidic anionic additive is considered to be responsible for specific orientational promotion/inhibition of HAp crystals within collagen scaffolds. This hypothesis about acidic protein is supported very well in this study. Herein our results suggest that the $\mathrm{CaCO}_{3}$ morphology created by each additive in combination with chitosan and gelatin is different. Monomeric additives in combination with chitosan and gelatin scaffolds result in calcite 
crystals and defected rhombohedra morphologies. In contrast polymeric additives have been found to control more strongly the morphology of $\mathrm{CaCO}_{3}$, due to the formation of a polyelectrolyte complex within and on the surface of the chitosan and gelatin scaffolds. They increase lateral growth of the calcium carbonate crystals within the chitosan template compared to when the templates are mineralized in the presence of monomers or without additives. However in the CaP crystallization the size of crystals is more influenced rather than morphology especially when the gelatin scaffold was used. Spherical and platelet assembled-nanoparticles of $\mathrm{CaP}$ crystals are grown throughout the hydrogel scaffolds in the case of PAS and PGL additives. The morphology and amount of $\mathrm{CaCO}_{3}$ and $\mathrm{CaP}$ mineralization are also influenced by the mineralization method used. The morphologies created in combination with different additives and scaffolds are different from each other.

To conclude this thesis, new advanced materials can be synthesized, inspired by natural materials such as bone and nacre. The use of simple mineralization methods in combination with insoluble organic hydrogels and water soluble acidic additives results in fabricating some fascinating new materials with interesting morphologies and various composite structures. A major outcome of this research is its potential biomedical research/industry for example as bone and teeth graft substitutes.

\section{Future work}

The next stage in this work is further investigation with respect to controlling the size of $\mathrm{CaCO}_{3}$ crystals within the hydrogel scaffold. This is particularly important as one of the limiting factors in calcium carbonate usage in bone grafting instead of calcium phosphate is the large size of calcium carbonate crystals. The large crystals structurally cannot dissipate the crack propagation energy through the composite made out of this crystal compared to the small platelet-shaped $\mathrm{CaP}$ crystals present in bone structure and would fail to provide mechanical toughness compared to bone. Therefore formation of platelet-like aragonite crystals inside the hydrogel scaffold might provide a similar structure as seen for HAp. This will be possible through acid or base-etching of the formed crystals as a one possibility.

One of the challenges in calcium phosphate precipitation is when and where the phase transformation occurs. Recently advanced electron microscopy facilities such as in situ cryoTEM enables researchers to probe how the nucleation starts and how disordered amorphous phases transform to the more ordered HAp phase. This would be an important next step in the exploration. Also an examination through SSNMR at various times during 
mineralization to show how the amorphous phase crystallizes within the hydrogel scaffolds. NMR has been used to study the mineral phase of natural bone, and therefore, there is a wealth of data in literature to which we can compare our results. This is applicable to the study of calcium carbonate as well. Combination of spectroscopy and structural examination using in situ electron microscopies will allow us to understand the biomineralization process from early stage to final composite materials.

There is still much to be learned about the mechanisms of hydroxyl apatite crystal size control in bone growth system. While the most investigations have been focused on the use of macromolecules such as negatively charged carboxylate-rich proteins on hydroxyapatite nucleation and growth within collagen hydrogel. The role of small organic molecules such as citrate have been considered important in controlling the size and the thickness of hydroxyl apatite growth in bone. The hypothesis that how the citrate ions binds to the surface of the hydroxyapatite crystals and collagen itself is still not very well developed and need further investigation. To achieve this, further research will be needed on the complex kinetic processes of citrate combination with collagen and soluble noncollagenous proteins in controlling of nucleation and crystal growth. Also it is now evident that the role of citrate in normal bone formation and its implications in bone diseases, and in bone repairment, now requires new attention and support for much needed research.

As it was shown and investigated in this research and in the literature reviewed in Chapter 1 considerable research has been directed towards developing 2-dimentional bone-like materials with properties comparable to natural bone. With the advancement and development of $3 \mathrm{D}$ printing technology it is a cutting edge of research to develop and investigate 3D-dimensional (3D) porous bone-like constructs via 3D printing of chitosan/gelatin hydrogel-based scaffolds and optimizing their mechanical strength to be comparable to that of bone via in situ induced mineralization inspired by nacre. This is already established and being investigated in our laboratory.

The results of this thesis demonstrated that, inspired by biomineralisation, the use of simple crystallization techniques and soluble anionic additives gives rise to various composite structures with morphologies identical to those observed in Nature can be synthesized for use in the biomedical field as implantable materials. 
